\title{
II. Sprachenrecht und Sprachpraxis
}

\section{A. Das tschechoslowakische Sprachenrecht: Entwicklung, Charakteristik, Grundprobleme}

Im allgemeinen Sinne ist das Sprachenrecht die "Gesamtheit der Rechtsnormen, die alle Beziehungen regeln, welche sich aus der Tatsache ergeben, daß die Bevölkerung des Staates im gegenseitigen Verkehr mehrere Sprachen gebraucht. " 1 Das tschechoslowakische Sprachenrecht regelte jedoch nicht „alle Beziehungen“, denn im Einklag mit dem Vertrag von St. Germain wurde „im Privat- und Handelsverkehr, in Religionsangelegenheiten, in der Presse und in allen Publikationen oder in öffentlichen Volksversammlungen“ der freie Gebrauch ,irgendeiner Sprache" verfassungsmäßig garantiert"; es wurde somit als die "Gesamtheit aller Rechtsnormen, durch die die Beziehungen der Bürger zur öffentlichen Macht in sprachlicher Hinsicht geregelt werden", definiert - und war in diesem Sinne ein Bestandteil des öffentlichen Rechts. ${ }^{3}$ Der Gegenstand der normativen Regelung war laut Sprachengesetz der innere sowie äußere Sprachgebrauch „aller Gerichte, Behörden, Anstalten, Unternehmungen und Organe der Republik“, der „autonomen Behörden, Vertretungskörper und alle(r) öffentlichen Körperschaften im Staate" sowie der Sprachgebrauch bei der Verwaltung der durch den Staat für die Angehörigen der nationalen Minderheiten errichteten Schulen und kulturellen Institutionen.

Formell gesehen lassen sich in der Entwicklung des tschechoslowakischen Sprachenrechts insgesamt vier Etappen unterscheiden. In der ersten bis Ende April 1920 wurden seine Grundlagen gelegt. Von den insgesamt 150 Rechtsnormen, die sprachliche Bestimmungen enthielten, wurden 37 - also beinahe ein Viertel - eben in diesem Zeitraum vom Gesetzgeber verabschiedet; unter ihnen befanden sich solch wichtige wie das Sprachengesetz (Nr. 122/1920 Slg.), das Gesetz über die Städte-, Gemeinde-, Ortschafts- und Straßennamen (Nr. 266/1920 Slg.), die Gesetze über die Geschäftsordnungen des Abgeordnetenhauses und des Senats der Nationalversammlung (Nr. 325/1920 und 326/1920 Slg.) sowie das Gesetz über die Bekanntmachung der Gesetze und Verordnungen (Nr. 139/1919 Slg.). Der größte Teil von ihnen wurde in den letzten Tagen der Amtsperiode der Revolutionären Nationalversammlung unmittelbar vor dem zu erwartenden Eintritt der Vertreter der Minderheiten ins Parlament verabschiedet, worin bereits die Zeitgenossen zweifellos zu Recht die Bemühung der tschechisch-slowakischen Politik erblickten, alle wichtigen sprachlichen Regelungen im Alleingang zu treffen. ${ }^{4}$ Dies wurde noch durch die Tatsache unterstrichen, daß seit April 1920 mit ei-

${ }^{1}$ Horáček, Jazykové právo, S. 4.

2 Gesetz Nr. 121 Slg. vom 29. 2. 1920 betreffend die Einführung der Verfassungsurkunde der Tschechoslowakischen Republik.

${ }^{3}$ Horáček, Jazykové právo, S. 4.

${ }^{4}$ Vgl. Klepetař, Sprachenkampf, S. 31. 
ner einzigen Ausnahme - dem Gesetz über die Einführung des Unterrichts in der Staatssprache und in den Sprachen der nationalen Minderheiten an Mittelschulen und Lehrerbildungsanstalten vom Juni 1923 (Nr. 137/1923 Slg.) - kein ausschließlich die sprachliche Problematik betreffendes Gesetz mehr dem Parlament vorgelegt wurde. Die Sprachregelung erfolgte in diesem Zeitraum auf dem Verordnungswege, dessen wichtigsten Eckpfeiler die Durchführungsverordnung zum Sprachengesetz vom $\mathrm{Fe}$ bruar 1926 darstellte, deren Herausgabe die zweite Etappe der Entwicklung des tschechoslowakischen Sprachrechts abschließt. Kennzeichnend für die dritte Etappe (1926-1936) ist vor allem die Tatsache, daß die legislative Tätigkeit auf dem sprachrechtlichen Gebiet praktisch zum Stillstand kam - seit 1926, abgesehen von der Regierungsverordnung betreffend die Regelung des Sprachgebrauches der Organe der Landes- und Bezirksverwaltungen vom Jahre 1928, wurde keine weitere genuin sprachliche Norm mehr erlassen. Das Sprachenrecht blieb jedoch auch in diesem Zeitraum nicht ganz konstant, sondern wurde in der Rechtssprechung des Obersten Verwaltungsgerichts besonders im Hinblick auf seine manchmal unklaren und strittigen $\mathrm{Be}$ stimmungen weiterentwickelt.

Erst ab Ende 1936 begann man, über weitere Schritte auf dem Gebiet des Sprachenrechts nachzudenken. Die anfänglichen Versuche in den Jahren 1936 bis 1937, Erleichterungen im Rahmen der bestehenden Sprachregelung zu suchen, die ohnehin spärlich blieben, wuchsen sich zu Bestrebungen aus, die grundlegenden Sprachnormen (das Sprachengesetz und die Durchführungsverordnung) zu novellieren und die von den Minderheiten kritisierten, manchmal sowohl juristisch als auch nationalpolitisch bedenklichen Regelungen abzuschaffen. Die entsprechende Normen wurden schließlich nicht verabschiedet, so daß das tschechoslowakische Sprachenrecht bis zum Untergang des Staates im März 1939 im Grunde genommen auf dem Stand des Jahres 1926 blieb.

Inhaltlich gesehen war das wohl auffallendste Merkmal der Entwicklung des Sprachenrechts besonders bis zum Jahre 1926 seine tendenzielle Veränderung zuungunsten der Minderheiten. Wie seltsam das auch klingen mag, die ersten Jahre der Republik, die Jahre der mehr oder weniger offenen „irredentistischen“ sudetendeutschen Politik und somit auch der großen Spannungen zwischen Tschechen und Deutschen, stellten gleichzeitig die liberalste Phase ihrer Sprachgesetzgebung dar. Charakteristisch für sie war die grundsätzliche Bereitschaft, das Deutsche in bestimmten Fällen auch als innere Amtssprache zuzulassen sowie das Prinzip der Zweckmäßigkeit im sprachlichen Verkehr stärker zu berücksichtigen. Hinzu kam auch die Tendenz, durch mannigfaltige Übergangsbestimmungen den Anpassungsprozeß der Deutschen an die neuen sprachlichen Verhältnisse zu erleichtern. Die Wende trat mit der Formierung der allnationalen Koalition in den Jahren 1920 bis 1922 ein. Die Möglichkeit, das Deutsche in der inneren Amtsführung zu verwenden, wurde nun endgültig fallengelassen; tschechischerseits gewann das Prestigedenken in den sprachlichen Angelegenheiten an Bedeutung, wenn nicht sogar die Oberhand, was der ursprünglich von den meisten tschechischen politischen Kräften beschworenen Entpolitisierung der Sprachenfrage zuwiderlief. Die sprachlichen Übergangsbestimmungen wurden schrittweise reduziert, wohl auch in der irreführenden Annahme, die Praxis erfordere diese mit fortschreitender Zeit nicht mehr. Die Durchführungsverordnung festigte ungeachtet der praktischen Bedürfnisse der alltäglichen Kommunikation die Vorrangstellung der „tschechoslowaki- 
schen" Sprache noch; darin waren sich viele Zeitgenossen, Tschechen wie Deutsche einig $^{5}$ - der deutsche agrarische Abgeordnete F. Spina charakterisierte 1926 diese Entwicklung: es sei im Jahre 1920 "mehr Hemmungen“ und "mehr Einsicht" vorhanden

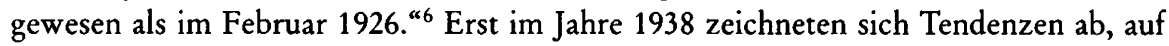
die Konzeption des Sprachenrechts der Jahre 1919/1920 zurückzugreifen, was u. a. darin zum Ausdruck kam, daß man tschechischerseits wieder bereit war - wenn auch nicht widerspruchslos -, die Minderheitensprachen als Amtssprachen zu akzeptieren und ihnen auch eine gewisse, nicht näher spezifizierte Rolle in der inneren Amtsführung einzuräumen.

Das grundlegende Merkmal des tschechoslowakischen Sprachenrechts war die Präponderanz einer bzw. mehrerer von auf dem Territorium des Staates gebrauchten Sprachen, nämlich des Tschechischen und des Slowakischen, die in der Gesetzgebung sowie im amtlichen Sprachgebrauch als "tschechoslowakische“ Sprache bezeichnet wurden.? Diese Vorrangstellung kam vor allem darin zum Ausdruck, daß sie von den Subjekten der öffentlichen Macht überall dort angewandt werden mußte, wo das Gesetz den Gebrauch einer anderen Sprache nicht ausdrücklich zuließ. Faktisch bedeutete dies im Prinzip, daß das "Tschechoslowakische" die ausschließliche innere Amtssprache aller Staatsorgane und -Betriebe war; Staatsangestellte bzw. Bewerber um den Staatsdienst mußten somit des Tschechischen oder Slowakischen mächtig sein. Die Anwendung von Minderheitensprachen blieb grundsätzlich auf den Parteienverkehr mit den Staatsbehörden, -betrieben und Organen der örtlichen oder beruflichen Selbstverwaltung beschränkt. Während jedoch Tschechen und Slowaken im gesamten Staatsgebiet das Recht hatten, in diesen Fällen ihre Muttersprache zu gebrauchen, mußten für die Anwendung von Minderheitensprachen spezifische Vorbedingungen erfüllt werden. Eine Minderheitensprache konnte auch als Geschäftssprache von autonomen Behörden, Vertretungskörpern und öffentlichen Körperschaften festgelegt oder ihr Gebrauch zugelassen werden, falls dies die Mehrheit ihrer Mitglieder bzw. die zuständige Vertretung beschloß; tschechische und slowakische Mitglieder dieser Gremien durften jedoch ex lege immer in ihrer Muttersprache das Wort ergreifen. Bei den Streitkräften, wo das „Tschechoslowakische“ als Kommando- und Dienstsprache galt, „konnten“ die Minderheitensprachen im Verkehr mit der Mannschaft gebraucht werden, die der Staatssprache nicht mächtig war.

5 „Das Sprachengesetz“, charakterisierte dies der deutsche Abgeordnete W. Zierhut (BdL), „hat uns Erleichterungen in Aussicht gestellt, die Sprachenverordnung hat uns Verschärfungen gebracht.“ Rede Zierhuts in der 13. Sitzung des Abgeordnetenhauses am 11.3. 1926, in: TZPS, 2. WP, S. 726. Vgl. auch: Klepetař, Sprachenkampf, S. 151-152; Peroutka, Budování, S. 1008; Sobota, Národnostní autonomie, S. 32-33; Sprachverordnung, S. 75. Auch die tschechische Historiographie der Nachkriegszeit vertritt einen eher negativen Standpunkt. Vgl. César-Černý, Politika, S. 354; Kural, Konflikt, S. 62.

${ }^{6}$ Rede Spinas, 14. Sitzung des Abgeordnetenhauses am 12. 3. 1926, in: TZPS, 2. WP, S. 834.

7 Da die Bezeichnung der Mehrheitssprachen, obwohl sie sachlich gesehen fraglich und umstritten war sowie deutscherseits regelmäßig scharf kritisiert wurde, für ihre faktische Stellung sowie für die der Minderheitensprachen irrelevant ist, wird auf diese Problematik nicht näher eingegangen werden. Zum tschechischen Standpunkt vgl. beispielsweise Bericht des Verfassungsausschusses über den Entwurf eines Gesetzes, durch das die Grundsätze des Sprachenrechts in der Tschechoslowakischen Republik festgelegt werden vom 24. 2. 1920, in: TTZRNS, Drucksache 2442; eine interessante und differenzierte Analyse vgl. Horáček, Jazykové právo, S. 18-23. Zur deutschen Kritik vgl. vor allem Spiegel, Verfassungsoktroi, S. 41-47; Denkschrift, S. 17-18; Spiegel, in: Bo 21. 12. 1921; Epstein, Sprachenrecht, S. 50; Klepetař, Sprachenkampf, S. 16-20; Sprachenverordnung, S. 8. 
Die gesetzlich verankerte Vorrangstellung sicherte der "tschechoslowakischen“ Staatssprache als der am meisten verbreiteten und manchmal auch der einzig möglichen Vermittlungssprache faktisches Prestige. Daneben waren in der Sprachgesetzgebung Bemühungen deutlich sichtbar, der Staatssprache auch formelles Prestige zu verschaffen, wodurch das ethnisch-sprachliche Selbstverständnis des Staates klar zum Ausdruck kommen sollte. Diese Tendenz trat besonders in der Bestimmung zutage, dergemäß die Staatssprache in zweisprachigen Texten immer den Vorrang haben mußte, obwohl es sicher besonders bei Aufschriften jeglicher Art vernünftiger gewesen wäre, die lokalen Mehrheitsverhältnisse zu berücksichtigen.

Auch die Einführung der viel kritisierten Praxis, Eingaben in den Minderheitensprachen zweisprachig zu erledigen, also sowohl in der Sprache der Eingabe als auch in der Staatssprache, ist weitgehend auf das Prestigedenken zurückzuführen, nämlich auf die Forderung, daß jeder schriftliche oder mündliche Akt der Staatsgewalt, falls sich der betreffende Staat als Nationalstaat verstand, in erster Linie in der Staatssprache zu erfolgen hatte. Die Autoren des Sprachengesetzes wollten ursprünglich an die Frage der doppelsprachigen Erledigungen offensichtlich als ein im Grunde genommen administratives Problem herangehen. Falls der Staat mit allen seinen Bürgern effektiv kommunizieren wollte, mußten die Staatsverwaltung sowie das Gerichtswesen auch auf den Gebrauch von Minderheitensprachen eingestellt sein, und die Frage lautete, ob alle ihre Organe oder nur ausgewählte, die für die übrigen eine Art Übersetzungsdienst leisten würden. Eben um diesen Punkt drehten sich die Diskussionen um die Jahreswende 1919/1920 über die eventuelle Einführung von doppelsprachigen Erledigungen. ${ }^{8}$ Diese hatten für den Fall der Berufung bei einer höheren Instanz einen gewissen Sinn, denn zur Grundlage der Behandlung konnte die tschechische bzw. slowakische Fassung werden, was die Administrative der Staatsbehörden oder Gerichte vor allem der zweiten und dritten Instanz doch erleichtert hätte. Andererseits drohte, daß die Organe der ersten Instanz zuviel mit Übersetzungsarbeiten belastet würden; auch die zweifache Ausfertigung von Erledigungen war mit einem gewissen administrativen Aufwand verbunden. Die Regierung ließ schließlich diese Frage offen, indem sie in ihrem ersten Entwurf des Sprachengesetzes zwar grundsätzlich doppelsprachige Erledigungen verankerte, die Vollzugsgewalt jedoch zu ermächtigen beabsichtigte, festzulegen, inwieweit und bei welchen Gerichten und Behörden (Organe kamen nicht hinzu) eine Erledigung bloß in der Minderheitensprache möglich sein würde. Dies schien der Opposition jedoch zu weitgehend, und im Sprachengesetz wurde schließlich ein Kompromiß verankert, nach dem sich die diesbezügliche Ermächtigung der Vollzugsgewalt nunmehr nur auf Gerichte und Behörden erstreckte, deren Wirksamkeit für einen einzigen Minderheitenbezirk galt, und auf die ihnen instanzmäßig unmittelbar übergeordnete Stufe. ${ }^{9}$ Um die Durchführung dieser Ermächtigung entfachte sich ein harter Kampf, der im irrationellen Jonglieren mit der prozentualen Grenze, ab der einsprachig deutsche Erledigungen erlaubt werden sollten, seinen Ausdruck fand: Diese lag 1920 bei mindestens 80 Prozent Angehöriger der Minderheitensprache im betreffenden Gerichtsbezirk, 1922 bei 50 und 1924 bei 60 Prozent, um in

\footnotetext{
${ }^{8}$ Vgl. beispielsweise APČR, RNS, Karton 33, 158. Sitzung des Verfassungsausschusses am 24. 2. 1920, Vormittag, S. 34-50.

9 Vgl. Kapitel I.A.4.
} 
der Endfassung von 1926 schließlich bei 66 Prozent zu landen ${ }^{10}$ - dies übrigens zur Mißstimmung der tschechischen Volkstumsverbände, die forderten, daß die Regierung von der diesbezüglichen Ermächtigung des Sprachengesetzes gar keinen Gebrauch machen sollte. ${ }^{11}$

In Gerichtsbezirken, in denen eine doppelsprachige Erledigung vorgeschrieben war, lebten im Jahre 1921 in den böhmischen Ländern insgesamt 560256 Deutsche $(18,84$ Prozent der gesamten deutschen Bevölkerung). 2.242821 Deutsche (75,44 Prozent) erhielten in der Regel eine einsprachige, nur deutsche Erledigung. Die Volkszählung von 1930 zeigte diesbezüglich nur geringfügige Veränderungen auf: Eine zweisprachige Erledigung bekamen 17,71 und eine einsprachige 74,74 Prozent der deutschen Bevölkerung. ${ }^{12}$ Von der gesamten Bevölkerung der böhmischen Länder machte der Anteil der Deutschen, die in Bezirken mit zweisprachiger Erledigung lebten, 5,7 Prozent aus. Die Belastung der Staatsverwaltung durch doppelsprachige Erledigungen mag somit nicht so dramatisch gewesen sein, selbst wenn man natürlich berücksichtigen muß, daß auch Gerichte und Behörden der höheren Instanz (Oberlandesgerichte, Landesbehörden, Ministerien usw.) deutsche Eingaben, soweit sie den gesetzlichen Voraussetzungen entsprachen, auch zweisprachig erledigten. Die deutschen Kritiker bewerteten doppelsprachige Erledigungen als Unding, das „unfruchtbare Zeit, Mühe und Kosten" erforderte und sprachen sich für eine Herabsetzung auf mindestens 50 Prozent aus. ${ }^{13}$ Die Staatsverwaltung, obwohl auch von der tschechischen Seite kritische Stimmen laut wurden, gab erst im Entwurf des neuen Sprachengesetzes von 1938 das Prinzip der zweisprachigen Erledigung im Parteienverkehr grundsätzlich auf. $^{14}$

„Der Tschechoslowakei wird stets der Ruhm bleiben, das verwickelteste und verworrenste Sprachenrecht der Welt zu besitzen. "15 Auch wenn dieses wenig schmeichelhafte Urteil des Deutschen Juristentages in der Tschechoslowakei voreingenommen und propagandistisch zugespitzt erscheinen mag, kann man sich dennoch nicht einfach über die Ansicht dieses anerkannten fachlichen Gremiums hinwegsetzen. Das Sprachenrecht war tatsächlich ein kaum übersehbares Normensystem, in dem sich auch Fachleute nur mühevoll zu orientieren vermochten. Bis zum Jahre 1926 wurden beinahe 90 und in den folgenden Jahren bis 1938 nochmals mehr als 60 Gesetze und Verord-

10 Vgl. Kapitel I.B.1.

11 SUA, MV-SR, Karton 1487, 14/1/4, Denkschrift des SNJM an den Ministerpräsidenten über das Sprachenrecht in der Tschechoslowakischen Republik, 12. 1. 1925.

12 Berechnet nach: Československá statistika, Bd. 9, S. 29-34 bzw. Bd. 98, S. 26-34.

13 Vgl. Sprachenverordnung, S. 23.

${ }^{14}$ So verlangte E. Sobota in seinem Exposé für Präsident Beneš von 1936, doppelsprachige Erledigungen "möglichst" einzuschränken. Vgl. ANM, NL Sobota, Karton 13, Exposé Sobotas "Über die Möglichkeit, den Forderungen der Minderheiten im Bereich des Sprachenrechts entgegenzukommen", undat. (1936). F. Plachý kritisierte 1937 doppelsprachige Erledigungen als „dekorative Beschriftung des Papiers“, die die „Rationalität der Amtsführung “ beeinträchtige. Ders., Je československé právo, S. 262. Aus der Doppelsprachigkeit wurde inzwischen eine Art Institution: Der Bestandteil einer doppelsprachigen Erledigung war auch der Umschlag bzw. die für den Empfänger bestimmte Drucksorte. Somit waren auch Stempel, Vorname (Familiennamen galten als „unübersetzbar"), Beruf des Antragsstellers und Adresse - d. h. Gemeindenamen (soweit die Gemeinde einen amtlichen deutschen Namen hatte) sowie Straßenbezeichnungen - zweisprachig anzuführen. Mit Rücksicht auf die Zeitersparnis war erlaubt, Name, Familienname und Beruf lediglich einsprachig auszufüllen. Vgl. SÚA, MF-P, Karton 245, Erlaß des Präsidiums der Landesfinanzdirektion in Prag, 16. 7. 1937. Vgl. auch Kapitel I.E.1. bzw. I.E.3.

15 Sprachenverordnung, S. 79. 
nungen erlassen, insgesamt also über 150 Rechtsnormen ${ }^{16}$, die im Rahmen der Grundsätze des Sprachengesetzes den Sprachgebrauch in verschiedensten Lebensbereichen direkt oder indirekt (beispielsweise durch ausdrückliche Überlassung einer meistens durch die Staatsorgane zu billigenden Geschäftsordnung) regelten bzw. den erforderlichen Umfang der Sprachkenntnisse für die Ausübung gewisser Funktionen - besonders im Staatsdienst - festlegten. Ihr konkreter Wirkungsbereich war natürlich sehr unterschiedlich und reichte von den sprachlichen Bedürfnissen des Alltags bis hin zu Subtilitäten wie der Beschriftung von Jubiläumsdukaten oder der obligatorischen Signierung des Hopfens. Auf den Sprachgebrauch im Bereich einzelner Ministerien bezogen sich weiter verschiedene interne Vorschriften, von denen beispielsweise allein die Postverwaltung für ihren Zuständigkeitsbereich in den Jahren 1919 bis 193827 herausgab, das Finanzministerium sogar $39 .{ }^{17}$

Der Vorwurf der Verworrenheit des tschechoslowakischen Sprachenrechts lag jedoch nicht unbedingt an der Menge seiner überaus zerstreuten Bestimmungen, sondern auch an seiner komplizierten Gesamtstruktur, die die Folge der Balancierung zwischen den Prestigeansprüchen und dem Bedürfnis war, dennoch eine funktionierende Kommunikation zu gewährleisten. Schwierigkeiten barg bereits die einfache Frage in sich, wer, wo und unter welchen Bedingungen eine andere als die staatliche/offizielle Sprache überhaupt gebrauchen durfte. Dem Sprachenrecht lag eine merkwürdige Kombination von Personalitäts- und Territorialitätsprinzip zugrunde. Das erstere kam darin zum Ausdruck, daß das Sprachenrecht an die Person gekoppelt war: Niemand anderer als ein Deutscher durfte eine deutschsprachige Eingabe an ein Staatsorgan richten. Staatsorganen wurde somit implizit auferlegt, die Nationalität bzw. Sprachzugehörigkeit der Partei zu überprüfen, es wurden ihnen hierzu jedoch keinerlei Instrumente bereitgestellt, denn die tschechoslowakischen Personaldokumente (Heimatscheine, Pässe usw.) enthielten keine derartige Rubrik. Laut Durchführungsverordnung zum Sprachengesetz konnten die Staatsorgane im „Zweifelsfall“ eine mündliche oder schriftliche Erklärung der Partei hinsichtlich ihrer Sprachzugehörigkeit einholen. Wann ein solcher Fall eintrat und worauf die Erklärung der Partei eigentlich basieren sollte, war jedoch nicht klar. ${ }^{18}$ Umso weniger stand fest, was eigentlich unter „Sprachzugehörigkeit“ zu verstehen war. Weder die Gesetzgebung noch die Rechtssprechung gelangten zu einer einheitlichen und vor allem stichhaltigen Definition ${ }^{19}$, was umso erstaunlicher war, als eine falsche Angabe der Sprachzugehörigkeit vor einem Staatsorgan eine Ordnungsstrafe bis zu 1000 Kronen zur Folge haben konnte. ${ }^{20}$ Als allerletzte Instanz konnte das Statistische Staats-

${ }^{16}$ Vgl. Epstein, Sprachenrecht, S. 267-310; Glück, Sprachenrecht, S. 216-262. Ausgenommen sind internationale Verträge.

17 SÚA, MŠ̌aNO-P, Karton 375, Mappe 20, MPaT an PMR, 7. 4. 1938; SÚA, MF-P, Karton 245, Übersicht über die Vorschriften über die Minderheitenrechte, undat, (1937).

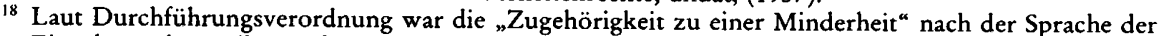
Eingabe zu beurteilen, sofern dem Gericht oder der Behörde nicht „anderweitig “ bekannt war, daß die Partei Angehöriger einer anderen Sprache war.

19 Spiegel, in: Bo vom 11.2. 1926. Zur Definition des Begriffs "Nationalität“ in der tschechoslowakischen Gesetzgebung vgl. Sobota, Nationalitätenrecht, S. 43-55.

20 Der Jurist F. Weyr meinte beispielsweise, den Staatsorganen in den sprachlich qualifizierten Bezirken stehe es überhaupt nicht zu, die Nationalität des Antragsstellers in jedem einzelnen Fall zu überprüfen. Diese seien verpflichtet, jede Eingabe in der betreffenden Minderheitensprache anzunehmen. Vgl. Weyr, Soustava, S. 409. 
amt gefragt werden, welche Nationalität der Betreffende bei der letzten Volkszählung angegeben hatte, doch dieser umständliche Weg wurde offensichtlich nur ungern beschritten.

Das Personalitätsprinzip war bereits im Regierungsentwurf des Sprachengesetzes vom November 1919 enthalten. Einige liberal gesinnte Persönlichkeiten waren offensichtlich davon ausgegangen, daß es den Bürgern frei stehen sollte, ob sie sich an ein Staatsorgan, das tschechisch und deutsch im Parteienverkehr amtierte, in der einen oder der anderen Sprache wenden würden. Im Verfassungsausschuß hatte V. Bouček versucht, in diesem Sinne eine Änderung der Regierungsvorlage zu veranlassen, allerdings vergeblich. ${ }^{21} \mathrm{Er}$ hatte sich besonders gegen $\mathrm{K}$. Kramář nicht durchsetzen können, der auf diesem Wege auf die Sicherung der Stellung des Tschechischen als erstrangige Verkehrssprache des Staates abgezielt hatte; deshalb müßten, meinte er, auch die Angehörigen tschechischer Nationalität durch das Gesetz gezwungen werden, ihre Eingaben tschechisch vorzubrigen. Auch ein Ungarn, selbst wenn er ausgezeichnet deutsch sprach, mußte etwa in Warnsdorf eine tschechische Klage einbringen, um ihm deutlich zu machen, so wieder Kramár̆, daß seine Verkehrssprache tschechisch und nicht deutsch sei. ${ }^{22}$

Das Territorialitätsprinzip äußerte sich im tschechoslowakischen Sprachenrecht in zweifacher Hinsicht: Zum einen waren Eingaben in einer anderen als in der Staatssprache lediglich bei Staatsorganen zulässig, deren Wirksamkeit sich auf einen $\mathrm{Ge}$ richtsbezirk erstreckte, in dem nach der letzten Volkszählung zu wenigsten 20 Prozent Staatsbürger „derselben, jedoch einer anderen als der tschechoslowakischen Sprache" wohnten. ${ }^{23}$ Zum anderen mußte die Angelegenheit auch in einem derartigen Gerichtsbezirk ihren Ursprung haben. Der Wohnort war somit nicht relevant; daher stand beispielsweise einem Prager Deutschen, der sich in seiner Heimatstadt nicht auf deutsch an Staatsorgane der ersten Instanz wenden konnte, das Recht zu, beim Bezirksgericht, etwa in Warnsdorf, seine Muttersprache zu gebrauchen. Mit dem Territorialitätsprinzip gab es im Alltag wohl noch größere Schwierigkeiten als mit dem Personalitätsprinzip; dies war besonders bei denjenigen Staatsorganen fast die Regel, deren Wirkungskreis sich auf ein kleineres oder aber auf ein größeres Gebiet als einen Gerichtsbezirk bzw. das ganze Land oder gar den gesamten Staat erstreckte. Hierzu entwickelte das Oberste Verwaltungsgericht eine umfangreiche, jedoch nicht immer konsistente Rechtsprechung, die manchmal sprachlich merkwürdige Zustände schuf. ${ }^{24}$ So wurde beispielsweise in Prozessen gegen den Staat in Angelegenheiten des Mar-

${ }^{21} \mathrm{Vgl}$. APČR, RNS, Karton 33, 158. Sitzung des Verfassungsausschusses am 24. 2. 1920, Vormittag, S. 49.

22 APČR, RNS, Karton 33, 158. Sitzung des Verfassungsausschusses am 24. 2. 1920, Vormittag, S. 44-45. Laut Durchführungsverordnung wurden derartige Eingaben zur „Berichtigung des Formgebrechens“ zurückgestellt oder "als zur gesetzmäßigen Einleitung der Verhandlung ungeeignet" abgewiesen. Daß Angehörige der "tschechoslowakischen“ Sprache kein Recht auf den Gebrauch einer Minderheitensprache hatten, bestätigte das Urteil des Obersten Verwaltungsgerichts Nr. 14769/22 vom 22. 1. 1923. Vgl. auch Epstein, Sprachenrecht, S. 69.

${ }^{23}$ Gesetz Nr. 122/1920 Slg. Maßgeblich waren die amtlich publizierten Ergebnisse der letzten Volkszählung. Als problematisch erblickte man die Tatsache, daß bei Volkszählungen nicht die Sprachzugehörigkeit, sondern die Nationalität ermittelt wurde. Erst das Urteil des Obersten Verwaltungsgericht Nr. 109/24 vom 7. 1. 1925 erklärte, daß beide Begriffe identisch seien. Vgl. Epstein, Sprachenrecht, S. 70.

${ }^{24}$ Vgl. Diwald, Jazykové právo, S. 72; Peška, Národní menšiny, S. 152-153; Epstein, Sprachenrecht, S. 88-97; Schmued, Sprachenrechte, S. 10. 
kenschutzes, für den das Zivilkreisgericht Prag zuständig war,- auch in Minderheitensprachen verhandelt. Bei demselben Gericht wurde jedoch auch die Landtafel geführt, und, falls das Gericht in seiner anderen Eigenschaft als Landtafelgericht auftrat, kam lediglich die Staatssprache zur Anwendung, selbst wenn das betreffende ländliche Gut etwa in dem bereits erwähnten Gerichtsbezirk Warnsdorf lag. ${ }^{25}$ Ebenso verfuhr man beim Patentgericht in Prag oder bei Klagen gegen den Fiskus, weil zur Entscheidung über die letztgenannten Klagen die Kreisgerichte am Sitz der böhmischen Finanzprokuratur - also in Prag - berufen waren, bei denen nur die Staatssprache zugelassen war, weil Prag keine zwanzigprozentige deutsche Minderheit aufwies. Besser erging es den Deutschen in Mähren, denn in Brünn, wo knapp über 20 Prozent Deutsche lebten, waren Behörden und Gerichte verpflichtet, deutsche Angaben anzunehmen. ${ }^{26}$

$\mathrm{Zu}$ den Problemen auf dem Gebiete des Sprachenrechts trug nicht nur seine komplizierte Gesamtstruktur bei, sondern auch seine mangelnde rechtstechnische Qualität. Die meisten grundlegenden Begriffe, wie „offizielle, staatliche Sprache“, „Amtieren“ bzw. „Amtsführung“, „Eingabe“, „Erledigung“ oder „Organe der Republik“, wurden nicht explizit definiert, sondern mußten anhand ihres Anwendungsbereichs in den Rechtsnormen oder analog gedeutet werden, was manche sowohl deutsche als auch tschechische Juristen kritisch reflektierten. ${ }^{27}$ Auch zahlreiche Bestimmungen der Sprachnormen waren bei weitem nicht klar und eindeutig. Zu denjenigen Formulierungen des Sprachenrechts, die ernste interpretatorische Probleme hervorriefen und somit einen nationalpolitischen Konfliktstoff lieferten, gehörte beispielsweise Paragraph 5 des Sprachengesetzes, der bestimmte, daß die für die nationalen Minderheiten errichteten Schulen und kulturellen Institutionen in der Sprache der betreffenden Minderheit verwaltet werden sollten. Was in deutscher Sprache eindeutig erscheint, stellt in der tschechischen - also authentischen und deshalb ausschlaggebenden - Fassung ein linguistisch-juristisches Rätsel dar: Die hier gebrauchte reflexive Verbform „spravuji se“ kann im Deutschen sowohl „verwalten sich“ als auch - so lautete allerdings die offizielle deutsche Übersetzung in der „Sammlung der Gesetze“ - „werden verwaltet" bedeuten. Während der hastigen Verhandlungen im Verfassungsausschuß oder im Plenum der Nationalversammlung bemerkte niemand, wie zweischneidig die gebrauchte Wendung war, und damit wurde für einen langjährigen Streit gesorgt, ob die Form passiv oder reflexiv zu verstehen war, also ob damit den Schulen der nationalen Minderheiten der Gebrauch ihrer Sprache bloß in der inneren Verwaltung gewährt wurde, oder sich auch auf den Verkehr mit den staatlichen Schulbehörden erstreckte. $^{28}$

${ }^{25}$ Die Landtafel war ein Register, in dem alle Grundstücke in adligem oder städtischem Besitz erfaßt wurden.

${ }^{26}$ Adler, Geist, S. 39-40.

27 Diwald, Jazykové právo, S. 68-70; Epstein, Sprachenrecht, S. 50-53; Klepetař, Sprachenkampf, S. 14-15, 20-21; Peška, Národní menšiny, S. 147; Sobota, Národnostní autonomie, S. 31; Sobota, Nationalitätenrecht, S. 82-93; Adler, Geist, S. 36-37; Perek, in: Národ vom 22. 7. 1920. Perek vermißte im Sprachgesetz die Definition auch solcher Begriffe, wie beispielsweise Nationalität, sprachliche und nationale Minderheit, Muttersprache, Umgangssprache u. a., was jedoch ein zu hoch gesteckter Anspruch an die Gesetzgebung war.

${ }^{28}$ Allerdings ist die in Paragraph 5 des Sprachengesetzes enthaltene Berufung auf Artikel 9 des Vertrages von St. Germain fehlerhaft. AKPR, T 392/22, Karton 92, Bělohrádek an Šámal, 2. 3. 1922, Sámal an Bělohrádek 6. 3. 1922. Der tschechische Jurist H. Diwald hielt den Paragraphen überhaupt für 
Während die Deutschen einheitlich den Standpunkt vertraten, daß Schulen mit deutscher Unterrichtssprache durch die vorgesetzten Organe auch in dieser Sprache verwaltet werden sollten, und verlangten, diesen Grundsatz zumindest in der Durchführungsverordnung unmißverständlich festzulegen ${ }^{29}$, vermochte sich die tschechische Seite zunächst zu keiner übereinstimmenden Auffassung durchzuringen. Die tschechischen Nationalisten verlangten, den strittigen Paragraphen dahingehend $\mathrm{zu}$ interpretieren, daß sich seine Bestimmungen nur auf die innere Verwaltung bezogen ${ }^{30}$; das Schulministerium dagegen ging in seinem Entwurf der Durchführungsverordnung zum Sprachengesetz vom Jahre 1921 davon aus, die Unterrichtssprache sei nicht nur die Sprache der inneren Verwaltung der Lehranstalten, sondern auch die des Verkehrs mit den vorgesetzten Schulbehörden und den zuständigen Organen der Schulaufsicht; sie konnte sogar auch im Verkehr mit Schulräten, Lehranstalten sowie Korporationen gebraucht werden, solange sie die gleiche Unterrichts- bzw. Geschäftssprache hatten. ${ }^{31}$ Jede Lehranstalt war zwar verpflichtet, Eingaben in der Staatssprache anzunehmen, die Sprache der Erledigung wurde jedoch nicht ausdrücklich angeordnet, was im Gesamtkontext implizierte, daß Eingaben in der Unterrichtssprache erledigt werden konnten. Die spätere Praxis unterschied sich wesentlich von diesen, wenn auch nicht in jedem Punkt klaren Bestimmungen des Entwurfes. Bereits 1923 beklagten die deutschen Abgeordneten, daß der Landesschulrat mit den Bezirks- und Ortsschulräten auschließlich in tschechischer Sprache zu verkehren begann. ${ }^{32}$ Der Standpunkt des Schulministeriums war eindeutig: Landesschulrat und Bezirksschulräte seien staatliche Behörden, deswegen würden sie im Sinne des Sprachengesetzes in der Staatssprache amtieren. Mit den Ortsschulräten würden die Bezirksschulräte zweisprachig korrespondieren. ${ }^{33}$ In dem Streit spiegelten sich u. a. auch unterschiedliche Ansichten über den Charakter der Schulbehörden wider, die als Überbleibsel der kulturellen Selbstverwaltung aus der Vorkriegszeit überlebt hatten und eigentlich mit der Einführung der geplanten Gauordnung durch staatliche Organe ersetzt werden sollten. Da sich jedoch die Verwaltungsreform verzögerte, existierten die Schulräte weiter, jedoch ohne eindeutige gesetzliche Grundlage. Die deutschen Parteien sahen in ihnen eine wichtige Komponente, nämlich entweder wertvolle Reste oder möglicherweise auch Keime einer neuen Schulautonomie; deswegen hielten sie den staatlichen Charakter dieser Behör-

überflüssig, weil diese Materie bereits durch die Verfassung in den Paragraphen 130 und 131 geregelt worden sei. Vgl. Diwald, Jazykové právo, S. 67.

${ }^{29} \mathrm{Vgl}$. Schmued, Sprachenrechte, S. 7; SÚA, MF-P, Karton 163, c 6784/21, Verband der deutschen Rechtsanwälte in Böhmen an MF, 5. 7. 1921; SÚA, MV-SR, Karton 1487, 14/1/14, Memorandum betreffend die Sprachverordnungen, überreicht von den Spitzenorganisationen der deutschen Staatsangestellten, undat. (Eingang MV 3.1.1925).

30 Vgl. Národ vom 22. 7. 1920, S. 219; SÚA, NRČ, Karton 491, 269, NRČ an PMR, 11. 10. 1920.

31 SUA, PMR, Karton 462, 1063, Verordnung der Regierung der Tschechoslowakischen Republik, undat. (1921, vgl. MŠaNO an PMR, 18.6. 1922, Anlage).

32 Interpellation der Abgeordneten Böhr, Křepek, Dr. Kafka und Genossen an die Regierung wegen Verdrängung der deutschen Sprache aus dem Verkehr der Landesschulräte mit den Bezirks- und Ortsschulräten vom 6. 2. 1923, in: TTZPS, 1. WP, Drucksache 3995/XVII; eine gleichlautende Interpellation reichten bereits am 23. 1.1923 die Senatoren der deutschen bürgerlichen Parteien ein, in: TTZS, 1. WP, Drucksache 1563/I; die deutschen Sozialdemokraten brachten eine eigene Interpellation vor, vgl: Interpellation der Abgeordneten Dr.Czech, Cermak, Hillebrand und Genossen in Angelegenheit der Änderung des Sprachverkehrs in den Schulbehörden vom 9. 2. 1923, in: TTZPS, 1. WP, Drucksache 4017/XVI.

33 SÚA, MV-SR, Karton 511, 20/2/203, Aktenvermerk MV, 10. 8. 1923. 
den zumindest für strittig. ${ }^{34}$ Dagegen war das Schulministerium der Ansicht, daß lediglich die Ortsschulräte einen autonomen Charakter hätten. ${ }^{35}$

Bekanntlich bezog sich die Durchführungsverordnung zum Sprachengesetz nicht auf den Bereich des Schulministeriums, und der nebulöse Zustand in der Schulverwaltung, dessen Rechtmäßigkeit weitgehend Ansichtssache sein konnte, dauerte weiter an. Im Juli 1929 erließ der Landesschulrat eine Anordnung, derzufolge mit den Mittelschulen ausschließlich in der Staatssprache zu verkehren war. Der Schulminister begründete diesen Schritt damit, die Direktion einer Mittelschule sei eine staatliche Behörde, und deswegen sei auch der Landesschulrat als eine ebenfalls staatliche Behörde verpflichtet, mit den Direktionen staatlicher Mittelschulen in der Staatssprache zu korrespondieren. ${ }^{36}$ In der Praxis wurden also die unklare Bestimmung des Sprachengesetzes im Laufe der Zeit tendenziell zuungunsten der Minderheitensprachen umgedeutet.

Wohl das auffallendste Beispiel für die strittige Auslegung der komplizierten und uneindeutigen Formulierungen des Sprachenrechts liefert der langjährige Streit über die Sprachenrechte der deutschsprachigen Ausländer. Zunächst schien die Angelegenheit ganz einfach zu sein: Die tschechoslowakische Rechtswissenschaft wie auch die Politik hegten nicht den leisesten Zweifel daran, daß sich der sprachliche Minderheitenschutz nur auf eigene Staatsbürger beziehen konnte. Diesen Grundsatz formulierte bereits im März 1919 das Oberste Verwaltungsgericht ${ }^{37}$; indirekt bestätigte ihn der Minderheitenschutzvertrag von St. Germain, der, wie später mehrfach hervorgehoben wurde, in keiner seiner Bestimmungen Ausländer erwähnte. Demzufolge schränkte der Regierungsentwurf des Sprachengesetzes vom November 1919 die Sprachenrechte ausdrücklich auf tschechoslowakische Staatsangehörige ein. In der durch die Regierung ausgearbeiteten Begründung zum Sprachengesetz vom November 1919 hieß es unmißverständlich: “... es kann vom Staat nicht verlangt werden, daß er Ausländern die Sprachenrechte gewährt, es ist im Gegenteil von Ausländern zu verlangen, daß sie sich der offiziellen Sprache des Staates anpassen, dessen Gastfreundschaft sie genie-

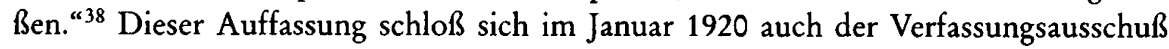
vorbehaltslos an.

In der letzten Phase der hastigen und manchmal emotionsgeladenen Verhandlungen des Verfassungsausschusses am 24. Februar zog Justizminister Veselý diesen Grundsatz in Zweifel, was für ihn als Regierungsmitglied ohnehin merkwürdig war; noch überraschender schloß sich ihm auch $\mathrm{K}$. Kramáŕ an. Er könne nicht verlangen, begründete der Oppositionsführer seine Haltung, daß ein Reichsdeutscher in sprachlich qualifizierten deutschen Bezirken der Tschechoslowakei eine tschechische Eingabe einreichen, also anders vorgehen müsse, als ein Deutscher, der tschechoslowakischer Staats-

${ }^{34}$ Interpellation der Abgeordneten Dr. Czech, Cermak, Hillebrand und Genossen in Angelegenheit der Änderung des Sprachverkehrs in den Schulbehörden vom 9. 2. 1923, in: TTZPS, 1. WP, Drucksache 4017/XVI.

${ }^{35}$ SÚA, MV-SR, Karton 511, 20/2/203, Aktenvermerk MV, 10. 8. 1923.

${ }^{36} \mathrm{Vgl}$. Interpellation des Abgeordneten Simm und Genossen an den Minister für Schulwesen und Volkskultur in Angelegenheit sprachlicher Verfügungen des Landesschulrates für Böhmen vom 28. 1. 1930, in: TTZPS, 3. WP, Drucksache 174/IX.; die Antwort des Schulministers vom 8. 10. 1930, in: ebda., Drucksache 699/IX.

37 SÚA, PMR, Karton 3295, 740/6/5, Entschließung des Obersten Verwaltungsgerichts in Prag vom 19. 3.1919 über die gültigen Grundsätze des Sprachenrechts in der Tschechoslowakischen Republik.

${ }^{38}$ SÚA, MV-SR, Karton 1, 1/2/2, Regierungsentwurf des Gesetzes, durch das die Grundsätze des Sprachenrechts in der Tschechoslowakischen Republik festgelegt werden, undat. (1919). 
bürger war. ${ }^{39}$ Daraufhin wurde in Paragraph 2, der den Umfang der Sprachenrechte der Minderheiten festlegte, der Ausdruck „Staatsbürger" durch die Wendung „Angehörige der Sprache der Minderheit" ersetzt. In der darauffolgenden Debatte im Plenum der Nationalversammlung versuchten zwar die nationaldemokratischen Abgeordneten J. Herben und F. Lukavský - wieder offenbarte sich die Kluft zwischen Kramář und seinen radikaleren Parteigenossen - eine dahingehende Änderung zu erreichen, daß sich die Bestimmungen von Paragraph 2 nur auf tschechoslowakische Staatsangehörige beziehen sollten. Ihre Initiative blieb jedoch wegen der stürmischen Auseinandersetzungen über die offizielle bzw. staatliche Sprache und die Sprachkenntnisse der Staatsangestellten praktisch unbeachtet und landete unter den abgelehnten Anträgen. ${ }^{40}$

Das Sprachengesetz garantierte folglich in Bezirken, in denen zu wenigstens 20 Prozent Staatsbürger einer Minderheitensprache wohnhaft waren, „den Angehörigen der Sprache dieser Minderheit" das Recht, Eingaben in ihrer Muttersprache einzureichen und Erledigungen in ihr zu erhalten. Auf den ersten Blick schien alles in Ordnung zu sein. Im Oktober 1921 bestätigte das Oberste Verwaltungsgericht ausdrücklich, daß sich diese Begünstigung nicht nur auf die Staatsbürger beschränke, sondern erkannte dieselben ohne Rücksicht auf die Staatszugehörigkeit jedem Angehörigen der betreffenden Minderheitensprache zu. ${ }^{41}$ Das Urteil wurde durch den Standpunkt des Obersten Gerichts hervorgerufen, das seit Mai 1920 an der entgegengesetzten Auffassung festhielt, Ausländern stünde kein sprachlicher Minderheitenschutz zu. Im Dezember 1921 bekräftigte das Oberste Gericht aufs neue seinen Standpukt, dem Sprachengesetz gemäß könnten bei einer Eingabe an ein Gericht nur tschechoslowakische Staatsbürger eine andere als die Staatssprache gebrauchen; ein Ausländer müsse in jedem Fall die Staatssprache benutzen, seine Nationalität sei in dieser Frage gegenstandslos. ${ }^{42}$

Die beiden Stellungnahmen der höchsten tschechoslowakischen Gerichtshöfe markierten den Anfang eines fünfzehn Jahre andauernden Streits in der tschechoslowakischen Justiz und Rechtswissenschaft. Zum Lager der Befürworter des Standpunktes des Obersten Verwaltungsgerichts gehörten praktisch alle deutschen Juristen, gleichzeitig aber eine Reihe von tschechischen und slowakischen Rechtswissenschaftlern und Richtern, beispielsweise F. Weyr, Z. Peška, J. Hausman oder E. Sobota. ${ }^{43}$ Unter den Kritikern des Obersten Verwaltungsgerichts waren lediglich tschechische und slowakische Juristen zu finden, neben dem Präsidenten des Obersten Gerichts A. Popelka beispielsweise J. Hoetzel, B. Říha, V. Hora, V. Joachim oder A. Meissner. ${ }^{44}$ Von ihrer Seite ertönten außer rein juristischen nicht nur vereinzelt auch nationalpolitisch ge-

${ }^{39}$ APČR, RNS, Karton 33, 158. Sitzung des Verfassungsausschusses am 24. 2. 1920, Vormittag, S. 44.

${ }^{40} \mathrm{Vgl}$. Antrag der Abgeordneten Herben und Lukavský auf Änderung etlicher Bestimmungen des Sprachgesetzes vom 28. 2. 1920, in: TZRNS, S. 3774 bzw. 3865.

${ }^{+1}$ SÚA, MV-SR, Karton 510, 20/2/131, Beschluß des NSS Nr. 12285 vom 21. 10. 1921; Véstník MV 3 (1921), S. 400-403.

${ }^{42}$ Beschluß des Obersten Gerichts Nr. R I 1426/21/1 vom 13.12. 1921, in: Vẽstník MV 4 (1922), S. 28-29.

${ }^{43}$ Vgl. Peška, Národní menšiny, S. 155. J. Hausman war Präsident des Oberlandesgerichts in Prag, in der zweiten Beamtenregierung im Jahre 1926 war er Justizminister.

${ }^{44}$ Peška, Studie, S. 181; Peška, Národní menšiny, S. 155; Meissner, in: LN vom 14. 8. 1932; Popelka, Nejvyšši soud, passim, řiha, Cizincům, passim. Vgl. SÚA, PMR, Karton 3296, 740/35, Resolution des Vereines tschechischer Rechtsanwälte in Mähren, 23. 10. 1928. Der Verein schloß sich einhellig der Auslegung des Sprachengesetzes an, wie sie in den Entscheidungen des Obersten Gerichts in Brünn enthalten gewesen war. 
färbte Argumente, u. a. die Warnung vor einem eventuellen, nicht näher spezifizierten, immerhin jedoch „bedenklichen“ Schaden für den Staat und seine Bewohner. Den Löwenanteil an dieser Entwicklung hatte die bisweilen kontroverse Haltung des Vorsitzenden des Obersten Gerichts, A. Popelka, der nicht selten das genuin juristische Feld verließ, um sich auf das der Politik zu begeben. Die Verfechter des Standpunktes des Obersten Gerichts wurden als Hüter von „Ehre und Prestige“ des Staates hingestellt, während die Anhänger der entgegengesetzten Ansicht diese mit Füßen treten würden. ${ }^{45}$

Aufgrund des Textes des Sprachengesetzes konnten beide Seiten zwar eine schlüssige, für ihre Opponenten aber kaum überzeugende Interpretation vorlegen. Das Oberste Verwaltungsgericht machte darauf aufmerksam, daß das Sprachengesetz ständig die Wendung "Staatsbürger derselben, aber anderer als der tschechoslowakischen Sprache“ benutzte. Die strittige Wendung „Angehörige der Sprache der Minderheit“ unterscheide sich dermaßen von der üblichen Terminologie des Gesetzes, daß sie sich nicht auf den identischen Personenkreis beziehen könne. Überall, meinte das Gericht, wo die Verfassungsurkunde oder das Sprachengesetz selbst die Gültigkeit ihrer Bestimmungen nur auf Staatsbürger einschränken wollten, sprechen sie dies deutlich aus, indem sie den Begriff „Staatsbürger" benutzten. ${ }^{46}$ Seine Kritiker vertraten dagegen den Standpunkt, daß der Schutz der Sprachenrechte der Ausländer eine dermaßen außerordentliche Erscheinung sei, daß er klare Vorschriften erfordere: „Beabsichtigte der Gesetzgeber den Schutz der Ausländer, dann hätte er es ganz klar und unumwunden aussprechen sol-

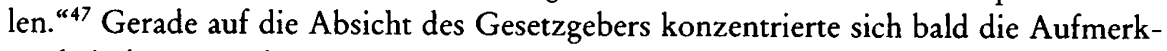
samkeit der Kontrahenten. Das Oberste Verwaltungsgericht führte den Verlauf der Debatte in der Nationalversammlung sowie Notizen seines Präsidenten, F. Pantůček, über die Verhandlungen des Verfassungsausschusses ins Feld, denen dieser zum Teil als Experte beigewohnt hatte. Anhand dieser Materialien kam es zu der Überzeugung, daß sowohl der Verfassungsausschuß als auch das Plenum der Nationalversammlung die Begünstigungen des Sprachengesetzes auch den Ausländern zu gewähren beabsichtigt hätten. ${ }^{48}$ Das Oberste Gericht hielt diese Begründung nicht für überzeugend. Dem Verwaltungsgericht warf es u. a. vor, mit unveröffentlichten Materialien zu argumentieren, gleichzeitig jedoch die Begründung zum Sprachengesetz, die nur Staatsbürger und keineswegs Ausländer erwähnt hatte, nicht genügend beachtet zu haben. ${ }^{49}$ Die Politiker, die an der Arbeit des Verfassungsausschusses im Jahre 1920 teilgenommen hatten, schwiegen übereinstimmend, und, was wohl noch merkwürdiger war, niemand versuchte, die Protokolle des Ausschusses als Beweismaterial hinzuzuziehen. ${ }^{50}$

45 Hora, K otázce, S. 367.

46 Véstník MV 3 (1921), S. 400-403, zit.nach: SÚA, MV-SR, Karton 510, 20/2/131, Beschluß des NSS Nr. 12285 vom 21. 10. 1921.

47 Hora, K otázce, S. 371.

48 SÚA, MV-SR, Karton 510, 20/2/131, Beschluß des NSS Nr. 12285 vom 21. 10. 1921; Vẽstník MV 3 (1921), S. 400-403. Pantůčeks Notizen bzw. persönliche Zeugnisse mögen bei der Entscheidung eine durchaus wichtige Rolle gespielt haben: Angeblich schloß sich das Plenum des NSS zunächst dem Standpunkt des Referenten an, der sich gegen die Zuerkennung der Sprachenrechte an Ausländer aussprach; schließlich entschieden sich jedoch die Richter dazu, dem Präsidenten des Gerichts zu folgen. Vgl. NáP vom 7. 3. 1931

49 AMZV, Sektion VI, Karton 105, Oberstes Gericht an MZV, 8. 4. 1922.

so Noch im Jahre 1937 sprach ein Bericht des Außenministeriums davon, der im Urteil des Verwaltungsgerichts beschriebene Verlauf der Verhandlungen des Verfassungsausschusses stütze sich auf 
Die Angelegenheit landete in einer juristischen Sackgasse. Der Versuch der deutschen Parteien, durch ein besonderes Gesetz eine authentische Interpretation der diesbezüglichen Bestimmungen des Sprachengesetzes zu erreichen, d. h. Ausländer ausdrücklich in dessen Begünstigungen einzubeziehen, lehnte das Parlament bereits 1922 ab. ${ }^{51}$ Der Vollzugsgewalt bot sich zwar die Gelegenheit, das Problem in der Durchführungsverordnung zum Sprachengesetz einer Lösung näherzubrigen, man nahm sie jedoch nicht wahr. ${ }^{52}$ Die Praxis sah ungefähr so aus: Ein Reichsdeutscher brachte beim Obersten Gericht ein Rechtsmittel in deutscher Sprache ein, das jedoch von dem Gericht als zur gesetzmäßigen Einleitung der Verhandlung ungeeignet zurückgewiesen wurde. Da Streitigkeiten über den Sprachgebrauch von den zuständigen Aufsichtsorganen als Angelegenheiten der Staatsverwaltung zu erledigen waren, kam eine Aufsichtbeschwerde in Frage, und zwar auf dem Instanzenweg, dessen höchste Stufe das Oberste Verwaltungsgericht war. Im konkreten Fall mußte man die Beschwerde beim Präsidium des Obersten Gerichts einbringen, falls es ihr nicht stattgab, beim Justizministerium und, falls auch dieses dem Antrag nicht entsprach, beim Obersten Verwaltungsgericht. Das Verwaltungsgericht erkannte zwar das Sprachenrecht der Ausländer an, das Oberste Gericht stand jedoch auf dem Standpunkt, seine Abweisung wegen sprachlicher Mangelhaftigkeit sei rechtmäßig - und die Angelegenheit damit auch in der Sache selbst erledigt. Diese Entscheidung konnte als ein Akt richterlicher Tätigkeit durch keine Aufsichtsbehörde überprüft werden. ${ }^{53}$ Die Partei konnte zwar einen Sieg in der Sprachstreitigkeit verbuchen, war jedoch außerstande zu erwirken, daß ihre Angelegenheit auch meritorisch behandelt wurde, zumal die gesetzliche Frist für die Berufung inzwischen manchmal abgelaufen war. ${ }^{54}$ Kein Wunder, daß die betroffenen Ausländer es unter diesen Bedingungen vorzogen, ihre Berufung in tschechischer Sprache einzubringen, statt nach nutzlosen Lorbeeren in einer Sprachstreitigkeit zu trachten. ${ }^{55}$

Die unklare Rechtslage stiftete natürlich allgemeine Verwirrung in Justiz und Staatsverwaltung: Gerichte und Behörden richteten sich nach freiem Ermessen entweder nach dem Standpunkt des einen oder des anderen Gerichts, wobei nicht selten, solange man die Beschwerden der tschechischen Schutzvereine ernst nehmen darf, die Nationalität des Richters ausschlagebend war. ${ }^{56}$ Unterschiedlich gingen auch einzelne Mini-

„persönliches Wissen“ des inzwischen (1925) verstorbenen Pantůček und sei durch „parlamentarische Belege" nicht verläßlich nachgewiesen. AMZV, Sektion VI., Karton 105, Information für den Herrn Minister, 21. 5. 1937

$5 t$ Antrag des Abgeordneten Dr. Lodgman und Genossen auf authentische Interpretation des $\$ 2$ des Gesetzes vom 29. 2. 1920, Nr. 122 Slg. vom 23. 3. 1922, in: TTZPS, 1. WP, Drucksache 3489. Die vorgeschlagene Änderung lag darin, daß hinter den Ausdruck „von den Angehörigen der Sprache der Minderheit" die Ergänzung ngleichgültig, ob sie tschechoslowakische Staatsbürger sind oder nicht" hinzugefügt werden sollte. Als Begründung enthielt der Antrag den genauen Wortlaut des Urteils des Obersten Verwaltungsgerichts vom 5.10.1921.

52 Die Meinungen hierzu waren übrigens geteilt: Einige Juristen - unter ihnen angeblich auch deutsche - vertraten den Standpunkt, die Verordnung habe die Frage in Art. 14 zu Ungunsten der Ausländer entschieden. Vgl. Řiha, Cizincům, S. 91 bzw. PT vom 16. 2. 1926

53 PA R 73858, Deutsche Gesandtschaft an AA, 24. 8. 1928; LN vom 17. 10. 1928; Meissner, in: LN vom 14. 8. 1932.

${ }^{54}$ Vgl. NáL (Abendblatt) vom 17.6. 1928.

55 Adler, Geist, S. 41.

56 ANM, NL Choc, Karton 4, Mappe 5/48, Brief des tschechischen Volkstumsvereines für Troppau an Choc, 22. 10. 1928; SÚA, MV-SR, Karton 2926, 8/1/24, MS an PMR und alle Ministerien, 7. 9. 1932. 
sterien vor. ${ }^{57}$ In einer besonders prekären Lage befand sich das Justizministerium, das sich mit einem Erlaß vom 2. November 1920 dem Standpunkt des Obersten Gerichts anschloß ${ }^{58}$ Das Oberste Verwaltungsgericht hob jedoch die Entscheidungen des Justizministeriums über sprachliche Beschwerden systematisch auf, was im Laufe der Zeit als immer unhaltbarer empfunden wurde. Im Juni 1926 teilte Justizminister J. Hausmann mit, er habe „im Interesse der Rechtssicherheit“ vor, in Zukunft den Beschwerden der Ausländer im Hinblick auf die Zuerkennung der Sprachenrechte zu entsprechen. Im Juli 1927 änderte das Ministerium tatsächlich die Praxis und hielt sie in den darauffolgenden Jahren konsequent ein, ohne sich jedoch, zumindest nach einer späteren Interpretation, mit dem Standpunkt des Obersten Verwaltungsgerichts ausdrücklich identifiziert zu haben. ${ }^{59}$

In der Praxis änderte sich jedoch nichts. ${ }^{60}$ Gestärkt durch die Tatsache, daß an der Spitze des Justizministeriums seit Oktober 1926 der deutsche Jurist R. Mayr-Harting stand, versuchten die deutschen Rechtsanwaltsverbände - angeblich auf das „Ansehen der tschechoslowakischen Justiz" bedacht - das Ministerium dazu zu bewegen, die Krise, in die die Justiz infolge des Vorgehens des Obersten Gerichts geraten sei, mit nicht näher spezifizierten „schärfsten Mitteln“ zu lösen. ${ }^{61}$ Dies erinnerte jedoch stark daran, die Gerichte beeeinflussen zu wollen. Gegen die Initiativen der deutschen Rechtsanwälte bezog der Präsident des Obersten Gerichts, A. Popelka, dermaßen energisch Stellung - er bezeichnete ihre Bemühungen als eine Verschwörung, die eine "verfassungswidrige Vergewaltigung der richterlichen Unabhängigkeit" verfolge ${ }^{62}-$, daß sich diese entweder dazu gezwungen sahen oder ganz einfach die Gelegenheit wahrnahmen, gegen ihn eine - übrigens erfolgslose - Klage wegen Beleidigung einzureichen. ${ }^{63}$ Das Justizministerium konnte nicht umhin, - angeblich tat es dies "stillschweigend" - den "Sprachentrotz" des Obersten Gerichts hinzunehmen, was in der deutschen Presse als eine "schwere Niederlage der staatlichen Autorität" gewertet wurde. ${ }^{64}$ Ganz aufrichtig war der Vorwurf auch nicht: Einen derartigen „Kompetenzen-Clinch“ zwischen den beiden höchsten Gerichtsinstanzen hatte die tschechoslowakische Rechtsordnung nicht vorhergesehen, und lediglich das Parlament bzw. die

57 Das Innen- sowie das Finanzministerium empfahlen beispielsweise, daß Erledigungen für ausländische Parteien, die Angehörige der Minderheiten waren, zweisprachig erfolgen sollten, falls die üblichen Vorbedingungen des Sprachengesetzes erfüllt waren. Vgl. SÚA, MF-P, Karton 244, 141/38 MV an MF, 6. 10. 1921; ebda, MF an untergeordnete Behörden, 10. 1. 1924. Vgl. auch SÚA, MSP, Karton 1807, E 4/a 1930, Aktenvermerk MSP, 18. 4. 1930; AMZV, Sektion VI, Karton 105, Information für den Herrn Minister, 21. 5. 1937.

58 Vgl. Peška, Studie, S. 181. Zur Begründung wies das Ministerium auf den Minderheitenschutzvertrag hin.

59 SÚA, PMR, Karton 3296, 740/32, MS an PMR, 5. 6. 1926; SÚA, MV-SR, Karton 2926, 8/1/24, MS an PMR und alle Ministerien, 7. 9. 1932. Vgl. auch AMZV, Sektion VI, Karton 105, Information für den Herrn Minister, 21. 5. 1937; PT vom 12. 8. 1927; Popelka, Nejvyšší, S. 499. Die Änderung der Praxis des Justizminsteriums wurde später irrtümlicherweise Mayr-Harting zugeschrieben. Vgl. Popelka,
in: NáL vom 3. 8. 1932 .

${ }_{60}^{60}$ PA R 73858, Deutsche Gesandtschaft an AA, 24. 8. 1928.

${ }^{61}$ Popelka, Nejvyšši soud, S. 506.

62 Popelka, Nejvyšší soud, S. 506. Mit dem Inhalt der Ausführungen Popelkas solidarisierten sich vorbehaltlos die tschechischen Rechtsanwälte; u. a. beschuldigten sie das Justizministerium, es habe im Streit mit dem Obersten Gericht seine Vollmachten überschritten und die Unabhängigkeit der Gerichte verletzt. SÚA, PMR, Karton 3296, 740/35, Resolution des Vereines tschechischer Rechtsanwälte in Mähren, 23. 10. 1928.

${ }^{63}$ Vgl. Bo vom 25. 10. 1928; PT vom 24. 11. 1928.

${ }^{64}$ Vgl. Bo vom 9. 10. 1928. 
Justiz selbst, jedoch keineswegs das Justizministerium, konnten in der Frage der Sprachenrechte der Ausländer Klarheit schaffen.

Anfang der dreißiger Jahre verstärkte sich der Druck, die Rechtsprechung der beiden obersten Gerichte zu vereinheitlichen. ${ }^{65}$ Den ersten Schritt stellte eine Entscheidung des Obersten Verwaltungsgerichts vom Februar 1931 dar, dergemäß die durch das Oberste Gericht aus sprachlichen Gründen erfolgte Abweisung einer Berufung als eine Entscheidung in der Hauptsache und folglich als unabänderlich anerkannt wurde, wodurch die ältere Praxis des Obersten Gerichts sanktioniert wurde. ${ }^{66}$ Entrüstete deutsche Juristen bezeichneten diese Rechtsprechung als eine der „unerquicklichsten und unraisonabelsten " in der Urteilspraxis des Verwaltungsgerichts überhaupt; auch tschechischerseits fehlte es nicht an zweifelnden Stimmen. ${ }^{67}$ Im November 1936 änderte des Oberste Verwaltungsgericht durch einen Beschluß des Fachplenums seine bisherige Judikatur und stellte sich auf den Standpunkt, daß Ausländern die Begünstigungen des Sprachengesetzes nicht zustanden. ${ }^{68}$ "Die Wahrheit siegte“, meldete die „Národní listy" und bezeichnete den 9. November, an dem das Gericht seinen Beschluß gefaßt hatte, als einen "höchst bedeutenden Tag“ in der Geschichte der tschechoslowakischen Justiz. Der Beschluß, blies das Blatt das Ereignis weiter auf, gebe die Sicherheit zurück, daß das Volk seine Angelegenheiten selbst regeln könne und lasse keinen Zweifel daran, daß der tschechoslowakische Staat ein Nationalstaat sei. ${ }^{69}$ Der Jubel der tschechischen nationalistischen Presse war der Lage der Dinge nicht ganz angemessen, denn in der Tat besiegelte die Entscheidung lediglich de jure die bereits seit Jahren eingefahrene Praxis. Die Problematik der Sprachrechte der deutschsprachigen Ausländer verschwand nicht völlig aus der Welt; sie wurde erneut besonders während der Diskussionen über das neue Sprachengesetz im Jahre 1938 thematisiert. Die Bemühungen jedoch, Ausländern die Kommunikation mit dem Staat in ihrer Muttersprache zu ermöglichen, wurden strikt abgewiesen. ${ }^{70}$

In der Aufzählung der fraglichen Punkte des tschechoslowakischen Sprachrechts darf man seine Unvollständigkeit nicht vergessen. Man habe, beschrieb der sudetendeutsche Publizist H. Klepetař die Lage mit ironischem Unterton, „eher vieles als viel geschaffen. Denn zwischen den engmaschigen, oft erschöpfend detaillierten Sprachenvorschriften klaffen gähnende Lücken, die meist durch sehr weit hergeholte Analogien ausgefüllt werden müssen." ${ }^{71}$ Zweifellos schwerwiegend war die Tatsache, daß das Sprachengesetz neben all seinen konzeptionellen und Unklarheiten in den Formulierungen sechs Jahre lang ohne Durchführungsverordnung blieb. Seine Realisierung wurde somit ein Konglomerat von spontanen Auslegungen, in deren Folge die Staatssprache manchmal in einem das Sprachengesetz überschreitenden Ausmaß favorisiert wurde, sowie von aus der konkreten Sprachpraxis abgeleiteten Improvisationen. ${ }^{72}$ Die

${ }^{65}$ U. a. spielte auch die Tatsache mit, daß reichsdeutsche Gerichte die Vollstreckbarkeit derjenigen Urteile zu leugnen begannen, in denen das tschechoslowakische Oberste Gericht Berufungen aus sprachlichen Gründen abgewiesen hatte. Vgl. Meissner, in: LN vom 14. 8. 1932.

${ }^{66}$ Vgl. Nál vom 17. 2. 1931 bzw. 21.2. 1931; PT vom 22. 2. 1931.

67 Adler, Geist, S. 41-42 bzw. NO 1 (1931), S. 271-274.

${ }^{68} \mathrm{PT}$ vom 10.11. 1936 und 11.11. 1936.

${ }^{69}$ Nál vom 11.11. 1936.

$70 \mathrm{Vgl}$. Kapitel I.C.

${ }^{71}$ Klepetař, Sprachenkampf, S. 25.

72 Das diesbezügliche kritische Urteil der Sudetendeutschen überrascht sicher nicht. Vgl. Sprachverordnung, S. 75. Auch die tschechische Bürokratie gab jedoch zu, daß die jetzige Sprachpraxis im Bereich 
Durchführungsverordnung von 1926 verbesserte diese Lage nur teilweise. Bekanntlich bezog sie sich nicht auf alle Sektoren der Staatsverwaltung, sondern lediglich auf den Bereich der Ministerien des Innern, der Justiz, der Finanzen, sowie der Ministerien für Industrie, Handel und Gewerbe, für öffentliche Arbeiten und schließlich für öffentliches Gesundheitswesen und körperliche Erziehung. Äußerst wichtige Ressorts wie Schulwesen, Post, Eisenbahn und Militär wurden nicht einbezogen. Für sie hätten nach Meinung des tschechischen Rechtswissenschaflers E. Sobota die Vorschriften der Sprachverordnung „höchstens explikative Bedeutung für die Auslegung des Sprachengesetzes" besitzen können ${ }^{73}$, was natürlich für die Herbeiführung einer einheitlichen und übersichtlichen Regelung kaum eine solide Grundlage bieten konnte.

einiger Ministerien „für den tschechoslowakischen Standpunkt günstiger" sei, als dies nach der Herausgabe der Sprachverordnung wahrscheinlich möglich sein würde. SÚA, PMR, Karton 462, 1063, Aktenvermerk PMR, 22. 5. 1922.

73 Sobota, Nationalitätenrecht, S. 74-75. 


\section{B. Der sprachliche Alltag}

\section{Massenkommunikation zwischen der öffentlichen Gewalt und dem Bürger}

Vom Standpunkt des einzelnen Bürgers betrachtet, war die wichtigste und häufigste Kommunikation die mit seiner Gemeinde und ihren Organen. Diese spielte sich grundsätzlich in deren Geschäftssprache ab, die die Gemeindevertretung als gewähltes Organ festlegte. Die traditionelle sprachliche Selbstbestimmung der Gemeinden wurde jedoch in der Ersten Tschechoslowakischen Republik eingeschränkt, indem das Sprachengesetz sowie die Durchführungsverordnung die Gemeinden verpflichtete, bei Entscheidungen über den eigenen Sprachgebrauch gewisse grundlegende Bedingungen einzuhalten, die die Festlegung der Geschäftssprache bzw. von Geschäftssprachen und den Sprachgebrauch in den Organen der Kommunalverwaltung sowie die Berücksichtigung von anderen Sprachen als der eigenen Geschäftssprache im Parteienverkehr betrafen. ${ }^{1}$ In der Sprachregelung für den Kommunalbereich widerspiegelte sich sehr deutlich der Konflikt zwischen dem nationalstaatlichen Anspruch, der verlangte, daß man tschechisch (slowakisch) auf dem gesamten Staatsgebiet bei allen öffentlichrechtlichen Betrieben Gehör finden mußte, und seiner Realisierbarkeit - es gab in vielen deutschen Gemeinden einfach niemanden, der die Staatssprache genügend beherrschte. Dieser Konflikt bedingte administrativ ziemlich komplizierte Regelungen, die die "gebührende“ Berücksichtigung der Staatssprache gewährleisten sollten; daraus resultierte, daß ihre Vorrangstellung gerade im kommunalen Bereich sehr ausgeprägt war.

Jede Gemeinde mußte ungeachtet ihrer Geschäftssprache eine schriftliche oder mündliche Eingabe in der Staatssprache annehmen, eine Eingabe in einer Minderheitensprache hingegen nur dann, falls in der Gemeinde über 20 Prozent Einwohner dieser Sprache lebten. Verfügte die Gemeinde über keine Amtskraft, die der Sprache der Eingabe in ausreichendem Maße mächtig war, um sie in die Geschäftssprache der Gemeinde zu übersetzen, konnte die Übersetzung den vorgesetzten Behörden übertragen werden - für die dadurch eventuell anfallenden Kosten mußte jedoch die betreffende Gemeinde selbst aufkommen. Erledigungen erfolgten grundsätzlich in der Geschäftssprache der Gemeinde; während ein Tscheche oder Slowake jedoch, der seine Erledigung in einer Minderheitensprache erhielt, das Recht hatte, sie durch die vorgesetzte Behörde in seine Muttersprache übersetzen zu lassen, stand eine derartige Berechtigung einem Angehörigen einer Minderheitensprache nicht zu. Darüber hinaus wurde festgelegt, daß eine Gemeinde automatisch verpflichtet war, in der Staatssprache eingebrachte Eingaben auch in dieser Sprache zu erledigen, falls in ihr zu über 20 Prozent tschechische oder slowakische Staatsangehörige wohnten, falls hier ein Gemeinde- oder Distriktnotar bestellt war bzw. ihrer Vertretung ein Tscheche oder Slowake angehörte, oder falls sie über 3000 Einwoh-

' Die Durchführungsverordnung legte ausdrücklich fest, daß ein Beschluß der Gemeinde, der im Widerspruch zu den Bestimmungen der Verordnung stand, ungültig sei. Vgl. auch Kapitel II.B.2. 
ner zählte. ${ }^{2}$ Auch im mündlichen Verkehr waren Tschechen bzw. Slowaken begünstigt, denn wenn eine Verständigung "mit Rücksicht auf die tatsächlichen Verhältnisse" nicht möglich war, konnten sie sich, falls sie der Geschäftssprache der Gemeinde nicht mächtig waren, an die vorgesetzte staatliche Behörde wenden, die die Angelegenheit mit ihm behandelte und dem Gemeindeamt den jeweiligen Inhalt mitteilte.

Bekanntmachungen der Gemeindeorgane erfolgten stets in der Geschäftssprache der Gemeinde; wohnten in der Gemeinde jedoch über 20 Prozent Einwohner einer anderen Sprache als der Geschäftssprache, waren die Bekanntmachungen auch in ihrer Sprache zu erlassen. Auch diesmal war die Staatssprache deutlich bevorrechtet: falls die Bekanntmachung "von größerer Wichtigkeit und allgemeinem Charakter" war, konnte die vorgesetzte politische Behörde ihre Veröffentlichung auch in der Staatssprache anordnen, mußte jedoch die Übersetzung beifügen. Gemeinden mit über 3000 Einwohnern mußten alle Bekanntmachungen automatisch auch in der Staatssprache herausgeben. Identische Regeln galten auch für Bezeichnungen von Gemeindeämtern und von Amtsräumen, das Gebäude des Gemeindeamtes selbst war aber immer auch in der Staatssprache zu beschildern. Ebenfalls Heimatscheine und Legitimationen für den Grenzverkehr mußten immer auch mit dem Text in der Staatssprache, und zwar an erster Stelle, ausgestellt werden, andere Dokumente - beispielsweise Mittellosigkeitszeugnisse auf Verlangen der Partei.

Der Sprachpraxis im Verkehr zwischen dem Bürger einerseits und Staatsbehörden und Gerichten andererseits wurde bereits in mehreren Zusammenhängen die Aufmerksamkeit gewidmet, deshalb sei nur zusammengefaßt: Alle Staatsorgane waren verpflichtet, Eingaben in der Staatssprache anzunehmen und auch zu erledigen; Eingaben in einer der Minderheitensprachen konnten nur angenommen werden, falls sie eine physische oder juristische Person der jeweiligen Sprachzugehörigkeit bei einem Staatsorgan einbrachte, dessen Wirkungskreis sich mindestens auf einen Gerichtsbezirk erstreckte, in dem über 20 Prozent Staatsbürger derselben Sprache wohnten. Die betreffende Angelegenheit mußte auch in einem derart sprachlich qualifizierten Gerichtsbezirk entstanden sein. Eingaben in einer Minderheitensprache wurden zweisprachig, in der Staatssprache und in der betreffenden Minderheitensprache, erledigt. Nur bei Gerichten und Behörden, deren Wirksamkeit auf einen einzigen Gerichtsbezirk beschränkt war, in dem über zwei Drittel Angehörige derselben Sprache wohnten, bzw. bei der ihnen unmittelbar vorgesetzten Instanz konnten sie ausschließlich in der betreffenden Minderheitensprache erledigt werden. ${ }^{3}$ Dieselben Regeln galten, falls der Erledigung keine Eingabe vorausging - vorausgesetzt, der Behörde war die Sprachzugehörigkeit der Partei bekannt. ${ }^{4}$ Bekannmachungen der Staatsorgane wurden in sprachlich qualifizierten Bezirken auch in der Sprache der Minderheiten herausgegeben. Diese Grundbestimmungen des Sprachenrechts blieben bis zum Jahre 1938 unver-

${ }^{2}$ Gemeinden mit über 3000 Bewohner waren daher verpflichtet, spätestens innerhalb von drei Jahren nach Inkrafttreten der Durchführungsverordnung von 1926 eine "nach dem Erfordernisse des Dienstes" genügende Anzahl von der Staatssprache in Wort und Schrift mächtigen Amtskräften, mindestens aber eine solche Kraft, einzustellen.

${ }_{4}^{3}$ Dies galt nicht, falls die Eingabe eine Eintragung in öffentliche Bücher zur Folge haben sollte.

4 Falls dies doch nur in der Staatssprache geschah, konnte eine Erledigung in der Minderheitensprache binnen drei Tagen gebührenfrei verlangt werden. 
ändert, erst im neuen Sprachengesetz erwog man bekanntlich bestimmte Änderungen, die auf eine Herabsetzung der prozentualen Grenze für die Geltendmachung der sprachlichen Minderheitenrechte und auf eine weitgehende Abschaffung von zweisprachigen Erledigungen hinausliefen. ${ }^{5}$

Äußerst umstritten entwickelte sich der Sprachgebrauch der Staatsbetriebe, vor allem der Staatseisenbahn und der Post. ${ }^{6}$ Für Schwierigkeiten auf diesem Gebiet sorgte bereits das Sprachengesetz mit seinen unklaren Bestimmungen. In Paragraph 1 des Gesetzes, der die Pflicht, in der Staatssprache zu „amtieren“, festlegte, war neben den Staatsorganen auch von Unternehmen und Anstalten der Republik die Rede. In Paragraph 2 dagegen, der den Anwendungsbereich der Minderheitensprachen bestimmte, wurden diese jedoch nicht erwähnt. K. Kramár̆, auf dessen Initiative die ausdrückliche Einbeziehung dieser Subjekte in das Sprachengesetz zurückzuführen war, behauptete in der Diskussion im Verfassungsausschuß im Februar 1920, er hätte ihre Aufzählung auch in diesem Paragraph vermutet; tatsächlich sah sein Entwurf des Sprachengesetzes dieselben Regeln sowohl für die Staatsorgane und Gerichte als auch für die Staatsbetriebe vor. ${ }^{7}$ Warum man diese in Paragraph 2 schließlich nicht aufnahm, geht aus den Protokollen nicht hervor; es drängt sich die Vermutung auf, daß der Ausschuß lediglich versehentlich oder aus Zeitgründen nicht mehr auf diese Problematik zurückkam. Welche Verwirrungen dieses Versäumnis später hervorrufen sollte, konnte sich 1920 niemand vorstellen.

Die verschiedenen sprachlichen Ressortvorschriften, mit denen der Sprachgebrauch bei den Staatsbetrieben seit 1920 geregelt wurde, entsprangen somit der Auffassung, daß sie im Parteienverkehr nicht an die Schutzbestimmungen des Sprachengesetzes gebunden seien. ${ }^{8}$ Bald kamen jedoch $\mathrm{Zweifel} \mathrm{auf,} \mathrm{die} \mathrm{vor} \mathrm{allem} \mathrm{damit} \mathrm{zusammenhingen,}$ daß Staatsbetriebe aufgrund der ihnen durch den Staat übertragenen Befugnisse sowie aus Betriebs- und Sicherheitsgründen - ein besonders markantes Beispiel war die Eisenbahn - der Öffentlichkeit gegenüber bisweilen auch Hoheitsfunktionen wahrnahmen, aber diesem Umstand trugen die Vorschriften keinerlei Rechnung. ${ }^{9}$ Man sollte denken, daß der einfachste Ausweg gewesen wäre, die Bestimmungen von Paragraph 2 des Sprachengesetzes auch auf staatliche Unternehmen auszudehnen, aber einfachen Lösungen war das tschechoslowakische Sprachenrecht beinahe notorisch abgeneigt. Im September 1924 entwickelte das Oberste Verwaltungsgericht eine viel diskutierte Rechtsprechung, dergemäß sich die Bestimmungen von Paragraph 2 des Sprachengesetzes auch auf diese Betriebe bezogen, soweit sie sich in Vertretung des Staates an die Öffentlichkeit wandten, also mit Akten der staatlichen Hoheitsverwaltung und demzufolge als seine Organe. ${ }^{10}$ Die Sprachregelung bei staatlichen Betrieben zerfiel da-

${ }^{5}$ Vgl. Kapitel I.E.1. bzw. I.E.3.

${ }^{6} \mathrm{Zu}$ den Unternehmen des Staates gehörten u. a. die Staatseisenbahn, die Tschechoslowakische Post, die Nationalbank, staatliche Berg- und Hüttenwerke, staatliche Forste, Bäder und Krankenhäuser, Druckereien sowie die Tabakfabriken.

7 Vgl. APČR, RNS, Karton 33, 158. Sitzung des Verfassungsausschusses am 24. 2. 1920, Vormittag, S. 29 bzw. 54.

8 Vgl. SÚA, PMR, Karton 3296, 740/43, MPaT an PMR, 12. 4. 1938; AKPR, D 952, Karton 116, Exposé "Stand der Sprachenfrage bei den Tschechoslowakischen Staatseisenbahnen“, 20.6. 1936; SÚA, MŽ, Karton 11, 821/38, Überblick der Vorschriften über die Minderheitenrechte im Bereich des Eisenbahnministeriums, undat. (1938).

9 Peška, Studie, S. 209.

10 Erkenntnis des NSS Nr. 15755 vom 16. 9. 1924, in: Věstník MV 7 (1925), S. 139-140; SÚA, MŽ, Karton 11, 821/38, Überblick der Vorschriften über die Minderheitenrechte im Bereich des Eisenbahn- 
mit im Grunde genommen in vier Bereiche: innerer Verkehr, Verkehr mit der Öffentlichkeit in der Eigenschaft eines Staatsorgans, Verkehr mit der Öffentlichkeit in der Eigenschaft eines Staatsbetriebs und schließlich Geschäftsverkehr.

In ihrer inneren Amtsführung waren Staatsbetriebe verpflichtet, ausschließlich die Staatssprache zu benutzen. Im äußeren Verkehr waren sie als Staatsorgane freilich den Bestimmungen von Paragraph 2 unterworfen. Die relative Eindeutigkeit dieser Regelung wurde durch die Tatsache entwertet, daß die Grenze, wann ein Staatsunternehmen in seiner Eigenschaft als Staatsbetrieb oder als Organ des Staates auftrat, nicht eindeutig feststand; das war des öfteren - beispielsweise bei Gebots- oder Verbotstafeln in Eisenbahnzügen, deren Nichtbefolgung sogar mit einer Verwaltungsstrafe geahndet wurde - reine Interpretationssache und folglich eine Quelle ständiger Unklarheiten und Streitigkeiten. ${ }^{11}$ Wohl die größten Schwierigkeiten ergaben sich bei der Sprachregelung in denjenigen Bereichen, in denen die Staatsbetriebe gegenüber der Öffentlichkeit als bloße Wirtschaftssubjekte aufzutreten glaubten, zumal sie in dieser Eigenschaft dem Bedarf von breiten Bevölkerungsschichten dienten und somit in einen sehr intensiven Kontakt zu ihnen kamen. Die Richtschnur der Sprachregelung sei, wie später beispielsweise das Postministerium behauptete, der „Geist und die Grundsätze des Sprachengesetzes“ “. ${ }^{12}$ Die Durchführungsverordnung von 1926 bezog sich bekanntlich nicht auf die Bereiche des Post- und des Eisenbahnministeriums, für diese konnte sie lediglich „den Rahmen“ andeuten ${ }^{13}$ - über die Art und Weise jedoch, in der gerade Post und Eisenbahn diesen Rahmen tatsächlich ausnutzten, gaben sich nicht einmal tschechische Juristen Illusionen hin: E. Sobota beispielsweise bewertete ihre Vorschriften als kasuistisch und lückenhaft, „mal mehr, mal weniger" analog zu den Bestimmungen der Sprachverordnung. ${ }^{14}$ Entscheidend blieb offensichtlich die mittlerweile eingefahrene Praxis.

In Bezirken mit mindestens 20 Prozent Angehörigen einer Minderheitensprache amtierten Postämter auch in dieser Sprache; alle Bezeichnungen und Orientierungstafeln, Drucksachen, Formulare sowie Stempel waren in diesen Bezirken zweisprachig. Ebenso wurden Eingaben in der betreffenden Minderheitensprache angenommen, jedoch nur in der Staatssprache erledigt. ${ }^{15} \mathrm{Zu}$ den umstrittensten Problemen gehörte die Verwendung von Orts- und Straßennamen, deren in sprachlicher Hinsicht unrichtiger Gebrauch konnte auch die Nichtzustellung von Postsendungen zur Folge haben. ${ }^{16}$ Die

ministeriums, undat. (1938), Anlage 2: Erlaß MŽ Nr. 53482 vom 4. 11. 1924. Vgl. auch Peška, Studie, S. 209-210; Sobota, Jazykový zákon, S. 101-102.

"Vgl. PT vom 18. 9. 1924; Bo vom 18.9. 1924 und 5. 11. 1924. Vgl. auch Interpellation des Abgeordneten Wagner an den Eisenbahnminister wegen der Sprachenpraxis der Staatsbahndirektion Pilsen, die im Gegensatze und im Widerspruche zur Spruchpraxis des Obersten Verwaltungsgerichts steht vom 28. 5. 1936, in; TTZPS, 4. WP, Drucksache 523/VI.

12 SÚA, PMR, Karton 3296, 740/43, MPaT an PMR, 12. 4. 1938.

13 SÚA, MV-SR, Karton 1491, 14/1/91, Aktenvermerk MV, 30. 1. 1928.

14 ANM, NL Sobota, Karton 13, Exposé E. Sobotas „Über die Möglichkeit, den Forderungen der Minderheiten im Bereich der Sprachenrechte entgegenzukommen, undat. (1936). Demgegenüber veröffentlichte auf dieser rechtlichen Grundlage beispielsweise die Nationalbank in Städten, in denen mehr als 20 Prozent der Bevölkerung einer anderen Nationalität als der "tschechoslowakischen “ lebten, Verlautbarungen stets mit einer Übersetzung in die betreffende Minderheitensprache. Im Geschäftsverkehr verhandelte oder korrespondierte die Bank mit ihren Partnern lediglich in deren Sprache. Vgl. SÚA, PMR, Karton 3296, 740/43, MF an PMR, 9. 4. 1938.

is SÚA, MŠ̀ NO-P, Karton 375, Mappe 20, MPaT an PMR, 7. 4. 1938.

16 Vgl. Kapitel II.D. 
Postverwaltung entwickelte hierzu eine merkwürdige juristische Interpretation, die auf eine Verwischung der Grenze zwischen der öffentlichrechtlichen und privaten Sphäre hinauslief, indem sie Postsendungen, aber auch beispielsweise die Bitte um mechanische Herstellung der Telefonverbidung für „Eingaben“ hielt: Ein Anruf, behauptete sie, sei eine „Eingabe“ und die Herstellung der Verbindung eine „Erledigung“. ${ }^{17}$ Wenn man noch die Probleme mit der Herausgabe der notwendigen Informationsmittel in den Minderheitensprachen (Telefonverzeichnisse usw.) hinzuzählt, ist der Horizont der deutschen Beschwerden grundsätzlich abgesteckt. ${ }^{18}$

Womöglich problematischer gestaltete sich der Sprachgebrauch im Bereich der Eisenbahnverwaltung. Dies war umso schwerwiegender, weil die Eisenbahn das wichtigste öffentliche Verkehrs- und Transportmittel war und demzufolge vielfältige Aufgaben im öffentlichen sowie im Wirtschaftsleben zu erfüllen hatte. Im Verkehr mit der reisenden Öffentlichkeit wurde seit dem Jahre 1919 an der Praxis festgehalten, die von einem Bevölkerungsschlüssel ausging: Wenn die Station nach einer Gemeinde benannt war, in der wenigstens 20 Prozent Angehörige einer Minderheitensprache lebten, waren alle für die Öffentlichkeit bestimmten Bahnhofs- und Orientierungsaufschriften zweisprachig anzufertigen, wobei die Staatssprache an erster Stelle stand. Die Stationsnamen wurden ebenfalls in beiden Sprachen ausgerufen. Bekanntmachungen, Fahrpläne, Fahrkarten - einschließlich der Stationsnamen, solange diese ein amtliches Äquivalent in der Minderheitensprache hatten -, amtliche Drucksachen (Bestellungen für Zeitkarten und Ausweise, Gepäckscheine, Aufnahmebescheinigungen, Nachnahmbegleitscheine, Vollmachten usw.) sowie verschiedene Werbeschriften wurden in solchen Stationen in beiden Sprachen herausgegeben bzw. aufgehängt. ${ }^{19}$

Die Deutschen äußerten ihre Unzufriedenheit mit der Sprachregelung bei der Staatseisenbahn von den ersten Tagen der Republik an. Aufschriften auf Stationsgebäuden, Orientierungstafeln, Bekanntmachungen sowie das Ausrufen der Stationsnamen sollten ihren Vorstellungen nach nur in der Sprache der Bevölkerungsmehrheit erfolgen, in "gemischtsprachigen" Ortschaften (näher wurde dieser Begriff nicht spezifiziert) sowie an großen Umsteigestationen, selbst wenn diese im rein tschechischen Sprachgebiet lagen (Prag wurde jedoch dabei nicht ausdrücklich erwähnt), zweisprachig. ${ }^{20} \mathrm{Spä-}$

17 AMZV, Sektion II, Karton 708, Denkschrift der deutschen Mitglieder der tschechoslowakischen Nationalversammlung betreffend die Nichteinhaltung des Vertrages de dato St. Germain-en-Laye vom 10. September 1919 durch die Gesetzgebung und Regierung der tschechoslowakischen Republik, undat. (1922).

$18 \mathrm{Vgl}$. beispielsweise Interpellation des Abgeordneten Ing. Kallina und Genossen an den Minister für Post- und Telegrafenwesen in Angelegenheit der Benachteiligung der deutschen Bevölkerungskreise bei Benützung der Einrichtungen des Post- und Telegrafen- und Telefonverkehrs vom 18. 3. 1930, in: TTZPS, 3. WP, Drucksache 306/VII.

19 Vgl. AKPR, D 952, Karton 116, MZ̆ an Staatsbahndirektion Prag, 19. 8. 1921. Der Erlaß beruft sich auf eine ältere Anordnung des MŽ vom 11. 10. 1920; ebda, Exposé „Stand der Sprachenfrage bei den Tschechoslowakischen Staatseisenbahnen“, 20.6. 1936. Zweisprachige Aufschriften waren nicht konsequent durchgeführt worden. Beispielsweise hatte Brünn, wo über 20 Prozent Deutsche lebten, während der ganzen Ersten Republik nur tschechische Aufschriften am Hauptbahnhof. Brünn wurde im Vermerk der KPR ausdrücklich als eine Ausnahme bezeichnet, ohne daß ein Grund dafür angegeben wurde. Vgl. ebda., Aktenvermerk KPR, 26. 10. 1937. Im Jahre 1936 wurden von insgesamt 105 Millionen Fahrkarten 72 Millionen einsprachig tschechisch, der Rest zweisprachig herausgegeben. Vgl. ebda., Aufzeichnung KPR, 26. 10. 1937.

20 Antrag des Abgeordneten Dr. Schollich und Genossen auf Regelung des Sprachgebrauches bei den Eisenbahnen vom 8.6.1920, in: TTZPS, 1. WP, Drucksache 186. Der Antrag wurde von allen Partei- 
ter gingen sie zu einem reduzierten Konzept über, in dessen Mittelpunkt die Forderung stand, daß Staatsbetriebe mit Angehörigen der Minderheitensprachen in jenem Ausmaß in deren Sprache verkehren sollten, das für Gerichte und Behörden durch das Sprachengesetz und die Durchführungsverordnung festgelegt worden war. ${ }^{21}$ Auch tschechischerseits hegte man gewisse Zweifel an der Sprachregelung bei Eisenbahnen. Man schlug beispielsweise vor, den Begriff "Amtieren“ lediglich auf den inneren Amtsverkehr der Staatsbetriebe einzuschränken, und im Parteien- und vor allem im Geschäftsverkehr der Staatsbetriebe den Sprachgebrauch vom Standpunkt der Zweckmäßigkeit her, also liberaler als bei anderen Staatsorganen, zu regeln oder zumindest den Unterschied zwischen einem Staatsorgane und einem Unternehmen der Republik genau abzugrenzen. ${ }^{22}$ Es gab jedoch auch entgegengesetzte Bestrebungen, die vor allem im Entwurf des Eisenbahnministeriums vom Jahre 1925 für ein neues Organisationsstatut ihren Ausdruck fanden. Die Vorlage war auf der Prämisse aufgebaut, der Staatseisenbahnbetrieb sei nicht verpflichtet, die Sprachen der nationalen Minderheiten zu gebrauchen, es sei denn, dies sei "unumgänglich notwendig“. ${ }^{23}$

Aus dieser Überzeugung heraus wurde eine Vorschrift vorbereitet, die den bisherigen Sprachgebrauch bei der Staatseisenbahn wesentlich zuungusten der Minderheitensprachen änderte. ${ }^{24}$ Vor allem sollten Aufschriften an Bahnhöfen sowie in Zügen und Bekanntmachungen der Eisenbahnverwaltung lediglich in Bezirken mit über 50 Prozent Minderheitenbevölkerung zweisprachig erfolgen, zudem nur dann, solange dies der Verkehr "unbedingt“ erforderte. Erledigungen von Eingaben in Minderheitensprachen hatten grundsätzlich nur in der Staatssprache zu erfolgen, höchstens konnte eine "freiwillige, unverbindliche Übersetzung in die Sprache der Partei“ beigefügt werden, aber nur dann, wenn das Subjekt (Privatpersonen tschechoslowakischer Staatsbürgerschaft, Gemeindebehörden und -betriebe, sowie privatrechtliche Körperschaften) seinen Sitz in einem Gerichtsbezirk hatte, in dem mehr als 50 Prozent Angehörige der betreffenden Minderheitensprache lebten. Die Partei mußte außerdem um eine Übersetzung in ihre Sprache ausdrücklich ersuchen und für die anfallenden Kosten aufkommen. Übrigens durften so nicht alle Eisenbahndienststellen verfahren, sondern nur diejenigen, die ihren Sitz in einem sprachlich qualifizierten Bezirk hatten. Völlig ausgeschlossen war dagegen der Gebrauch von Minderheitensprachen im Verkehr mit Rechtsanwälten, Notaren und Reklamationsbüros, solange diese eine Partei vertraten, weiter mit Firmen, die über 100 Angestellte hatten, sowie mit anderen Eisenbahnbetrieben (Schlepp-, Waldbahnen usw.). Ein Teil der tschechisch-slowakischen politi-

en des Deutschen Parlamentarischen Verbandes mit Ausnahme der Deutschdemokratischen Freiheitspartei unterzeichnet.

${ }^{21}$ SÚA, PMR, Karton 3296, 740/43, Memorandum der deutschen Wirtschaftsverbände an den Ministerpräsidenten, Oktober 1937.

22 Peška, Studie, S. 185; ANM, NL Sobota, Karton 13, Exposé E. Sobotas „Über die Möglichkeit, den Forderungen der Minderheiten im Bereich der Sprachenrechte entgegenzukommen“, undat. (1936) bzw. Plachý, Je československé právo, S. 264.

${ }^{23}$ SỨA, MŽ, Karton 407, 18099/25, Aktenvermerk MŽ, 2. 4. 1925.

24 SÚA, PMR, Karton 463, 1063/3, Bd. 1, Organisationsstatut der Staatseisenbahnen, Sprachliche Bestimmungen, undat. (1925). Vgl. auch SÚA, MŽ, Karton 550, 13010/27, Osnova „Všeobecneho organizačního řádu podniku CSD“, Praha 1926, sprachliche Bestimmungen S. 38-42. Symptomatisch ist allerdings, daß sich der Entwurf der Durchführungsverordnung zum Sprachengesetz für den Bereich des Eisenbahnministeriums vom Jahre 1921/1922 noch grundsätzlich an die Bestimmungen des Sprachengesetzes hielt. Vgl. ANM, NL Kramáŕ, Karton 92, Mappe: Jazykové zákonodárství, undat. 
schen Szene befürchtete jedoch, das neue Statut könnte die Unzufriedenheit der Minderheiten mit dem Stand der Sprachenrechte noch steigern, und die Norm wurde spätestens Ende der zwanziger Jahre ad acta gelegt. ${ }^{25}$

In den Jahren 1936 und 1937 faßte das Eisenbahnministerium endlich bestimmte Änderungen ins Auge, von einem innovativen Herangehen kann jedoch keine Rede sein. In erster Linie wollte man die Frage der Aufschriften bzw. Bekanntmachungen in Eisenbahnwagen aufgreifen. Diese waren meistens einsprachig tschechisch, was einen ewigen Streitpunkt darstellte. ${ }^{26}$ Nunmehr sollten in Zügen, die vorwiegend durch Bezirke mit mehrheitlicher Minderheitenbevölkerung, vor allem auf Lokalstrecken, verkehrten, alle Aufschriften zweisprachig angebracht werden. In Zügen, die die Sprachgrenze passierten und auch durch Gebiete fuhren, in denen keine Minderheiten ansässig waren, sollte die bisherige Praxis beibehalten werden; man beabsichtigte jedoch, die Aufschriften zu minimalisieren, indem man sie durch für beide Sprachen angeblich verständliche Abkürzungen wie $\mathrm{N}$ : Nichtraucher-Nekuřáci, O: Offen-Otevřeno, Z: Zugemacht (sic!)-Zavřeno bzw. durch Piktogramme ersetzen wollte. ${ }^{27}$ Der Entwurf des Sprachengesetzes von 1938 versuchte einen Schlußstrich unter die Problematik zu ziehen, indem es ausdrücklich festlegte, daß die Bestimmungen über Gerichte, Behörden und Organe der Republik auch für staatliche Anstalten und Betriebe sowie deren Einrichtungen gelten sollten, auch wenn man es abermals - für alle Fälle - nicht versäumte, das Zauberwort „angemessen“ („gelten angemessen“) in den Text einzuflechten. ${ }^{28} \mathrm{Im}$ Verkehr mit der reisenden Öffentlichkeit waren zwar mit Rücksicht auf die Handelsinteressen der Staatsbetriebe ausdrücklich auch andere Sprachen zugelassen, konkrete Vorschriften auf dieser Grundlage wurden jedoch offensichtlich nicht vorbereitet, so daß die Frage, ob die Regelung für die Minderheiten zufriedenstellend gewesen wäre, offen bleiben muß.

Die Kritik und die Zweifel an den Grundbestimmungen des tschechoslowakischen Sprachenrechts wurden bereits eingehend behandelt. Die hier zu beantwortende Frage lautet, inwieweit die Sprachgesetzgebung ihre primäre Aufgabe erfüllte, nämlich eine effektive Kommunikation zwischen dem Bürger einer Minderheitennationalität und dem Staat zu gewährleisten. In Verwaltungseinheiten (Gemeinden, Gerichtsbezirke), in denen über 20 Prozent Minderheitenbevölkerung lebten, war der Verkehr von Angehörigen der betreffenden Minderheitensprache mit der öffentlichen Gewalt in ihrer Muttersprache relativ gut gesichert. In Bezirken mit einer mehr als zwanzigprozentigen deutschen Minderheit lebten nach der Volkszählung vom Jahre 1921 in den böhmischen Ländern 2.803077 (94,28 Prozent), in den sogenannten rein tschechischen 170047 Deutsche (5,72 Prozent). Die Volkszählung von 1930 ergab ein für die Deutschen ungünstigeres Bild: Die Zahl ihrer im rein tschechischen Sprachgebiet lebenden

${ }^{25}$ Vgl. Kapitel I.D.1.

${ }^{26}$ Vgl. beispielsweise Interpellation des Abgeordneten Wagner an den Eisenbahnminister wegen der Sprachenpraxis der Staatsbahndirektion Pilsen, die im Gegensatze und im Widerspruche zur Spruchpraxis des Obersten Verwaltungsgerichts steht vom 28. 5. 1936, in; TTZPS, 4.WP, Drucksache 523/ VI.

27 AKPR, D 952, Karton 116, Aufzeichnung KPR, 26. 10. 1937. Vgl. auch SÚA, MŽ, Karton 11, 821/ 38, Überblick der Vorschriften über die Minderheitenrechte im Bereich des Eisenbahnministeriums, undat. (1938), Anlage 24: Erlaß MŽ Nr. 55918/37 vom 3. 11. 1937.

28 SÚA, PMR, Karton 1714, 401/7, Verfassungsgesetz, durch das die Grundsätze des Sprachenrechts in der Tschechoslowakischen Republik festgelegt werden, undat. (nach 12.7. 1938). 
Angehörigen stieg auf 231754 (7,55 Prozent), in den qualifizierten Minderheitenbezirken lebten somit nur noch 92,45 Prozent der gesamten deutschen Bevölkerung. ${ }^{29}$

Selbst wenn man von einer Berechnung auf der Grundlage der Gemeinden ein verändertes Bild erwarten kann, schneidet das tschechoslowakische Sprachenrecht im Gesamturteil nicht schlecht ab: Der weitaus größte Teil der sudetendeutschen Bevölkerung konnte im Verkehr mit den Subjekten der öffentlichen Macht auf der Orts- und Bezirksebene seine Muttersprache gebrauchen. Zieht man den „Aktionsradius" eines Durchschnittsbürgers in Betracht, scheint es sehr wahrscheinlich, daß für die Mehrheit der Sudetendeutschen die Kenntnis des Tschechischen entbehrlich war. Der problematische Punkt des tschechoslowakischen Sprachenrechts lag vielmehr in der ungenügenden Berücksichtigung des Deutschen außerhalb der sprachlich qualifizierten Verwaltungseinheiten, also in denen mit über 80 Prozent tschechischer Bevölkerung. Zwar war der Gebrauch von Minderheitensprachen hier nicht völlig ausgeschlossen, er war jedoch auf ein Minimum eingeschränkt, nämlich auf den Schutz besonders vor eventuellen strafrechtlichen Folgen, die sich aus der Unkenntnis der Staatssprache hätten ergeben können. ${ }^{30}$ Dieser Zustand berührte nicht nur die Interessen der erwähnten etwa fünf bis acht Prozent der sudetendeutschen Bevölkerung, die im mehrheitlich tschechisch besiedelten Landesinneren lebten, sondern auch die derjenigen Gruppen, deren Aktivitäten über die Orts- oder Bezirksebene bzw. über die Sprachgrenze hinausgingen. Dies traf besonders auf Geschäftsleute, Politiker sowie die Intelligenz zu, für die der Kontakt zu dem tschechischen Sprachgebiet manchmal unvermeidlich war, zumal hier, wo das eigentliche Machtzentrum des Gesamtstaates lag, wichtige zentrale politische, wirtschaftliche und kulturelle Subjekte ihren Sitz hatten. Zwar war der Parteienverkehr mit den Zentralstellen, falls die Bedingungen des Sprachenrechts erfüllt wurden, in der Muttersprache immer noch möglich, doch war die aktive gleichberechtigte Teilnahme an ihrer Tätigkeit und somit an den grundlegenden Mitbestimmungsund Mitgestaltungsprozessen für Angehörige der Minderheiten wesentlich erschwert, wie im folgenden am Beispiel des Sprachgebrauchs in der Politik und im Geschäftsverkehr gezeigt wird.

\section{Die Sprache in der Politik}

Bei den Bedingungen der parlamentarischen Demokratie, unter denen sich die Tschechoslowakei der Zwischenkriegszeit entwickelte, kam dem Sprachgebrauch im Bereich der Politik eine verstärkte Bedeutung zu. Die Freiheit der Meinungsäußerung schloß selbstverständlicherweise auch die - übrigens verfassungsmäßig garantierte - Freiheit ein, diese Äußerung in einer beliebigen Sprache zu machen. ${ }^{31}$ Obwohl die tschechoslowakische Verfassung in dieser Hinsicht bestimmte Vorbehaltsformulierungen enthielt, ist kein Fall bekannt, in dem eine Privatperson an einer wie auch immer gearteten po-

${ }^{29}$ Berechnet nach: Československá statistika, Bd. 9, S. 29-34, bzw. Bd. 98, S. 26-34.

${ }^{30}$ Zeugen oder Beschuldigte, die der Staatssprache nicht mächtig waren, wurden in ihrer Muttersprache vernommen bzw. die Angelegenheit wurde "in Fällen von besonderer Wichtigkeit “ an ein anderes Gericht oder eine andere Behörde delegiert, die über Beamte mit den erforderlichen Sprachkenntnissen verfügte.

${ }^{31}$ Die tschechoslowakische Verfassung garantierte den freien Sprachgebrauch u. a. im Privatverkehr, in der Presse und allen Publikationen sowie in öffentlichen Volksversammlungen. 
litischen Äußerung nur deswegen gehindert worden wäre, weil diese in einer anderen als der Staatssprache, also etwa in einer der Minderheitensprachen erfolgte. ${ }^{32} \mathrm{Im}$ Mittelpunkt der Aufmerksamkeit kann somit nur der Sprachgebrauch in den politischen Organen des Staates stehen, vor allem in den gewählten Vertretungskörpern, namentlich im Parlament sowie in den Landes-, Bezirks- und Gemeindevertretungen. Die Notwendigkeit, den Sprachgebrauch in diesen Organen zu regeln, ergab sich zum einen daraus, daß das allgemeine und gleiche Wahlrecht den Angehörigen der Minderheiten den Zugang in diese Körperschaften sicherte, zum anderen daraus, daß das passive Wahlrecht von der Kenntnis keiner konkreten Sprache abhängig gemacht wurde. ${ }^{33}$

Der Sprachgebrauch in den verschiedenen Vertretungskörperschaften richtete sich nach keiner einheitlichen Norm, im Prinzip galt, daß die Entscheidung über die Geschäftssprache dem autonomen Beschluß des jeweiligen Gremiums überlassen blieb. Der Majorisierung von nationalen Minderheiten war kein Riegel vorgeschoben, dort jedoch, wo ihre Vertreter angesichts der Bevölkerungsverhältnisse die Mehrheit erreichen konnten, hatte man verpflichtende Vorkehrungen zugunsten der Staatssprache geschaffen. Die Repräsentanten der Minderheiten nahmen an der Entstehung der diesbezüglichen Normen in sehr unterschiedlichem Maße teil. Die Parlamentsgeschäftsordnung (beschlossen im April 192034) kam gänzlich ohne ihre Mitwirkung zustande. Die Geschäftsordnung für die Landes- und Bezirksvertretungen (erlassen 1928 durch eine Regierungsverordnung ${ }^{35}$ ) wurde durch die tschechisch-deutsche Koalitionsregierung ausgearbeitet und auch von den deutschen Ministern mitunterzeichnet. Die Möglichkeit jedoch, diese Geschäftsordnungen nachträglich durch einen Mehrheitsbeschluß der Vertretungen zu ändern (wozu übrigens die Zustimmung der Regierung bzw. des Innenministeriums nötig gewesen wäre) wurde, soweit bekannt, nie wahrgenommen. Erst im Kommunalbereich legte die Durchführungsverordnung zum Sprachengesetz von 1926 die Entscheidung über die Geschäftssprache in die Hände der betreffenden Vertretungen, doch auch in diesem Fall wurde dem vorgesetzten Staatsorgan, der politischen Bezirksbehörde, ein Einspruchsrecht eingeräumt. Auch der Status der einzelnen Sprachen war unterschiedlich. Im Parlament sowie in den Landes- und

${ }^{32}$ Vgl. Denkschrift, S. 31; Adamovich, Grundriß, S. 84.

33 Vgl. Epstein, Grundsätze, S. 88. Nur im Falle einer einzigen gewählten Funktion verlangte das tschechoslowakische Sprachenrecht die Kenntnis der Staatssprache: Laut Durchführungsverordnung zum Sprachengesetz von 1926 mußten die Bürgermeister von Städten mit eigenem Statut sowie deren Stellvertreter das Tschechische oder Slowakische "vollkommen“ beherrschen. Diese deutscherseits vielfach kritisierte Bestimmung bestand, soweit bekannt, nur auf dem Papier; es sind keine Vorschriften darüber bekannt, wie und wann die Bürgermeister bzw. die Kandidaten für diese Posten einen Nachweis der Kenntnis der Staatssprache vorzulegen hatten; ebensowenig ist bekannt, daß ein Bürgermeister aus diesem Grunde seines Amtes enthoben worden wäre. $\mathrm{Zu}$ bedenken ist auch, daß die Magistrate dieser Städte (zu ihnen gehörte z. B. Prag, Reichenberg, Brünn, Olmütz, Iglau, Znaim, Troppau, Friedek, seit 1928 nur noch Prag, Reichenberg, Brünn, Olmütz und Troppau) auch Aufgaben der politischen und finanziellen Staatsverwaltung wahrzunehmen hatten. Bezeichnend ist, daß diese Bestimmung in der ursprünglichen, "liberalen“ Fassung der Sprachverordnung von 1920 nicht enthalten gewesen war; sie tauchte erst in der Fassung von 1924 auf. Offensichtlich handelte sich um eine Konzession an die tschechischen nationalen Radikalen, die übrigens verlangten, daß alle Bürgermeister der Staatssprache mächtig zu sein hatten. Vgl. SUA, MV-SR, Karton 506, 20/2/53(2), Entwurf der Regierungsverordnung zur Durchführung des Gesetzes Nr. 122/1920 Slg., undat. (1924) bzw. ebda, Karton 1487, 14/1/4, Denkschrift des SNJM an den Ministerpräsidenten, 12.1. 1925.

${ }^{34}$ Gesetz Nr. 325/1920 Slg. (Geschäftsordnung des Abgeordnetenhauses), Gesetz Nr. 326/1920 Slg. (Geschäftsordnung des Senats). Die sprachlichen Bestimmungen für beide Häuser waren identisch.

${ }^{35}$ Regierungsverordnung Nr. 229/1928 Slg. 
Bezirksvertretungen galt nur die Staatssprache als Geschäftssprache. Immerhin wurde in Bezirksvertretungen, falls sich ihr Wirkungskreis auf Bezirke mit über 50 Prozent Minderheitenbevölkerung erstreckte, der Text in der betreffenden Minderheitensprache als authentisch anerkannt, $d$. h. er konnte als Verhandlungsgrundlage herangezogen werden, in Bezirken mit über 75 Prozent Angehörigen der Minderheiten sogar ohne in die Staatssprache übersetzt werden zu müssen. Erst auf der Gemeindeebene konnte eine Minderheitensprache als Geschäftssprache festgelegt werden.

Das Hauptaugenmerk richtete sich selbstverständlich auf den Sprachgebrauch im Parlament - nicht nur weil dieses das oberste gesetzgebende Organ des Staates war, sondern auch weil die Anwendung von Minderheitensprachen hier relativ am stärksten eingeschränkt war. Mit der Ausarbeitung der Parlamentsgeschäftsordnung wurde bereits Anfang 1919 ein besonderer parlamentarischer Ausschuß beauftragt. Die erste Fassung vom Mai und Juni enthielt vorläufig keine sprachlichen Bestimmungen, weil man eine grundsätzliche Sprachregelung durch die Verfassung bzw. das Sprachengesetz abwartete. ${ }^{36}$ Die Sprachenfrage im künftigen Parlament kam erst im März 1920 auf die Tagesordnung, die Verhandlung konnte aber wegen nicht näher ausgeführten Meinungsverschiedenheiten erst in einer gemeinsamen Sitzung des Verfassungs- und des Ausschusses für Änderung der Geschäftsordnung Anfang April abgeschlossen werden; am 14. April wurde die Norm dem Plenum der Nationalversammlung vorgelegt und ohne Diskussion angenommen. ${ }^{37}$

Der Parlamentsgeschäftsordnung gemäß durften die Abgeordneten in offiziellen Wortmeldungen nur die eigene Muttersprache oder die Staatssprache gebrauchen die letztere vermieden die Abgeordneten der Minderheiten verständlicherweise peinlichst. ${ }^{38} \mathrm{Da}$ die Reden nicht übersetzt wurden, benachteiligte diese Praxis im Endeffekt alle Abgeordneten ohne Unterschied der Nationalität, die der eben benutzten Sprache

${ }^{36}$ Vgl. ANM, NL Hajn, Karton 153, 4274, Brief an die Mitglieder des Ausschusses für die Änderung der Geschäftsordnung, 20. 2. 1919; APČR, RNS, Karton 88, Mappe: řád jednací, Parlamentskanzlei an die Mitglieder des Ausschusses für die Änderung der Geschäftsordnung, 5. 5. 1919; APČR, RNS, Karton 14, Geschäftsordnung der Tschechoslowakischen Nationalversammlung, undat. (Protokoll der 11. Sitzung des Ausschusses für die Änderung der Geschäftsordnung am 23. 6. 1919, Anlage); ANM, NL Kramár̆, Karton 92, Mappe: K osnově jednacího řádu, Geschäftsordnung der Tschechoslowakischen Nationalversammlung, undat. (Parlamentskanzlei an Verfassungsausschuß, 16. 7. 1919, Anlage).

37 APČR, RNS, Karton 14, 21. Sitzung des Ausschusses für die Änderung der Geschäftsordnung am 20. 3. 1920. Es ist kein Protokoll, sondern lediglich eine Aufzeichnung über die Sitzung vorhanden. Nachdem wahrscheinlich ziemlich unterschiedliche Änderungsanträge eingereicht worden waren, empfahl der Ausschuß einvernehmlich, die Angelegenheit in der Klubobmännerkonferenz zu besprechen. Vgl. auch NáP vom 25. 3. 1920. Zur Verabschiedung der Geschäftsordnung vgl. APČR, RNS, Karton 35, 178. Sitzung des Verfassungsausschusses am 8. 4. 1920; 144. Sitzung der Revolutionären Nationalversammlung am 14. 4. 1920, in: TZRNS, S. 4228-4231.

${ }^{38}$ Die Nationalität der Abgeordneten war jedoch ein Problem sui generis. Die Gesetze vom Jahre 1920 (d.h. Nr. 123 über die Wahlen zur Nationalversammlung sowie Nr. 325 und Nr. 326 über die Geschäftsordnungen) enthielten jedoch keine Bestimmung, nach der die Nationalität der Abgeordneten ermittelt werden konnte. Als eine Art Nationalitätenbekenntnis galt bis dahin, in welcher Sprache der betreffende Abgeordnete das Gelöbnis ablegte. Einige Abgeordnete führten jedoch angeblich mehrere Nationalitäten an, um auch andere Sprachen gebrauchen zu können. Dies habe vor allem für einige ungarische Abgeordnete zugetroffen, die sich zur "deutsch-ungarischen“ Nationalität bekannten. Von den deutschen Abgeordneten habe der Kommunist K. Kreibich im Parlament sowohl deutsch als auch tschechisch gesprochen. Vgl. ČsR vom 7. 2. 1930. Erst das Gesetz Nr. 205/1925 Slg. über die Wahlordnung für die Nationalversammlung legte fest, daß den Kandidatenlisten aller Parteien eine schriftliche Erklärung aller Kandidaten beizufügen war, die u. a. die Angabe enthalten sollte, zu welcher Nationalität sie sich bekannten. 
nicht mächtig waren. Eine effiziente Kommunikation unter den Abgeordneten, die insgesamt sechs Sprachen verwendeten (deutsch, polnisch, ruthenisch, slowakisch, tschechisch und ungarisch), war somit kaum möglich; Debatten im klassischen Sinne kamen im Plenum sowie - was wohl noch schwerwiegender gewesen sein mag - in den Ausschüssen nur selten zustande. Das trug natürlich nicht gerade zur Kultivierung des gegenseitigen Verhältnisses bei. ${ }^{39}$ Kein schriftliches oder mündliches Wort in der Staatssprache - Regierungserklärungen oder -anträge nicht ausgenommen - wurden in eine der Minderheitensprachen übersetzt; die einzige Ausnahme bildeten die Botschaften des Präsidenten. ${ }^{40}$ Selbständigen Anträgen, Anfragen und Interpellationen in den Minderheitensprachen mußte eine Übersetzung in die Staatssprache beigefügt werden, die entweder der Abgeordnete selbst oder die Parlamentskanzlei anfertigte, sonst konnten sie nicht behandelt werden. ${ }^{41}$ Auch formelle Anträge, sowie Neben-, Abänderungs- und Zusatzanträge waren schriftlich mit einer Übersetzung in der Staatssprache vorzulegen, anderenfalls wurden sie übergangen. Nur wenn solche Anträge „kurz und einfach“" waren, und wenn es die Verhandlung nicht verzögerte, konnte sie der Vorsitzende "nach seinem Ermessen“ durch den anwesenden Dolmetscher übersetzen lassen und in die Verhandlung oder Abstimmung einbeziehen.

Schwierig gestaltete sich auch die Kommunikation mit der Exekutive. Regierungsmitglieder bzw. deren Vertreter durften nur in der Staatssprache das Wort ergreifen; eine wirksame Teilnahme der Minderheiten am legislativen Prozeß wurde dadurch wesentlich erschwert, daß, wie bereits erwähnt, auch Regierungsvorlagen nur in der Staatssprache eingebracht wurden. Einzig einer schriftlichen Antwort der Regierungsmitglieder auf eine Anfrage oder Interpellation in einer Minderheitensprache mußte eine Übersetzung in der betreffenden Sprache beigefügt werden. Eine eventuelle Handhabe gegen die Minderheiten barg freilich die Bestimmung in sich, dergemäß die mündliche Antwort des Ministers auf eine Anfrage oder Interpellation nicht übersetzt werden mußte. Soweit bekannt, wurde jedoch bei schriftlich eingebrachten Anfragen bzw. Interpellationen offensichtlich eine schriftliche Beantwortung eindeutig bevorzugt. $^{42}$

Das Protokoll wurde in der Staatssprache geführt und veröffentlicht, der originale Wortlaut der in den Minderheitensprachen vorgetragenen Reden wurde als Anlage beigefügt. Dabei ging man bis in die kleinsten Details: Selbst im deutschen Wortlaut der Reden der deutschen Abgeordneten sind die Bemerkungen über die jeweiligen Begleitumstände in der Kammer (Zurufe, Lachen, Beifall, links, rechts usw.) bzw. über den Inhalt der Zwischenrufe nur tschechisch (slowakisch) angeführt. Auch Einladungen

39 Vgl. Luschka, Parlament, S. 235; W. Medinger, in: PT vom 24. 11. 1921.

40 Die Vorlage der Ansprachen des Präsidenten erfolgte schriftlich. Dies hatte wenig Sinn, weil den Ansprachen des Präsidenten - im Unterschied beispielsweise zu Regierungserklärungen - keine Debatte im Plenum folgte.

41 War jedoch ein Antrag oder eine Interpellation dermaßen umfangreich bzw. wurden mehrere auf einmal vorgelegt, so daß die Kanzlei nicht in der Lage war, diese innerhalb der festgelegten Wochenfrist zu übersetzen, konnten sie den Antragstellern zur Übersetzung zurückgestellt werden. Wenn dies innerhalb der gegebenen Frist nicht geschah, galt der Antrag oder die Interpellation als nicht überreicht. Es sei aber nie vorgekommen, daß deutsche Interpellationen oder Anträge wegen ihres Umfangs oder Überlastung der Kanzlei zur Übersetzung in die Staatssprache an die Antragssteller zurückgestellt worden wären. Vgl. Glück, Sprachenrecht, S. 176.

42 Ebda., S. 177. 
zu Sitzungen bekamen alle Abgeordneten und Senatoren lediglich in der Staatssprache. $^{43}$

Tschechischerseits vertrat man bei der Abstimmung über die Geschäftsordnung im April 1920 die optimistische Meinung, die Lösung entspreche „ohne Kleinlichkeiten und Engstirnigkeit allen gerechten und vernünftigen Ansprüchen, die die Abgeordneten anderer Nationalitäten unserer Republik in dieser Hinsicht erheben können. " ${ }^{44}$ Sicherlich war die Regelung besonders im Vergleich zum altösterreichischen Zustand ein Fortschritt, denn die Protokollierung von Reden im Wiener Reichstag beispielsweise, die in anderen Sprachen als deutsch gehalten worden waren, konnte erst 1917 durchgesetzt werden. ${ }^{45} \mathrm{Ob}$ der 1920 festgelegte Modus tatsächlich den Erfordernissen einer modernen parlamentarischen Demokratie Rechnung trug, ist jedoch zu bezweifeln. Schließlich gelang dem Gesetzgeber weder die Entwicklung eines funktionsfähigen Kommunikationssystem im Parlament, noch konnte eine vollkommen gleichberechtigte Teilnahme aller Abgeordneten an der Arbeit des Gremiums gewährleistet werden. Zugegeben, die Einführung simultaner Übersetzungen war angesichts der komplizierten sprachlichen Lage ein für die damaligen Verhältnisse technisch-organisatorisches Problem. Aber selbst die Entwicklung der Kommunikationstechnik bewog die tschechisch-slowakische Mehrheit nicht, am gültigen Sprachgebrauch im Parlament etwas zu ändern.

Der Anfang der Parlamentstätigkeit brachte die praktischen Probleme der Sprachregelung bald zu Tage. Die deutschen Parteien zählten nicht genügend Mitglieder, die über die entsprechenden Sprachkenntnisse verfügten. Schätzungsweise gab es von den insgesamt 72 deutschen Abgeordneten etwa 10 bis 12, die das Tschechische vollkommen beherrschten, etwa ein Viertel verstand „zur Not, d. h. meist falsch“ und der Rest - über die Hälfte - gar kein Wort tschechisch. ${ }^{46}$ Diese könnten, klagte bereits im Juli 1920 der christlichsoziale Abgeordnete J. Böhr in der Klubobmännerkonferenz, die Debatte nicht verfolgen und würden somit das Interesse verlieren. Besonders schwerwiegend war dies in den Ausschüssen. Hier variierte zwar die Praxis - der Chef der Volkspartei Šrámek klagte sogar darüber, in manchen Ausschüssen würden weitgehende Konzessionen gemacht und "gefährliche" Präzedenzfälle geschaffen ${ }^{47}$ von einer gleichberechtigten und effektiven Teilnahme der Deutschen konnte jedoch immer noch keine Rede sein. Den deutschen Abgeordneten konnten aus sprachlichen Gründen keine Referate anvertraut werden; ihre Anwesenheit in diesen Gremien, resü-

${ }^{43}$ Ebda., S. 174. Vgl. auch NáP vom 1. 4. 1930.

44 Bericht des Ausschusses für Änderung der Geschäftsordnung zur Herausgabe des Gesetzes über die Geschäftsordnung des Abgeordnetenhauses der Nationalversammlung vom 8. 4. 1920, in: TTZRNS, Drucksache 2750.

${ }^{45}$ Vgl. Stourzh, Gleichberechtigung, S. 93.

46 Deutsche Gesandtschaft an AA, 18. 7. 1921, in: Gesandtschaftsberichte I., Dokument Nr. 202, S. 487. Am schlimmsten war angeblich die Lage unter den deutschen Sozialdemokraten, die deswegen für ihre Abgeordneten tschechische Sprachkurse organisierten. Vgl. auch PL vom 11.11. 1921. Saenger stützte sich offensichtlich auf Angaben des Abgeordneten der DNP, W. Medinger. Vgl. Medingers Aufsatz in: PT vom 26. 11. 1921. Hier wird die Zahl der Abgeordneten, die das Tschechische "auch in den juristischen Ausdrücken" beherrschten, mit 8-10 angegeben. Im Jahre 1930 konstatierte Medinger ein "gewisses Wachsen" der tschechischen Sprachkenntnisse, doch noch immer war nach seinen Angaben für 71 von insgesamt 99 deutschen Abgeordneten und Senatoren die jetzige Geschäftsordnung in sprachlicher Hinsicht "unerträglich“. Vgl. Deutsche Presse vom 20.4. 1930.

47 APČR, 1. WP, Karton 92, Konferenz der Klubobmänner des Abgeordnetenhauses am 20. 1. 1921. 
mierte der Nationalsozialist R. Jung, sei eigentlich überflüssig. ${ }^{48}$ Die deutschen Parteien verlangten deswegen, daß die Reden der Regierungsmitglieder, vor allem des Premierministers, sowie die Referate in den Ausschüssen übersetzt, oder zumindest in einer Kurzform bzw. inhaltlich deutsch wiedergegeben wurden. Als diese Bemühungen mißlungen waren, versuchten sie zumindest durchzusetzen, daß Parteisekretäre an Ausschußsitzungen teilnehmen konnten, um den deutschen Abgeordneten zu dolmetschen - auch dies wurde jedoch abgelehnt. Der tschechischerseits formulierte Einwand, in einer Ausschußsitzung hätten irgendwelche Sekretäre nichts zu suchen, war zwar im Grunde genommen richtig, traf jedoch natürlich nicht den Kern des Problems. $^{49}$

Die trostlose Lage der Minderheiten im Parlament illustrierte auch der durch die Sprachregelung - gekoppelt mit einem gewissen, diesmal auch deutscherseits manifestierten nationalen Prestigedenken - eingeengte Handlungsspielraum der deutschen Parlamentsfunktionäre. ${ }^{50}$ Die Besetzung der einzelnen Funktionen erfolgte nach dem Verhältnisprinzip: demgemäß sollten den deutschen Parteien die Sitze des stellvertretenden Vorsitzenden des Abgeordnetenhauses sowie der Vorsitzenden von drei Parlamentsausschüssen zufallen. ${ }^{51}$ Problematisch war jedoch, daß laut Geschäftsordnung die Parlamentsfunktionäre das Wort nur in der Staatssprache ergreifen durften, wodurch die Chancen der Vertreter der Minderheiten, diese Funktionen überhaupt bzw. wirksam wahrnehmen zu können, rapide sanken. Offensichtlich aus sprachlichen Gründen übernahmen die deutschen Parteien nicht den Vorsitz in Ausschüssen bzw. schieden bald aus diesen Funktionen aus. ${ }^{52}$ Auf den Posten destellvertretenden Vorsitzenden, den in der ersten Wahlperiode der sozialdemokratische Politiker L. Czech übernahm, verzichteten die Sozialdemokraten zwar nicht; aber Czech, obwohl er tschechisch konnte, leitete die Sitzungen des Hauses jedoch nie, weil er „dabei nicht deutsch reden durfte". .53

Hält man sich die sprachlichen Bestimmungen der Parlamentsgeschäftsordnung vor Augen, überrascht gewiß nicht das äußerst negative Fazit der deutschen Politik, deren Kernaussage war, die Sprachregelung hindere die deutschen Abgeordneten an der Erfüllung der ihnen von der Wählerschaft übertragenen Pflichten; das Zugeständnis der gleichen politischen Rechte aller Staatsbürger verliere somit für die Deutschen „wesentlich an Wert und an praktischer Bedeutung “. ${ }^{54}$ Dies war sicher ein ernstzunehmender Vorwurf.

${ }^{48}$ Vgl. APČR, 1. WP, Karton 92, Konferenz der Klubobmänner des Abgeordnetenhauses am 8. 7. 1920.

${ }^{49} \mathrm{Vgl}$. APČR, 1. WP, Karton 92, Konferenz der Klubobmänner des Abgeordnetenhauses am 8.7. 1920; ebda, Konferenz der Klubobmänner des Abgeordnetenhauses am 25. 10. 1920; ebda, Konferenz der Klubobmänner des Abgeordnetenhauses am 20. 1. 1921.

${ }^{50} \mathrm{Zu}$ diesen gehörten der Kammervorsitzende und seine Stellvertreter, Ausschuß- und Kommissionsvorsitzende sowie Berichterstatter.

51 Vgl. APČR, 1. WP, Karton 92, Konferenz der Klubobmänner des Abgeordnetenhauses am 25. 5. 1920. Die deutschen Parteien sollten den Vorsitz in drei Ausschüssen übernehmen: der Deutsche Parlamentarische Verband im Immunitäts- und Rechtsausschuß, die DSAP im Versorgungsausschuß. Vgl. ebda, Konferenz der Klubobmänner des Abgeordnetenhauses am 10. 6. 1920.

52 Der Parlamentarische Verband verzichtete auf die Ausübung dieser Funktionen, wobei der eigentliche Grund nicht angegeben wurde. Die DSAP verlangte statt einen zwei Vorsitzenden-Posten, die sie dann tatsächlich (den Immunitäts- und den Versorgungsauschuß) erhielt. APČR, 1. WP, Karton 92, Konferenz der Klubobmänner des Abgeordnetenhauses am 10.6. 1920.

53 Sünden, S. 7. Vgl. auch Lidové listy vom 28. 3. 1929.

54 AMZV, Sektion II, Karton 708, Denkschrift der deutschen Mitglieder der tschechoslowakischen Na- 
Zumindest ein Teil der tschechischen politischen Szene war tatsächlich nicht abgeneigt, den sudetendeutschen Beschwerden Gehör zu schenken. Im Oktober 1920 sprach sich Präsident Masaryk dafür aus, den Minderheiten in dieser Frage „nach Möglichkeit" entgegenzukommen. ${ }^{55}$ Gestützt auf diese Rückendeckung empfahl der sozialdemokratische Parlamentspräsident Tomášek den Deutschen, offiziell eine Änderung der Parlamentsgeschäftsordnung anzuregen. Dies, meinte er, würde ein Echo auf tschechischer Seite finden. ${ }^{56}$ In diesem Punkt war man sich hier jedoch keineswegs einig. Die Volkspartei betrachtete die Lage mit einer gewissen Schicksalsergebenheit: In einem mehrsprachigen Parlament, behauptete ihr Vorsitzender Šrámek, gebe es immer Sprachprobleme, man könne ihnen jedoch im Rahmen der existierenden Geschäftsordnung abhelfen. Gemeinsam mit dem Sozialisten Franke und dem Nationaldemokraten Lukavský neigte er schließlich zur Meinung, ein Entgegenkommen in dieser Frage setze voraus, daß die Vertreter der Minderheiten den Willen zur "tatkräftigen“ Mitarbeit zeigten, statt die Republik zu "unterminieren und anzugreifen “. ${ }^{57}$ Damit drohte man wieder bei der uralten Frage aller nationalpolitischen Ausgleichsversuche nach Vorund Gegenleistungen zu landen.

Der Sprachgebrauch im Parlament wurde offensichtlich auch in den Verhandlungen zwischen den deutschen und tschechisch-slowakischen Parteien über eine eventuelle deutsche Regierungsteilnahme thematisiert, die im Herbst 1920 angebahnt wurden. Über ihren Verlauf sind keine Belege vorhanden; bekannt ist lediglich, daß die Deutschen die Errichtung eines amtlichen Übersetzungsbüros für die Parlamentsausschüsse verlangten - dies scheint jedoch in Anbetracht der generellen deutschen Unzufriedenheit mit der Geschäftsordnung des Parlaments eher eine der Minimalforderungen gewesen zu sein. ${ }^{58}$ Bekanntlich führten die Verhandlungen über den Regierungseintritt der Deutschen zu keinem Ergebnis und kamen relativ bald zum Stillstand, die Diskussionen zwischen den tschechisch-slowakischen und deutschen Parteien über eine eventuelle Änderung der Geschäftsordnung wurden jedoch offensichtlich fortgesetzt. ${ }^{59} \mathrm{Die}$ deutschen Vorstellungen faßte ein Antrag des Deutschen Parlamentarischen Verbandes auf Abänderung der Geschäftsordnung des Abgeordnetenhauses vom Mai 1921 zusammen. ${ }^{60}$ Man verlangte, Reden von Regierungsmitgliedern sowie Parlamentsfunktio-

tionalversammlung betreffend die Nichteinhaltung des Vertrages de dato St. Germain-en-Laye vom 10. September 1919 durch die Gesetzgebung und Regierung der tschechoslowakischen Republik, undat. (1922), S. 7.

${ }^{55}$ AKPR, D 7674, Karton 6, Aktenvermerk KPR, 16. 10. 1920. Masaryk reagierte auf einen Bericht des Kanzlers Šámal über die Bemühungen der tschechischen sozialdemokratischen Senatoren, zumindest die Mitteilungen des Senatsvorstandes über die Ergebnisse seiner Verhandlungen ins Deutsche zu übersetzen.

56 Vgl. APČR, 1. WP, Karton 92, Konferenz der Klubobmänner des Abgeordnetenhauses am 25. 10. 1920.

57 Ebda.

58 Deutsche Gesandtschaft an AA, 2.12. 1920, in: Gesandtschaftsberichte I., Dokument Nr. 149, S. 363 .

59 AKPR, Karton 134, T12/25, Aktenvermerk KPR, 29. 3. 1921. Der Vermerk berichtet über einen Besuch des Abgeordneten R. Mayr-Harting, der u. a. über die Erwartung der deutschen Parteien sprach, daß man ihren Standpunkt bei der Änderung der Geschäftsordnung berücksichtigen würde. Vgl. auch NáL vom 26. 4. 1921. Der Bericht erwähnt Beratungen zwischen den Parteien über die Geschäftsordnung des Senats.

60 Antrag der Abgeordneten Patzel, Dr. Baeran, Křepek, Böhr, Ing. Jung, Dr. Kafka und Genossen, betreffend die Änderung der Geschäftsordnung des Abgeordnetenhauses im Hinblick auf den Sprachgebrauch vom 19. 5. 1921, in: TTZPS, 1. WP, Drucksache 2257. 
nären auf Ansuchen der Abgeordneten der Minderheitenvölker in deren Sprache zu übersetzen. Die Vorsitzenden der Parlamentsausschüsse und -Kommissionen sowie deren Berichterstatter sollten die deutsche Sprache (von anderen Sprachen war im Antrag nicht die Rede) gebrauchen dürfen und hätten gleichzeitig für eine Übersetzung ihrer Äußerungen zu sorgen. Den Abgeordneten sollte außerdem erlaubt werden, eine beliebige im Parlament zugelassene Sprache zu benutzen. Die Aussichten auf einen Erfolg dieser Bemühungen verdüsterten sich zu diesem Zeitpunkt allerdings wesentlich. Ende April lehnte R. Lodgman im Namen des Deutschen Parlamentarischen Verbandes, wie Saenger meinte, „zwecklos, taktlos und daher schädlich“ eine Audienz bei Masaryk ab, was die politische Lage begreiflicherweise verschlechterte. ${ }^{61}$ Die tschechischen Parteien erklärten daraufhin, für Verhandlungen mit den Deutschen sei eine bessere Atmosphäre notwendig als die jetzt herrschende, was wahrscheinlich einen weitgehenden Abbruch der Kontakte zur sudetendeutschen Politik und somit auch die mangelnde Bereitschaft zur Folge hatte, ihren Wünschen entgegenzukommen. ${ }^{62}$ Der oben erwähnte Antrag des parlamentarischen Verbandes wurde zwar dem Verfassungsausschuß zugewiesen, verschwand hier jedoch sang- und klanglos von der Bildfläche. ${ }^{63}$

Die tschechischen Parteien der sich nunmehr formierenden „allnationalen“ Koalition standen Änderungen der Parlamentsgeschäftsordnung zwar differenziert, in ihrer Mehrheit jedoch eher skeptisch gegenüber. Wie Masaryk Kanzler Sámal im Herbst 1921 anvertraute, habe der "Fünferausschuß“ den Deutschen Dolmetscher in den Parlamentsausschüssen sowie im Plenum zugesagt, dieses Versprechen jedoch, wie der Präsident bitter feststellte, nicht eingehalten. ${ }^{64}$ Dem Bestreben Masaryks, die Sache einer Lösung zuzuführen, schloß sich nur die tschechische Sozialdemokratie an, die öffentlich anzuerkennen bereit war, daß die deutschen Abgeordneten in den Parlamentsauschüssen ähnliche Schwierigkeiten hätten wie seinerzeit die Tschechen im Wiener Reichsrat. ${ }^{65}$ Die Praxis der einzelnen Ausschüsse war übrigens ziemlich unterschiedlich, wohl je nach der Person des Vorsitzenden - in einigen wurden Dolmetscher eingeladen, oder man unterbrach die Sitzung, um die deutschen Abgeordneten über den Inhalt der Verhandlung zu informieren. ${ }^{66}$ Darin erblickte die Partei die reale Möglichkeit, den Sprachgebrauch in allen Ausschüssen den Wünschen der Minderheiten stärker anzupassen; gleichzeitig warnten auch die Sozialdemokraten sie vor zu weitreichenden Forderungen im Hinblick auf die Gleichbehandlung aller Minderheitenvölker, die, wie sie befürchteten, die parlamentarische Arbeit in technischer Hinsicht hätten erschweren können.

61 Gesandtschaft Prag an AA, 26. 4. 1921, in: Gesandtschaftsberichte I., Dokument Nr. 184, S. 427. Die DSAP folgte der Einladung des Präsidenten. Die strikte Ablehnung stieß auch in der deutschen Öffentlichkeit auf wenig Verständnis. Vgl. Gesandtschaft Prag an AA, 3. 5. 1921, in: ebda., Dokument Nr. 186, S. 434.

62 PP vom 26. 4. 1921.

63 Vgl. Antrag der Abgeordneten Patzel, Dr. Spina, Dr. Luschka, Dr. Keibl und Genossen auf Abänderung des Gesetzes vom 15. April $1920 \mathrm{Nr}$. $325 \mathrm{Slg}$. über die Geschäftsordnung des Abgeordnetenhauses der Nationalversammlung vom 18. 12. 1925, in: TTZPS, 2. WP, Drucksache 64.

64 AKPR, T 12/24, Karton 134, Śámal an Tomášek, 9. 11. 1921.

65 Vgl. PL vom 11.11. 1921.

66 Einige positive Beispiele dafür nannte auch der deutschnationale Abgeordnete W. Medinger während eines Besuches in der Kanzlei des Präsidenten Ende November - Anfang Dezember 1921. Vgl. AKPR, T 12/24, Karton 134, Aktenvermerk KPR, 5. 12. 1921. 
Nur einige Tage darauf, am 16. November 1921, hielt der neue Ministerpräsident Beneš im Parlament eine große Rede zur Außenpolitik. Ihr Inhalt ist im hier behandelten Zusammenhang weniger interessant als die Form - erstmals wurde eine Rede des Ministerpräsidenten auch in deutscher Übersetzung gedruckt und gleichzeitig mit seinem Auftreten im Parlament verteilt. Vielleicht handelte es sich um eine Art "Versuchsballon“, den Beneš im Einvernehmen mit Masaryk sowie anderen, der „Burg“ angeschlossenen Kräften, aufsteigen ließ. Die negative Reaktion vor allem der Nationaldemokraten kam sofort. Die nationaldemokratische „Národní listy“ beschuldigte Beneš am nächsten Tag in einem vom Abgeordneten V. Dyk unterzeichneten Artikel, er wolle durch eine "Hintertür" den Deutschen entgegenkommen - ein Anzeichen dafür sei bereits die Tatsache, daß die Übersetzung nicht durch das Präsidium des Parlaments, sondern auf Kosten des Außenministeriums angefertigt worden war. ${ }^{67}$ Dyk warnte nachdrücklich vor einem Präzedenzfall: Man wisse ja, wie geschickt die Deutschen alle Zugeständnisse auszunutzen verstünden, die man ihnen - entgegen den klaren Bestimmungen der Geschäftsordnung - in der Praxis gemacht habe. Er griff zur schwersten Artillerie und warnte davor, auf diesem Weg eine Abkehr vom nationalstaatlichen Charakter des Staates einzuleiten. Derjenige, forderte Dyk abschließend, der die Verantwortung für diesen Kurswechsel übernehmen wolle, solle „direkt und klar" auftreten. Für eine derartige Kraftprobe waren Beneš und wahrscheinlich der gesamte Burg-Flügel nicht stark genug, und das Problem der Geschäftsordnung des Parlaments schlief für einige Jahre ein.

Der Regierungseintritt der Deutschen im Herbst 1926 konnte möglicherweise Hoffnungen erwecken, daß die Zeit für eine Abänderung der Geschäftsordnung des Parlaments endlich heranreifte. Bald kam jedoch eine Ernüchterung, denn in dieser Frage war ihnen keinerlei Erfolg beschert. Das Ziel der ersten Bestrebungen der deutschen Regierungsparteien war der Sprachgebrauch in den Parlamentsauschüssen, wo sie durchzusetzen versuchten, daß Berichterstatter, die bis dahin nur die Staatssprache gebrauchen durften, auch deutsch reden konnten. In der November-Sitzung des Budgetausschusses ergriff der deutsche agrarische Abgeordnete Windirsch das Wort, um zum Haushalt des Versorgungsministeriums zu referieren. Nachdem er etwa drei Sätze verlesen hatte, fing er an, deutsch zu reden. ${ }^{68} \mathrm{Er}$ wurde durch den Ausschußvorsitzenden B. Bradáč einige Male zur Ordnung gerufen, daraufhin wurde die Sitzung unterbrochen. In der anschließenden leidenschaftlichen Debatte versuchten Windirsch und seine Kollegen den Vorgang zu rechtfertigen. Sie wiesen darauf hin, mit der Übernahme der Referate hätten die deutschen Regierungsparteien die Bereitschaft zur Mitarbeit zum Ausdruck gebracht; dies setze jedoch bereits aus Sachgründen voraus, daß man sich der Sprache bediene, die man am besten beherrsche. ${ }^{69}$ Die Begründung wurde jedoch nicht akzeptiert, und Windirsch setzte sein Exposé tschechisch fort, ergänzte es noch in der anschließenden Debatte, in der er - nunmehr als „einfacher“ Abgeordneter - wieder deutsch reden konnte. ${ }^{70}$ Der Vorfall hatte übrigens ein Vorspiel: Bereits Anfang November 1926 kam der neue Justizminister R. Mayr-Harting in den Budgetausschuß, um zum Haushaltskapitel seines Ministeriums zu referieren. Offensichtlich in

67 NL vom 17. 11. 1921, zitiert nach: Dyk, O národní stát 1919-1922, S. 335.

68 APČR, 2. WP, Karton 56, 43. Sitzung des Budgetausschusses am 12.11. 1926, S. 30.

69 Ebda., S. 31.

70 Ebda., S. 56-57. 
Vorahnung bestimmter Schwierigkeiten - sein Exposé war angeblich deutsch verfaßt traf er sich kurz mit dem Ausschußvorsitzenden Bradáč und verließ daraufhin das Parlament. In der Ausschußsitzung erschien dann ein hoher Beamter seines Ministeriums und verlas das Referat tschechisch. ${ }^{71}$ Die deutschen Regierungsparteien beabsichtigten wahrscheinlich, die Bereitschaft der Koalition zum Entgegenkommen in nationalpolitischen Fragen zu testen; die Rolle des "Versuchsobjekts" übernahm schließlich der Abgeordnete Windirsch, wohl um die deutschen Minister nicht zu kompromittieren. ${ }^{72}$

Der Versuch war insofern unglücklich, als ihn nicht einmal die tschechischen national gemäßigten Kreise unterstützten sondern argwöhnten, man drohe hier die geltenden Gesetze in Frage zu stellen. Übrigens, meditierte die „Národní osvobozeni“", seien die Verhältnisse in der Regierungskoalition recht merkwürdig, wenn die Deutschen zu öffentlichen nationalpolitischen Demonstrationen greifen müßten, statt direkt unter den Koalitionsparteien von vornherein eine Übereinstimmung zu erzielen. ${ }^{73}$ Die deutschen Regierungsparteien initiierten schließlich eine Koalitionsverhandlung über die Änderung der Geschäftsordnung, konnten sich jedoch mit ihren Ansichten nicht durchsetzen. Der im Dezember 1926 vorgelegte Antrag der Koalition auf Abänderung der Geschäftsordnung des Abgeordnetenhauses betraf lediglich die Erhöhung der Anzahl der stellvertretenden Vorsitzenden und der Schriftführer und ging mit keinem Wort auf die sprachliche Problematik ein. ${ }^{74}$

Im März 1927 unternahm Justizminister Mayr-Harting einen neuen Anlauf. Aus Rücksicht auf die reale politische Lage verzichtete er auf eine Novelle der Geschäftsordnung und versuchte, im Rahmen des bestehenden Gesetzes deren Bestimmung zugunsten der Vertreter der Minderheiten neu zu interpretieren. Der Minister ging davon aus, daß die Bestimmungen der Geschäftsordnung nicht ausschließen würden, daß Funktionäre der Häuser sowie die Regierungsmitglieder ihren Reden Übersetzungen in den Minderheitensprachen beifügten. Ebenso glaubte er, aus der Diktion des Gesetzes ableiten zu können, daß sich Regierungsmitglieder, soweit sie gleichzeitig Abgeordnete waren, ihrer Muttersprache wie andere Abgeordnete auch bedienen könnten. ${ }^{75}$ $\mathrm{Zu}$ dieser Initiative nahm jedoch das Innenministerium eine negative Haltung ein. Seine Begründung brachte in knapper Form die gesamte Philosophie der tschechoslowakischen Sprachgesetzgebung zum Ausdruck: Indem das Gesetz keine andere Möglichkeit erwähne, schließe es diese aus, denn laut Sprachengesetz sei der Gebrauch einer Minderheitensprache eine Ausnahme von der Regel und deswegen nur dort zulässig, wo es das Gesetz expressis verbis vorsehe. ${ }^{76}$ Damit war das Urteil gefällt, und die deutschen Parteien verzichteten in den darauffolgenden Jahren auf weitere Versuche, auf diesem Gebiet Änderungen zu erzwingen. Die deutschen Minister sowie Parlaments-

71 Vgl. Schütz, Mayr-Harting, S. 281 bzw. NáO vom 13. 11. 1926. Vgl. auch APČR, 2. WP, Karton 55, 32. Sitzung des Budgetausschusses am 4.11. 1926.

72 Am 11.11. 1926 nahm auch Minister Spina an den Verhandlungen des Budgetausschusses teil. Auch er überließ die Verlesung des entsprechenden Referats einem Beamten seines Ministeriums. Vgl. APČR, 2. WP, Karton 56, 42. Sitzung des Budgetausschusses am 11.11. 1926.

${ }^{73}$ NáO vom 13.11. 1926.

74 Antrag der Abgeordneten Bradáč, Dr. Dolanský, Hlinka, Dr. Lukavský, Pekárek, Windirsch, Dr. Luschka und Genossen auf Abänderung des $\$ 5$ des Gesetzes Nr. 325 vom 15. April 1920 Slg. über die Geschäftsordnung des Abgeordnetenhauses vom 10.11. 1926, in: TTZPS, 2. WP, Drucksache 661.

75 AKPR, T 198/26, Karton 154 , Aktenvermerk KPR, undat. (Eingang KPR 16. 3. 1927).

${ }^{76}$ Ebda. 
funktionäre gebrauchten in ihren Erklärungen sowohl in den Ausschüssen als auch im Plenum des Parlaments die tschechische Sprache. Diese Praxis akzeptierte auch die deutsche Sozialdemokratie nach ihrem Regierungseintritt im Jahre 1929, obwohl sie bis dahin die deutschen Regierungsparteien gerade wegen ihrer Haltung in der Sprachenfrage im Parlament heftig kritisiert hatte."

$\mathrm{Daß}$ die Geschäftsordnung weiterhin ein wunder Punkt blieb, verrät die Tatsache, daß eine Neuregelung ihrer sprachlichen Bestimmungen auch Gegenstand des Memorandums der deutschen aktivistischen Parteien vom Januar 1937 war. Demgemäß waren besonders Spracherleichterungen zu schaffen, um die Ausübung der parlamentarischen Funktionen durch die Angehörigen aller Nationen des Staates zu ermöglichen. Der zweite Wunsch betraf die Möglichkeit einer effektiveren Mitwirkung an der Gesetzgebung: Alle parlamentarischen Materialien, insbesondere Regierungsanträge sowie Begründungen zu Regierungsanträgen sollten auch in den Minderheitensprachen vorgelegt werden. ${ }^{78}$ In ihrem Kommuniqué zum Memorandum der deutschen aktivistischen Parteien ging die Regierung allerdings auf diese Problematik mit keinem Wort ein, und die im Jahre 1920 beschlossene Geschäftsordnung blieb in sprachlicher Hinsicht bis zum Jahre 1938 unverändert. Das Nationalitätenstatut bestätigte grundsätzlich die bestehende Geschäftsordnung sowie das Recht des Parlaments, über seine Bestimmungen selbst zu entscheiden. Soweit bekannt, wurde eine Änderung der bisherigen Regelung nicht erwogen. Wahrscheinlich war vielen tschechischen Politikern der Gedanke, den im Jahre 1930 die sozialistische "České slovo" formulierte, weiterhin eng vertraut: Es sollte die Pflicht der deutschen Wähler sein, nur solche Vertreter ins Parlament zu entsenden, die die Staatssprache verstanden. „Es ist doch viel einfacher, achtzig tschechisch sprechende Deutsche zu finden, als die Änderung des gesamten Systems und des gesamten Charakters des Staates zu verlangen. “79

Die Vorbereitung der Geschäftsordnung für die Landes- und Bezirksvertretungen wurde bereits im Kapitel über die Entwicklung der Sprachenfrage in der zweiten Hälfte der zwanziger Jahre ausführlich behandelt. ${ }^{80}$ Die notwendige Rücksicht auf die zu erwartende nationale Zusammensetzung dieser Körperschaften und vielleicht auch die Teilnahme der sudetendeutschen aktivistischen Parteien an der Ausarbeitung der Norm verursachte, daß der Aspekt der Zweckmäßigkeit stärker in den Mittelpunkt rückte; im Vergleich zur Parlamentsgeschäftsordnung erfolgte eine Erweiterung des Anwendungsbereichs der Minderheitensprachen. Im Falle der Landesvertretungen war relevant, ob in dem betreffenden Land zumindest 20 Prozent Angehörige eines Minderheitenvolkes lebten. Da sowohl das Land Böhmen als auch Mähren-Schlesien

7 Vgl. beispielsweise Der Sozialdemokrat vom 7. 11. 1926 oder Sünden, S. 7. Hier kritisierte die DSAP vor allem den stellvertretenden Vorsitzenden des Abgeordnetenhauses W. Zierhut (BdL), der sich bei der Leitung der Parlamentssitzungen des Tschechischen zu bedienen begann. Dies rief übrigens Mißstimmung bei der innerparteilichen Opposition im BdL selbst um die Abgeordneten J. Mayer und G. Hanreich hervor. Vgl. ebda.

78 Zajicek, Dokumente, S. 7. Einen Antrag auf Ergänzung der Geschäftsordnungen beider Häuser, der die verpflichtende Übersetzung von Regierungsanträgen und Motivenberichten in die Minderheitensprachen vorsah, legten im Jahre 1935 die oppositionellen deutschen (SdP und DCSVP) und ungarischen Parteien vor. Vgl. Antrag der Abgeordneten Frank, Szentiványi, Luschka und Genossen betreffend die Ergänzung der Geschäftsordnung der beiden Häuser vom 26. 6. 1935, in: TTZPS, 4. WP, Drucksache 58.

79 ČS vom 23. 4. 1930.

so Vgl. Kapitel I.D.1. 
diese Bedingung erfüllten, konnten die deutschen Vertreter somit in beiden Landesvertretungen sowie in deren Ausschüssen und Kommissionen in ihrer Muttersprache Erklärungen abgeben sowie Anträge, Anfragen und Beschwerden vorlegen. Im Unterschied zum Parlament konnten Funktionäre der Vertretungen sowie Beamte der Landesbehörden ihren Erklärungen eine Übersetzung in der Sprache der betreffenden nationalen Minderheit beifügen bzw. - wenn es der Vorsitzende billigte - ihre Reden zugleich auch in der Minderheitensprache halten, „soweit dies der glatte Geschäftsgang und der Schutz vor Schäden aus Unkenntnis der Staatssprache erfordern." Trotz dieser vorbehaltlichen Formulierung trug diese Bestimmung gewiß zur Verbesserung der Kommunikation zwischen den nichttschechischen bzw. nichtslowakischen Abgeordneten der Vertretung einerseits und deren Leitung bzw. der Landesexekutive andererseits bei. Auch die Ausübung der genannten Funktionen durch Angehörige der Minderheiten wurde teilweise erleichtert: Falls sie gleichzeitig Mitglieder der Vertretung waren, konnten sie in Debatten das Wort in ihrer Muttersprache ergreifen, die Berichterstattung erfolgte jedoch nur in der Staatssprache.

Bei Anfragen oder Beschwerden in einer Minderheitensprache verfuhr man ähnlich wie im Parlament: Ihre Autoren konnten eine Übersetzung in der Staatssprache beifügen; falls sie dies nicht taten, war die Übersetzung von der Landesbehörde zu besorgen. Beantwortete der Landespräsident eine Anfrage oder Beschwerde schriftlich, war eine Übersetzung in der Sprache des Antragstellers oder Beschwerdeführers beizufügen; wenn Vorschläge, Anfragen oder Beschwerden in der Minderheitensprache kurz und einfach waren, und wenn dadurch die Verhandlung nicht aufgehalten wurde, gab sie der Vorsitzende "nach seinem Ermessen“ sofort selbst in der Staatssprache wider oder ließ sie mündlich übersetzen. Wie im Parlament wurden aber die in der Staatssprache eingebrachten Anträge oder Anfragen nicht in die Minderheitensprachen übersetzt; die Protokolle wurden nur in der Staatssprache geführt, lediglich wenn über die Verhandlung ein stenographischer Bericht aufgenommen wurde, schloß man die deutschsprachigen Erklärungen in Form einer Beilage an.

Die Bezirksvertretungen wurden implizit in vier Typen eingeteilt (weniger als 20, über 20, 50 und 75 Prozent Minderheitenbevölkerung), wobei die Bestimmungen für die ersten zwei im Hinblick auf die Voraussetzungen sowie den Umfang des Gebrauchs der Minderheitensprachen analog mit denen für die Landesvertretungen waren. Der wichtige Unterschied lag darin, daß die deutschen Vertreter nicht nur Erklärungen abgeben und Anträge, Anfragen und Beschwerden in ihrer Sprache vorbringen, sondern diese auch in der Berichterstattung gebrauchen konnten. In den Gerichtsbezirken mit über 50 und 75 Prozent wurden alle von Mitgliedern der Vertretung, der Ausschüsse und Kommissionen vorgelegten Berichte, Anträge, Anfragen und Beschwerden in die Minderheitensprache, beispielsweise also ins Deutsche übersetzt; wie bereits erwähnt wurde, konnte auch der deutsche Wortlaut als Grundlage der Verhandlung herangezogen werden. Das Protokoll wurde doppelsprachig tschechisch-deutsch geführt. In den Bezirken mit zu über 75 Prozent deutscher Bevölkerung wurde von der Übersetzung der deutsch vorgebrachten Anträge, Berichte, Anfragen und Beschwerden in die Staatssprache Abstand genommen, sofern nicht ein Mitglied der Vertretung um die Übersetzung ersuchte oder der Vorsitzende selbst sie als notwendig erachtete.

Eine allgemeine Zufriedenheit mit dieser Regelung herrschte deutscherseits allerdings nicht. Als problematisch erachtete man, daß vieles dem „Ermessen“ - oder, wie 
die deutsche Sozialdemokratie monierte, der "Willkür“ - des jeweiligen Vorsitzenden und zum Teil auch dem guten Willen der tschechischen Mitglieder der Vertretungen überlassen wurde, von denen, und nicht etwa von den Bestimmungen der Verordnung selbst, das Entgegenkommen hinsichtlich der sprachlichen Bedürfnisse der Vertreter der Minderheiten weitgehend abhänge. ${ }^{81}$ Die deutsche Presse kritisierte auch die ungenügende Berücksichtigung des Deutschen in Bezirken mit unter 50 Prozent deutscher Bevölkerung, wo man identische Bedingungen verlangte wie in Bezirken mit einer absoluten deutschen Mehrheit; in den letzteren sollte deutsch überhaupt explizit als Geschäftssprache festgelegt werden. ${ }^{82}$ Die oppositionellen deutschen Sozialdemokraten legten in der ersten Sitzung der böhmischen sowie der mährischen Landesvertretung erfolglos gleichlautende Anträge auf Regelung des Sprachgebrauchs in diesen Gremien vor, deren leitender Gedanke war, daß die beiden Vertretungen als Körperschaften der Selbstverwaltung gemäß dem Sprachengesetz grundsätzlich berechtigt seien, ihre Geschäftssprache selbst festzulegen. Laut Antrag sollte die Geschäftssprache der Landesvertretungen die "tschechoslowakische“ und die deutsche Sprache sein; jedem Mitglied hätte das Recht zugestanden, sich beider Sprachen frei zu bedienen. Die Leitung der Verhandlungen sollte in der Sprache der Mehrheit der Landesvertretung erfolgen, alle Äußerungen sollten in die jeweils andere Landessprache übersetzt werden. Berichte waren in einer der beiden Sprachen zu erstatten, Protokolle ebenfalls in beiden Sprachen zu führen. Anfragen und Beschwerden sollten in der Sprache, in der sie eingebracht worden waren, beantwortet werden. ${ }^{83}$

Im Unterschied zum Parlament und zu den Landes- und Bezirksvertretungen wurde der Sprachgebrauch in Gemeinde- und Stadtvertretungen sowie in anderen Organen der Kommunalverwaltung durch keine eigene Rechtsnorm geregelt; er unterlag speziellen Bestimmungen des Sprachengesetzes und besonders der Durchführungsverordnung vom Jahre 1926. Die Problematik des Sprachgebrauchs im kommunalen Bereich rückte bald nach der Entstehung der Republik, vor allem nach den Gemeindewahlen im Juni 1919, in den Mittelpunkt der Aufmerksamkeit. Die Wahlen wurden das erste Mal nach dem allgemeinen Wahlrecht abgehalten, und in deren Zuge errangen die Vertreter der sozial niedriger gestellten tschechischen Schichten in den sprachlich gemischten Gebieten in verstärktem Maße Sitze in den Kommunalorganen. Die Forderung, den neuen Verhältnissen in der Kommunalverwaltung auch in sprachlicher Hinsicht Rechnung zu tragen, ließ verständlicherweise nicht lange auf sich warten.

Mancherorts wurde eine neue Regelung im Einvernehmen zwischen den deutschen und tschechischen Vertretern erreicht, mancherorts mußte die Staatsverwaltung - was mangels einer Rechtsgrundlage jedoch nur indirekt möglich war - eingreifen. Es wurde angedroht, diejenigen Gemeindevertretungen aufzulösen und durch eine ernannte Verwaltungskommission zu ersetzen, die in ihrer Tätigkeit aus welchen Gründen auch immer - somit auch aus sprachlichen - beeinträchtigt wurden. ${ }^{84}$ Inwieweit dieser Druck

81 PA R 73858, Gesandtschaft Prag an AA, 17. 1. 1929 bzw. Der Sozialdemokrat vom 1. 6. 1929.

82 Bo vom 27. 1. 1929.

${ }^{83}$ Der Sozialdemokrat vom 17. 1. 1929.

${ }^{84}$ SÚA, PMR, Karton 3295, MV an die politische Bezirksverwaltung Saaz, 1.9. 1919. Die - v. a. im Hinblick auf die mehrheitlich deutschen Gemeinden - wirksame Drohung bestand darin, eine Verwaltungskommission einzusetzen, die natürlich mehrheitlich aus tschechischen Mitgliedern bestand. Es ist natürlich nicht ausgeschlossen, daß dies den Boden für eine planmäßige Obstruktionspolitik in 
oder die Einsicht der Politiker für die Suche nach notwendigen Kompromissen ausschlaggebend waren, muß dahingestellt bleiben; auf jeden Fall basierten einige bekannte Vereinbarungen über den Sprachgebrauch in Gemeindevertretungen auf einer beinahe vorzüglichen sprachlichen Gleichberechtigung. ${ }^{85}$ Ansonsten herrschte auf dem Gebiet des Sprachgebrauchs in der kommunalen Selbstverwaltung zumindest bis 1926, in einiger Hinsicht jedoch auch länger, ein nicht ganz klarer Zustand.

Dies betraf in erster Linie die Festlegung der Geschäftssprache der Gemeinde, die in der österreichischen Gesetzgebung zu den ausschließlichen Kompetenzen der Gemeindevertretung gehört hatte. Das Sprachengesetz ließ diese Frage ungeregelt, was die Annahme nahelegte, daß dieses Recht jeder Gemeinde nicht angetastet wurde. Als man jedoch in der Durchführungsverordnung zum Sprachengesetz dieses Prinzip ausdrücklich bestätigen wollte, wehrten sich die tschechischen Schutzverbände entschieden dagegen. Das postulierte Recht der Gemeinden, ihre Geschäftssprache selbst zu bestimmen, bezeichneten sie als "laut Sprachgesetz und Friedensvertrag“ unzulässig; sie waren allenfalls bereit zu akzeptieren, daß eine andere Geschäftssprache als die Staatssprache von der Regierung aufgrund eines „begründeten“ Gesuchs und für einen begrenzten Zeitraum (höchstens zehn Jahre) bewilligt werden konnte. ${ }^{86}$ Mit diesen Forderungen setzten sich die tschechischen Nationalisten schließlich nicht durch; das Recht der Gemeinde, ihre Geschäftssprache selbst zu bestimmen, wurde beibehalten - wenn auch mit gewissen, in den einzelnen Fassungen der Durchführungsverordnung zwischen 1920 und 1926 immer stärker zunehmenden Einschränkungen zugunsten der Staatssprache. Immerhin bezog sich schließlich die Verpflichtung, neben einer bestimmten Sprache auch die Staatssprache als Geschäftssprache der Gemeinde festlegen zu müssen, eher auf Ausnahmefälle und konnte in der Praxis eigentlich nur selten mit der Willensäußerung der Gemeindevertretung in Widerspruch geraten. ${ }^{87}$

$\mathrm{Da}$ die Festlegung der Geschäftssprache der Gemeinde trotz bestimmter Einschränkungen weitgehend in ihrer eigenen Regie stand, rückten in den Mittelpunkt der Aufmerksamkeit die Bestimmungen hinsichtlich der Möglichkeit, in Sitzungen von Gemeindevertretungen auch eine andere als die Geschäftssprache gebrauchen zu dürfen. Eben hier schuf man für die Staatssprache gewaltige Begünstigungen: diese konnte jederzeit gebraucht werden, die in ihr vorgelegten Anträge und Anregungen

der Sprachenfrage durch tschechische Nationalisten bereitete; konkrete Fälle konnten allerdings bisher nicht ermittelt werden.

85 SÚA, PMR, 3295, Vertreter der deutschen Parteien der Stadt Postelberg an den Ministerpräsidenten, 25. 10. 1919. Jedes Mitglied des Stadtrates oder der Stadtverwaltung hatte das Recht, sich in den Sitzungen seiner Muttersprache zu bedienen; für die simultane Übersetzung sorgte ein durch den Bürgermeister bestimmtes Mitglied der Vertretung oder ein Dolmetscher. Das Protokoll wurde einheitlich geführt, und zwar jeweils in der Sprache, in der die betreffende Erklärung usw. abgegeben wurde. Vgl. auch SÚA, PMR, Karton 3295, 740/17, MV an PMR, 27. 5. 1920. In der Gemeindevertretung in Seestadtl (Bezirk Komotau) wurde beispielsweie u. a. verabredet, von dem deutsch geführten Protokoll eine amtliche tschechische Übersetzung zu besorgen.

86 SÚA, MV-SR, Karton 1487, 14/1/4, NJS an PMR, MV und MA, 23. 12.1924 bzw. ebda, Denkschrift des SNJM an den Ministerpräsidenten, 12.1. 1925.

87 So mußte in den Gemeinden, in denen über 80 Prozent Angehörige tschechischer oder slowakischer Nationalität wohnhaft waren, die Staatssprache stets die Geschäftssprache sein. Automatisch erlangte sie diese Stellung, wenn in einer Gemeinde mehr Angehörige der Staatssprache lebten als Angehörige einer Minderheitensprache, die als Geschäftssprache festgesetzt wurde. Schließlich wurde diejenige Sprache zur Geschäftssprache, welcher in der Gemeinde wenigstens 50 Prozent der dort ansässigen Staatsbürger angehörten. 
mußten immer Gegenstand der Verhandlung werden. Die in der Geschäftssprache der Gemeinde gestellten Anträge mußten in die Staatssprache übersetzt werden und umgekehrt, wenn ein Mitglied der Vertretung darum ersuchte. Für die Minderheitensprachen galt Identisches nur dann, falls in der Gemeinde über 20 Prozent ihrer Angehörigen wohnten. Eine gewisse Begünstigung der Staatssprache bezog sich auch auf das Protokollieren: die Protokolle wurden zwar grundsätzlich in der Geschäftssprache der Gemeinde geführt, die in der Staatssprache vorgebrachten Anträge und Erklärungen mußten auf Verlangen tschechisch oder slowakisch protokolliert, aber nur dann, wenn die Gemeinde wenigstens 3000 Einwohnern hatte, oder ein Notar für sie bestellt war bzw. ein Tscheche (Slowake) ihrer Vertretung angehörte. Ansonsten mußten die in anderen Sprachen vorgebrachten Anträge und Erklärungen auf Verlangen des Antragsstellers in der Sprache aufgenommen werden, in der sie erfolgt waren, wenn in der Gemeinde wenigstens 20 Prozent Angehörige dieser Sprache wohnten. Diese potentielle „Allgegenwart" der Staatssprache erweckte deutscherseits Befürchtungen, daß ein einziger tschechischer Gemeindevertreter ihre Tätigkeit relativ einfach lahmlegen konnte, indem er beispielsweise tschechische Anträge einbrachte, die außer ihm niemand zu verstehen bzw. zu übersetzen in der Lage war. ${ }^{88}$ Inwieweit sich diese Gefahr auch in der Praxis bestätigte, läßt sich nicht eindeutig feststellen. Natürlich kann man Obstruktionen von beiden Seiten nicht von vornherein ausschließen, zu einem massiven Problem wurden sie jedoch offensichtlich nicht. Als problematisch wurde auch die Bestimmung erachtet, dergemäß der Gemeindevorsteher, der zufälligerweise der anderen, in der Sitzung eventuell zu gebrauchenden Sprache nicht mächtig war, eine andere Person "zur Mitleitung" (seinen Stellvertreter, ein anderes Mitglied der Vertretung) bzw. „zur Vermittlung“ (einen Beamten) berufen mußte, die über die entsprechenden Sprachkenntnisse verfügte. Deutscherseits betrachtete man dieses Verfahren im Hinblick auf die Gemeindeordnung für Böhmen als gesetzwidrig; von tschechischer Seite, die im Grunde genommen ähnlich, wenn auch bei weitem nicht in gleichem Umfang tangiert war, ist eine derartige Reaktion nicht bekannt. ${ }^{89}$

Wie dieses System in der Praxis funktionierte, muß weiteren Untersuchungen überlassen werden, vieles hing von der Verständigungsbereitschaft beider Seiten ab: Dort, wo diese nicht vorhanden war, kam eine effektive Kommunikation kaum zustande. Die Verlockung mancher Tschechen, in der Gemeindevertretung ihre Sprachenrechte demonstrativ und unzweckmäßig geltend zu machen, war manchmal wohl nicht gering. Auch die Deutschen reagierten bisweilen überstürzt; sicher war es nicht notwendig, daß Deutsche die Sitzung der Gemeindevertretung verließen, als ein tschechisches Mitglied das Wort in seiner Muttersprache ergriff, wie dies beispielsweise 1926 in Eger passierte. ${ }^{90} \mathrm{Da}$ derartige Beschwerden in den Folgejahren eher selten waren, kann man vermuten, daß die Sprachregelung im Kommunalbereich leidlich funktionierte; auf jeden Fall wurde deren Änderung nicht einmal während der Verhandlungen über das Nationalitätenstatut im Jahre 1938 erwogen.

88 Vgl. Denkschrift, S. 17, Sprachenverordnung, S. 45 bzw. 77.

${ }^{89}$ Rede Zierhuts in der 13. Sitzung des Abgeordnetenhauses am 11. 3. 1926, in: TZPS, 2. WP, S. 727.

90 Vgl. Egerer Zeitung vom 20. 2. 1926. 


\section{Die Sprache im Geschäftsverkehr}

Auf den ersten Blick würde man in diesem Bereich des Sprachgebrauchs die wenigsten Probleme erwarten, denn die tschechoslowakische Verfassung garantierte im Einklang mit dem Minderheitenschutzvertrag von St. Germain den freien Gebrauch der Sprache „im Privat- und Handelsverkehr“ ${ }^{91}$ Trotzdem waren diverse Aktivitäten im Prozeß der privaten Erwerbstätigkeit in sprachlicher Hinsicht nicht ganz frei von verschiedenen Zwängen, die sich - ganz grob gesagt - aus der notwendigen Berührung des privaten Bereichs mit dem der öffentlichen Gewalt ergaben. Eine gewisse Spannung in diesem Bereich wurde auch dadurch verursacht, daß die Ansichten darüber, wo die Grenze zwischen den beiden eigentlich verlief, ziemlich unterschiedlich waren, was auf das abweichende Demokratieverständnis besonders im Spannungsfeld zwischen Etatismus und Liberalismus zurückging, zumal - dies war in dieser Hinsicht für beide Seiten ein grundlegender Beweggrund - der Nationalstaat das Staatsinteresse verkörperte. Die Minderheiten verlangten, daß die staatliche Verwaltung die freie Rechtssphäre der Staatsbürger "möglichst wenig“ einenge oder, wenn dies unvermeidlich war, ihre Einengung "wenn möglich" nicht gegen den Willen der Minderheiten herbeiführe. ${ }^{92}$ In sprachlicher Hinsicht hieß es deutscherseits, der Geschäftsverkehr passe sich „von selbst den jeweiligen sprachlichen Erfordernissen an“. Tschechischerseits war man dagegen eher bereit, dem Staat auch auf diesem Gebiet gewisse Befugnisse einzuräumen, vor allem dort, wo es auf Seiten der Minderheiten angeblich „an gutem Willen und genügendem Verständnis für die Bedürfnisse des Staates und aller seiner Angehörigen“ fehlte. ${ }^{93}$ Die grundlegende Tendenz der Entwicklung der Sprachpraxis im Geschäftsverkehr war die Einschränkung des freien Sprachgebrauchs. Dafür mögen nicht primär nationalpolitische Gründe ausschlaggebend gewesen sein, sondern auch das Ungleichgewicht der privaten und öffentlich-rechtlichen Sphäre in sprachlicher Hinsicht, von denen die eine - in Gestalt des kodifizierten Sprachenrechts - fest normiert war, während die andere dagegen lediglich negativ abgesteckt war - hierher gehörte alles, was das Sprachengesetz nicht berührte. Eine positive Absteckung gab es nicht, zumal nicht einmal eine Definition dessen vorhanden war, was unter „Handels-“ bzw. „Geschäftsverkehr" zu verstehen war. Indem das tschechoslowakische Sprachenrecht vom Grundsatz ausging, der Gebrauch von Minderheitensprachen sei nur dort zulässig, wo es das Gesetz ausdrücklich erlaube, war die tendenzielle Einengung des normativ "schwächeren" Bereichs - nämlich des freien Sprachgebrauchs - nahezu programmiert, bis er sich im Laufe der Zeit praktisch auf Kontakte zwischen den einzelnen privaten Wirtschaftssubjekten untereinander reduzierte. Hinzu kam, daß nicht wenige Eingriffe in diesen Bereich tatsächlich „Vorstösse" waren, die auf die Zurückdrängung des Deutschen in bestimmten Anwendungsbereichen abzielten, und somit vice versa die Stellung der tschechischen bzw. slowakischen Sprache ausbauten. Noch etwas ermunterte die Verfechter einer verstärkten staatlichen Einflußnahme auf den Sprachgebrauch im Geschäftsverkehr in ihren Aktivitäten, nämlich der durch sie oft vertretene Rechts-

91 In der amtlichen Übersetzung des Vertrages (vgl. Nr. 508/1921 Slg.) wurde der Begriff „Handelsverkehr" gebraucht. Stattdessen wandten deutsche Autoren den Ausdruck "Geschäftsverkehr" als passender an. Vgl. Schranil-Janka, Verfassungsgesetze, S. 355.

92 Epstein, Grundsätze, S. 85.

93 SUA, PMR, Karton 3296, MpSZaOS an PMR, 5. 4. 1938. 
standpunkt, die tschechoslowakische Verfassungsurkunde sähe die Notwendigkeit einer Sprachregelung auch im Geschäftsverkehr vor. Die Grundsteine ihrer Argumentation waren die bereits einige Male erwähnte vorbehaltliche Formulierung der Verfassung, nach der die Freiheit des Sprachgebrauchs im Privat- und Geschäftsverkehr ,innerhalb der Grenzen der allgemeinen Gesetze" gewährt wurde, bzw. der hier verankerte Vorbehalt, daß durch den freien Sprachgebrauch diejenigen Rechte nicht berührt werden durften, die „den Staatsorganen in diesen Belangen aufgrund der bestehenden oder künftig zu erlassenden Gesetze aus Gründen der öffentlichen Ordnung und der staatlichen Sicherheit sowie der wirksamen Aufsicht" zukommen würden. ${ }^{94}$

Im Jahre 1924 bestätigte das Oberste Verwaltungsgericht ausdrücklich, daß sich der Begriff "Handelsverkehr" nicht auf den Verkehr mit Staatsorganen, Gemeinden und öffentlichen Körperschaften bezog. ${ }^{95}$ Firmen, Gewerbetreibende und Angehörige der sogenannten freien Berufe waren somit, falls sie sich an diese Organe in deren Eigenschaft als Staatsgewalt wandten, wie jede physische oder juristiche Person den allgemeinen Regeln des Sprachenrechts unterworfen. Sie konnten somit ihre beispielsweise deutsche Geschäftssprache etwa im Verkehr mit Organen der Finanz- oder Zollverwaltung nur im Einklang mit den diesbezüglichen Bestimmungen des Sprachengesetzes gebrauchen. Äußerst schwierig gestaltete sich der Verkehr der sudetendeutschen Wirtschafts- und Geschäftswelt mit staatlichen Betrieben. ${ }^{96}$ Wie bereits dargelegt wurde, war der Parteienverkehr mit ihnen ein Problem sui generis ${ }^{97}$; der Geschäftsverkehr war gar dem Ermessen ihrer Beamtenschaft ausgeliefert. Die Staatsbetriebe waren laut Durchführungsverordnung im Hinblick auf ihre geschäftliche oder fachliche Korrespondenz sowie ihre fachlichen Publikationen zwar aus den Bestimmungen des Sprachengesetzes ausgenommen, jedoch unter dem Hinweis, auch in solchen Fällen eine andere Sprache als die Staatssprache nur dann zu gebrauchen, wenn es „unumgänglich notwendig" sei.

Dementsprechend war auch die Praxis der staatlichen Betriebe in dieser Hinsicht eher engherzig. Am deutlichsten zeigt dies die Praxis der staatlichen Eisenbahn, des größten Staatsbetriebs, dessen Bedeutung für die damalige Wirtschaft wohl nicht besonders hervorgehoben werden muß. Kommerzielle Briefe sowie Eingaben in einer Minderheitensprache wurden nur von Firmen angenommen, die ihren Sitz in einem sprachlich qualifizierten Gerichtsbezirk hatten. Für den Frachtverkehr wichtige Hilfsmittel (Tarif- und Entfernungstabellen, Verzeichnisse der Eisenbahnstationen) standen nur in der Staatssprache zur Verfügung. Verträge mit der Staatseisenbahn wurden ebenfalls nur tschechisch oder slowakisch geschlossen. Zuglisten und Frachtbriefe lagen in Stationen, die nach einer Gemeinde benannt wurden, in der wenigstens 20 Prozent Angehörige einer Minderheitensprache lebten, in zweisprachiger Ausführung vor und konnten zweisprachig oder sogar nur einsprachig - also etwa deutsch - ausgefüllt werden, falls auch in der Bestimmungstation eine solcherart qualifizierte Minderheit

94 Man berief sich dabei auf die Absätze 3 und 4 des Paragraphen 128 der Verfassungsurkunde. Vgl. SÚA, PMR, Karton 3296, MpSZaOS an PMR, 5. 4. 1938.

$95 \mathrm{Vgl.} \mathrm{Schranil-Janka,} \mathrm{Verfassungsgesetze,} \mathrm{S.} 354$.

$96 \mathrm{Zu}$ diesen gehörten u. a. die Staatseisenbahn, die Tschechoslowakische Post, die Nationalbank, staatliche Berg- und Hüttenwerke, staatliche Forste, Bäder und Krankenhäuser, Druckereien sowie die Tabakfabriken.

97 Vgl. Kapitel II.B.1. 
bestand. ${ }^{98}$ Das Eisenbahnministerium war noch im Jahre 1936 davon überzeugt, daß diese Praxis „,im Grunde genommen“ der „notwendigen administrativen Zweckmäßigkeit" entspreche. ${ }^{99}$ Anderer Meinung war beispielsweise der tschechische Rechtsexperte E. Sobota, der in seinem Exposé für Präsident Beneš vom Jahre 1936 empfahl, den Geschäftsverkehr der Staatsbetriebe gar keinen Vorschriften zu unterwerfen. Eine andere als die Staatssprache sollte nach Sobota immer gebraucht werden, wenn dies vom Standpunkt der Effizienz aus wünschenswert erschien. ${ }^{100}$ Erst der Entwurf des neuen Sprachengesetzes von 1938 ließ mit Rücksicht auf die Fach- und Handelsinteressen der Staatsbetriebe in ihrem Parteien- und Geschäftsverkehr ausdrücklich auch den Gebrauch von anderen Sprachen zu. ${ }^{101}$

Im Zusammenhang mit dem Sprachgebrauch im Geschäftsverkehr muß ein weiterer Umstand beleuchtet werden, nämlich die "Sprachzugehörigkeit“ eines Unternehmens. Das Sprachengesetz selbst machte zwar zwischen physischen und juristischen Personen keinen Unterschied; der Grundsatz jedoch, daß auch die zweitgenannten Angehörige einer Sprache waren, etablierte sich sowohl in der Gesetzgebung als auch in der Praxis bereits seit Anfang der zwanziger Jahre. ${ }^{102}$ Explizit wurde er durch die Durchführungsverordnung zum Sprachengesetz festgelegt, übrigens entgegen den Vorstellungen der tschechischen Schutzvereine, die verlangten, die Minderheitensprachenrechte lediglich physischen Personen zuzuerkennen. ${ }^{103}$ Laut Verordnung war für die Bestimmung der Sprachzugehörigkeit juristischer Personen und „diesen ähnliche(n) selbständige(n) Rechtssubjekte(n) " die Sprache der Eintragung in das öffentliche Register ${ }^{104}$ bzw. ihre Geschäftssprache entscheidend, wie sie in den Statuten, der Geschäftsordnung oder anderen internen Vorschriften festgelegt war. ${ }^{105}$ Auch wenn diese Regelung eindeutig aussehen mag, war sie in der Praxis bei weitem nicht klar, denn sie schloß unter gewissen Voraussetzungen nicht aus, daß eine deutsche Firma, die das Tschechische nie als ihre Geschäftssprache festgelegt hatte, diese dennoch im Verkehr mit Staatsor-

${ }^{98}$ AKPR, D 952, Karton 116, Exposé „Stand der Sprachenfrage bei den Tschechoslowakischen Staatseisenbahnen", 20.6. 1936; ebda, Aktenvermerk KPR, 26. 10. 1937; Deutsche Gesandtschaft an AA, 2. 8. 1921, in: Gesandtschaftsberichte I., Dokument Nr. 205, S. 517-518.SÚA, PMR, Karton 3296, 740/43, Memorandum der deutschen Wirtschaftsverbände an den Ministerpräsidenten, Oktober 1937.

99 AKPR, D 952, Karton 116, Exposé „Der Stand der Sprachenfrage bei den Tschechoslowakischen Staatseisenbahnen", 20.6. 1936.

100 ANM, NL Sobota, Karton 13, Exposé E. Sobotas „Über die Möglichkeit, den Forderungen der Minderheiten im Bereich der Sprachenrechte entgegenzukommen“, undat. (1936).

101 SÚA, PMR, Karton 1714, 401/7, Verfassungsgesetz, durch das die Grundsätze des Sprachenrechts in der Tschechoslowakischen Republik festgelegt werden, undat. (12. 7. 1938).

102 Eine diesbezügliche Bestimmung enthielt bereits der Entwurf der Durchführungsverordnung zum Sprachgesetz vom Jahre 1920, vgl. SÚA, MV-SR, Karton 506, 20/2/53(1), Entwurf der Regierungsverordnung zur Durchführung des Gesetzes Nr. 122/1920 Slg., undat. (verschickt am 7. 10. 1920).

${ }^{103}$ SÚA, MV-SR, Karton 1487, 14/1/4, NJS an PMR, MV und MS, 23. 12. 1924.

104 Die Gesuche um Eintragung ins öffentliche Register waren laut Durchführungsverordnung, Art. 30, Eingaben an Staatsorgane, sie richteten sich deswegen nach dem Sitz des Subjekts bzw. bei Firmen auch nach dem der einzutragenen Zweigniederlassung. Beispielsweise mußte eine in Prag ansässige deutsche Firma einen tschechisch verfaßten Antrag an das zuständige Registergericht stellen; in die Eintragung selbst wurde jedoch der vom Gesuchsteller gewählte Wortlaut übernommen, in welcher Sprache er auch immer abgefaßt war.

105 Nach dem Urteil des Obersten Verwaltungsgerichts Nr. 29648/28 vom 15. 1. 1929 waren auch durch ein dazu berufenes Organ mündlich herausgegebene Vorschriften bzw. „eine aus konkludenten Taten öffentlich sichtbare Willenserklärung “ maßgebend, vgl. SÚA, PMR, Karton 3296, 740/43, MS an PMR, 6. 4. 1938. 
ganen bzw. -Betrieben gebrauchen mußte. ${ }^{106}$ Als besonders problematisch erwies sich im Laufe der Zeit der Umstand, daß sich in den Anfangsjahren der Republik nicht wenige deutsche Firmen und Gesellschaften im Handelsregister tschechisch hatten eintragen lassen bzw. auch das Tschechische als Geschäftssprache angeführt hatten. Dafür waren mehrere Gründe ausschlaggebend: vor allem ein bis zur Herausgabe der Sprachverordnung 1926 unklarer Stand im Hinblick auf die Bestimmung der sprachlichen $\mathrm{Zu}$ gehörigkeit einer Firma, Opportunismus, den man als „Respekt vor der Staatssprache“ $\mathrm{zu}$ kaschieren versuchte ${ }^{107}$, sowie praktische Bedürfnisse. Manche Firmen und Gesellschaften nahmen nach der Entstehung der Republik angeblich „unter dem Einfluß der Staatsverwaltung " ${ }^{108}$ oder aber aus wirtschaftspolitischen Überlegungen tschechische Mitglieder in die Verwaltungsräte auf und ließen - oft wohl nur formal - auch tschechisch als Geschäftssprache zu. Nach dem Erlaß der Durchführungsverordnung im Jahre 1926 gelangten diese Firmen in eine prekäre Lage, denn von nun an wurden sie als der Staatssprache zugehörig angesehen, was natürlich ihren Verkehr mit Staatsorganen und -betrieben zusätzlich komplizierte - so mußten sie beispielsweise ihre deutschen Kunden in den Minderheitsbezirken in tschechischer Sprache verklagen. Kein Wunder, daß mit dem durch die Sprachverordnung eingeführten Verfahren niemand besonders zufrieden war; auch tschechischerseits wurden Bedenken hinsichtliche der Unklarheiten der Regelung laut. ${ }^{109}$ Der Forderung der deutschen Wirtschaftsverbände vom Ende der dreißiger Jahre, nur die Geschäftssprache bzw. die innere Amtssprache der Firma als relevant zu berücksichtigen, folgte die Staatsverwaltung - und auch da nur zögerlich - erst im Entwurf des Nationalitätenstatuts vom Jahre 1938. ${ }^{110}$ Dies geschah allerdings auch hier nicht ganz eindeutig, denn die Sprachzugehörigkeit juristischer Personen sollte "in erster Linie" nach der Sprache beurteilt werden, die in ihrer inneren Verwaltung gebraucht wurde - welche Aspekte gegebenfalls außerdem ausschlaggebend sein sollten, stand nicht fest. ${ }^{111}$

Vom Standpunkt der "nationalwirtschaftlichen" Interessen her gesehen stand die Sprachpraxis bei der Vergabe von Staatsaufträgen im Mittelpunkt der Aufmerksamkeit sudetendeutscher Unternehmerkreise. Die Vergabeordnung Nr. 667/1920 Slg. enthielt keine sprachlichen Bestimmungen, und es konnte scheinen, daß dadurch Raum für eine den praktischen Bedürfnissen angepaßte Regelung geschaffen wurde, zumal man dem Staat selbst unterstellte, er sei eminent daran interessiert, daß die günstigsten Angebote in das Entscheidungsverfahren gelangten und nicht aus formellen, etwa sprachlichen, Gründen ausgeschlossen wurden. ${ }^{12}$ Derartige Hoffnungen erfüllten sich jedoch

106 Dies trat dann ein, wenn die Firma mehrere Geschäftssprachen außer dem Tschechischen oder Slowakischen hatte, im Register jedoch in der Staatssprache eingetragen war. Hatte sie jedoch nur eine Geschäftssprache, war ausschließlich diese maßgeblich, selbst wenn die Eintragung im Register in mehreren Sprachen - darunter auch in der Staatssprache - erfolgt war. Vgl. SÚA, PMR, Karton 3296, 740/43, MS an PMR 6. 4. 1938.

107 SÚA, PMR, Karton 3296, 740/43, Memorandum der deutschen Wirtschaftsverbände an den Ministerpräsidenten, Oktober 1937.

108 Sprachenverordnung, S. 18.

109 SÚA, PMR, Karton 3296, 740/43, MpSZaOS an PMR, 15. 4. 1938.

130 SÚA, PMR, Karton 3296, 740/43, Memorandum der deutschen Wirtschaftsverbände an den Ministerpräsidenten, Oktober 1937; AMZV, Sektion VI, Karton 105, MV an PMR, 8. 4. 1938.

111 ANM, NL Sobota, Karton 13, Nationalitätenstatut der Tschechoslowakischen Republik, undat. (ca. Mai 1938). In der Fassung des Nationalitätenstatuts vom Juli 1938 fehlte diese Bestimmung völlig.

112 ZfKv 10 (1930), S. 1107-1109. 
nicht, denn sowohl einzelne Ministerien als auch untergeordnete Staatsorgane, u.a. auch politische Behörden in den mehrheitlich deutschen Bezirken, gebrauchten bei der Ausschreibung von Staatsaufträgen sowie im Auswahlverfahren ausschließlich die Staatssprache. ${ }^{113}$ Diese Praxis entsprang dem Rechtsstandpunkt, demgemäß sich die sprachlichen Schutzbestimmungen des Sprachengesetzes auf Gerichte, Behörden und Organe des Staates erstreckten, soweit diese als Partei in Verhandlungen auftraten; in diesem Fall - also beispielsweise auch bei der Vergabe von Staatsaufträgen - hatten sie stets die Staatssprache zu gebrauchen. ${ }^{114}$ Die einsprachige Praxis bei der Auschreibung von Staatsaufträgen wurde auch durch den Umstand begünstigt, daß das Amtsblatt der Tschechoslowakischen Republik sowie die Amtsblätter der einzelnen Ministerien, in denen die Ausschreibungen veröffentlicht wurden, vorwiegend tschechisch bzw. slowakisch erschienen; bloß die Amtsblätter der politischen Landesverwaltungen sowie die der Bezirksverwaltungen in den sprachlich qualifizierten Bezirken erschienen auch auf deutsch; wie jedoch das Innenministerium selbst zugab, war dies nicht immer die Regel. ${ }^{15}$ Angebotsformulare sowie weitere Unterlagen für das Auswahlverfahren einschließlich verschiedener Hilfsmittel, wie Karten, Pläne, Arbeitsnachweise, Preistarife, technische Begründungen usw., waren nur in tschechischer bzw. slowakischer Sprache vorhanden. Deutsch ausgefüllte Formulare wurden aber akzeptiert, weil die Vergabeordnung im Hinblick auf die sprachliche Ausführung der Angebote keine einschlägigen Bestimmungen enthielt und deswegen keine rechtliche Grundlage dafür bot, diese abzulehnen. Von dieser Möglichkeit machten deutsche Unternehmer lediglich in vereinzelten Fällen Gebrauch - wenn dies der Fall war, waren es meist kleine Gewerbetreibende aus dem deutschen Sprachgebiet. ${ }^{116}$ Bedenken, man könnte bei dem Vergabeverfahren aus sprachlichen Gründen benachteiligt werden, spielten hier offensichtlich eine große Rolle, ob zu Recht oder Unrecht, muß dahingestellt bleiben.

Die Anregungen der deutschen Wirtschaftskreise hinsichtlich der Vergabe von Staatsaufträgen betrafen sowohl eine bessere Publizität der Ausschreibungen überhaupt als auch die Einführung von Angebotsformularen sowie anderer Unterlagen auch in deutscher Sprache. ${ }^{117}$ Sie empfahlen - in diesem Punkt übrigens durch ihre tschechischen und slowakischen Partner unterstützt - einen besonderen Lieferungsanzeiger als Beilage des Amtsblattes sowohl tschechisch als auch deutsch herauszugeben. Ausschreibungen sollten verstärkt in der deutschen Presse veröffentlicht werden, und zwar auch in der regionalen, besonders wenn die Arbeiten bzw. Lieferungen in einem deutschsprachigen Bezirk durchzuführen waren. ${ }^{118}$ Tschechischerseits war man beson-

113 SÚA, PMR, Karton 465, 1063/S, MO an MNO, MV und MF, 20. 7. 1929.

114 Vgl. Beschluß des NSS Nr. 3187 vom 23. 2. 1923; Peška, Studie, S. 211. Vgl. auch SÚA, PMR, Karton 465, 1063/S, MO an MNO, MV und MF, 20. 7. 1929.

115 Zur Vergabe von Staatsaufträgen vgl. Verordnung Nr. 667/1920 Slg.; Bericht des Verbandes mährischer Industrieller in Brünn 1931, S. 164-165; SUA, PMR, Karton 465, 1063/S, MO an MNO, MV und MF, 20. 7. 1929. So gaben das Justizministerium und das Ministerium für soziale Fürsorge auszugsweise auch das Schul- und das Gesundheitsministerium ihre Amtsblätter auch auf deutsch heraus, vgl. SÚA, PMR, Karton 3296, 740/43, Memorandum der deutschen Wirtschaftsverbände an den Ministerpräsidenten, Oktober 1937; ebda., MŠaNO an PMR, 8. 4. 1938; ebda., MVZaTV an PMR, 8. 4. 1938. SÚA, MV-SR, Karton 511, 20/2/91, Aktenvermerk MV, 9. 4. 1923.

116 SÚA, PMR, Karton 465, 1063/S, MO an MNO, MV und MF, 20. 7. 1929.

117 Vgl. SÚA, MV-SR, Karton 2927, 8/1/56, DHI an MO, 7. 5. 1929.

118 Vgl. Dringende Interpellation der Abgeordneten Křepek, Dr. Lodgman, Böhr, Ing. Jung, Dr. Kafka und Genossen an den Minister für öffentliche Arbeiten wegen Herausgabe der amtlichen Verlautbarung seines Ressorts auch in deutscher Sprache vom 11. 11. 1920, in: TTZPS, 1. WP, Drucksache 859; 
ders Ende der zwanziger Jahre bereit anzuerkennen, daß die Sprachenfrage bei Ausschreibung und Vergabe von Staatslieferungen deutschen Firmen gewisse Schwierigkeiten verursachen konnte, selbst wenn man glaubte, diese seien weder allgemein noch unüberwindlich. ${ }^{119}$ Man schloß entgegenkommende Schritte nicht von vornherein aus, doch der in demselben Atemzug formulierte Vorbehalt, die Staatsverwaltung dürfe dadurch keine "wesentliche Belastung" erfahren ${ }^{120}$, führte zu einer Unflexibilität, die trotz wiederholter Anläufe sudetendeutscher Wirtschaftskreise bis 1938 andauerte. ${ }^{121}$ Denn sowohl die Herausgabe von Ressortamtsblättern in deutscher Version als auch die voraussichtlich zeitraubende und folglich kostspielige Übersetzung von Unterlagen und Hilfsmitteln zu den Ausschreibungen hätten zusätzliche Geldmittel erfordert, die der Staatshaushalt nicht bereit war zur Verfügung zu stellen. ${ }^{122}$ Erst der Entwurf der neuen Nationalitätenregelung im Jahre 1938 griff entschieden in diese Problematik hinein. Erstens sah das Nationalitätenstatut die Aufteilung von Staatsaufträgen auf inländische Firmen nach Maßgabe der nationalen Zusammensetzung der Bevölkerung des Staates sowie eine verstärkte Berücksichtigung von ortsansässigen Firmen vor; zweitens legte der Entwurf der Durchführungsverordnung zum neuen Sprachengesetz ausdrücklich fest, daß Staatsaufträge, die die „sprachlich qualifizierten“ Bezirke des Staates betrafen, auch in der jeweiligen Minderheitensprache auszuschreiben waren. ${ }^{123}$

Wenn die sprachliche Seite des Verkehrs mit den Staatsorganen bzw. -betrieben von deutscher Seite häufig angegriffen wurde, richtete sich doch die heftigste Kritik gegen Maßnahmen, die als unmittelbarer Eingriff des Staates in den Bereich des freien Sprachgebrauchs privater Wirtschaftssubjekte erachtet werden konnten. ${ }^{124}$ Diese manchmal fraglichen und unzweckmäßigen Regelungen waren teils die Folge unklarer Bestimmungen des Sprachenrechts, teils sind sie tatsächlich auf des Bestreben zurück-

Interpellation des Abgeordneten Kraus und Genossen an die Gesamtregierung wegen Vergebung öffentlicher Lieferungen an das deutsche Gewerbe vom 3. 5. 1923, in: TTZPS, 1. WP, Drucksache 4152/VI.; SÚA, PMR, Karton 3533, 814/31/23-37, Stadtrat Eger an PMR, 25. 10. 1927; Wirtschaftsprogramm der Industrie der Tschechoslowakei, April 1930, in: MDHI 11 (1930), Anlage zu Folge 16, unpag. Der ausschreibenden Institution stand es frei, in welcher Presse sie die Ausschreibung veröffentlichte bzw. ob sie es überhaupt tat. Vgl. SÚA, PMR, Karton 465, 1063/S, MO an MNO, MV und MF, 20.7. 1929.

119 Vgl. SÚA, PMR, Karton 465, 1063/S, MO an MNO, MV und MF, 20. 7. 1929; SÚA, MV-SR, Karton 2927, 8/1/56, Zentraler Kaufmannsrat an MO, 23.9. 1929.

120 SÚA, MV-SR, Karton 2927, 8/1/56, Zentraler Kaufmannsrat an MO, 23. 9. 1929.

$121 \mathrm{Zu}$ den deutschen Initiativen vgl. SUUA, MPOŽ, Karton 396, 2203-21, 1936, Bericht des Gewerbeausschusses der Handels- und Gewerbekammer Reichenberg über den Entwurf der neuen Vergabeordnung, undat. (Der Bericht wurde in der Sitzung am 7.4. 1936 vorgelegt) bzw. Bo vom 9. 4. 1936; SUA, PMR, Karton 3296, 740/43, Memorandum der deutschen Wirtschaftsverbände an den Ministerpräsidenten, Oktober 1937.

122 Erlaß MO vom 14. 1. 1925, in: MDHI 6 (1925), S. 193. - Der Hinweis auf die Unrentabilität wegen des relativ beschränkten Kreises von Interessenten und daher auf die Notwendigkeit zusätzlicher staatlicher Subventionen wurde auch später als Hauptargument den Bestrebungen entgegengestellt, einzelne Amtsblätter der Ministerien auch in deutscher Sprache herauszugeben. Prinzipiell waren die einzelnen Ressorts nicht dagegen. Vgl. SÚA, PMR, Karton 3296, 749/43, MZV an PMR, 6. 4. 1938; ebda, MV an PMR, 8. 4. 1938; ebda MPaT an PMR, 12.4. 1938; ebda, MŽ an PMR, 15. 4. 1938; ebda, MO an PMR, 22. 4. 1938.

123 SÚA, PMR, Karton 3997, Gesetz, durch das das Nationalitätenstatut der Tschechoslowakischen Republik herausgegeben wird, undat. (nach 19. 7. 1938); SÚA, PMR, Karton 1714, 401/7-2, Information über den Inhalt der vorbereiteten Vorlage einer neuen Durchführungsverordnung zum Sprachengesetz, undat. (vor 1.9. 1938).

124 Vgl. beispielsweise Klepetař, Sprachenkampf, S. 132. 
zuführen, der Staatssprache stärkere Geltung zu verschaffen. Nicht immer war jedoch der zweitgenannte Aspekt ausgesprochen nationalpolitisch motiviert; hier waren bisweilen auch sachliche Motive mit im Spiel, beispielsweise Arbeitsicherheit oder Kundenschutz. So lag beispielsweise den Diskussionen über die sprachliche Befähigung bestimmter Angestelltenkategorien im privaten Bergbau, die vor allem in den dreißiger Jahren ausbrachen, eine besondere Mischung von praktischen Gründen und nationalpolitischen Bestrebungen zugrunde. Nach der großen Grubenkatastrophe in Osseg bei Dux im nordböhmischen Kohlenrevier im Januar 1934 nahm das Parlament in einer Novelle zum Bergbaugesetz vom Jahre 1854, die bereits seit 1932 in den Parlamentsausschüssen vorlag, zahlreiche Änderungen vor; darunter befand sich auch die Ermächtigung der Regierung, auf dem Verordnungswege die Sprachkenntnisse der verantwortlichen Betriebsverwalter, Betriebsingenieure und Aufseher festzulegen. Diese mußten der Staatssprache in einem durch die zu erlassende Verordnung zu definierenden Umfang mächtig sein; die auf diesen Posten bereits angestellten Personen sollten diese Verpflichtung in einer durch das Bergamt festgesetzten Frist erfüllen. ${ }^{125}$ Diese Maßnahmen, auch wenn sie durch die mangelnden Sicherheitsvorschriften im Bergbau unmittelbar hervorgerufen wurden, folgten dem Trend der jahrenlangen Diskussionen im tschechischen politischen Lager, die sich um die Verstärkung des staatlichen Einflusses auf den sich überwiegend in deutschen Händen befindlichen Kohlenbergbau drehten. ${ }^{126}$ Über die Methode, wie diese Lage zu ändern sei, war man sich tschechischerseits bei weitem nicht einig. Neben der Verstaatlichung, für die sich lediglich die Sozialisten - aber auch ein großer Teil von ihnen eher halbherzig ${ }^{127}$ - aussprachen, schwebte vor allem den nationalistischen Kreisen eine andere Art der „Nationalisierung“ vor: Nämlich die Überführung der Bergwerke in die Hände tschechischer und slowakischer Besitzer, was natürlich ein in jeder Hinsicht schwer zu handhabender Prozeß war. ${ }^{128}$ Anfang der dreißiger Jahre war von Enteignungsmaßnahmen keine Rede mehr, vielmehr erblickte man die Lösung des Problems in einer Stärkung des staatlichen Einflusses auf die Lenkung der Produktion des Bergbaus. ${ }^{129} \mathrm{Im}$ Sinne dieser Bestrebungen nahm das Ministerium für öffentliche Arbeiten unter dem Minister J. Dostálek von der Tschechoslowakischen Volkspartei eine gesetzliche Regelung der Sprachenfrage im Bergbau in Angriff. Der Angelpunkt der Überlegungen des Ministeriums war die These, daß das Rohstoffmonopol des Staates diesen auch berechtige, den Sprachgebrauch im Verkehr zwischen den Bergbauunternehmern und den staatlichen Organen sowie anderen Subjekten, die zum Bergbau direkte Dienstbeziehungen unterhielten (beispielsweise Angestellte tschechischer und slowakischer Nationalität und deren Vertretungsorgane bzw. Korporationen, sowie Organisationen, die auf die Produkte des Bergbaus angewiesen waren, wie Eisenbahn usw.), zu regeln. Auf der

125 Vgl. Gesetz Nr. 8/1934 Slg; Národní shromáždění II., S. 522. Vgl. auch PA R 89750, Gesandtschaft Prag an AA, 31. 1. 1934; Hospodářská politika 8, 20.1. 1934, S. 43.

126 SÚA, NRČ, Karton 471, Mappe 2, Tagung zum Stand unserer Gruben und Hütten am 26. 1. 1923. Vgl. auch NáP vom 21. 1. 1932.

127 PA R 89750, Deutsche Gesandtschaft an AA, 10.6. 1925. Der Gesandte Koch bemerkte in seinem Bericht, daß das Schlagwort von der "Nationalisierung" der Bergwerke von der tschechischen Volkssozialistischen Partei immer wieder hervorgeholt würde, wenn sich die Wahlen näherten.

128 Vgl. Pŕítomnost 11 (1934), S. 470.

129 Die Staatsinteressen im Bergbauunternehmen in der Tschechoslowakei (Eine Stellungnahme des NRČ), in: Hospodárský parlament 1 (1933), S. 233. 
Grundlage des Bergbaugesetzes von 1854 beabsichtigte das Ministerium, hierzu entweder die Herausgabe einer auf das Sprachengesetz gestützten Verordnung oder eines besonderen Gesetzes zu initiieren. ${ }^{130}$ In den Akten läßt sich das weitere Schicksal der Anregung des Ministeriums für öffentliche Arbeiten nicht verfolgen. Alles deutet jedoch darauf hin, daß sie sang- und klanglos unterging. Auch die in der Novelle des Bergbaugesetzes angekündigte Verordnung über die Sprachkenntnisse der Betriebsverwalter, Bergbauingenieure sowie Grubenaufseher wurde bis zum Jahre 1938 nie erlassen.

Ständigen Konfliktstoff lieferten die Bestrebungen, bestimmte Privatunternehmen in ihrem Kundenverkehr zur verstärkten Berücksichtigung der landesüblichen Sprachen zu bewegen. Bei einigen, besonders im Bereich des Gesundheitswesens (Apotheken, Krankenhäuser, Sanatorien) entbehrten diese Schritte nicht plausibler sachlicher Gründe. Fragwürdiger - sieht man vorläufig von konkreten Sicherheitsgründen ab - war die Tendenz, derartige Verpflichtungen auch auf andere Bereiche auszudehnen, beispielsweise auf Kinotheater, Tabakläden oder auf Friedhöfe und Krematorien, bei denen die Staatsmacht meistens den Umstand ausnutzte, daß ihr bereits aufgrund der altösterreichischen Rechtsordnung besondere Rechte im Hinblick auf diese Unternehmen über die Lizenzierung zukamen. ${ }^{131}$ In diesem Fall kann man nicht umhin, dahinter erstrangig nationalpolitische Motive zu erblicken - nämlich die Verstärkung der Präsenz der Staatssprache in den mehrheitlich deutsch besiedelten Gebieten. Verstärkt wird dieser Eindruck übrigens dadurch, daß sich der eventuelle Schutz der Interessen des Kunden meistens nur auf Angehörige der Staatssprache bezog, eine reziproke Rücksichtnahme auf die Staatsbürger anderer Nationalitäten blieb aus. Aufschriften und Orientierungstafeln in den oben genannten Einrichtungen mußten zweisprachig sein, an erster Stelle natürlich in der Staatssprache. Ebenfalls waren Arznei- und Heilmittel in Apotheken immer tschechisch oder slowakisch zu beschriften. ${ }^{132}$ In Kinos kam auch die Verpflichtung der Vertriebsfirmen hinzu, Filmplakate zweisprachig zu gestalten. ${ }^{133}$ Die Sprachenfrage in der Welt des Films wurde übrigens mit der Ausbreitung des Tonfilms abermals aktuell, und zwar nicht nur wegen der Krawalle, die tschechische Nationalisten, verstimmt durch den Erfolg der ersten deutschen Tonfilme beim Prager Publikum, im November 1930 in Prag provozierten. Da deutsche Filme im Angebot der importierten kinematographischen Produktion deutlich überwogen, wurde im Jahre 1934 angeordnet, daß alle nach dem 1. Januar 1934 eingeführten deutschsprachigen Filme mit tschechischen Untertiteln versehen werden mußten. ${ }^{134}$ Der Gebrauch von Minderheitensprachen wurde weder empfohlen, geschweige denn angeordnet. Die einzige Ausnahme waren die Tabakläden, die in qualifizierten Bezirken auch in der betreffenden Minderheitensprache zu bezeichnen waren. Von den Verkäufern deutscher Nationalität wurde die Kenntnis der Staatssprache verlangt, und zwar in einem Aus-

130 SÚA, PMR, Karton 3296, 740/40, MVP an PMR, 6. 2. 1934.

131 So war aufgrund des staatlichen Monopols der Verkauf von Tabak durch die Finanzverwaltung lizenziert; Kinolizenzen wurden zwar durch die Gemeinde erteilt, doch Ende der zwanziger Jahre erkannte das Oberste Verwaltungsgericht das Recht der Staatsverwaltung an, Lichtspieltheatern Anordnungen zur Verwendung der Staatssprache zu erteilen. Vgl. Beschluß des NSS Nr. 34868 vom 2. 1. 1929, vgl. Klapka, Útok, S. 50; Glück, Sprachenrecht, S. 42-43.

132 Vgl. Klepetař, Sprachenkampf, S. 130-131. Vgl. auch Glück, Sprachenrecht, S. 44; SÚA, MV-SR, Karton 1489, 14/1/36, Aktenvermerk MV, 16. 4. 1924.

133 Glück, Sprachenrecht, S. 42-43.

134 SÚA, MV-SR, Karton 5023, 8/1/67, Aktenvermerk MV, 23.11. 1936. Vgl. auch Glück, Sprachenrecht, S. 43, Anm. 11. 
maß, um „der Nachfrage seitens eines tschechischen Kunden nachkommen zu können". Gleichzeitig erachtete es das Finanzministerium als Pflicht jedes Verkäufers, neben der Staatssprache entsprechend den Anforderungen des Kundenverkehrs auch eine Minderheitensprache zu beherrschen. ${ }^{135}$

Jahrelang zogen die Gefechte um den Sprachgebrauch in privaten Bädereinrichtungen die Aufmerksamkeit der breiteren Öffentlichkeit auf sich. Die nationalpolitische Motivierung der auf diesem Gebiet angestrebten Maßnahmen war ganz unverhohlen: Der Hinweis auf den tschechischen Kunden, der in den meistens deutschsprachigen Kurorten keineswegs eine Massenerscheinung darstellte, war nur ein Nebenposten im Kampf um die Positionen in der Branche, deren volkswirtschaftliche sowie repräsentiv-gesellschaftliche Bedeutung als unumstritten galt. Auch hier schlossen die Bestrebungen, den tschechischen Einfluß besonders in den weltberühmten westböhmischen Bäderstädten entscheidend geltend zu machen, in ihrer radikalsten Form die Forderungen nach Bäderverstaatlichung ein. Vor derart tiefgreifenden Eingriffen in die Eigentumsverhältnisse schreckte man schließlich zurück, und man war bereit, sich mit einer verstärkten Berücksichtigung der tschechischen Sprache in den Kurorten zufriedenzugeben. Wie üblich kam die Initiative von den tschechischen Schutzvereinen, die bereits im Frühjahr 1920 ihren Unmut über den „Mißstand“ zum Ausdruck brachten, daß sich der "Geist" besonders in den westböhmischen Kurorten seit dem Umsturz nicht geändert habe. Ausländische Besucher gewännen den Eindruck, so die Meinung, sie seien gar nicht in den Kurorten der Tschechoslowakischen Republik, und danach würden sie auch "die tschechische Kraft und die Stärke der Republik bewerten“. ${ }^{136}$ Aus diesen Überlegungen heraus brachten die nationaldemokratischen Abgeordneten im Juni 1921 einen Gesetzantrag ein, der den Sprachgebrauch in Kurorten und anderen touristisch bedeutenden Ortschaften zum Gegenstand hatte. Das Paket der vorgeschlagenen Maßnahmen schloß neben der Bezeichnung aller Straßen, Plätze, Wege, Gebäude, und öffentlichen Verkehrsmittel in den Kurorten auch Eingriffe in die Verwaltung der Bäderanstalten ein. Die Besitzer, Pächter, Verwaltungen und Unternehmerschaften waren demnach verpflichtet, alle Bezeichnungen, Aufschriften und Bekanntmachungen auch in der Staatssprache anzubringen bzw. herauszugeben sowie der Staatssprache mächtige Personen einzustellen. ${ }^{137}$ Der Antrag ging ohne größeres Aufsehen über die Parlamentsbühne und wurde nicht weiter behandelt. Seine Grundgedanken verschwanden jedoch nicht spurlos aus der Welt: Die Regierungsverordnung über die Orts- und Straßennamen vom August 1921 führte eine verpflichtende zweisprachige

135 Vgl. SÚA, MV-SR, Karton 1489, 14/1/36, Aktenvermerk MV 16. 4. 1924; SÚA, Klepetař, Sprachenkampf, S. 132. Im Verkehr mit den Tabakverkäufern richtete sich die Tabakregie nach den allgemeinen Vorschriften des Sprachenrechts; die Vorschriften für Tabakverkäufer wurden sowohl tschechisch als auch deutsch herausgegeben, lediglich die Bestellungsbücher waren Ende der Dreißiger nur einsprachig, was jedoch in der Praxis - man füllte lediglich den Namen des Erzeugnisses und in Ziffern den bestellten finanziellen Wert aus - kaum ernste sprachliche Probleme mit sich brachte. Vgl. PMR, Karton 3296, 740/43, MF an PMR, 9. 4. 1938.

136 AKPR, D 9175, Karton 40, NJS und NJP an MV, 1.6. 1920.

${ }^{137}$ Hierzu gehörten neben Karlsbad, Marienbad, Franzensbad und Joachimstal noch Teplitz-Schönau, Bilin, Gießhübel, Königswart, Gräfenberg, Karlsbrunn, Johannisbad, Nieder Lindenwiese sowie "andere Kurorte und touristisch bedeutende Orte“, die das Innenministerium durch eine Verordnung bestimmen sollte. Vgl. Antrag der Abgeordneten Špaček, Lukavský, Hajn, Dr. Matoušek, Dyk und Genossen auf die Herausgabe des Gesetzes, durch das der Gebrauch der Staatssprache auf den öffentlichen Aufschriften in den Kur- und touristisch bedeutenden Orten der C CRR geregelt wird vom 24. 6. 1921, in: TTZPS, 1. WP, Drucksache 2593. 
Straßenbezeichnung in den Kurorten ein. ${ }^{138}$ Auch der Entwurf des Bädergesetzes, dessen erste Fassung seit dem Frühjahr 1922 diskutiert wurde, griff offensichtlich auf das nationaldemokratische Gedankengut zurück, ja in einiger Hinsicht ging er sogar weiter: Die Verwaltungen der Kurbetriebe waren verpflichtet, sprachlich „vorschriftsgemäß“ qualifizierte Personen „in einer dem Bedarf der Gäste entsprechenden Anzahl“ einzustellen, leitende Kräfte sollten "durchwegs" die Staatssprache beherrschen. ${ }^{139}$

Etwa zur gleichen Zeit eröffneten die militanten nationalistischen Kreise um den Prager Bürgermeister Baxa eine neue Gefechtslinie, nämlich die Frage des Sprachgebrauchs im Gastronomiegewerbe. Diese wurde schließlich zu einer der spektakulärsten Auseinandersetzungen auf dem Gebiet des Sprachenrechts in der Tschechoslowakei der Zwischenkriegszeit überhaupt. Die außerordentliche Heftigkeit der Diskussionen war nicht allein auf die nationalpolitischen Hintergründe, die u. a. in der Hebung des Prestiges der Staatssprache lagen, zurückzuführen. Sie ergab sich vielmehr daraus, daß sich die angestrebten Maßnahmen gegen kleine gewerbliche, nicht selten Ein-Mannoder Familienbetriebe richteten, die manchmal objektiv nicht imstande waren, den Forderungen nach gebührender Berücksichtigung der Staatssprache nachzukommen.

Die ersten Schüsse auf diesem Frontabschnitt fielen bereits im April 1921, als das Handelsministerium, in dem die Nationaldemokraten eine traditionell starke Position innehatten, auf die Regelung des Sprachgebrauchs in Berghütten im Riesengebirge zu dringen begann. Dem ersten Anlauf der politischen Landesverwaltung, an die sich das Ministerium offensichtlich an allen Instanzwegen vorbei wandte, um die diesbezüglichen Forderungen in die Praxis umzusetzen, war kein durchschlagender Erfolg beschert, und im Dezember 1922 sah sich die Behörde, übrigens angeblich erneut auf „ausdrücklichen Wunsch“ Baxas, zu weiteren Schritten gezwungen, um „den bereits herausgegebenen sprachlichen Vorschriften Geltung zu verschaffen. “140 Den unmittelbaren Impuls zu diesem zweiten Anlauf gab der Internationale Skikongreß in Prag im Februar 1923, während dessen man auch einen Besucherstrom in das Riesengebirge und somit in die dortigen meistens in deutschem Besitz befindlichen Gastwirtschaften und Hotels erwartete. „Im Interesse des guten Rufes unseres Staates und der Ordnung seiner Verhältnisse sowie der Vertiefung seines Ansehens in den Augen des Auslandes" sollten die betreffenden Bezirksverwaltungen allen Besitzern von Gasthäusern anordnen, spätestens bis Weihnachten 1922 an ihren Gebäuden und in den für den Kundenverkehr bestimmten Räumlichkeiten tschechische Aufschriften anzubringen. Sämtliche Bekanntmachungen und Speisekarten waren auch in tschechischer Sprache anzufertigen, darüber hinaus waren tschechische Bedienungen anzustellen. ${ }^{141}$ Einige Tage darauf gab die politische Landesverwaltung in Prag wohl aus eigener Initiative einen anderen Erlaß heraus, der identische Maßnahmen auch in anderen Bezirken, u. a. in den west-

138 Vgl. Kapitel II.D.

139 SUA, MV-SR, Karton 510, 20/2/140, Entwurf des Bädergesetzes, undat.

$140 \mathrm{Vgl}$. SÚA, MV-SR, Karton 511, 20/2/179, Präsidium der politischen Landesverwaltung Prag an MO, 25. 2. 1923. Auch diesmal sei der "Kanal“ via Handelsministerium in Betrieb gewesen; Handelsminister L. Novák (Nationaldemokratie) wollte sich jedoch, nachdem sich die Beschwerden gegen den Vorgang der politischen Landesverwaltung gemehrt hatten, nicht zu der Angelegenheit bekennen. Vgl. AMZV, Sektion II, Karton 708, Aktenvermerk MZV, 17. 2. 1923.

141 SUUA, MV-SR, Karton 511, 20/2/179, Erlaß des Präsidiums der politischen Landesverwaltung Prag Nr. 39874, 6. 12. 1922. Der Erlaß war an die Vorsteher der politischen Bezirksverwaltungen Friedland, Gablonz, Reichenberg, Semil, Starkenbach, N. Paka, Hohenelbe, Trautenau und Braunau gerichtet. 
böhmischen Kurorten verordnete. ${ }^{142}$ Dabei öffnete man dem bürokratischen Ermessen Tür und Tor: Die Vorschrift traf nämlich nicht alle Einrichtungen des Gastgewerbes, sondern lediglich die von ausländischen Besuchern „in größerem Umfang“ besuchten Hotels und Gastwirtschaften. Daß eben ausländische Gäste kaum auf tschechische Orientierungsaufschriften oder Speisekarten brannten, war in diesem Moment zweitrangig. In Kurorten sollte der Erlaß bis zur Eröffnung der Frühjahrssaison 1923, in Zentren, wo die Skisaison bereits im Gange war, möglichst unverzüglich in die Praxis umgesetzt werden. Diesmal, wahrscheinlich bewegt durch den drohenden Ton des Erlasses, reagierten die zuständigen Bezirskverwaltungen prompt und begannen die betroffenen Gewerbeleute zu drängen, den Weisungen tatsächlich zu folgen; das angeblich nichts ahnende Innenministerium erfuhr von der ganzen Sache erst aus der Presse. ${ }^{143}$

Die Welle der deutschen Proteste gegen diese Maßnahmen ${ }^{144}$ konnte die Bürokratie kaum aus der Fassung bringen; letzten Endes standen deutsche Klagen praktisch immer auf der Tagesordnung. Ende Januar $1923 \mathrm{kam}$ jedoch ein Alarmruf aus einer ganz unerwarteten Richtung, nämlich aus Genf. Der deutsche Abgeordnete W. Medinger, der gleichzeitig Vorsitzender der Deutschen Völkerbundliga in der Tschechoslowakei war, hatte die ruhige Weihnachtszeit zur Abfassung eines Briefes an den Chef der Minderheitensektion des Völkerbundes, E. Colban, genutzt. ${ }^{145}$ Unter mehreren Beschwerdepunkten, die Medinger in seinem Brief vorbrachte, fehlte natürlich der „frische“ Fall der deutschen Gastwirtschaften nicht. Zur Überraschung der tschechoslowakischen Diplomaten in Genf neigte Colban dazu, diesen Vorgang für eine Verletzung der Minderheitenrechte zu halten - die Versuche, ihn von diesem Standpunkt abzubringen, schlugen, wie man nach Prag meldete, fehl. ${ }^{146}$ Anfang Februar kam in Prag eine Abschrift des inkriminierten Briefes von Medinger an, was übrigens von einem gut funktionierenden Draht zwischen dem Völkerbund und dem hiesigen Außenministerium zeugt. ${ }^{147}$ Die Warnung aus Genf nahm man hier ernst. Die tschechoslowakische Diplomatie vermutete, daß, wenn sich die Deutschen mit einer Beschwerde an den Völkerbund wenden würden, der Völkerbundsrat aufgrund des negativen Urteils von Colban die tschechoslowakische Regierung auffordern könnte, die Vorschriften als zu den gültigen internationalen Verpflichtungen im Widerspruch stehend aufzuheben. „Man kann keinen Zweifel daran hegen“, schlußfolgerte das Außenministerium, „in welchem Maße dies die feindliche Propaganda im Ausland gegen uns ausnutzen würde. ${ }^{148} \mathrm{Be}$ zeichnenderweise dachte man im Außenministerium weniger über Schritte zur Beseiti-

142 SÚA, MV-SR, Karton 511, 20/2/179, Erlaß des Präsidiums der politischen Landesverwaltung Nr. 41858, 18. 12. 1922. Der Erlaß war an die politischen Bezirksverwaltung Joachimstal, Starkenbach, Karlsbad, Marienbad, Teplitz-Schönau, Trautenau, Hohenelbe und Eger gerichtet.

${ }^{143}$ AMZV, Sektion II, Karton 708, Aktenvermerk MZV, 16. 2. 1923.

144 Vgl. AMZV, Sektion II, Karton 708, Entschließung der Gemeindevertretung Trautenau vom 22. 12. 1922.

145 AdV, R 1622, 41/25803/1296, Medinger an Colban, 30. 12. 1922.

${ }_{146}$ AMZV, Sektion II, Karton 708, Gesandtschaft Genf an MZV, 30. 1. 1923.

147 AMZV, Sektion II, Karton 708, Medinger an Colban, 30. 12. 1922, Abschrift. Es ist nicht ganz klar, ob Colban wußte, daß Prag Medingers Brief erhielt. Das Außenministerium hatte ursprünglich vorausgesetzt, daß Colban den Brief an die tschechoslowakischen Diplomaten halboffiziell hatte weiterleiten lassen, woraus man schloß, daß eine Stellungnahme zu dem Brief erwünscht sei. Bei der Vorbereitung von Unterlagen für eine Verhandlung mit Colban im März 1923 ging man für alle Fälle davon aus, daß Colban über die Weiterleitung des Brief an Prag nicht unterrichtet war. Vgl. AMZV, Sektion II, Karton 708, Aktenvermerk MZV, 12. 2. 1923; ebda, Aktenvermerk MZV, 7. 3. 1923.

148 AMZV, Sektion II, Karton 708, MZV an MV und MS, Konzept, 12. 2. 1923. 
gung des Mißstandes nach, sondern man war vielmehr bestrebt, juristische Argumente zu sammeln, die "gegebenfalls auf dem internationalen Forum standhalten könnten. “149

Eine plausible rechtliche Begründung war jedoch nicht ganz einfach zu finden. Die Verfechter des Vorgehens der politischen Landesverwaltung argumentierten mit Paragraph 54 der Gewerbeordnung Nr. 26/1907 RGBl., der u. a. das Gasthaus- und Ausschankgewerbe der gewerbepolizeilichen Regelung unterwarf, d. h. den Behörden das Recht einräumte, bei der Errichtung sowie der Ausführung des Gasthausgewerbes den Gewerbetreibenden im öffentlichen Interesse bestimmte Verpflichtungen aufzuerlegen. Die Gewerbeordnung erwähnte zwar die Sprachenregelung nicht, das Handelsministerium, die politische Landesbehörde in Prag sowie schließlich auch das Innenministerium vertraten jedoch den Standpunkt, daß es das Gesetz dem freien Ermessen der Behörde überlasse, je nach Art des Gewerbes sowie dem zeitlichen und örtlichen Bedarf auch diese Frage zu regeln. Die Gasthaus- und Ausschankbetriebe in größeren Städten und in Kurorten, führte man aus, seien nicht nur für die örtliche Bevölkerung bestimmt, sondern vor allem für fremde Besucher, und deswegen sei es notwendig, daß sie sich auch in sprachlicher Hinsicht den öffentlichen Interessen und dem Bedarf dieser Besucher anpaßten. Als ein durch den Staat konzessioniertes Gewerbe öffentlich-rechtlichen Charakters, lautete das Fazit des Innenministeriums, fielen derartige Gewerbebetriebe nicht unter die Bestimmungen des Minderheitenschutzvertrages, die den freien Gebrauch im Handels- und Privatverkehr garantierten. Die Sprachenrechte der Angehörigen der Minderheitennationalitäten seien darüber hinaus durch die Anordnung, neben ihrer eigenen Sprache auch die Staatssprache „anständig“ geltend zu machen, nicht verletzt oder beeinträchtigt worden. ${ }^{150}$

Besonders am letztgenannten Punkt hegten die Kritiker der Maßnahmen gegen das Gastgewerbe ernste Zweifel. Die Interpretation des Umfangs des sprachlichen Minderheitenschutzes hielten sie für zu restriktiv: Dieser gewähre jedem Bürger die volle Freiheit, meinte das Außenministerium, in gewissen Bereichen welche Sprache auch immer zu gebrauchen. Das bedeute wahrscheinlich auch, daß der Bürger den Sprachgebrauch in solchen Bereichen völlig frei bestimmen könne - und diese freie Wahl werde zweifellos beeinträchtigt, wenn vorgeschrieben werde, daß eine bestimmte Sprache gebraucht werden müsse. ${ }^{151}$ Die Referenten des Außenministeriums waren nicht die einzigen, die die angesprochene Rechtsauffassung nicht teilten. Über 300 betroffene deutsche Gasthausbesitzer brachten eine Beschwerde beim Obersten Verwaltungsgericht ein, das, wie das Außenministerium bereits im April 1923 vertraulich erfuhr, dazu neigte, die Verordnung als ungesetzlich anzusehen. ${ }^{152}$

Vorgewarnt durch diese Signale nahm die Staatsverwaltung nunmehr eine distanzierte Haltung zu derartigen Initiativen der tschechischen nationalen Radikalen ein. So wurde der 1924 durch den Prager Magistrat vorbereitete Erlaß nie realisiert, der u. a. die sprachliche Ausführung von Firmenschildern und Speisekarten in Hotelier- und

1+9 AMZV, Sektion II, Karton 708, Aktenvermerk MZV, 17. 2. 1923.

150 SÚA, MV-SR, Karton 511, 20/2/179, Präsidium der politischen Landesverwaltung Prag an MO, 25. 2. 1923; ebda, Präsidium der politischen Landesverwaltung an MO, 5. 3. 1923; AMZV, Sektion II, Karton 708, MO an MZV, 16. 3. 1923; AMZV, Sektion II, Karton 710, MO an MZV, 16. 3. 1924; AMZV, Sektion II, Karton 708, MV an MZV, 7. 4. 1923.

151 AMZV, Sektion II, Karton 708, Aktenvermerk, 17.4. 1923. AMZV, Sektion III, Karton 608, Mappe 8, Aktenvermerk MZV, 28. 5. 1923.

152 AMZV, Sektion II, Karton 708, Aktenvermerk MZV, 17. 4. 1923. 
Gastronomiebetrieben in Prag bestimmte: Speisekarten sollten beispielsweise, Presseberichten zufolge, ausschließlich in der Staatssprache beschriftet werden, und nur diejenigen Betriebe, die von Ausländern oder Staatsbürgern anderer Nationalitäten besucht wurden, durften auch anderssprachige Speisekarten benutzen, jedoch lediglich in einer durch das Gewerbeamt gebilligten Form. ${ }^{153}$ Der Prager Bürgermeister Baxa und der Prager Magistrat entwickelten zu dieser Zeit überhaupt schier unermündliche Aktivitäten, die bessere Ziele verdient gehabt hätten. Wahrscheinlich im Frühjahr 1924 bereiteten Baxa und, wie sich Präsident Masaryk in diesem Zusammenhang vertraulich despektierlich äußerte, „seine Kumpel“ einen Erlaß vor, der sogar das Benehmen von Kunden zu regeln beabsichtigte: diesen sollte nämlich verboten werden, deutsche Lieder in Prager Gasthäusern zu singen. Mit merklicher Genugtuung bemerkte der Präsident, dem Innenministerium sei es „rechtzeitig“ gelungen, die Herausgabe des Erlasses zu unterbinden. ${ }^{154}$ Ebenso hob die politische Landesbehörde in Prag eine Verordnung der politischen Bezirksverwaltung in Münchengrätz vom März 1925 auf, die Kaufleuten und Gewerbetreibenden in national gemischten Gemeinden des Gerichtsbezirkes die Pflicht auferlegte, ihre Betriebe innerhalb von vier Wochen mit doppelsprachigen Aufschriften (selbstverständlich zuerst in der Staatssprache) zu versehen und, „soweit dies möglich sei“, die Kunden auch in tschechischer Sprache zu bedienen. Der Grund lag für den Bezirkshauptmann in Münchengrätz klar auf der Hand: Die in den gemischten Gebieten wohnende tschechische Bevölkerung sei mit ihren Bedürfnissen auf das örtliche Gewerbe angewiesen und habe deswegen einen Anspruch darauf, daß die Gewerbeinhaber ihre nationalen Gefühle achteten. ${ }^{155}$ Neu war an dieser Eigeninitiative des Bezirkshauptmanns, daß sich die Maßnahmen auf alle Gewerbebetriebe erstrecken sollte, ganz gleich ob sie der gewerbepolizeilichen Regelung unterlagen oder nicht.

Es wäre jedoch verfrüht, in der Aufhebung dieser Erlasse eine plötzliche nationalpolitische Besonnenheit der Behörden erblicken zu wollen. Auch tschechische Gewerbeleute wurden mittlerweile durch die extensive Kompetenzerweiterung der Bürokratie beunruhigt. Auch wenn die sprachlichen Aspekte derartiger Bestrebungen manchen von ihnen zusagen mochten, handelte es sich schließlich um einen unerwünschten Präzedenzfall für eventuelle weitere Eingriffe in die private Unternehmersphäre. ${ }^{156}$ Es bestand übrigens noch ein weiterer Grund, derartigen Initiativen lieber abfuhr zu erteilen: Seit März 1925 war der Rechtsstandpunkt des Obersten Verwaltungsgerichts bekannt, der die Verordnungen hinsichtlich der Sprachregelung im Gasthausgewerbe als ungesetzlich bezeichnete und rückgängig machte. In der Begründung befaßte sich das Gericht, nebenbei bemerkt, gar nicht mit den Einwendungen der Beschwerden, die angefochtenen Anordnungen würden der Verfassungsurkunde, dem Sprachgesetz und dem Minderheitenschutzvertrag widersprechen, sondern rechtfertigte seine Entschei-

153 Interpellation der Abgeordneten Kafka, Kostka und Genossen an die Regierung betreffend einen gesetzwidrigen Erlaß des Bürgermeisters der Stadt Prag, Dr. Baxa vom 18. 11. 1924, in: TTZPS, 2. WP, Drucksache 4952/IV.

154 ANM, NL Sobota, Karton 13, Aufzeichnung über ein Teegespräch beim Präsidenten der Republik am 7. 7. 1924.

155 SÚA, MV-SR, Karton 1555, 14/136/13, Aktenvermerk MV, 19. 6. 1925. Vgl. auch BA-P, 15.01, 5820, Preußischer Minister des Innern an den Regierungspräsidenten in Breslau, 16. 6. 1925; Bo vom 22. 3. 1925.

156 SÚA, MV-SR, Karton 1555, 14/136/12, MO an MV, 24. 7. 1925. 
dung damit, die getroffenen Maßnahmen würden nicht unter den Begriff der gewerbepolizeilichen Regelung fallen. Die Gewerbeordnung, so das Gericht, nehme auf die Konsumenten nur ausnahmsweise Rücksicht, und demzufolge sei es nicht die Aufgabe der gewerbepolizeilichen Verwaltung, dafür Sorge zu tragen, daß Hotels und Gasthäuser so geführt würden, daß es allen Besuchern zusage. ${ }^{157}$

Das erst am 20. Januar 1926 verkündete Urteil des Obersten Verwaltungsgerichts rief selbstverständlich entgegengesetzte Reaktionen hervor. Auf der Seite der tschechischen nationalistischen Kreise herrschte unermeßliche Enttäuschung. Außer Klagen über die „Niederlage des Staatsrechts“ sowie den eingetretenen „Zustand einer völligen Rechtlosigkeit" ${ }^{158}$ verlangten sie sofortige Schritte, die die Folgen der Entscheidung des Gerichts gutmachen sollten: Die Durchführungsverordnung zum Sprachengesetz sollte unverzüglich herausgegeben, die Gewerbeordnung novelliert, sowie das bereits vorbereitete Bädergesetz, das im Laufe der Zeit wegen vielfältiger Meinungsverschiedenheiten zum Mißfallen der Nationalisten unter den Teppich gekehrt und schließlich bis 1938 nie erlassen wurde, beschlossen werden. Nicht das erste Mal wurden aus dieser Ecke Stimmen laut, die Kompetenzen des Obersten Verwaltungsgerichts zu beschränken. ${ }^{159}$ Aus den Reihen der Regierungskoalition sprach besonders die Sozialdemokratie ihre Achtung an die Adresse des Obersten Verwaltungsgerichts aus. Ihr Standpunkt war durch die Überzeugung geprägt, daß bürokratische bzw. polizeiliche Maßnahmen in einem demokratischen Staat nicht das Maß der objektiv nachweisbaren Unerläßlichkeit überschreiten sollten. Es sei zwar sicher sehr unangenehm, meinte „Právo lidu“, daß 339 Gasthausbesitzer die tschechischen Aufschriften entfernen würden, aber dafür dürfe man dem Obersten Verwaltungsgericht keine Schuld zuweisen, sondern umgekehrt: „Seine Tat männlicher Objektivität erfüllt uns mit Stolz, der nicht nur einmal den unangenehmen Gedanken ausgleicht, daß die Gaststätte , $U$ slunce' in diesem oder jenem deutschen Kaff ,Zur Sonne“ heißen darf. “160

Einige Tage nach der Veröffentlichung der Entscheidung des Obersten Verwaltungsgericht wurde die Durchführungsverordnung mit dem Artikel 99 erlassen ${ }^{161}$, der bald zu einer der meist umstrittenen Bestimmungen des gesamten Sprachenrechts wurde. Die Bedenken reichten von Einwänden gegen eine weitreichende Bevollmächtigung der Bürokratie zu Eingriffen in die Privatsphäre bis zur Ansicht, die Freiheit des Sprachgebrauchs könne nur durch ein Gesetz und nicht durch Verordnungen der Vollzugsgewalt beschränkt werden. ${ }^{162}$ Die tschechischen Radikalen konnten dagegen ihre Genugtuung nur schwer verbergen: Mit dem Artikel, meinte die nationaldemokratische "Národní politika“, gebe die Sprachverordnung den Behörden eine noch bessere Grundlage für die Anordnung tschechischer Aufschriften an Hotels und Gasthäusern im gemischten Gebiet als Paragraph 54 der Gewerbeordnung; man brachte zudem die

157 PT vom 20. 1. 1926.

158 Vgl. NáL vom 19. 1. 1926; Večer (Abendblatt der NáL) vom 23. 1. 1926; NM 6 (1926), S. 2.

159 Vgl. NáP vom 21. 1. 1926; SÚA, MV-SR, Karton 1490, 14/1/47, NJP an MV 28. 1. 1926; SÚA, PMR, Karton 463. 1063/3, NRC an PMR, 3. 2. 1926; SÚA, ÚMŠ-SNJM, Karton 740, Protokoll der Sitzung der Kommission für Begutachtung der Sprachverordnung, 17. 2. 1926.

160 Večerník Práva lidu vom 21. 2. 1926.

161 Vgl. Kapitel I.B.2.

162 Vgl. PT vom 7. 2. 1926 bzw. Peška, Studie, S. 178; ders., Národní, S. 140. Verschiedenartig begründete Vorbehalte äußerten auch andere tschechische Juristen, vgl. Budík, Jazyková nařízení, S. 35; Sobota, Nationalitätenrecht, S. 81. 
Überzeugung zum Ausdruck, daß die Behörden dies auch unverzüglich in die Tat umsetzen würden. ${ }^{163}$ Derartiger Optimismus erwies sich jedoch als unbegründet - vielleicht war Artikel 99 ursprünglich tatsächlich als Handhabe gegen die Entscheidung des Obersten Verwaltungsgerichts und überhaupt als Grundlage für Eingriffe in das Gewerbeunternehmen konzipiert worden, auf dem Gebiet der Gasthausaufschriften fand er jedoch, soweit bekannt, keine Anwendung.

Die Frage der Gasthausaufschriften blieb weiterhin Quelle ständiger Irritationen. Dazu trug vor allem der Umstand bei, daß sich die Entscheidungen des Obersten Verwaltungsgerichts jeweils nur auf den konkreten Fall bezogen, durch den sie hervorgerufen wurden, und für weitere Verfügungen der Staatsorgane in den gleichen Angelegenheiten nicht richtungsweisend oder gar verbindlich waren. Die Entscheidung vom Januar 1926 bezog sich demgemäß nur auf die Beschwerdeführer, den übrigen Gewerbetreibenden, die gegebenfalls den Beschluß faßten, die tschechischen Aufschriften an ihren Betrieben zu entfernen, drohte eine Strafe. ${ }^{164}$ Keine Fortschritte machte auch die seit der ersten Hälfte der zwanziger Jahre angestrebte Novelle der Gewerbeordnung. Die diesbezüglichen Bemühungen hatten nicht unbedingt nationalpolitische Hintergründe, denn die Vereinheitlichung der Gewerbeordnung im ganzen Staatsgebiet und gleichzeitig deren Anpassung an die aktuellen wirtschaftlichen und sozialen Realitäten erwies sich als immer dringender. Natürlich war man dabei nicht abgeneigt, eventuell zwei Fliegen mit einer Klappe zu schlagen, aber auch diesmal blieben allzu optimistische nationalpolitische Erwartungen unerfüllt, die besonders die tschechischen Schutzvereine unermüdlich hegten. ${ }^{165}$

Im September 1924 brachte die Regierung einen Entwurf auf Änderung des Paragraphen 54 der Gewerbeordnung im Parlament ein. ${ }^{166}$ Danach konnte die Gewerbebehörde bestimmten Gewerbebetrieben, unter ihnen auch Gasthäusern, Maßnahmen vorschreiben, die „sie als notwendig erachtet, um den Bedürfnissen derjenigen, denen diese Gewerbe dienen, entsprechend gerecht zu werden." Die Begründung des Entwurfes war mehr als lakonisch: Die Regierung habe die Novellierung in Angriff genommen, weil „der bisherige Wortlaut dieser Vorschriften der öffentlichen Verwaltung Schwierigkeiten bereitete." Der Senat billigte zwar den Entwurf, im Abgeordnetenhaus blieb er jedoch bereits in den Ausschüssen stecken. ${ }^{167}$ Erst im Juli 1933 konnte die Angelegenheit wieder in Gang gebracht werden, indem die Exekutive von der ihr durch das

163 PT vom 7.2. 1926.

164 Vgl. Interpellation des Abgeordneten Dr. Schollich und Genossen an den Minister des Innern betreffend die Anbringung tschechischer Gatshausaufschriften vom 19. 2. 1929, in: TTZPS, 2. WP, Drucksache 2048/XI; Interpellation des Abgeordneten Frank an den Minister des Innern betreffend gesetzwidrige Anordnungen über den Sprachgebrauch im Gastgewerbe vom 6. 6. 1936, in: TTZPS, 4. WP, Drucksache 523/VII.

165 Vgl. beispielsweise SÚA, MV-SR, Karton 2927, 8/1/81, NJS an MV, 16. 11. 1934; SÚA, MV-SR, Karton 5023, 8/1/67, NJS an MV, 20. 3. 1936; SÚA, PMR, Karton 465, 1063/S, NJS an PMR und MV, 15. 4. 1937.

166 Vgl. Bericht des Ausschusses für Handel, Industrie und Gewerbe und des sozialpolitischen Ausschusses über den Regierungsentwurf der Gewerbeordnung für das Gebiet der Slowakei und der Karpatoukraine vom 26.6. 1924, in: TTZPS, 1. WP, Drucksache 4773. Die Resolution wurde am 25. 9. 1924 vom Abgeordnetenhaus angenommen, vgl. TTZS, 1. WP, Drucksache 1970. Vgl. auch Národní v druhém, S. 710; Regierungsentwurf eines Gesetzes, durch das $\$ \$ 82$ und 54 der Gewerbeordnung und $\$ 70$ des Gewerbegesetzes für das Gebiet der Slowakei und der Karpatoukraine abgeändert werden, vom 17. 9. 1925, in: TTZS, 1. WP, Drucksache 2223.

167 Národní shromáždění I., S. 712; Národní shromáždění II., S. 532. 
Gesetz Nr. 95/1933 Slg. vorübergehend gewährten außerordentlichen Verordnungsgewalt Gebrauch machte und Paragraph 54 der Gewerbeordnung durch eine Regierungsverordnung novellierte, und zwar in der Fassung, in der ihn der Gewerbeausschuß des Senats im Jahre 1925 gebilligt hatte. ${ }^{168}$ Das Innenministerium war zwar zunächst der optimistischen Meinung, daß dies eine gesetzliche Grundlage dafür liefere, die Bezeichnung von Gasthäusern in der Staatssprache anzuordnen, aber die Praxis war schließlich viel bescheidener: sprachliche Bestimmungen wurden nur neu konzessionierten Betrieben auferlegt, indem man sie direkt in die Betriebsbedingungen aufnahm; die bestehenden Gewerbeunternehmen wurden also durch diese Maßnahme nicht betroffen. ${ }^{169}$

Als Mitte der dreißiger Jahre endlich die Novelle der Gewerbeordnung vorbereitet wurde, kam die Frage der Gasthausaufschriften nochmals auf den Verhandlungstisch. Angeblich auf Verlangen des Staatsgewerberates, jedoch gegen die Stimmen seiner deutschen Mitglieder ${ }^{170}$, beabsichtigte das Handelsministerium, Bestimmungen in das Gesetz aufzunehmen, nach denen die Bezeichnung jedes Gewerbebetriebes an erster Stelle in der Staatsprache, und zwar „zumindest“ im gleichen Ausmaß und in derselben Ausstattung wie die Bezeichnung in einer anderen Sprache, erfolgen mußte. Von inneren Aufschriften, Speisekarten und tschechischsprachigem Personal war zwar auf der einen Seite nicht mehr die Rede, auf der anderen sollte die neue Regelung aber alle Gewerbebereiche betreffen. ${ }^{171}$ Schließlich kam auch diese Initiative nicht durch, und die sprachlichen Bestimmungen wurden während der interministeriellen Beratungen Ende 1937 weggelassen, übrigens nicht ohne Einwände der tschechischen Bürokratie. $^{172}$

In Berührung mit dem Tschechischen kamen sudetendeutsche Unternehmerkreise bzw. Angehörige der sogenannten freien Berufe ebenfalls in den beruflichen Selbstverwaltungskörpern, zu denen sie verpflichtend zusammengefaßt waren. Mit dem Sprachgebrauch in Körperschaften des öffentlichen Rechts, in erster Linie in Kammern (hierzu gehörten die Advokaten-, Ärzte-, Notar-, Ingenieur- sowie Handels- und Gewerbekammer) sowie in Korporationen jeder Art (beispielsweise verschiedene staatliche Kommissionen, Apothekergremien, Pharmazeutenausschüsse, Gewerbegenossenschaf-

168 Verordnung Nr. 163/1933 Slg. Die Verordnung war mit der durch den Senat 1925 beschlossen Fassung identisch. Vgl. Bericht des Gewerbe- und Handelsausschusses und des sozialpolitischen Ausschusses über den Regierungsentwurf des Gesetzes, durch das $\$ \$ 82$ und 54 der Gewerbeordnung und $\ 70$ des Gewerbegesetzes für das Gebiet der Slowakei und der Karpatoukraine abgeändert werden, vom 1. 10. 1925, in: TTZS, 1. WP, Drucksache 2245.

169 SÚA, MV-SR, Karton 2927, 8/1/62, Aktenvermerk MV, 30. 9.1933 bzw. Glück, Sprachenrecht, S. 42 .

170 SÚA, PMR, Karton 3296, 740/43, MO an PMR, 22. 4. 1938. - SÚA, MV-SR, Karton 2927, 8/1/90, Erklärung der Vertreter des deutschen Gewerbe- und Handelsstandes im Staatsgewerberat vom 12. 12. 1934, MO an MV, 30. 1. 1935, Anlage. Die Frage wurde bereits im Jahre 1933 im Staatsgewerberat thematisiert. Die Initiative im Hinblick auf die Bezeichnung der Gewerbebetriebe in der Staatssprache lehnten die deutschen Mitglieder unter Berufung auf die Verfassung ab und drohten mit einer Beschwerde beim Völkerbund. Vgl. Nál vom 13. 4. 1933.

171 SÚA, MV, 2927, 8/1/90, Entwurf der Gewerbeordnung, undat., MO an MV, 30. 1. 1935, Anlage.

172 SÚA, PMR, Karton 3296, 740/43, MO an PMR, 22. 4. 1938. Das Ministerium für die Vereinheitlichung der Gesetze beispielsweise hielt es "im Interesse des staatlichen Prestiges sowie im Interesse des Handels selbst“ für notwendig, daß zumindest in der Hauptstadt der Republik, in den Landeshauptstädten, in Kurorten sowie an Orten mit regem Touristenverkehr Gewerbebetriebe an erster Stelle in der Staatssprache bezeichnet wurden. Vgl. SÚA, PMR, Karton 3296, MpSZaOS an PMR, 15. 4. 1938. 
ten) beschäftigte sich bereits das Sprachengesetz, ausführlich wurde diese Frage jedoch erst durch die Durchführungsverordnung von 1926 geregelt. Bis dahin war die Praxis unterschiedlich; sie richtete sich meistens noch nach den Vorschriften aus der Vorkriegszeit, die teilweise der neuen Lage nach der Entstehung der Republik Rechnung trugen; nur für die Ingenieurskammer, die 1920 neu errichtet worden war, wurde durch eine Regierungsverordnung eine neue Geschäftsordnung festgelegt. ${ }^{173}$

Bei der Ausarbeitung der diesbezüglichen Bestimmungen der Durchführungsverordnung hielt man sich im Grunde genommen an das Vorbild der territorialen Selbstverwaltungskörper: Der Sprachgebrauch richtete sich nach Vorschriften, die die betreffenden Korporationen mit der Genehmigung des zuständigen Ministers selbst beschlossen, natürlich im Rahmen gewisser Grundsätze, die die Rechte der Staatssprache garantierten. Das Tschechische oder Slowakische konnte in Sitzungen und Beratungen der Kammer stets gebraucht werden, in ihnen vorgebrachte Anträge und Anregungen mußten immer Gegenstand der Verhandlung werden. Eingaben sowohl der Parteien als auch der Kammermitglieder in der Staatssprache waren unter allen Umständen anzunehmen und in dieser auch zu erledigen, Bekanntmachungen der Kammer gab man stets auch tschechisch oder slowakisch heraus, Sitz und Amtsräume mußten ebenfalls in einer dieser Sprachen bezeichnet werden. Im Hinblick auf die Rechte der Minderheitensprachen war die Verordnung eher wortkarg. Für den Parteienverkehr galten analog die Bestimmungen des Sprachengesetzes, falls sich die Wirksamkeit der Kammer auf einen sprachlich qualifizierten Bezirk erstreckte. Bekanntmachungen, soweit sie einen Bezirk mit einer nationalen Minderheit betrafen, wurden auch in der Sprache dieser Minderheit abgefaßt. Die Sprachenrechte der Kammermitglieder waren durch den Grundsatz gewährleistet, demgemäß kein Mitglied der Korporation weniger Rechte haben durfte als eine Partei.

Übrigens kam diese Regelung nicht ganz einfach zustande, denn auch auf diesem Gebiet wurden Versuche unternommen, den Anwendungsbereich der Minderheitensprachen einzuengen. Die heftigsten Diskussionen entbrannten Anfang der zwanziger Jahre im Zusammenhang mit der Vorbereitung der Geschäftsordnung der Ingenieurskammer, der wohl nicht Wenige die Rolle eines Präzedenzfalles zugedacht hatten. Wichtig war, daß das Recht, die Geschäftssprache selbst zu bestimmen, den Kammern faktisch weitgehend entzogen werden sollte, indem die "tschechoslowakische“ Sprache als Amtssprache der Kammer durch die Regierung festgelegt wurde. Der Gebrauch der Minderheitensprachen sollte sich weitgehend nach der Parlamentsgeschäftsordnung richten: Kammermitglieder durften zwar sowohl im Vorstand als auch in der Vollversammlung ihre Muttersprache gebrauchen, ihren Anfragen oder Anträgen mußten sie jedoch eine Übersetzung in der Staatssprache beifügen. Eingaben in einer Minderheitensprache wurden angenommen und auf Verlangen zweisprachig erledigt, solange der Kammer nach dem Stande des abgelaufenen Jahres mindestens 20 Prozent Mitglieder dieser Sprache angehörten. Die sprachlichen Bestimmungen wiesen zahlreiche Lücken auf, was zum Teil darauf zurückzuführen war, daß man zu diesem Zeitpunkt, also im Herbst 1920, eine relativ baldige Herausgabe der Durchführungsverordnung zum Sprachengesetz und somit eine generelle Regelung erwartete. Da dies nicht passierte, versuchte die Kammer verschiedenartig zu improvi-

${ }^{173}$ Vgl. Regierungsverordnung Nr. 654/1920 Slg. 
sieren, wobei die tschechische Mehrheit mangelnde Bereitschaft zeigte, im Interesse einer reibungslosen Abwicklung der Kommunikation aber auch einer kollegialen Atmosphäre die sprachlichen Bedürfnisse der Minderheitenvölker zu berücksichtigen. Die Krise setzte im Februar 1922 ein, als die mit der Sprachregelung unzufriedenen Deutschen den Vorstand der Ingenieurskammer verließen. Dies nutzten seine tschechischen Mitglieder aus, und im September 1922 billigte die Vollversammlung der Kammer den Entwurf einer neuen Geschäftsordnung, der die Minderheitensprachen vollkommen aus der inneren Tätigkeit der Kammer verdrängte: Ihr Gebrauch in Verhandlungen der Kammer wurde völlig ausgeschlossen; die Vorstandsmitglieder waren ungeachtet ihrer Nationalität verpflichtet, "tschechoslowakisch" zu beherrschen. ${ }^{174}$ Das zuständige Ministerium für öffentliche Arbeiten, an dessen Spitze der sozialdemokratische Politiker A. Srba stand, fand den Entwurf äußerst fraglich und arbeitete, „um die Tätigkeit der Kammer nicht weiter zu gefährden“, einen eigenen Entwurf aus, der ausdrücklich das Recht der deutschen Mitglieder anerkannte, in Verhandlungen der Kammer auch ihre Muttersprache zu gebrauchen. Der Entwurf kehrte zu den meisten sprachlichen Bestimmung der alten Geschäftsordnung zurück, führte aber eine bedeutende Neuerung ein: Mit Zustimmung des Vorsitzenden konnten Erklärungen oder Anträge der deutschen Mitglieder durch einen Dolmetscher simultan übersetzt werden. ${ }^{175}$

Der offensichtlich schockierte tschechische Kammervorstand begann sofort Alarm zu schlagen, denn seine Mitglieder waren ehrlich davon überzeugt, daß der Gebrauch von Minderheitensprachen außerhalb von Bezirken mit über 20 Prozent der Minderheitenbevölkerung überhaupt unzulässig sei, somit auch in den Verhandlungen der Kammer, die ihren Sitz in Prag hatte, wo die Deutschen diese prozentuale Grenze bekanntlich nicht erreichten. Die Deutschen müßten daher, so der grundsätzliche Standpunkt des Vorstandes, in die Organe der Kammer sowie anderer Korporationen ausschließlich Vertreter entsenden, die der tschechischen Sprache mächtig seien. ${ }^{176}$ Diese Interpretation zog das Innenministerium grundsätzlich in Zweifel: Die Kammer sei verpflichtet, in Verhandlungen die deutsche Sprache zuzulassen. Die Bestimmung, daß die Vorstandsmitglieder der Staatssprache mächtig sein müßten, entbehre jeder gesetzlichen Grundlage, ebenso wie die Annahme, daß Angehörige der Minderheitensprachen außerhalb von Bezirken mit einer zwanzigprozentigen Minderheit keine Sprachenrechte hätten. ${ }^{177}$ Man zog auch die Bestimmung in Zweifel, dergemäß das Recht, in den Sitzungen der Körperschaften die Muttersprache gebrauchen zu können, vom Anteil der Angehörigen der Minderheitensprache an der Gesamtzahl der Mitglieder der Kammer abgeleitet worden war. ${ }^{178}$ Schließlich setzte sich, im Einklang mit den allgemeinen Grundsätzen des Sprachenrechts, der Standpunkt durch, daß die Minderheitensprachenrechte denjenigen Kammermitgliedern und Parteien zustanden, die ih-

174 SÚA, PMR, Karton 3296, Geschäftsordnung der Ingenieurskammer, MVP an MV, 31. 7. 1923, Anlage. Abgesehen von dieser Bestimmung legte die Geschäftsordnung fest, daß alle amtlichen Kundmachungen, Mitteilungen sowie andere schriftliche Materialien der Kammer nur in der „tschechoslowakischen" Sprache herausgegeben wurden.

175 SÚA, PMR, Karton 3296, 740/24, Geschäftsordnung der Ingenieurskammer, undat. (1922).

176 SÚA, PMR, Karton 3296, 740/24, Ingenieurskammer an den Abgeordnetenklub der Tschechoslowakischen sozialdemokratischen Partei, 7. 3. 1923.

177 SÚA, PMR, Karton 3296, 740/24, MV an PMR, 28. 9. 1923.

178 SÚA, PMR, Karton 3296, 740/24, MS an MVP, 29. 10. 1923; ebda, MV an MVP 12. 12. 1923. 
ren Sitz in einem Gerichtsbezirk hatten, in dem zu über 20 Prozent Staatsbürger derselben Sprache wohnhaft waren; die Angelegenheit mußte freilich auch in einem sprachlich qualifizierten Bezirk entstehen. ${ }^{179}$ Dagegen mußte das Ministerium für öffentliche Arbeiten auf das simultane Dolmetschen in den Sitzungen der Kammern vollkommen verzichten; alle Übersetzungen waren nach wie vor schriftlich vorzulegen. ${ }^{180}$

Die Durchführungsverordnung schrieb den Kammern - die Ingenieurskammer ausgenommen - vor, dem vorgesetzten Minister innerhalb von drei Monaten einen $\mathrm{Be}-$ schluß über den Sprachgebrauch zur Genehmigung vorzulegen. Der Anwendungsbereich der Minderheitensprachen entsprach weitgehend der Praxis im Parlament, allerdings mit einer Ausnahme: Man unterschied nicht zwischen Mitgliedern und Funktionären der Kammer, so daß auch die Zweitgenannten in ihren Äußerungen ihre Muttersprache gebrauchen durften. Falls eine Kammer deutsch als Geschäftssprache festlegte, akzeptierte der Staat diese Entscheidung. ${ }^{181}$ Angesichts der in der Verordnung verankerten Vorbehalte zugunsten der Staatssprache, manchmal jedoch auch dank der Einsicht der deutschen Seite, war diese in solchen Fällen faktisch mit der Geschäftssprache gleichberechtigt; so wurden beispielsweise in der Handels- und Gewerbekammer Reichenberg, die einen großen Anteil tschechischer Mitglieder hatte, deutsch eingebrachte Anträge und Berichte zumindest inhaltlich ins Tschechische übersetzt; protokolliert wurde nur deutsch, wobei tschechisch eingebrachte Anträge auch tschechisch ins Protokoll aufgenommen werden konnten. Die deutsche Geschäftssprache wurde auch im Verkehr mit dem Dachorgan, der Zentrale der Handels- und Gewerbekammern, sowie mit Staatsbehörden - soweit sie eine deutschsprachige Eingabe überhaupt annehmen konnten - weitgehend respektiert. ${ }^{182}$ Das Handelsministerium führte nach einer $\mathrm{Ab}$ sprache mit den Kammern die Praxis ein, daß die beiden mehrheitlich deutschen Kammern in Eger und Reichenberg sich nur auf deutsch an das Ministerium wandten, das Ministerium seinerseits nur in der Staatssprache mit diesen Kammern korrespondierte. ${ }^{183}$

Eine spezifische Form des Sprachenzwanges in der privaten Erwerbstätigkeit war auch die gesetzlich auferlegte Verpflichtung zur Kenntnis der Staatssprache für Angehörige bestimmter Berufe, die in besonderer Weise den Bereich der sogenannten freien Berufe betraf. Die gesetzliche Grundlage für eine derartige Verpflichtung lieferte das Sprachengesetz, das "tschechoslowakisch“ als Sprache nicht nur der Gerichte und Behörden, sondern auch der „Organe der Republik“ festlegte. Der Begriff wurde nicht näher erläutert, und die Frage, worauf er sich eigentlich beziehen sollte, war jahrelang

179 AMZV, Sektion VI, Karton 486, Mappe 6, Entwurf einer Regierungsverordnung, durch den der Sprachgebrauch in der Ingenieurskammer geregelt wird, undat. (nach Februar 1926); SÚA, MV-SR, Karton 2935, 8/22/12, Regelung des Sprachgebrauchs in der Ärztekammer für das Land Böhmen, undat., (Aufzeichnung MV, 17. 7. 1930, Anlage).

180 Vgl. SÚA, PMR, Karton 3296, 740/24, MVP an die Ingenieurskammer, 20. 2. 1924. Vgl. auch NáL vom 13. 5. 1923.

181 Von den neun Handels- und Gewerbekammern in den böhmischen Ländern hatten zwei (Reichenberg und Eger) deutsch und eine (Troppau) deutsch und tschechisch als Geschäftssprachen.

182 Vgl. SÚA, MV-SR, Karton 507, 20/2/53, MO an MV, 10. 5. 1928, Anlage „Handels- und Gewerbekammer Eger“; ebda MO an MV, 10.5. 1928, Anlage „Handels- und Gewerbekammer Reichenberg". Auch die Zentrale der Handels- und Gewerbekammern fügte eine Übersetzung bei. Vgl. SÚA, MV-SR, Karton 507, 20/2/53, Zentrale der Gewerbe- und Handelskammern an MO, undat., MO an MV 10. 5. 1928, Anlage.

183 SÚA, PMR, Karton 3296, 740/43, MO an PMR, 22. 4. 1938. 
heftig umstritten. Bereits die erste Fassung der Durchführungsverordnung vom Jahre 1920 erlegte diesen Personen, ohne sie jedoch näher zu bestimmen, analoge sprachliche Verpflichtungen auf wie den Staatsangestellten, d. h. die vollkommene Kenntnis der Staatssprache, die sowohl Bewerber als die bereits angestellten Personen innerhalb einer bestimmten Frist vorlegen mußten. ${ }^{184}$ Der Verordnungsentwurf von 1922 zählte zu den "Organen der Republik" ausdrücklich öffentliche Notare, Dolmetscher und autorisierte Ziviltechniker; die Formulierung „oder andere von der staatlichen Verwaltung mit ihrem Amt oder Dienst oder mit der Wahrnehmung von Regierungsaufgaben im öffentlichen Interesse betraute Personen" enthielt nicht nur den Versuch einer Definition der „Organe der Republik", sondern ließ auch eine Hintertür für die weitere Ausdehnung des Begriffs offen. ${ }^{185}$ Dies geschah dann tatsächlich in den weiteren Fassungen der Verordnung: 1924 kamen Bergbauingenieure sowie die Gemeinde- und Bezirksärzte und 1926 Landvermesser hinzu. Die Deutschen bezeichneten diese Regelung als Versuch, ganze Berufszweige auf solche Weise zu tschechisieren und deutschen Staatsbürgern unzugänglich zu machen. ${ }^{186}$ Neben der deutschen Kritik an nationalpolitischen Aspekten kamen jedoch - und dies auch auf tschechischer Seite - ernste juristische Zweifel auf ${ }^{187}$, die in einiger Hinsicht auch das Oberste Verwaltungsgericht bestätigte. In der zweiten Hälfte der zwanziger Jahre gelangte es in einer Reihe von Entscheidungen zu dem Rechtsstandpunkt, autorisierte Ziviltechniker, Landvermesser und Dolmetscher seien keine Organe der Republik; Notare und Bergbauingenieure seien dies lediglich dort, wo sie als Staatsorgane auftraten. Die diesbezüglichen Urteile entsprangen einer abweichenden Auffassung des Begriffs: Während die Autoren der Durchführungsverordnung bei „Organen der Republik“ von bestimmten physischen, durch den Staat mit bestimmten Aufgaben betrauten Personen ausgingen, verstand das Gericht unter dem Begriff nur abstrakte, mit gewisser örtlicher und sachlicher Kompetenz ausgestattete, von einer konkreten Person unabhängige Institutionen. ${ }^{188}$

Äußerst schwierig ist die Frage zu beantworten, inwieweit die Sprachregelung im Geschäftsverkehr die Stellung der einzelnen deutschen Betriebe bzw. der sudetendeutschen Wirtschaft in der Tschechoslowakei überhaupt beeinflußte. Dem sudetendeutschen Wirtschaftsexperten K. Janowsky gemäß brachten die Benachteiligungen auf sprachlichem Gebiet für deutsche Unternehmer einen "großen" materiellen Nachteil mit sich. Das Einstellen von der tschechischen Sprache mächtigen Angestellten „lediglich“ zu Zwecken der Wahrnehmung des notwendigen tschechischsprachigen Parteienund Geschäftsverkehrs erhöhe, so Janowsky, die Generalunkosten der deutschen Betriebe. ${ }^{189}$ Derartige negative Auswirkungen waren sicher unterschiedlich, in erster $\mathrm{Li}$ nie je nach der Größe des Unternehmens. Für größere Betriebe stellte die Gewährleistung des tschechischsprachigen Verkehrs kaum eine nennenswerte Belastung dar. Demgegenüber war die Möglichkeit vor allem von Gewerbetreibenden, den sprachli-

184 Vgl. SÚA, MV-SR, Karton 506, 20/2/53/1, Entwurf der Regierungsverordnung zur Durchführung des Gesetzes Nr. 122/1920 Slg., undat. (verschickt am 7. 10. 1920). Zu den sprachlichen Verpflichtungen der Staatsangestellten vgl. Kapitel II.C.2. bzw. II.C.3.

185 SÚA, MV-SR, Karton 506, 20/2/53(2), Entwurf der Regierungsverordnung zur Durchführung des Gesetzes Nr. 122/1920 Slg., undat. (1922).

186 Sprachenverordnung, S. 75.

187 Vgl. beispielsweise Peška, Národní menšiny, S. 147.

188 Diwald, Jazykové právo, S. 69; Peška, Národní menšiny, S. 147-148. Vgl. auch Nál vom 20. 3. 1929.

189 Janowsky, Jahre, S. 25. 
chen Erfordernissen beispielsweise im Hinblick auf Staatsaufträge oder auf die Sicherstellung des ständigen tschechischsprachigen Verkehrs mit der Kundschaft zu entsprechen, viel geringer. Kleinen Gewerbetreibenden wie auch besonders Angehörigen der oben erwähnten freien Berufe konnten die sprachlichen Verpflichtungen als eine und zwar wohl nicht unwichtige - Komponente der unmittelbaren existentiellen Bedrohung erscheinen. Sicher waren die Auswirkungen auch je nach der Branche unterschiedlich, ebenso wie auf einzelnen "Konfliktfeldern“. Hier stößt man jedoch auf grundsätzliche Probleme. Erstens sind einschlägige Studien über einzelne Wirtschaftsbereiche und wirtschaftspolitische Prozesse kaum vorhanden. Zweitens können auch dann noch keine endgültigen Urteile gefällt werden, auch wenn für einzelne Bereiche derartige Arbeiten vorliegen. Die jüngste Forschung zeigte beispielsweise unmißverständlich, daß die sudetendeutschen Beschwerden wegen ungenügender Berücksichtigung der sudetendeutschen Wirtschaft bei der Vergabe von Staatsaufträgen begründet waren. ${ }^{190}$ Inwieweit dabei jedoch die Sprachregelung eine Rolle spielte, die ungleiche Bedingungen für den Zugang von Interessenten zu Staatsaufträgen schuf, inwieweit man im Auswahlverfahren - möglicherweise nur unterschwellig - andere nationalpolitische Kriterien gelten ließ oder aber die Angebote der sudetendeutschen Betriebe in ihrer Mehrzahl einfach kaum konkurrenzfähig waren, bleibt immer noch offen. 


\section{Die Sprache und die Staatsangestelltenfrage}

\section{Die Staatsangestelltenfrage als Problem der Nationalitätenpolitik}

Neben "Sprache“ und „Schule“ gehörte der Kampf um den Arbeitsplatz im Staatsdienst zur zeitgenössischen Trias der lebenswichtigsten Probleme der Deutschen in der Tschechoslowakei. Der deutsche Anteil am Staatsapparat, der Abbau von deutschen Beamten, ihre zwangsweisen Versetzungen in das tschechische Sprachgebiet, die Durchsetzung von deutschen Gemeinden mit tschechischen Staatsangestellten dies waren fast tagtäglich aufgegriffene Themen, die die Aufmerksamkeit der gesamten Gesellschaft ständig auf diese Problematik lenkten. Im Ringen um den "nationalen Besitzstand" im Staatsdienst kamen keineswegs zu unterschätzende soziale Motive zum Ausdruck; schließlich standen zahlreiche existentiell relativ gesicherte, also wenig krisenanfällige, von den Risiken des privatwirtschaftlichen Unternehmens losgelöste und pensionsberechtigte Arbeitsplätze auf dem Spiel. Nach der Zählung vom Jahre 1924 gab es in der Tschechoslowakei beinahe 350000 Staatsangestellte; insgesamt waren etwa 10,6 Prozent der Gesamtbevölkerung der Republik vom „staatsgesellschaftlichen Sektor" sozial abhängig. ${ }^{2}$ Mit anderen Worten: der Anteil der einzelnen Nationalitäten des Staates am öffentlichen Sektor hatte erhebliche Auswirkungen auf die soziale, indirekt auch wirtschaftliche Stellung der jeweiligen Nationalität. ${ }^{3}$ Diese sozialpolitische Bedeutung der Staatsangestelltenfrage wurde von ihrer nationalpolitischen Brisanz weitgehend überlagert. In nationalpolitischer Hinsicht ging es nicht nur um das eventuelle Gefühl der Minderheiten, als Kollektivität gerecht und gleichberechtigt behandelt zu werden, das die der Größe und Bedeutung der jeweiligen Minderheit Rechnung tragende Staatsangestelltenpolitik vermitteln konnte, sondern um eine grundlegende Machtfrage, nämlich um den Einfluß auf den exekutiven bürokratischen Bereich. Dieser Aspekt der Staatsangestelltenfrage entsprang der Überzeugung, daß die gerechte Vertretung des einen oder anderen Volksstammes in der Staatsverwaltung gleichzeitig eine ausgewogene Wahrnehmung seiner Interessen als Ganzes oder einzelner Angehöriger der jeweiligen Nationalität durch den Staat garantierte. Obwohl das Loyalitätsverhältnis gegenüber dem Staat einerseits und der eigenen Nationalität andererseits als individuelle Einstellung nie konstant sein konnte, erwartete der Zeitgeist von Staatsangestellten, besonders natürlich von Staatsbeamten, fast automatisch eine Interessensidentität mit der Bevölkerung derselben Nationalität; deutscherseits wurde offen empfohlen, die Angehörigen der Minderheiten im öffentlichen Dienst "tunlichst derart zu verwenden, daß sie im Interesse der Minderheit, der sie selbst angehören, tätig sind. ${ }^{4}$ Der andere Grund, warum man deutscherseits prinzipiell verlangte, die deut-

1 Vgl. Státní zaměstnanci, S. 5.

2 Ziegler, Gliederung, S. 195.

${ }^{3}$ Die Herabsetzung der "wirtschaftlichen Leistungsfähigkeit" der deutschen Beamtenschaft gehöre, so die Beschwerden der Sudetendeutschen, als Massenerscheinung ,zu den die sudetendeutsche $\mathrm{Na}$ tionalwirtschaft ungünstig beeinflussenden Faktoren“. Vgl. Arens, Einbußen, S. 420.

+ Epstein, Grundsätze, S. 86. 
sche Bevölkerung durch Beamte der gleichen Nationalität „verwaltungsmäßig zu bedienen "5, war die Überzeugung, daß die tschechische Beamtenschaft ihrem „völkischen Bedürfnis" kein Verständnis entgegenbringe. ${ }^{6}$ Tschechische Beamte, meinte der sudetendeutsche Politiker G. Peters, seien gegen die Deutschen ohnehin voreingenommen und würden dank der Bindung an die örtlichen tschechischen Minderheiten oft in Konflikt gerade mit der notwendigen behördlichen Objektivität geraten. ${ }^{7}$ Vom Standpunkt der Sudetendeutschen her gesehen kam zur üblichen Entfremdung zwischen Staatsapparat und Bürger eine Überfremdung hinzu, die die Herausbildung eines Vertrauensverhältnisses bzw. ihre Identifizierung mit dem Staat tatsächlich erschwerte. ${ }^{8}$ Der tschechische oder deutsche Angestellte markierte somit nicht nur den unmittelbaren Bereich des jeweiligen "nationalen Besitzstandes“ im Staatsdienst, sondern auch eventuelle Freiräume für gesellschaftliche Aktivitäten seiner gleichsprachigen Mitbürger innerhalb seines amtlichen Wirkungsbereichs. Wurde beispielsweise ein deutscher durch einen tschechischen Beamten ersetzt, erfolgte für den Begriff des zeitgenössischen deutschen Beobachters die Festigung oder sogar die Erweiterung der Machtstellung der Tschechen; ihm schwebte die Gefahr vor, daß die Aktivitäten in allen gesellschaftlichen Bereichen zunehmend bis in die letzten Ausläufer „dem tschechischen Ermessen und der tschechischen Kontrolle" ausgeliefert würden. ${ }^{9}$

Dieser Aspekt der „Auslieferung“ wurde natürlich dort am stärksten empfunden, wo bis zur Entstehung der Republik die einzelnen Lebensbereiche der deutschen Gesellschaft intakt gewesen waren, nämlich im deutschen Sprachgebiet; darüber hinaus hatte die Staatsangestelltenpolitik hier tatsächliche oder potentielle Auswirkungen auf die Siedlungsverhältnisse. Tschechische Staatsangestellte im deutschen Sprachgebiet wurden in der Tat nicht selten Keimzellen der fortschreitenden tschechischen Besiedlung in bis dahin rein oder fast rein deutschen Gemeinden und gehörten des öfteren zu führenden Exponenten des politischen und gesellschaftlichen Lebens der tschechischen Sprachinseln. In den Augen der deutschen Öffentlichkeit galten die tschechischen Staatsangestellten - neben den Schutzvereinen - als einer der „zwei Generalträger der tschechischen Expansion" in das deutsche Sprachgebiet oder als "gefährlicher Schrittmacher tschechischer Eroberungspolitik ". ${ }^{10}$

In der Wahrnehmung der sudetendeutschen Bevölkerung erschien zwar die Zunahme der tschechischen Bevölkerung in den mehrheitlich deutsch besiedelten Bezirken als imposant sowie eindeutig als Folge einer zielgerichteten tschechischen Staatspolitik, das Verhältnis der tschechischen Gesellschaft und Politik zum Phänomen „Grenzgebiete" war jedoch differenzierter. Gewiß hatte die Mehrheit der Tschechen nichts dage-

${ }^{5}$ Simm, Fragen, S. 15; Epstein, Grundsätze, S. 85.

6 SÚA, MV-SR, Karton 502, 20/2/28, Bürgermeisteramt Haida an die Regierung, 11. 12. 1919.

7 Peters, in: Rundschau von 28. 4. 1935.

8 SÚA, MV-SR, Karton 502, 20/2/28, Bürgermeisteramt Haida an die Regierung, 11. 12. 1919. In der Einführung der inneren Amtssprache erblickte die Gemeindevertretung eine Maßnahme, die dazu „angetan ist, die deutsche Beamtenschaft in Pflichtkollision zu versetzen, sie unmöglich zu machen, beiseite zu schieben und zu verelenden, um der tschechischen Beamtenschaft Platz zu machen und das deutsche Volk zu nötigen, Recht und Schutz bei Beamten zu suchen, welche seinem völkischen Bedürfnisse kein Verständnis entgegenbringen und welchen zufolge der durch die neue politische Lage bis aufs Äußerste gespannten nationalen Gegnerschaft kein Vertrauen entgegengebracht werden kann."

9 Montagsblatt aus Böhmen vom 16.5.1921.

10 Eszler, Jahre, S. 52 bzw. Arens, Einbußen, S. 421. 
gen einzuwenden, daß diese Regionen ungeachtet ihrer nationalen Zusammensetzung ein Bestandteil der Republik waren. Diese allgemeine Genugtuung bedeutete freilich noch lange keine Bereitschaft zum persönlichen Engagement für nationalpolitische Zielsetzungen, die etwa auf die Veränderung des nationalen Charakters der Grenzgebiete hinausgelaufen wären. Zwischen dem in mancher Hinsicht national saturierten tschechischen Landesinneren und den tschechischen Minderheiten im deutschen Sprachgebiet herrschte ein eigenartiges Verhältnis: Zwar war der Hinweis auf ihre Existenz eines der wichtigen Argumente der tschechoslowakischen Delegation auf der Friedenskonferenz im Jahre 1919, mit dem man den tschechischen Anspruch auf die Zugehörigkeit der mehrheitlich deutsch besiedelten Gebiete zum tschechoslowakischen Staat begründet hatte. ${ }^{11}$ Auch unterstrich die Entstehung der selbständigen Tschechoslowakei die Bedeutung der tschechischen Bevölkerungsinseln im deutschen Sprachgebiet nicht nur in nationalpolitischer, sondern auch in wirtschaftlicher und strategischer Hinsicht. Der tatsächliche Rückhalt durch die binnenländische tschechische Mehrheit blieb jedoch weit hinter den Erwartungen der nationalen Radikalen sowohl innerhalb der tschechischen Minderheiten als auch unter den Funktionären der Volkstumsvereine zurück, was bereits Anfang der zwanziger Jahre in der resignierten Feststellung gipfelte, die Republik sei den Tschechen im Grenzgebiet eine „weder liebevolle noch umsichtige Mutter". ${ }^{12}$

Im Hinblick auf die Verstärkung der tschechischen Präsenz in den deutschsprachigen Bezirken warteten besonders die tschechischen Schutzvereine mit einem umfangreichen Forderungskatalog an die tschechische Gesellschaft und den Staat auf. Dieser enthielt neben der direkten wirtschaftlichen Unterstützung der tschechischen Minderheiten auch sozialpolitische Regelungen (beispielsweise im Bereich des Mieterschutzes) sowie weitgehende Eingriffe in die Struktur der Eigentumsverhältnisse im deutschsprachigen Gebiet, und zwar im Wege der Bodenreform und der Verstaatlichung der Grenzwälder sowie der privaten Eisenbahnen bzw. der Bäder usw. Hierzu gehörte auch eine folgerichtige Anwendung der entsprechenden sprachlichen Normen, worunter man die konsequente Geltendmachung des "Tschechoslowakischen" als innerer und äußerer Amtssprache, den Gebrauch von Ortsnamen, sowie die Frage der öffentlichen Aufschriften jeglicher Art verstand. Die Staatsangestelltenfrage spielte unter diesen Forderungen eine hervorragende Rolle. Die Dienststellen in den Grenzgebieten sollten systematisch von Tschechen besetzt, deutsche Beamte dagegen ins Landesinnere versetzt werden. ${ }^{13}$ Vom tschechischen Beamten im deutschsprachigen Gebiet wurde ein starkes nationalpolitisches Engagement erwartet, und zwar nicht nur in seinem eigentlichen Dienst, sondern auch "nebenamtlich“: er sollte in der tschechischen Bevölkerung wirken und zur Hebung des kulturellen Niveaus des tschechischen Elements, der Konsolidierung ihres gesellschaftlichen Lebens, der Vertiefung des Staatsgedankens

$11 \mathrm{Vgl}$. die Argumentation des Memorandums Nr. III, das die tschechoslowakische Delegation auf der Pariser Friedenskonferenz im Jahre 1919 vorlegte, in: Die tschechoslowakischen Denkschriften, S. 86-89.

12 NM 2 (1922), S. 83.

13 Vgl. beispielsweise SÚA, MS, Karton 377, Mappe: Němci, Resolution der Tagung des tschechischen Volkes in Aussig/Elbe am 31. 7. 1921; SÚA, MV-SR, Karton 1487, 14/1/6, politische Bezirksverwaltung Jitschin an das Präsidium der politischen Landesverwaltung Prag, 1. 12. 1921; ebda, Karton 511, 20/2/177, SNJM an PMR, 20. 9. 1922; SÚA, NRČ, Karton 413, 236-237, Resolution der Tagung der tschechischen Bevölkerung Nordmährens am 12. 11. 1922; SÚA, MPOŽ, Karton 693, 36299/29, Resolution der Tagung des NJS am 21.4. 1929. 
usw. beitragen - dies bedeutete u. a., mit den Angehörigen der tschechischen Minderheiten „intimere Beziehungen“ zu pflegen, eine Art „Vermittler und Vertrauensmann“ für sie zu sein. ${ }^{14}$

Die tschechische Politik machte sich die einzelnen Posten des Katalogs allerdings nur zögernd und teilweise zu eigen. Der Gedanke zwar, den deutschen territorialen Besitzstand zu reduzieren, war ihr nicht fremd, sie war jedoch offensichtlich nicht gewillt, den Staat vollkommen für die Zwecke der nationalen Expansion einspannen zu lassen. Im Grunde genommen verhinderte dies auch die demokratische Staatsmacht; die Instrumente, die sie auf diesem Gebiet einsetzen konnte, waren außerdem ohnehin begrenzt. Eine großangelegte, planmäßige „Eroberungsaktion“, wie sie die tschechischen nationalen Radikalen ersehnten, blieb aus; die Staatsmacht beschränkte sich auf selektive Einzelmaßnahmen, das Schwergewicht der nationalen Expansion war der - manchmal mit bürokratischer Autorität bemäntelten - Eigeninitiative tschechischer Beamter oder der Privatinitiative beispielsweise der Volkstumsvereine überlassen. Der Staat unterstützte diese Initiative weniger durch direkte Eingriffe zugunsten des Mehrheitsvolkes als vielmehr durch den ungenügenden Schutz der Minderheiten vor dem - durch Österreich „jahrelang“ unterdrückten - „natürlichen Expansionsdrang“ der Tschechen, auf den man als den entscheidenden Faktor rechnete.

$\mathrm{Daß}$ gerade in der Staatsangestelltenfrage die reale Entwicklung den Vorstellungen der nationalistischen Kreise weit hinterherhinkte, lag teilweise an objektiven Bedingungen: Das höhere Preisniveau in den Grenzgebieten, die immerwährende dortige Wohnungsnot, die nicht einmal der Bau von „Staatshäusern“ für Staatsangestellte lösen konnte, sowie psychologische Probleme, die das Leben in einer vorwiegend andersnationalen Umgebung gemeinsam mit den Folgeerscheinungen des Nationalitätenkampfes mit sich brachte - dies alles, kombiniert mit der ohnehin komplizierten sozialen Lage der Staatsangestellten in der Ersten Republik, verursachte, daß die Posten im deutschen Sprachgebiet kaum zu den ersehnten gehörten. ${ }^{15}$ Laut ursprünglichen Intentionen der Schutzverbände sollten Staatsangestellte in die Grenzgebiete versetzt werden, die sich freiwillig meldeten ${ }^{16}$, darüber hinaus waren nur „die Besten der Besten“ tatsächlich zu entsenden. ${ }^{17}$ Der nationale Eifer der Angestellten konnte die vor allem sozialen Nachteile des Dienstes in den Grenzgebieten offensichtlich nicht wettmachen, und das Interesse war gering. Als illusorisch erwiesen sich auch die Hoffnungen der nationalen Radikalen auf junge tschechische Staatsangestellte, für die der Dienst in den Grenzgebieten die Aussicht auf eine schnellere berufliche Karriere eröffnen sollte. Aber erstens akzeptierte die Staatsverwaltung nicht die Forderung der nationalen Radikalen, zwei bis drei abgeleistete Dienstjahre im sogenannten "gemischten“ Gebiet zur grundlegenden Voraussetzung für die weitere berufliche Karriere zu machen. ${ }^{18}$

14 SÚA, MV-SR, Karton 1487, 14/1/6, Ministerialrat in Leitmeritz an das Präsidium der politischen Landesverwaltung in Prag, 19. 12. 1921 bzw. NM 2 (1922), S. 83.

15 Wie beständig diese Probleme waren, belegen auch die Klagen der oppositionellen tschechischen Sozialisten vom Jahre 1929. Vgl. Interpellation der Abgeordneten Bergman, Zeminova, Spatný und Genossen an die Regierung betreffend die kritische Situation tschechischer Staatsangestellten an den national gemischten Orten vom 6.6. 1929, in: TTZPS, 2. WP, Drucksache 2313/VII.

${ }^{16}$ NM 2 (1922), S. 84.

17 Ebda., S. 83.

18 Ebda., S. 83. Vgl auch Resolution der Generaltagung der tschechischen Minderheiten in Prag am 1.-2. 4. 1922, in: ebda, S. 151 bzw. SÚA, PMR, Karton 626, 1766/S, Memorandum der Direktoren, 
Zweitens stellte sich relativ bald heraus, daß der tschechischen Jugend an sich die Gedankenwelt des Volkstumskampfes weitgehend fremd war - ihr Desinteresse an der Volkstumsarbeit und der daraus resultierende Nachwuchsmangel der Schutzvereine sowie das sinkende Echo auf deren Tätigkeit in der gesamten tschechischen Gesellschaft waren praktisch seit Anfang der zwanziger Jahre eine Konstante in der Beschwerdeliste der Vereinsfunktionäre. ${ }^{19}$ Dementsprechend war auch die Bereitschaft von jungen Beamten und Angestellten, sich im Sinne der Vorstellungen der nationalen Radikalen zu engagieren, relativ gering. Ihr eher indifferentes nationales Empfinden brachte einen unerwünschten Nebeneffekt mit sich: Junge ledige tschechische Staatsangestellte in den Grenzgebieten würden, wie später die Schutzverbände mürrisch feststellen mußten, deutsche Frauen heiraten und allmählich zur deutschen Nationalität wechseln, zumindest würden ihre Kinder deutsch erzogen..$^{20}$ Der Mangel an Interessenten um den Dienst in den Grenzgebieten verursachte, daß hier wohl nicht wenige Bestellungen aus disziplinarischen Gründen erfolgten: Mancherorts, dramatisierte der Schutzverein für Nordböhmen offensichtlich die Lage, würden in tschechischen Minderheiten „Strafkolonien“ für diejenigen Staatsangestellten geschaffen, die sich anderswo nicht bewährt bzw. an ihrem alten Dienstort im tschechischen Sprachgebiet verschiedene Probleme - den Alkoholismus nicht ausgenommen - gehabt hätten. ${ }^{21}$

Ungehört verhallte die grundlegende Forderung der tschechischen Radikalen, die in den Grenzgebieten dienenden tschechischen Staatsangestellten außerordentlich zu besolden und dadurch den Dienst dort sozial attraktiver zu machen. ${ }^{22}$ Das Einkommen "dieser treuen und hingebungsvollen Diener des Staates" sollte dermaßen erhöht werden, daß es nicht nur der exponierten Stellung, sondern auch der außeramtlichen, zugunsten der nationalen Sache geleisteten Arbeit entsprach. ${ }^{23}$ Der Staat war jedoch offensichtlich kaum bereit, seine Angestellten für etwas zu bezahlen, was nicht zu ihren Dienstpflichten gehörte. Als sich die damals oppositionelle sozialistische Partei im Jahre 1929 dieser mittlerweile traditionellen Forderung annahm und im Parlament verlangte, den tschechischen Staatsangestellten einen „Minderheitenzuschuß“ zu gewähren, der ihnen angeblich nach dem Umsturz zugesagt worden war $^{24}$, antwortete die Regierung kurz und entschieden: Ein Zuschuß für Angestellte einer bestimmten Nationalität stünde im Widerspruch zum „Geist der Verfassung“. ${ }^{25}$ Dieser Ausgang bestä-

Verwaltungsleiter und Professorenkollegien der tschechischen Mittelschulen im national gemischten Gebiet, 4. 1. 1922.

19 Vgl. SÚA, ÚMŠ-SNJM, Karton 740, Bericht für die Generalversammlung des SNJM am 22. 6. 1926. So war beispielsweise die Bemühung des SNJM im Jahre 1925, daß Aufsätze über die Bedeutung der Schutzvereine in Schullesebücher aufgenommen wurden, "von keinem Erfolg gekrönt“.

20 SÚA, PMR, Karton 462, 1063, Bericht über die Sitzung des Tschechoslowakischen Nationalrates am 21. 9. 1922. Vgl. auch Jirmus, in: Hraničár vom 15. 3. 1930.

${ }^{21}$ NM 3 (1923), S. 118.

22 NM 2 (1922) S. 125; Resolution der Generaltagung der tschechischen Minderheiten in Prag am 1.-2. 4. 1922, in: ebda., S. 151.

23 Entschließung der Arbeitstagung der tschechischen Minderheiten in Braunau am 17. 8. 1924, in: NM 4 (1924), S. 175.

24 Interpellation der Abgeordneten Bergman, Zemínová, Špatný und Genossen an die Regierung betreffend die kritische Situation tschechischer Staatsangestellten an den national gemischten Orten vom 6. 6. 1929, in: TTZPS, 2. WP, Drucksache 2313/VII. Die Interpellenten handelten aufgrund eines Briefes des Schutzvereines für Nordböhmen vom 24. 5. 1929, dessen Wortlaut in der Interpellation auch wiedergegeben wird.

${ }_{25}$ SÚA, MŽ, Karton 9, 1625/29, Aktenvermerk MŽ, 24. 7. 1929. 
tigte das bereits Mitte der zwanziger Jahre formulierte Urteil der Schutzverbände, der tschechische Staatsangestellte im Grenzgebiet werde "gesellschaftlich, kulturell, psychologisch sowie existentiell“ geopfert $^{26}$, wodurch sein Selbstbewußtsein und seine Autorität verringert würden. ${ }^{27}$

Waren tschechischerseits die Versetzungen von Staatsangestellten an andere, im andersnationalen Sprachgebiet gelegene Dienstorte kein einfach zu bewältigendes Problem, war ihre nationalpolitische Brisanz deutscherseits womöglich noch größer, denn es drohte noch die Gefahr der Entnationalisierung bzw. Assimilierung von deutschen ins tschechischen Binnenland versetzten Beamten oder zumindest deren Kindern, die wohl nicht selten tschechische Schulen besuchen mußten, da es dort manchmal keine deutsche gab. Die Staatsangestelltenversetzungen waren jedoch eben einer der Prozesse, in denen sich, voneinander kaum genau differenzierbar, sowohl dienstliche Bedürfnisse als auch sprachliche und nationalpolitische Momente im weiteren Sinne des Wortes überlagerten. Deswegen ist eine eindeutige Entscheidung sehr schwierig zu treffen, inwieweit die für die Deutschen zweifellos negativen nationalpolitischen Auswirkungen der Versetzungen nur ein - von der tschechischen Seite her gesehen - erwünschter Nebeneffekt eines ganz normalen dienstlichen Vorganges waren, oder inwieweit die allgemeingültigen Dienstregeln im nationalpolitischen Interesse schlicht mißbraucht wurden. Die formelle Begründung von Versetzungen war sehr breit und schloß vor allem in den ersten Jahren der Republik neben den üblichen dienstlichen auch spezifische Gründe ein, zu denen u. a. die Gewährleistung der notwendigen Kommunikation in der Staatssprache sowohl mit der Bevölkerung als auch mit den vorgesetzten Behörden, die Aneignung von entsprechenden Sprachkenntnissen sowie die staatliche Loyalität gehörten.

Wie die Hintergründe ist auch der zahlenmäßige Umfang der Versetzungen unklar. Sie waren besonders in den ersten Jahren nach der Entstehung der Republik der Regelfall, wenn auch offensichtlich nicht immer ausschließlich aus nationalpolitischen bzw. sprachlichen Gründen. Die Entsendung eines Teiles vor allem der tschechischen Beamtenschaft in die Slowakei sowie die Herausbildung einer den neuen Gebietsverhältnissen entsprechenden Verwaltungsstruktur vor allem im Verkehrs- und Postwesen machte Versetzungen objektiv notwendig. Offensichtlich wurden sie jedoch auch dann fortgesetzt, als sich die Verhältnisse bereits stabilisiert hatten, und zwar in einem Umfang, der für die Zeitgenossen auffallend war. ${ }^{28}$ Die sudetendeutsche Politik war nicht grundsätzlich gegen die Versetzungen. Sogar die Nationalsozialisten erklärten sich 1931 bereit, „einem zeitweiligen Austausch der Beamten zu sprachlichen Zwecken zu-

${ }^{26}$ NM 4 (1924), S. 213. „Der tschechische Beamte muß auf erbitterten Kampf, gesellschaftlichen Boykott, wirtschaftliche und Ernährungsprobleme, Einsamkeit in seinem Amt, auf eine Unlust, die dem Staat gegenüber geradezu zur Schau gestellt wird, ja in feindliche Taten gipfelt, vorbereitet sein ..." Vgl, AKPR, D 516/B, Karton 40, Präsidium der Landesfinanzdirektion an MF-P, 31.8. 1920 bzw. SÚA, PMR, Karton 626, 1766/S, Memorandum der Direktoren, Verwaltungsleiter und Professorenkollegien der tschechischen Mittelschulen im national gemischten Gebiet, 4. 1. 1922.

27 SÚA, PMR, Karton 462, 1063, Bericht über die Sitzung des Tschechoslowakischen Nationalrates am 21. 9.1922.

${ }^{28}$ So berichtete beispielsweise die Prager deutsche Gesandtschaft im Jahre 1923, daß "wohl“ aus nationalpolitischen Beweggründen Richter, Offiziere, Steuer- und Zollbeamte andauernd zwischen den verschiedenen Sprachgebieten ausgetauscht würden. Vgl. BA-P, 15.01, 5819, Deutsche Gesandtschaft an AA, 17. 12. 1923. Vgl. auch Dringende Interpellation des Abgeordneten Křǐž und Genossen an den Eisenbahnminister betreffend Versetzung der Eisenbahnangestellten aus nationalen Gründen vom 28. 11. 1923, in: TTZPS, 1. WP, Drucksache 4329. 
zustimmen“, falls gewisse "nationale Sicherungen“ gewährleistet würden. ${ }^{29} \mathrm{Zu}$ diesen gehörte u. a., daß im tschechischen Sprachgebiet eingesetzte deutsche Beamte, welche die Sprachprüfung erfolgreich ablegten, ins deutsche Gebiet zurückversetzt werden sollten; der Vorgang durfte mit keiner Schädigung des betreffenden Beamten verbunden sein, und alle anfallenden Kosten hatte der Staat zu tragen..$^{30}$

Über die Auswirkungen der Staatsangestelltenpolitik auf die nationale Zusammensetzung der Bevölkerung der Grenzgebiete hatte die sudetendeutsche Gesellschaft ziemlich dramatische Vorstellungen. Selbst die deutschen Regierungsparteien vertraten Ende der zwanziger Jahre die Ansicht, die deutschen Siedlungsgebiete seien mit tschechischen Beamten "überschwemmt" worden. ${ }^{31}$ Dieses Bild findet jedoch in der Statistik kaum Halt. Um die Wende von den zwanziger zu den dreißiger Jahren waren in den mehrheitlich deutsch besiedelten Gerichtsbezirken ca. 154000 Personen vom staatlichen Sektor abhängig, von ihnen bekannten sich fast 70000 zur tschechischen und 84000 zur deutschen Nationalität. Außerhalb des deutschen Sprachgebietes lebten 26000 von diesem Sektor abhängige Personen deutscher Volkszugehörigkeit. ${ }^{32} \mathrm{Da}$ diese Zahlen nicht nur Staatsangestellte, sondern auch deren Familienangehörige einschließen, lassen sich daraus selbstverständlich keine weitreichenden Schlüsse ziehen; zumindest deuten sie an, daß die Deutschen im deutschen Sprachgebiet mehr als die Hälfte der dort dienenden Staatsangestellten ausmachten, und daß etwa ein Viertel aller deutschen Staatsangestellten in mehrheitlich tschechischen Bezirken eingesetzt war. ${ }^{33}$ Das Urteil der Sudetendeutschen über die „Überschwemmung“ der deutschsprachigen Gebiete mit tschechischen Staatsangestellten entsprang offensichtlich der Erfahrung mit der Entwicklung in den großen Städten der Grenzgebiete. Hier, vor allem an wichtigen Verkehrsknotenpunkten bzw. in administrativen Zentren, wuchs die Zahl tschechischer Staatsangestellter in den zwanziger Jahren auf das zwei- bis dreifache an, während die Zahl der deutschen etwa auf die Hälfte sank. ${ }^{34}$ Der Zustrom tschechischer Staatsangestellter - wie übrigens die gesamte tschechische Zuwanderung überhaupt konnte die nationale Zusammensetzung des geschlossenen deutschen Sprachgebietes jedoch erst in einer langfristigen Perspektive beeinflussen, jedoch offensichtlich nicht grundsätzlich ändern: Selbst nach Angaben deutscher Propagandaschriften lebten in den mehrheitlich deutschen Gemeinden im Jahre 1910142442 (ca. 4,5 Prozent der Gesamtbevölkerung), im Jahre 1921256353 Tschechen (ca. 8,8 Prozent) und im Jahre

29 Simm, Fragen, S. 15-16.

30 Bereits in den zwanziger Jahren verlangten die deutschen Staatsangestellten, daß bei Zuweisungen an einen anderen Dienstort zwecks Erlernung der Staatssprache entsprechende Geldentschädigungen gewährt werden sollten. Vgl. Sudetendeutsche Zeitung vom 25. 3. 1924.

31 SÚA, PMR, Karton 267, Memorandum der im „Deutschen Verband“ zusammengeschlossenen deutschen Parteien, 20. 12. 1928.

32 Boháč, Čeští zaměstnanci, S. 291. Die Zahlen betreffen lediglich die Bereiche „öffentliche Verwaltung", "Postwesen“ und "Eisenbahn“, schließen jedoch auch die Angestellten nichtstaatlicher Verkehrsbetriebe und der Selbstverwaltungskörper ein, die jedoch nur ein Bruchteil (weniger als 1/16) der genannten Bereiche ausmachten. Vgl. Ebda, S. 290.

33 Die Angabe wird außerdem dadurch relativiert, daß nicht alle Staatsangestellten, die an einen anderen Dienstort versetzt wurden, gleichzeitig auch ihren ständigen Wohnort wechselten. Bei der Volkszählung 1930 wurde jedoch bloß die Wohnbevölkerung ermittelt.

3+ ANM, NL Boháč, Karton 10, unveröffentlichtes Manuskript „Nationales Gebiet", S. 66-67, 75-76, 84-85, 101-102, 112, 119-120, 146-147, 154-155. Boháčs Untersuchungen betrafen vor allem die demographische Entwicklung in Nord- und Nordwestböhmen (Bezirke Tannwald, Gablonz, Saaz, Komotau, Brüx, Dux, Teplitz und Aussig). Vgl. auch Havránek, Češi, S. 248-249. 
1930333533 (ca. 11 Prozent) - das relative sowie absolute Wachstum nach der sprunghaften Entwicklung der ersten Nachkriegsjahre ist klar sichtbar. Auf Zuwanderung entfiel in den Jahren 1921-1930 angeblich der Zuwachs von 60000 Personen. ${ }^{35}$ Freilich kann man diesen Zahlen eine gewisse nationalpolitische Bedeutung nicht absprechen: Mancherorts entstanden ganz neue tschechische Sprachinseln, die Tschechen tauchten in Kommunalorganen auf und machten hier ihre Sprachenrechte geltend; manche Gemeinden waren nun gezwungen, die Straßen auch tschechisch zu bezeichnen. ${ }^{36}$ Vor allem dort, wo bis dahin gar keine Tschechen gelebt hatten, und die deutsche Bevölkerung keine unmittelbaren alltäglichen Erfahrungen mit dem tschechischen Bevölkerungsteil sowie mit dem multiethnischen Zusammenleben hatte machen können, mochte diese Entwicklung übertriebene Angstgefühle und den ihnen meistens entspringenden nationalen Radikalismus mit sich bringen.

Die tschechoslowakische Verfassung von 1920 erklärte im Einklang mit dem Minderheitenschutzvertrag von St. Germain den Grundsatz, daß die Sprachzugehörigkeit der Staatsbürger kein Hindernis für den Zugang zu „öffentlichen Diensten, Ämtern und Würden" darstelle; auch in diesem Fall wurde dieser Grundsatz durch den berüchtigten Zusatz „innerhalb der Grenzen der allgemeinen Gesetze" potentiell relativiert. Trotz dieser prinzipiellen individuellen Gleichberechtigung war ein weitreichender Abbauprozeß der Deutschen im Staatsdienst ein Charakteristikum der Staatsangestelltenpolitik der Ersten Republik. In der schrittweisen Herabsetzung der Zahl der deutschen Staatsangestellten, die sich vor allem in der ersten Hälfte der zwanziger Jahre vollzog, griffen jedoch mehrere Prozesse ineinander, die sowohl mit der Entstehung des neuen Staates als auch mit den allgemeinen Entwicklungstendenzen der modernen Verwaltungsapparate in den europäischen Ländern der frühen Zwischenkriegszeit zusammenhingen. Die einzelnen Gebiete des Staates hatten bis dahin unterschiedlichen Rechtsordnungen angehört. Die bestehenden Strukturen der Verwaltungs- und Gerichtsorgane mußten den neuen territorialen Anforderungen sowie der Staatsform angepaßt und instanzenmäßig ergänzt werden. Bald, bereits Anfang der zwanziger Jahre, wurde die Politik in der Staatsangestelltenfrage durch einen anderen Faktor geprägt: Nämlich durch die steigenden Ausgaben der Staatsverwaltung bei sinkender oder zumindest stagnierender Effizienz. Diesbezügliche Probleme waren kein Spezifikum der Tschechoslowakei, und ihre Lösung stand auch in anderen europäischen Ländern an. Die Abbaumaßnahmen der zwanziger Jahre waren nicht ausschließlich gegen die Deutschen gerichtet; ihre Ausschaltung aus dem Staatsdienst vollzog sich nicht planmäßig, etwa nach einer vorgegebenen Richtlinie, sondern war eine spontane, wenn auch von nicht wenigen Tschechen ersehnte Nebenwirkung von Schritten, die, wie oben angedeutet, plausible sachliche Hintergründe hatten. Funktionsfähigkeit, Rentabilität, Loyalität: dies waren Ansprüche, die zu Recht an die Staatsverwaltung gestellt wurden. In unterschiedlicher Intensität sowie mit unterschiedlichen Folgen wurden ihnen jedoch auch nationalpolitische Momente beigemischt. Die Stärkung des tschechischen (slowakischen) Elements im Staatsdienst entsprang nicht nur funktionalen (vor allem sprachlichen) oder sicherheitspolitischen Bedürfnissen, sondern war auch durch die Bemühung motiviert, die „Ungerechtigkeiten“, die das alte Regime den Tschechen 
angetan habe, wiedergutzumachen, und zwar sowohl in personeller als auch in struktureller Hinsicht. So gab es Bereiche, wie beispielsweise der Zolldienst, die ausschließlich eine Domäne der Deutschen waren; beklagt wurde auch der aufzuholende Vorsprung der deutschen Gebiete hinsichtlich der Infrastruktur (Postämter und Telekommunikationslinien) und bestimmter Organe der Staatsmacht (beispielsweise Gerichte). ${ }^{37}$ Auch der Begriff der staatspolitischen Sicherheit entbehrte nicht nationalpolitischer Konnotationen. Das Interesse des Staates, nur solche Beamte zu beschäftigen, die politisch nicht kompromittiert waren und seine republikanische Staatsform sowie seinen territorialen Bestand vorbehaltlos bejahten, war im Prinzip legitim. Problematisch jedoch war, daß der Begriff der staatlichen Loyalität a priori mit der Volksbzw. Sprachzugehörigkeit identifiziert wurde - alles Deutsche galt automatisch als nicht vertrauenswürdig bzw. sogar als antitschechisch und deswegen auch als staatsfeindlich.

So heterogen die Gründe für die Entfernung der Deutschen aus dem Staatsapparat auch waren, die grundlegendste Änderung, die die meisten deutschen Staatsangestellten direkt traf, war die Einführung der tschechischen bzw. slowakischen inneren Amtssprache, die de iure kurz nach dem Umsturz erfolgt war, allerdings erst später tatsächlich auch durchgesetzt werden konnte. Hinter diesem Schritt verbarg sich nicht nur das Bestreben, eine sprachlich einheitliche innere Amtsführung zu gewährleisten, sondern auch der Wunsch, die "nationale Identität" des neuen Staates zum Ausdruck zu bringen. Die Staatsangestelltenfrage liefert somit eines der markantesten Beispiele dafür, inwieweit die Sprache zum direkten Mittel der Verdrängung der Minderheitenvölker aus einem der wichtigen Bereiche des gesellschaftlichen Lebens werden konnte. Manifestierte sich die Ideologie des tschechoslowakischen Nationalstaates, abgesehen von den gesetzlich festgelegten Prärogativen der "tschechoslowakischen“ Staatssprache, vorwiegend auf der Ebene proklamativer Aussagen, so fand sie in der „Überfremdung“, im damaligen Sprachgebrauch "Tschechisierung“, des Staatsapparates ihren konkreten, für jeden Zeitgenossen sichtbaren Ausdruck. Eine Seite der Medaille war, daß die rigorose Forderung nach vollkommener Kenntnis der Staatssprache als Vorwand zur Entfernung mancher deutschen Angestellten aus dem Staatsdienst ausgenutzt werden konnte und auch ausgenutzt wurde. Schwerwiegender jedoch war, daß diese Forderung sowie ihre manchmal - zumindest in den Augen der deutschen Bevölkerung - schikanöse Durchsetzung, gekoppelt mit der Entfremdung der Sudetendeutschen dem Staat gegenüber, den Staatsdienst als Karrieremuster für die Deutschen uninteressant machten. Obwohl genaue Angaben fehlen, läßt sich doch vermuten, die Abnahme der deutschen Staatsangestellten wurde zum Teil auch durch die Tatsache verursacht, daß sich nur wenige deutsche Bewerber meldeten.

Die deutschen Staatsangestellten betrachteten sich wohl in ihrer Mehrheit als staatserhaltendes Element; ihre Volkszugehörigkeit sowie die daraus resultierende „nationale" Loyalität stand mit dieser Gesinnung offensichtlich nicht im Widerspruch. Bestimmend für diese Einstellung, wie dies eine der Petitionen der deutschen Staatsangestellten formulierte, war ihre Bildung, ihr ausgeprägtes Pflichtbewußtsein und der angeborene Sinn für Ordnung, aber auch die Erkenntnis, daß die Erhaltung des Staates und

37 SÚA, MV-SR, Karton 144, 3/72/3, Aufzeichnung einer Beratung über die Regelung der Nationalitätenfrage am 28.7. 1919. 
nicht dessen Zerstörung ihnen „Arbeit und Verdienst" geben könne. ${ }^{38} \mathrm{Zu}$ Recht wiesen sie auf den Umstand hin, daß die meisten von ihnen seit der Enstehung der Republik pflichtbewußt und gewissenhaft ihre Aufgaben erfüllt hatten, was übrigens die Staatsverwaltung, zumindest bei einem Teil der deutschen Staatsangestellten, auch anerkannte. ${ }^{39}$ Symptomatisch war, daß der im Dezember 1920 gegründete Dachverband der deutschen Staatsangestellten-Vereinigunge ${ }^{40}$ relativ bald Kontakte zu den entsprechenden tschechischen Organisationen anknüpfte und seit 1928 ständiges Mitglied der Exekutive der öffentlichen Angestellten war. ${ }^{41}$ Es gelang den deutschen Angestellten zwar nicht, bei ihren tschechischen Kollegen Unterstützung für ihre nationalen Forderungen zu erhalten; die Zusammenarbeit auf sozialem Gebiet funktionierte jedoch seit der Mitte der zwanziger Jahre offensichtlich nicht schlecht - zumindest im Vergleich zu den ersten Nachkriegsjahren, als beispielsweise bei den deutschen Eisenbahnern der Eindruck vorherrschte, der Kampf gegen die anderssprachigen Berufskollegen sei für die tschechischen Eisenbahnergewerkschaften wichtiger als der Kampf für soziale Belange. ${ }^{42}$ Der Verband der deutschen Staatsangestellten-Vereinigungen nahm nachweislich noch im Juni 1938 an der Tätigkeit der „Exekutive“ teil und war somit eine der wenigen sudetendeutschen Interessenorganisationen, die zu dieser Zeit noch Kontakte zu ihren tschechischen Pendants aufrechterhielten. ${ }^{43}$

Deswegen liegt die Vermutung nahe, daß der Staat mit seinem Vorgehen in der Staatsangestelltenfrage wohl nicht wenige Deutsche, die zur Zusammenarbeit über die nationalen Grenzen hinweg bereit waren, enttäuschte und der Republik entfremdete. Gemeinsam mit der Sprachen- gehört auch die Staatsangestelltenfrage somit zu den schwerwiegendsten Versäumnissen der tschechoslowakischen Nationalitätenpolitik. Ihre eventuelle identitätsstiftende Potenz versuchte man nicht auszunutzen; die entgegenkommenden Schritte, die die Regierung Ende der dreißiger Jahre noch in die Wege leitete, kamen zu spät. ${ }^{44}$

\section{Die "tschechoslowakische" Amtssprache und die deutschen Staatsangestellten}

Bereits zur Zeit der Entstehung der Republik im Oktober 1918 stand so gut wie fest, daß die innere Amtssprache des Staates das Tschechische bzw. das Slowakische sein

${ }^{38}$ SÚA, MF-P, Karton 163, c 5244/21, VdDSv an PMR, 26.1. 1921.

39 AKPR, D 516/B, Karton 40, Präsidium der Landesfinanzdirektion an MF, 31. 8. 1920.

${ }^{40} \mathrm{Im}$ VdDSV schlossen sich ursprünglich 13 Beamten-Gewerkschaften aus dem Bereich der politischen Verwaltung, der Justiz, des Finanzwesens und der Post, Lehrerverbände sowie Vereine der Staatsangestellten in Böhmen und in Mähren zusammen. Vgl. SÚA, MF-P, Karton 163, c 5244/21, VdDSV an MF, 20.1. 1921. Die mitgliederstarken Verbände der Post- und Eisenbahnangestellten (im Jahre 1926 zählten sie insgesamt 35874 Mitglieder) waren im Deutschen Gewerkschaftsbund und in der Reichsvereinigung der deutschen Gewerkschaften organisiert. Vgl. DSa 6 (1926), Nr. 4, S. 1-2. Bei seiner Gründung hatte der VdDSV 9944 Mitglieder, ihre Zahl sank, z. T. auch infolge des Austritts der Lehrerorganisationen im Jahre 1922, ständig; im Jahre 1930 wies er 5161 zum 1. 1. 1938 nur noch 4692 Mitglieder auf. Vgl. DSa 11 (1931), Nr. 6, S. 1 bzw. DSa 18 (1938), Nr. 3, S. 6.

41 Die "Exekutive der öffentlichen Angestellten“" war ein Koordinierungsorgan der Gewerkschaftsorganisationen der Staatsangestellten. Im Jahre 1933 waren in der „Exekutive“ 203 Organisationen vertreten, davon 21 deutsche. Vgl. AKPR, D 1300, Karton 230, Mappe: Exekutiva veřejných zaměstnanců, Generaltagung der Exekutive der öffentlichen Angestellten, 14. 5. 1933

42 Der Eisenbahner vom 19. 12. 1924.

${ }^{43}$ Vgl. DSa 18, Nr. 6, 20.6. 1938.

44 Vgl. Kapitel 2.3.5. 
würden. An der grundlegenden Verpflichtung der Staatsangestellten, tschechisch oder slowakisch zu beherrschen, konnte daher die bis zum Herbst 1920 erwogene Zulassung von Minderheitensprachen als "Nebenamtssprachen " auch in der inneren Amtsführung nichts ändern; auch war in diesem Zusammenhang die Tatsache unerheblich, daß das Deutsche aus praktischen Gründen bis Anfang 1920 mancherorts als ausschließliche Vermittlungssprache vor allem im Verkehr mit Behörden in den mehrheitlich deutsch besiedelten Gebieten bzw. mit deutschen Staatsangestellten gebraucht werden konnte. ${ }^{45}$ Bereits Anfang 1919 wurde intern und teilweise auch öffentlich bekanntgegeben, daß es in nicht allzu ferner Zukunft notwendig sein werde, von den Staatsangestellten eine entsprechende sprachliche Qualifikation - die Kenntnis der tschechischen bzw. slowakischen Sprache - zu verlangen, selbst wenn noch nicht ganz klar war, ob sich die Verpflichtung zur Kenntnis des Tschechischen bzw. Slowakischen auf alle Kategorien oder Altersgruppen der Staatsangestellten beziehen würde. ${ }^{46}$ Diese Frage wurde durch das Sprachengesetz nicht eindeutig beantwortet. Wie bereits angedeutet wurde, gab es zwischen Opposition und Koalition in der Frage der Sprachkenntnisse der Staatsangestellten faktisch keine nennenswerten Meinungsverschiedenheiten; die Regierung schien freilich nicht gewillt, die Verpflichtung der Staatsangestellten zur Kenntnis der Staatssprache im Gesetz offen auszusprechen. Für die weitere Entwicklung der Staatsangestelltenfrage war jedoch vor allem folgender Umstand wichtig: Obgleich während der Vorbereitung des Sprachengesetzes sowohl die Nationaldemokraten als auch die Regierungskoalition ${ }^{47}$ Erleichterungen für bestimmte Gruppen der Staatsangestellten je nach der Beschaffenheit ihres Dienstes nicht ausgeschlossen hatten, und selbst die diesbezügliche Bestimmung des Sprachengesetzes dies implizite zugelassen hatte, wurde in der Folgezeit von dieser Möglichkeit nie Gebrauch gemacht.

Der legislative Prozeß im Bereich des Sprachenrechts sollte bekanntlich in seinen Hauptzügen durch die Herausgabe einer bzw. mehrerer Verordnungen zur Durchführung des Sprachengesetzes, das als Rahmengesetz aufgefaßt und konzipiert wurde, abgeschlossen werden. Daß die Verordnung erst nach sechs Jahren erlassen werden konnte, war zweifellos der problematischste Punkt der gesamten Sprachgesetzgebung; dies wirkte sich auf die Behandlung der Angehörigen der Minderheiten gerade im Staats-

45 SÚA, MV-SR, Karton 502, 20/2/5, Protokoll der interministeriellen Beratung am 13.1. 1919. Die deutschsprachigen Angestellten waren berechtigt, bei Eingaben in ihren persönlichen dienstlichen Angelegenheiten ihre Muttersprache zu benutzen; die Erledigung erfolgte zweisprachig. Ebenfalls sollten dienstliche Urkunden (Arbeitsverträge, Anstellungs- und Ernennungsdekrete, Zeugnisse u. a.) mit einer Übersetzung versehen werden. Der Diensteid wurde in der Muttersprache abgelegt, ein Disziplinarverfahren ebenfalls in der Muttersprache geführt. Vgl. SÚA, MV-SR, Karton 502, 20/2/5, Erlaß MŽ, 3. 5. 1919; SÚA, PMR, Karton 3295, 740/6, Erlaß MPaT, undat. (MPaT an PMR, 12. 8. 1919, Anlage).

46 Vgl. Verordnung des Justizministeriums vom 30. Januar 1919 Nr. 56 Slg. über die Besetzung der Stellen bei Gerichten und Staatsanwaltschaften, dergemäß die Bewerber um den Justizdienst der tschechischen (slowakischen) Sprache mächtig sein mußten. Auch die interministerielle Sprachkommission faßte Anfang Februar 1919 einen Beschluß, demgemäß die Staatsbehörden die Interessenten für den Staatsdienst zu informieren hätten, daß diese „zu einem gewissen Zeitpunkt“", um eine definitive Ernennung zu erreichen, einen Nachweis der Kenntnis der tschechischen Sprache würden vorlegen müssen. Vgl. SÚA, MV-SR, Karton 502, 20/2/5, Protokoll der Beratung der interministeriellen Sprachkommission am 3. 2. 1919.

47 Vgl. beispielsweise Rede Hnídeks in der 125. Sitzung der Nationalversammlung am 27.2.1920, in: TZRNS, S. 3684. Vgl. auch Kapitel I.A.4. 
dienst am negativsten aus. Alle Versionen der Durchführungsverordnung aus den Jahren 1920-1926 gingen übereinstimmend vom Grundprinzip aus, daß sowohl die im Dienst stehenden Richter, Beamten, Anwärter, Offiziere der Gendarmerie und Bediensteten als auch die Bewerber um den Staatsdienst innerhalb einer bestimmten Frist die volle Kenntnis der Staatssprache nachweisen mußten ${ }^{48}$ In den einzelnen Fassungen der Verordnung wurden einige konkrete Fragen unterschiedlich geregelt, vor allem die eventuelle Länge der Fristen zum Erlernen der Staatssprache und die zu gewährenden Erleichterungen für bestimmte Kategorien von Staatsangestellten; wie in manchen anderen Punkten wiesen jedoch auch die diesbezüglichen Bestimmungen eine tendenzielle Verschlechterung der Position der Angehörigen der Minderheitensprachen auf.

Die erste Fassung der Verordnung vom Jahre 1920 legte im Falle der Bewerber um den Staatsdienst die Frist für den Nachweis der Kenntnis der Staatssprache auf ein Jahr fest. Der zuständige Minister konnte diese Frist aus gewichtigen Gründen um ein halbes Jahr verlängern. Die bereits angestellten Richter, Beamten, Anwärter und "sonstigen Bediensteten", deren Kenntnis der Staatssprache aufgrund ihrer bisherigen Tätigkeit nicht außer Zweifel stand, mußten innerhalb von zwei Jahren nach dem Inkrafttreten des Sprachengesetzes, also bis zum 6. März 1922, nachweisen, daß sie die Staatssprache in ausreichendem Maße beherrschten, um in ihr selbständig sachlich sowie sprachlich richtig ihr Amt ausüben zu können. Sowohl die Bewerber als auch die bereits im Dienst stehenden Staatsangestellten konnten die Kenntnis der Staatsprache durch ein Zeugnis einer erfolgreich besuchten öffentlichen Unterrichtsanstalt mit "tschechoslowakischer" Sprache oder durch ein Zeugnis belegen, daß der Betreffende eine praktische Prüfung für seinen Dienstbereich ganz oder teilweise in der Staatssprache abgelegt hatte. Sonst mußte man die entsprechende Befähigung entweder bei einer teilweise in der Staatssprache abgelegten praktischen Prüfung oder durch eine Sprachprüfung vor einer zu diesem Zweck speziell bestellten Prüfungskommission nachweisen. Von einer derartigen Prüfung konnten lediglich Angestellte befreit werden, bei denen aus ihrer bisherigen Tätigkeit die volle Kenntnis der Staatssprache zweifellos hervorging ${ }^{49}$, oder diejenigen, die am Tage des Inkrafttretens des Sprachengesetzes, also am 6. März 1920 bereits mindestens zwanzig Dienstjahre aufzuweisen hatten. Der Leiter der vorgesetzten Behörde mußte in diesem Fall jedoch bestätigen, daß diese Angestellten „unbeschadet ihrer Pflichten“ den Dienst weiter ausüben konnten. Um die Erlangung der erforderlichen sprachlichen Befähigung zu erleichtern, sollten bei Gerichten und Behörden Sprachkurse organisiert werden; gegebenenfalls waren die vorgesetzten Organe ermächtigt, die betreffenden Staatsangestellten „auf eine der Ausbildung angemessenen Zeit" in das tschechische oder slowakische Sprachgebiet zu versetzen, um ihnen das Erlernen der entsprechenden Sprache zu ermöglichen. Falls die Kenntnis der Staatssprache in der vorgeschriebenen Frist nicht nachgewiesen wurde, war dies ein Hindernis für Beförderungen oder galt als Grund dafür, eine minder entsprechende oder nicht entsprechende Qualifikation zu bescheinigen; Richter, die sich weigerten, eine Sprachprüfung abzulegen, konnten durch das Disziplinargericht wegen Unfähigkeit zur Amtsausübung in den Ruhestand versetzt werden.

48 SÚA, MV-SR, Karton 506, 20/2/53(1), Entwurf der Regierungsverordnung zur Durchführung des Gesetzes Nr. 122/1920 Slg., undat. (1920), Artikel 54 und 55.

49 Diese Tatsache wurde durch den Leiter der vorgesetzten Dienststelle bestätigt. 
Sinngemäß übernahm auch die Fassung der Durchführungsverordnung vom Jahre 1922 die entscheidenden Bestimmungen ${ }^{50}$, deren Wortlaut mit dem endgültigen vom Jahre 1926 grundsätzlich identisch war. Der Personenkreis, von dem man den Nachweis der Kenntnis der Staatssprache verlangte, wurde erweitert, indem zu jedem „wie (auch) immer gearteten Dienste, sei es ein definitiver, provisorischer, Vorbereitungs-, Aushilfs- oder Vertragsdienst" 51 nur diejenigen Bewerber zugelassen werden sollten, die der Staatssprache mächtig genug waren, um „selbständig und auch in der Sache richtig“ das Amt oder den Dienst auszuüben und mit den Parteien zu verhandeln. Die früher vorgesehene Möglichkeit, die Prüfung in der Staatssprache erst binnen Jahresfrist bzw. bei Zustimmung des zuständigen Ministers innerhalb von achtzehn Monaten abzulegen, ließ man fallen; im Prinzip mußten alle Bewerber den Nachweis ihrer Sprachkenntnis sofort vorlegen. Eine Ausnahme von dieser Regel wurde auf die Ressorts eingeschränkt, in denen Mangel an fachlich gebildeten, sprachlich vollkommen qualifizierten Kräften herrschte und wo durch Einstellung von Bewerbern, die der Staatssprache nicht vollkommen mächtig waren, weder das "Ansehen des Dienstes" noch der Parteienverkehr litt. Die Bewerber mußten sich schriftlich verpflichten, binnen Jahresfrist (bei Zustimmung des zuständigen Ministers innerhalb von achtzehn Monaten) die volle Kenntnis nachzuweisen; bis dahin waren sie lediglich provisorisch eingestellt. Auch in diesem Fall galt als Voraussetzung für die Einstellung, daß die Bewerber teilweise tschechisch oder slowakisch beherrschten. Wichtige Änderungen waren bei den bereits im Dienst stehenden Staatsangestellten zu verzeichnen. Der Nachweis der Kenntnis der Staatssprache war bis zum 5. März 1923 vorzulegen, also nicht innerhalb von zwei, sondern etwa binnen eines Jahres. ${ }^{52}$ Darüber hinaus konnte vom Nachweis lediglich dann abgesehen werden, falls nicht mehr der unmittelbare Vorgesetzte, sondern der zuständige Minister die volle Kenntnis der Staatssprache bestätigte oder die betroffenen Angestellten bis zum 6. März 1920, statt der ursprünglichen zwanzig, fünfundzwanzig Dienstjahre hinter sich hatten und wenigstens teilweise Tschechisch- oder Slowakischkenntnisse aufwiesen. Zu den Sanktionen im Falle einer Verweigerung bzw. dem Nichtablegen der Prüfung kam, statt des früheren allgemeinen Hinweises auf die Dienstordnung vom Jahre 1914, ausdrücklich die Versetzung in den Ruhestand hinzu.

Die nächsten Fassungen der Verordnung sowie die endgültige vom Februar 1926 Nr. 17 Slg. brachten nur noch wenige Änderungen. Die wichtigsten betrafen die bereits in Dienst stehenden Staatsangestellten, die den Nachweis der Kenntnis der Staatssprache bereits innerhalb von sechs Monaten nach Inkrafttreten der Verordnung vorzulegen hatten. Übrigens kam es auch zu einer gewissen Verbesserung: Der zuständige Minister konnte Staatsangestellte von dem Nachweis der Kenntnis der Staatssprache befreien, die am Tage des Inkrafttretens der Verordnung bereits wenigstens 50 Jahre alt waren; auch diese mußten jedoch zumindest teilweise tschechisch oder slowakisch können.

50 SÚA, MV-SR, Karton 506, 20/2/53(2), Entwurf der Regierungsverordnung zur Durchführung des Gesetzes Nr. 122/1920 Slg., undat. (1922).

51 Die Bestimmung bezog sich ,in der Regel“ auch auf Laienrichter und Beisitzer.

52 Die Festlegung der diesbezüglichen Frist bis zum Jahresende 1922 oder spätestens bis zum Februarende 1923 entsprach völlig den Forderungen des Tschechoslowakischen Nationalrates. Vgl. SÚA, PMR, Karton 463, 1063, NRČ an den Ministerpräsidenten, 21. 1. 1922. 
Während die Durchführungsverordnung Gegenstand heftiger parteipolitischer Gefechte war und durch die Ministerien sowie die Regierung jahrelang geisterte, stand der amtliche Alltag vor einer relativ schnell zu lösenden praktischen Frage: Einerseits legte das Sprachengesetz allen Staatsorganen und -betrieben die Verpflichtung auf, die innere sowie äußere Amtsführung auf "tschechoslowakisch" vorzunehmen; lediglich im zweitgenannten Bereich, im Parteienverkehr, war unter gewissen Bedingungen der Gebrauch von Minderheitensprachen zulässig. Andererseits gab es in der Staatsverwaltung sowie in den staatlichen Betrieben genug Personen, die diesem Anspruch aus sprachlichen Gründen nicht gerecht werden konnten. Wie sehr man auch in den politischen Debatten im Parlament behauptete, das Sprachengesetz enthalte die Verpflichtung zur Kenntnis der Staatssprache, bestand, juristisch gesehen, zwischen seinen allgemeinen Formulierungen und den tatsächlichen Möglichkeiten, die der Staatssprache nicht mächtigen Staatsangestellten zum Erlernen des Tschechischen oder Slowakischen zu zwingen oder diese aus sprachlichen Gründen aus dem Dienst zu entfernen, ein großer Unterschied. Die diesbezüglichen Bestimmungen des Sprachengesetzes oder anderer Normen wurden zudem bei weitem nicht übereinstimmend interpretiert, und somit entstand eine Art rechtliches Vakuum, das zunächst durch improvisierte Schritte der einzelnen Ressorts ausgefüllt wurde. ${ }^{53}$ Sobald deutlich wurde, daß die Herausgabe der Durchführungsverordnung immer mehr ins Reich der Wunschträume gehörte, griff die Praxis seinen Bestimmungen ganz einfach vor, was in einem Staat, der sich als Rechtsstaat verstehen wollte, sicher ein merkwürdiger Vorgang war.

Um die Diskrepanz zwischen den Forderungen des Sprachengesetzes und der realen Situation in ihren Apparaten zumindest zu verringern, bot sich der Staatsverwaltung als eine der naheliegendsten Maßnahmen an, die Aufnahme derjenigen Bewerber in den Staatsdienst einzustellen, die der Staatssprache nicht mächtig waren. Einen derartigen Erlaß gab beispielsweise das Justizministerium im September 1920 heraus. ${ }^{54}$ Diese angeblich zeitweilige Verfahrensweise wurde mit der kritischen sprachlichen Lage im Ressort begründet: Die Hälfte der deutschen Richter könne gar nicht tschechisch, weitere 25 Prozent nur teilweise. Vom rein sachlichen Standpunkt war die Maßnahme zumindest fraglich, denn zu dieser Zeit fehlten, wie das Ministerium selbst gestand, allein in den böhmischen Ländern beinahe 140 Richter. Der Erlaß ziele darauf ab, meinte der Justizminister der Beamtenregierung Černý, A. Popelka, zweckoptimistisch, den deutschen juristischen Nachwuchs dazu zu bewegen, tschechisch zu lernen, was dieser bis dahin, „zwei Jahre nach dem Umsturz", noch nicht ausreichend in Angriff genommen habe. ${ }^{55}$ Die Regel, daß neue Bewerber um den Staatsdienst der Staatssprache unbedingt mächtig sein mußten, wurde in kurzer Zeit in wahrscheinlich allen Ressorts geltend gemacht ${ }^{56}$, wie im Justizdienst auch hier allerdings des öfteren zum Nachteil der tatsäch-

53 Das Oberste Verwaltungsgericht beschäftigte sich mit dieser Frage erst im Jahre 1931; seine Entscheidung Nr. 12945 vom 21. 11. 1931 ging davon aus, daß bereits das Sprachengesetz selbst den Staatsangestellten die allgemeine Pflicht auferlegt habe, „sich die Staatssprache anzueignen und (diese - J. K.) zu können." Vgl. NáL vom 20.1. 1932.

54 Antwort des Justizministers auf die Interpellation der Senatoren Heller, Niessner und Genossen betreffend die Aufnahme der Rechtspraktikanten deutscher Nationalität vom 8. 1. 1921, in: T"TZS, 1. WP, Druckssache 375.

55 Ebda.

56 Vgl. beispielsweise: SÚA, PMR, Karton 463, MVP an MPaT, 14. 3. 1923 bzw. SÚA, MV, Karton 125, 3/41/23, MVP an MV, 15. 5. 1923. 
lichen Bedürfnisse: Verschiedentlich gab es nicht ausreichend fachlich qualifizierte tschechische Bewerber, um u. a. die Lücken aufzufüllen, die infolge der Berufung tschechischer Staatsangestellter in die Slowakei oder in die Karpatoukraine entstanden waren. $^{57}$

Die Einstellung der Aufnahme neuer, der Staatssprache nicht mächtiger Arbeitskräfte konnte die augenblicklichen sprachlichen Schwierigkeiten der Staatsverwaltung kaum lösen, und man versuchte deswegen, die deutschen Staatsangestellten zum Erlernen der tschechischen Sprache zu bewegen. Dies geschah zum Teil durch Appelle, zum Teil durch praktische Hilfe: Bereits seit dem Jahre 1919 wurden verschiedene, in einigen Ressorts sogar kostenlose Sprachkurse organisiert. ${ }^{58}$ Der Erfolg blieb offensichtlich beschränkt, und im Staatsapparat gab es weiterhin nicht wenige deutsche Beamte und Angestellte, die die Staatssprache nur teilweise, manchmal gar nicht beherrschten. Nicht selten wurde nur deutsch amtiert bzw. verschiedenartig improvisiert; beispielsweise wurden bei einigen Gerichten in den böhmischen Ländern die tschechischen Parteien zwar in ihrer Muttersprache verhört, die Aussagen wurden jedoch deutsch protokolliert usw..$^{59}$ Es waren jedoch nicht nur praktische Probleme, die den Ministerialbürokraten Kopfschmerzen bereiteten, sondern die bisweilen zügellose Kritik seitens tschechischer nationalistischer Kreise. Diese starteten bereits im Spätsommer 1920 eine gewaltige Kampagne, die einige Jahre intensiv andauerte. Eine der wichtigsten Zielscheiben der Kritik war eben die Staatsangestelltenfrage. Permanent wurden Klagen über die „ungenügende Berücksichtigung" der Staatssprache durch die Staatsorgane in den Grenzgebieten sowie über das Verbleiben vieler deutscher, der Staatssprache mangelhaft mächtiger Beamter in ihren Ämtern, manchmal sogar in leitenden Positionen, laut. ${ }^{60}$ In der Staatsverwaltung war man sich nicht darüber im klaren, wie man weiter verfahren sollte. Das Justizministerium meinte beispielsweise, radikale Eingriffe gegen die Angestellten wegen der Unkenntnis der Dienstsprache müßten bis zur Her-

57 Vgl. AKPR, D 9254, Karton 8, Mappe C, MS an KPR, 17. 4. 1920; AKPR, D 516/b, Karton 40, MŽ an KPR, 14. 9. 1920. Das Eisenbahnministerium führte an, daß 7000 ausgebildete Eisenbahner in die östlichen Teile der Republik entsandt werden mußten. Vgl. auch ebda, MPaT an KPR, 21. 10. 1920.

58 SÚA, MV-SR, Karton 125, 3/41/24, Runderlaß des MPaT, Kostenlose Kurse in der tschechischen Sprache für Postangestellte deutscher Nationalität, undat. (August 1919). Der Kurs (3 Stunden wöchentlich) dauerte insgesamt 5 Monate, die Postverwaltung kam auch für Fahrt- und andere, beispielsweise Heizkosten auf. Vgl. auch SÚA, PMR, Karton 463, Runderlaß des MŽ, Instruktionen für die Kurse in der Dienstsprache, die im Jahre 1923-1924 für Eisenbahnangestellte organisiert werden, 27. 1. 1923. Die Absolventen bezahlten Schulgeld, die Eisenbahnverwaltung trug lediglich die Fahrt- und teilweise auch die Nebenkosten. Der Kurs dauerte 150-200 Unterrichtsstunden. Am Kurs konnten auch Angestellte der Privatbahnen teilnehmen. Vgl. auch SÚA, MV-SR, Karton 152, 5/2/104, Politische Landesverwaltung Prag an MV, 1. 11. 1924.

59 AKPR, D 9254, Karton 8, Mappe C, MS an KPR, 17.4. 1920. - Unter der Überschrift „Das Sprachengesetz wird bei unseren Gerichten nicht durchgeführt" thematisierte die NáP vom "26. 2. 1921 diese Frage. Für den Zustand wurde hier die Justizverwaltung verantwortlich gemacht, weil sie noch vor kurzer Zeit gestattet habe, daß deutsche Bewerber die richterlichen Prüfungen ausschließlich deutsch hätten ablegen können.

60 Vgl. beispielsweise SÚA, MV-SR, Karton 511, 20/2/177, Denkschrift des SNJM bezüglich einer Verbesserung der Verhältnisse an national gemischten Orten, 14. 9. 1920, siehe SNJM an PMR, 20. 9. 1920, Anlage; SÚA, MS, Karton 377, Mappe 20, Resolution NJS, 31. 7. 1921. Der Verband verlangte u. a., alle der Staatssprache nicht mächtigen Staatsbeamten abzuberufen; SÚA, MVP, Karton 5, IIIe/ 1921, Denkschrift der tschechischen politischen Parteien und Selbstverwaltungskörperschaften in Raudnitz, 7. 8. 1921; SÚA, NRČ, Karton 413, Mappe 2, Resolution der zweiten Tagung des tschechischen Volkes Nordböhmens in Schönberg am 12.11. 1922. 
ausgabe der Durchführungsverordnung unterbleiben ${ }^{61}$; dagegen veranstaltete das Finanzministerium besonders in den Reihen der Finanzwache ohne Rücksicht auf die juristischen Bedenken beinahe eine "Säuberungswelle“ ${ }^{62} \mathrm{Ob}$ absichtlich, ob aus politischer Ohnmacht - die Beamtenregierung sowie das darauffolgende Kabinett von Beněs waren in ihrer Amtszeit in den Jahren 1920-1922 in der Sprachenfrage angesichts der politischen Kräfteverhältnisse besonders unbeweglich - gelang es nicht einmal der politischen Spitze, eine autoritative Position zu beziehen: Man lehnte den Standpunkt der Vertreter der deutschen Staatsangestellten nicht direkt ab, demgemäß bis zur Herausgabe der Durchführungsverordnung derart einschneidende Verfügungen wie Entlassung bzw. Pensionierung, Disqualifikation oder Versetzung vollkommen gesetzwidrig waren; gleichzeitig unternahm man jedoch nichts, was die Zustände zumindest ansatzweise geändert hätte. ${ }^{63}$

Auch in der darauffolgenden Zeit unter Ministerpräsident Švehla konnte sich die „allnationale" Koalition nicht auf eine legislative Regelung der Staatsangestelltenfrage einigen, geschweige denn auf eine Lösung, die zumindest in einiger Hinsicht den deutschen Vorstellungen Rechnung getragen hätte. Die faktische Entwicklung wartete jedoch nicht auf die politischen Entscheidungen, und besonders in den Jahren 1922/1923 begannen die vormals eher improvisierten Maßnahmen der einzelnen Ressorts, die auf die Durchsetzung von Tschechisch- bzw. Slowakischkenntnissen bei allen Staatsangestellten abzielten, in eine systematische Praxis der gesamten Staatsverwaltung überzugehen; zunehmend zeichnete sich die Tendenz ab, die Kenntnis der Staatssprache für einen untrennbaren Bestandteil der fachlichen Qualifikation zu halten; ihre Unkenntnis begann man als ausreichenden Grund für die Versetzung in den Ruhestand zu erachten. ${ }^{64}$ Forciert wurden die diesbezügliche Schritte durch die andauernden sprachlichen Schwierigkeiten im Staatsdienst, aber auch durch den Eindruck der tschechischen Seite, das Interesse der deutschen Staatsangestellten, die Dienstsprache zu lernen, lasse kontinuierlich nach ${ }^{65}$ Zunächst mahnte man die Deutschen, es liege in ihrem eigenen Interesse, die Staatssprache rechtzeitig zu erlernen, weil sie nach Herausgabe einer Durchführungsverordnung zum Sprachengesetz, spätestens jedoch nach Ablauf der in diesem Gesetz genannten Fristen, also nach fünf Jahren, „im Falle der Unkenntnis der Staatssprache in eine Situation geraten würden, die für sie laut Dienstpragmatik unangenehme Folgen dienstlichen und eventuell auch finanziellen Charakters hätte. "66 Später ging man in einzelnen Bereichen dazu über, feste Fristen (beispielsweise sechs Monate) zum Erlernen der Staatssprache festzusetzen. Eventuelle, offensichtlich jedoch vereinzelte Einwände gegen diesen sich einfahrenden Vorgang wandten sich nicht gegen das Vorgehen selbst, sondern entsprangen Befürchtungen vor einer Lähmung des Staatsapparates. Beispielsweise war Präsident Masaryk noch im Jahre 1922 angeblich der Meinung, man könne deutsche Beamte und Richter durch Vorschriften nicht dazu anhalten, tsche-

61 AKPR, D 9254, Karton 8, Mappe C, MS an KPR, 17. 4. 1920.

$62 \mathrm{Vgl}$. SÚA, MF-P, Karton 163, c 5244/21, VdDSa an MF, 26. 5. 1921.

63 SUA, MF-P, Karton 163, c 5244/21, Entschließung der Gründungskonferenz des VdDSV am 19. 12. 1920 bzw. ebda., VdDSa an MF, 26. 5. 1921. Vgl. auch DSa 1 (1921), Nr. 7, S. 2.

64 SÚA, PMR, Karton 463, MZV an MPaT, 10. 3. 1923; ebda, MVP an MPaT, 14. 3. 1923.

65 SÚA, PMR, Karton 463, MZV an MPaT, 10. 3. 1923; ebda, MVP an MPaT, 14. 3. 1923.

66 SÚA, MV-SR, Karton 510, 20/2/138, MPaT an MV, 23. 2. 1922. - DSa 2 (1922), Nr. 7, S. 5. Diejenigen Angestellten, die der Erlaß betraf, mußten schriftlich bestätigen, die Verlautbarung zur Kenntnis genommen zu haben. 
chisch zu lernen, denn bei Nichtbefolgung müßten entsprechende Schlußfolgerungen gezogen werden, die zur Zersetzung der Staatsverwaltung führen würden. ${ }^{67}$

Seine mahnende Stimme verhallte jedoch ungehört: Im Februar 1923 gab das Eisenbahnministerium - wahrscheinlich als erstes Ressort überhaupt - einen Erlaß heraus, in dem Sprachprüfungen angeordnet sowie deren Rahmenbedingungen festgelegt wurden. ${ }^{68}$ Über Verlauf sowie Ergebnisse dieser Prüfungen sind wir nicht informiert; die deutsche Presse berichtete, es seien allein im Jahre 19245000 deutsche Beamte und Bedienstete dabei durchgefallen; welche Folgen sich jedoch aus dieser Tatsache ergaben, wissen wir nicht. ${ }^{69}$ Im Oktober 1924 zogen die sprachlichen Zustände im Bereich des Eisenbahnministeriums die allgemeine Aufmerksamkeit auf sich, als nach einem $\mathrm{Zu}$ sammenprall zweier Züge in Böhmisch Leipa der verantwortliche Weichensteller sein Versehen dadurch erklärte, seine Sinne seien wegen der bevorstehenden Sprachprüfung total verwirrt gewesen. Die „Falken“ auf beiden Seiten zogen aus dem Ereignis ziemlich unterschiedliche Schlüsse: Die einen erblickten darin einen Beweis dafür, wie im Interesse der Befriedigung des tschechischen Chauvinismus „ein gewissenloses Spiel mit Menschenleben“ getrieben werde. Die anderen fühlten sich in ihrer Ansicht bestätigt, es sei das Gebot der Stunde, daß die deutschen Staatsangestellten endlich die Staatssprache ordentlich beherrschten. ${ }^{70}$

Im Dezember 1924 beschloß das Parlament das seinerzeit vieldiskutierte Gesetz Nr. 286 Slg., durch das ein umfangreicher Angestelltenabbau im Staatsdienst in die Wege geleitet wurde. Seine Intention, die Gesamtzahl der Staatsangestellten innerhalb des Jahres 1925 um mindestens zehn Prozent zu verringern, entsprang den vergeblichen Bemühungen, Effizienz und Kosten der Staatsverwaltung in Einklang zu bringen, die sich bereits seit Anfang der zwanziger Jahre bemerkbar machten. ${ }^{71}$ Die bisherige Praxis der verantwortlichen Stellen in der Staatsangestelltenfrage mußte in deutschen politischen Kreisen von Anfang an den begründeten Verdacht aufkommen lassen, daß "dieses Gesetz eine Handhabe zu einer weitgehenden Verminderung der deutschstämmigen Beamtenschaft bieten" würde. ${ }^{72}$ Vor allem das Vorgehen des Eisenbahnministeriums, in dessen Bereich bereits im Jahre 1924 angeblich viele deutsche Staatsangestellte von der Beförderung ausgeschlossen worden seien, weil sie bei den Sprachprüfungen mit "ungenügend" bewertet worden waren, bewog die deutschen Sozialdemokraten, den Antrag auf ein Gesetz vorzulegen, nach dem die sprachliche Befähigung kein Merkmal der allgemeinen dienstlichen Qualifikation der Staatsangestellten bilden und deswegen auf deren Beförderung keinen Einfluß haben sollte. ${ }^{73}$ Der Antrag wurde, wie übrigens kaum anders zu erwarten war, abgelehnt.

67 SÚA, PMR, Karton 462, 1063, Bericht über die Sitzung des NRČ am 21. 9. 1922.

68 Erlaß MŽ Nr. 1742/I-4 vom 27. 1. 1923, in: Úřední věstník MŽ 5 (1923), S. 67-69. Die Frist zur Ablegung der Sprachprüfung wurde bis zum 31. 5. 1924 festgesetzt.

${ }^{69}$ Bo vom 16. 10. 1924.

70 NáP vom 12. 10. 1924.

71 Durch das Gesetz Nr. 301/1921 Slg. wurde eine parlamentarische Sparkommission errichtet, deren Aufgabe darin bestand, „allseitige und zweckmäßige Sparsamkeit in Staatsverwaltung und Staatswirtschaft“" zu erreichen, vgl. Runderlaß des MV Nr. 26674-pres. vom 15. 10. 1921, in: Véstník MV 3 (1921), S. 373.

72 PA R 74070, Gesandtschaft Prag an AA, 27. 12. 1924. Vgl. auch AdV, R 1624, 41/44572/1296, Medinger an den Generalsekretär des Völkerbundes, 6. 6. 1925.

73 Antrag der Abgeordneten Grünzer, Taub, Haas, Hoffmann und Genossen auf Erlassung eines Gesetzes über den Einfluß der sprachlichen Befähigung auf die allgemeine dienstliche Qualifikation 
Das Abbaugesetz war nicht ausschließlich nationalpolitisch angelegt, trotzdem traf seine Durchführung in erheblich stärkerem Maße die Deutschen als die Angehörigen des Staatsvolkes. Ausschlaggebend für die Entscheidung darüber, wer aus dem Dienst ausscheiden sollte, war zwar laut Gesetz Nr. 286/1924 Slg. „die dienstliche Eignung, die Leistungsfähigkeit, die Verwendbarkeit, die wirtschaftlichen und die Familienverhältnisse und andere triftige Umstände“. Keineswegs, so die Darstellung des Postministeriums, sei die Volkszugehörigkeit der Angestellten der Beweggrund für die Versetzung in den Ruhestand gewesen. ${ }^{74}$ Dieser an und für sich sicher richtige Grundsatz wurde jedoch in Frage gestellt, indem das Ministerium daran festhielt, daß die Unkenntnis der Staatssprache „eine beträchtliche Einschränkung der dienstlichen Eignung, Leistungsfähigkeit und Verwendbarkeit" bedeute und deswegen im Sinne des Paragraphen 14 des „Abbaugesetzes“ ein ausreichender Grund für die Pensionierung sei. Eine tendenziell stärkere Auswirkung der Abbaumaßnahmen auf diejenigen Staatsangestellten, deren Muttersprache nicht tschechisch oder slowakisch war, war damit so gut wie programmiert.

Leider - vielleicht auch wohlweislich - legten die einzelnen Ministerien keine nach Nationalitäten aufgeschlüsselten Aufstellungen über die aus sprachlichen Gründen entlassenen Angestellten vor, so daß ein endgültiges Urteil über die Rolle der Sprachkenntnisse im Abbauprozeß immer noch ausbleiben muß. Nur der Bericht des Postministeriums gewährt einen Einblick; demgemäß schieden 3818 Angestellte aus, davon 2181 zwangsweise. Unter den Zweitgenannten befanden sich 1138 Deutsche, von denen 386, also etwa ein Drittel, ausschließlich wegen der Unkenntnis der Staatssprache pensioniert worden seien. Dagegen sei der größte Teil derjenigen Angestellten deutscher Nationalität im Dienst belassen worden, die zwar die Staatssprache nicht beherrschten, jedoch zumindest eine gewisse Mühe gezeigt hätten, sie zu erlernen. ${ }^{75}$

Im Kontext der Entwicklung der Staatsangestelltenfrage ist vor allem ein Umstand von Bedeutung: Auf den Grundsatz, die Kenntnis der Staatssprache bedinge die dienstliche Qualifikation, einigten sich die meisten Ministerien. Dieser war also bereits ein Jahr vor der Herausgabe der Durchführungsverordnung zum Sprachengesetz durch die Staatsverwaltung allgemein akzeptiert und mit entsprechenden rechtlichen Folgen auch praktisch angewandt worden. Die Tatsache, daß die Verordnung bis dahin nicht erlassen worden war, stand, so das Postministerium ausdrücklich, diesem Verfahren nicht im Wege. ${ }^{76}$ Durch ihre Herausgabe Anfang Februar 1926 wurde die inzwischen

der Staatsbediensteten vom 12. 2. 1925, in: TTZPS, 1. WP, Drucksache 5053. Das Gesetz sollte rückwirkend vom 1.1.1923 an wirksam sein.

74 SÚA, PMR, Karton 521, 1292/S, MPaT an MZV, 15.1. 1926. Neben der Qualifikation wurden bei den für den Abbau in Frage kommenden Angestellten auch andere Aspekte in Erwägung gezogen: Alter, gesundheitlicher Zustand, dienstliche Disziplin sowie die soziale Lage ihrer Familien.

75 SÚA, PMR, Karton 521, 1292/S, MPaT an MZV, 15. 1. 1926.

${ }^{76}$ Ebda. Durch einen Erlaß vom April 1925 ordnete das Postministerium an, daß alle Postangestellten bis zum 31. Oktober 1925 den Nachweis der Kenntnis der Staatssprache vorlegen mußten. Interessanterweise waren seine Bestimmungen nur teilweise mit denen der vorbereiteten Durchführungsverordnung zum Sprachengesetz in der Fassung vom Jahre 1924 identisch. Befreit vom Nachweis waren diejenigen, die eine Schule mit "tschechoslowakischer" Unterrichtssprache besucht, eine Fachprüfung in der Staatssprache oder bereits früher eine Sprachprüfung abgelegt hatten, weiter diejenigen, die durch ihre bisherige Arbeit die vollständige Kenntnis in Schrift und Wort nachgewiesen hatten, und schließlich Angestellte „an subalternen Stellen“, die das 50. Lebensjahr erreicht und sich bemüht hatten, die Staatssprache zu erlernen. Eine Wiederholung der Prüfung war bis 30.4. 1926 möglich. Erlaß MPaT Nr. 34 vom 9. 4. 1925, in: DSa 5 (1925), Nr. 8, S. 2-3. 
etablierte Praxis lediglich sanktioniert; nichtsdestotrotz nahm die Staatsverwaltung die sich bietende Gelegenheit wahr und veranstaltete eine neue Welle von Sprachprüfungen. Über ihren Umfang und Ausgang sind wir leider nicht eingehend informiert; die Klagen der deutschen Staatsangestellten-Vereinigungen deuten an, daß die Durchführung der Prüfungen in einigen Bereichen kaum die "bewährte" nationalpolitische Schiene verließ. Man habe, so ihre Denkschrift an die Regierung vom Jahre 1929, von der Begünstigung, dergemäß ältere Angestellte von der Sprachprüfung befreit werden konnten, recht selten Gebrauch gemacht; mancherorts seien auch Beamte zu Prüfungen eingeladen worden, die entweder bis dahin ihren Dienst in der Staatssprache einwandfrei versehen bzw. sogar Fachprüfungen in ihr abgelegt hatten."

Man kann nicht sagen, daß die Deutschen grundsätzlich abgeneigt waren, die Verpflichtung der Staatsangestellten und besonders der -Beamten zur Kenntnis der Staatssprache zu akzeptieren. ${ }^{78}$ Die von L. Epstein ausgearbeiteten „Grundsätze des Weltminderheitenrechts“ vom Jahre 1923 enthielten zwar im Rahmen des „erhöhten“ Minderheitenschutzes die Forderung, die Sprache der Minderheit im Verkehr der öffentlichen Stellen untereinander zuzulassen und bei Angestellten "gewisser öffentlicher Stellen " von der Kenntnis der offiziellen Sprache abzusehen. ${ }^{79}$ Zumindest die deutschen Aktivisten erkannten es jedoch ,als eine Forderung der Zweckmäßigkeit und Ökonomie der Verwaltung" an, daß sich die Staatsämter und Behörden in ihrem internen Verkehr einer einheitlichen Sprache bedienten. ${ }^{80}$ Ihre Vorschläge in den Anfangsjahren der Republik zielten vor allem darauf ab, daß das Deutsche als innere Amtssprache im Verkehr mit Dienst- und Zweigstellen in Orten mit überwiegend deutscher Mehrheit oder auch in Personalangelegenheiten mit denjenigen Staatsangestellten beibehalten wurde, die der Staatssprache nicht mächtig waren. ${ }^{81} \mathrm{Da}$ sich derartig weitgehende Forderungen als immer aussichtsloser erwiesen, schwenkten die Interessenverbände der deutschen Staatsangestellten auf ein reduziertes Konzept ein, und versuchten, Erleichterungen für zumindest bestimmte Gruppen, je nach dem Alter der Beamten oder der Beschaffenheit des Dienstes zu erwirken. Diesem Konzept lag das verständliche Interesse zugrunde, vor allem die jetzige Generation der deutschen Staatsangestellten zu schützen; die Kenntnis der Staatssprache könne von den Bewerbern um den Staatsdienst verlangt werden und werde von diesen „auch ohne $Z$ wang als unerläßlich für das freie Fortkommen" akzeptiert. ${ }^{82}$ Im Hinblick auf die im Dienst stehenden Staatsangestellten war man zunächst bestrebt, unter Berufung auf die Tatsache, daß bei der Übernahme der deutschen Staatsangestellten aus Österreich-Ungarn „die schwere Bedingung, die

SÚA, PMR, Karton 463, 1063/3, VdDSv an PMR, 1. 11. 1929.

78 Vgl. PA R 74070, Gesandtschaft Prag an AA 18. 1. 1926: „Soweit sie (die Forderung der Kennntnis der Staatssprache - J. K.) an höhere Beamte gestellt wird oder an Beamte oder Angestellte, deren dienstliche Tätigkeit mündliche und schriftliche Äußerungen in der Staatssprache nötig macht, kann sie aus praktischen Gründen als gerechtfertigt erscheinen." - Später formulierte der deutsche nationaldemokratische Abgeordnete O. Horpynka den Standpunkt wie folgt: „Wir Deutsche wissen sehr gut und anerkennen auch, daß deutsche Beamte im tschechischen Staate die Staatssprache beherrschen müssen. “, in: DSa 10 (1930), Nr. 10, S. 1.

79 Epstein, Grundsätze, S. 95.

${ }^{80}$ Deutsche Landpost vom 8. 1. 1929.

81 SÚA, MF-P, Karton 163, c 5244/21, Entschließung der Gründungskonferenz des Verbandes der deutschen Staatsangestellten-Vereinigungen, 19.12. 1920; „Forderungen der deutschen Postler und die Sprachenfrage“, in: DSa 3 (1923), Nr. 13, S. 2.

${ }^{82}$ DSa 3 (1923), Nr. 13, S. 2. 
Kenntnis der tschechischen Sprache," nicht gestellt worden war, die Anwendung des Sprachengesetzes zu verhindern. Man lehnte es ab, eine Parallele mit der Lage der tschechischen Beamten im alten Österreich zu ziehen: Diese hätten gewußt, daß für die Aufnahme in den Staatsdienst die Kenntnis der deutschen Sprache notwendig gewesen war, während das jetzige Sprachengesetz „die Aneignung der tschechischen Sprache von deutschen Beamten bei anstrengendem Dienste in zu kurzer Zeit und im höheren Lebensalter" fordere. ${ }^{83} \mathrm{Da}$ ein "Generalpardon" höchst unwahrscheinlich war, versuchten die deutschen Staatsangestellten wenigstens zu erreichen, daß vom Nachweis der Kenntnis der Staatssprache für bestimmte Alters- bzw. Berufsgruppen (beispielsweise Arbeiter der Staatsbetriebe, Beamte und Bedienstete der staatlichen Schulen mit deutscher Unterrichtssprache) abgesehen wurde oder die Fristen zu ihrem Erlernen verlängert wurden. Als Altersgrenze schlug man ursprünglich 35 Jahre vor, später war man bereit, sich auch mit 40 zufriedenzugeben. ${ }^{84}$ Ähnlich entwickelten sich die Vorstellungen hinsichtlich der Fristen zum Erlernen des Tschechischen: Von ursprünglich zehn Jahren gelangte man zu einer Frist zwischen zwei bis drei Jahren, wobei stets im Auge behalten wurde, daß die sprachlichen Ansprüche den tatsächlichen Erfordernissen des Dienstes entsprachen. ${ }^{85}$ Darüber hinaus vertrat man den Rechtsstandpunkt, daß alle in der Durchführungsverordnung zum Sprachengesetz genannten Fristen "frühestens" vom Tage ihres Inkrafttretens beginnen würden und nicht seit Inkrafttreten des Sprachengesetzes. ${ }^{86}$ Dies zielte selbstverständlich nicht nur auf die de-facto-Verlängerung des gewährten Zeitraums für das Erlernen der Staatssprache ab, sondern auch auf die Aufhebung aller Maßnahmen, die im Hinblick auf die Sprachkenntnisse der Staatsangestellten bis zur Herausgabe der Durchführungsverordnung getroffen worden waren und die, wie bereits erläutert wurde, die deutschen Staatsangestellten-Verbände für gesetzwidrig hielten. Nach 1926 versuchten die deut-

83 Ebda., S. 2.

8435 Jahre schlugen beispielsweise die deutschen Rechtsanwälte im Jahre 1921 oder zwei Jahre später die deutschen Postangestellten vor. Vgl. SÚA, MF-P, Karton 163, c 6784/21, Verband der deutschen Rechtsanwälte in Böhmen an MF, 5. 7. 1921 bzw. DSa 3 (1923), Nr. 13, S. 2. Die höhere Grenze akzeptierten seit 1924 die deutschen Eisenbahner sowie der Verband der deutschen StaatsangestelltenVereinigungen. Vgl. DSa 4 (1924), Nr. 8, S. 5; SÚA, MV-SR, Karton 1487, 14/1/14, Memorandum betreffend die Sprachverordnungen, überreicht von den unterzeichneten Spitzenorganisationen der deutschen Staatsangestellten, undat. (Eingang MV 3. 1. 1925); DSa 6 (1926), Nr. 8, S. 2 bzw. Sudetendeutsche Tageszeitung vom 25. 3. 1924. Nach Meinung der deutschen Lehrer sollte die Festlegung der diesbezüglichen Altersgrenze nicht der "Willkür überlassen werden“, sondern unter Heranziehung der pädagogischen Psychologie erfolgen. Deswegen beabsichtigten sie, ein Gutachten durch eine "neutrale Kapazität“ ausarbeiten zu lassen, dessen zentraler Punkt die Antwort darauf sein sollte, „bis zu welchem Lebensalter ein normal begabtes Individuum eine derart schwere Sprache wie die tschechische überhaupt noch vollständig erlernen" könne. Vgl. DSa 3 (1923), Nr. 18, S. 2. Über den weiteren Verlauf dieser Initiative ist nichts bekannt. Zu deutschen Beamten und Bediensteten im Bereich des Schulwesens vgl. SÚA, PMR, Karton 464, 1063/S, Bd. 2, VdDSv an PMR, 27. 4. 1926.

85 Zur ersteren vgl. SÚA, MF-P, Karton 163, c 6784/21, Verband der deutschen Rechtsanwälte in Böhmen an MF, 5. 7. 1921 bzw. DSa 3 (1923), Nr. 13, S. 2. Dem Memorandum gemäß sollte auch den Bewerbern für den Staatsdienst eine fünfjährige Frist gewährt werden. Der Deutsche Juristentages verlangte für die im Dienst stehenden Staatsangestellten fünf Jahre. Vgl. NáD vom 24. 5. 1921. Für zwei Jahre sprachen sich die deutschen Eisenbahner 1924 bzw. der Verband der deutschen Staatsangestellten-Vereinigungen 1925 aus. Vgl. Sudetendeutsche Zeitung vom 25. 3. 1924 bzw. SÚA, MV-SR, Karton 1487, 14/1/14, Memorandum betreffend die Sprachverordnungen, überreicht von den unterzeichneten Spitzenorganisationen der deutschen Staatsangestellten, undat. (Eingang MV 3. 1. 1925). Man verlangte gleichzeitig, daß die Wiederholung einer nicht bestandenen Sprachprüfung innerhalb eines Jahres möglich sein sollte.

${ }^{86} \mathrm{Vgl}$. beispielsweise Sudetendeutsche Tageszeitung vom 25. 3. 1924 bzw. DSa 4 (1924), Nr. 8, S. 5. 
schen Staatsangestellten, zum Teil mit Unterstützung der deutschen Regierungsparteien, eine Milderung der beruflichen Folgen für diejenigen Angestellten zu erwirken, die nachträglich die Sprachprüfung doch noch bestanden, jedoch ohne Erfolg. ${ }^{87}$

Obwohl das Prinzip, nach dem alle Staatsangestellten der Staatssprache vollkommen mächtig sein mußten, seit 1926 auf einer gesetzlichen Grundlage basierte, entsprach ihm die Realität noch jahrelang nur zum Teil. Im Jahre 1936 meldete das Eisenbahnministerium in seinem Ressort immer noch 1164 Deutsche (beinahe neun Prozent von den insgesamt 12084 bei der Staatseisenbahn angestellten Deutschen), die der Staatssprache nicht mächtig waren. Zum größten Teil ( 90 Prozent) handelte sich um Bedienstete und Hilfsarbeiter; vor allem in der zweitgenannten Kategorie machten sie über 40 Prozent aus. ${ }^{88}$ Bei der Beurteilung dieser Tatsache ist jedoch Vorsicht geboten: Es gibt nämlich keinen Grund anzunehmen, daß dies die Folge einer entgegenkommenden Haltung der Staatsverwaltung war. In den mehrheitlich deutsch besiedelten Bezirken meldeten sich in den genannten Berufskategorien tschechische Bewerber in offensichtlich unzureichender Zahl. Auf jeden Fall ist dies ein Beweis dafür, daß auf bestimmten Posten der Dienst auch ohne Tschechischkenntnisse problemlos ausgeübt werden konnte, und die Forderung nach einer vollkommenen Kenntnis der Staatssprache des öfteren nicht dem faktischen dienstlichen Bedarf angemessen war.

Im Zusammenhang mit der sprachlichen Befähigung der Staatsangestellten und besonders der Staatsbeamten muß eine Besonderheit des tschechoslowakischen Sprachenrechts erwähnt werden: Keine gesetzliche Norm verlangte, daß Staatsbeamte, die den Dienst in Minderheitenbezirken antreten sollten, auch die Sprache der jeweiligen Bevölkerungsmehrheit beherrschen mußten. Zwar behauptete die Staatsverwaltung, darauf „folgerichtig“ zu achten, daß die in derartigen Bezirken dienenden Staatsangestellten entsprechende Sprachkenntnisse hatten oder durch ihre Ausbildung und Fähigkeiten zumindest die Gewähr boten, „die notwendige sprachliche Qualifikation möglichst bald zu erreichen". ${ }^{89}$ Sudetendeutsche Klagen jedoch zeugen eher davon, daß diese Mühe nicht immer von Erfolg gekrönt war. Freilich war die Forderung realitätsfremd, daß die im deutschen Sprachgebiet dienenden Staatsangestellten auch den örtlichen Dialekt beherrschen sollten ${ }^{90}$, zumal sich auch gebürtige Deutsche, soweit sie nicht ortsansässig waren, diese Kenntnis erst nach einem längeren Aufenthalt in dem betreffenden Gebiet aneignen konnten; das Recht der deutschsprachigen Bürger jedoch, eine sprachlich korrekte Erledigung ihrer Eingaben zu erhalten, wurde durch diese unangemessenen Wünsche nicht hinfällig.

Darüber hinaus blieb auch die uneingeschränkte Durchsetzung des Tschechischen bzw. Slowakischen als ausschließlicher innerer Amtssprache besonders im Verkehr zwischen Organen der politischen Bezirksverwaltung und Gemeinden mit deutscher Geschäftssprache bis zu einem gewissen Maße immer eine Illusion. Zum Bedauern der tschechischen nationalistischen Kreise, die die ungenügende Berücksichtigung der

87 Vgl. SÚA, PMR, Karton 463, 1063/3, VdDSv an PMR, 1. 11. 1926 bzw. ebda, 1063/2-3, Justizminister Mayr-Harting an den Ministerpräsidenten, 13. 5. 1929. Vbl. auch DSa 6 (1926), Nr. 8, S. 2.

88 SÚA, PMR, Karton 612, Aufstellung der Eisenbahnangestellten unter Berücksichtigung der Kenntnis der Dienstsprache, Stand zum 30. 9. 1936.

89 SÚA, MV-P, Karton 293, VIJ3, MF an MV, 28. 11. 1931.

90 Interpellation der Senatoren Stöhr, Lippert, Luksch, Kahler und Genossen an die Gesamtregierung betreffs mangelnder Sprachkenntnisse der Staatsbeamten im Bezirke Plan vom 15.7. 1931, in: TTZS, 3. WP, Drucksache 577/V. 
Staatssprache in diesem Bereich ständig beklagten, mußte hier das sprachliche Prestige den praktischen Bedürfnissen des Alltags Platz machen. ${ }^{91}$ Um den Verkehr mit deutschsprachigen Gemeinden nicht lahmzulegen, die - vor allem die kleinen - manchmal kein tschechischsprechendes Mitglied im Gemeinderat oder in der Gemeindevertretung hatten oder in denen überhaupt kein Tscheche lebte bzw. niemand von den Einwohnern tschechisch beherrschte, verfaßte die politische Verwaltung ihre Schriftstücke meistens zweisprachig; die betreffenden Gemeinden wandten sich in ihrer $\mathrm{Ge}$ schäftssprache an die Staatsorgane, zumindest an diejenigen, die verpflichtet waren, Eingaben auch auf deutsch anzunehmen. ${ }^{92}$ An dieser Praxis änderten die Urteile des Obersten Verwaltungsgerichts aus den Jahren 1927 bis 1928 nichts, die das sprachliche Selbstbestimmungsrecht der Gemeinden einschränkten und die Schutzbestimmungen des Sprachengesetzes lediglich auf den Parteienverkehr bezogen. Die Staatsverwaltung paßte sich zwar zunächst der neuen Rechtsprechung grundsätzlich an, wobei Gemeinden, die nicht in der Lage waren, interne Zuschriften in der Staatssprache anzunehmen und zu erledigen, eine Übersetzung auf eigene Kosten (in Deutsch-Gabel verlangte die Bezirksbehörde beispielsweise 20 Heller pro Zeile) anfordern konnten. ${ }^{93}$ Offensichtlich gab es bei dieser Praxis mannigfaltige Probleme: Im Sommer 1930 forderte die Landesbehörde Prag einige Bezirksbehörden (unter ihnen auch die in Deutsch-Gabel), die wahrscheinlich die neue Praxis zu rigoros handhabten, dazu auf, ihren Erlassen auch den Text in der Geschäftssprache der Gemeinde kostenlos beizufügen, falls es sich um Gemeinden handele, „in denen angesichts der Ortsverhältnisse sowie der Beschaffenheit des Erlasses (Briefes) eine einwandfreie Erledigung nicht sichergestellt" sei. ${ }^{94}$ Trotz dieser "unterschwelligen“ Erleichterungen - das Innenministerium sah sich nicht imstande, gegen die konstante Rechtsprechung des Obersten Verwaltungsgerichts in dieser Frage offen vorzugehen ${ }^{95}$ - gehörte der Verkehr zwischen Gemeinden und Staatsbehörden zu den permanenten Problemen der Ersten Republik. In den Jahren 1936 bis 1937 sanktionierte die Regierung, wenn auch nicht in vollem Ausmaß, dieses Vorgehen offiziell ${ }^{96}$; der Entwurf des neuen Sprachengesetzes von 1938 ermöglichte die Korrespondenz sogar grundsätzlich nur in der Geschäftssprache der Gemeinde. ${ }^{97}$ Trotz dieser faktischen Anerkennung der Minderheitensprachen als innerer

91 Vgl. beispielsweise J. Matoušek, in: LN vom 28. 12.1926.

92 AMZV, Sektion II, Karton 255, MS an MVP, 14. 7. 1926; SÚA, MV-SR, Karton 1490, 14/1/70, Aktenvermerk MV, 12. 1. 1928. Justizorgane dagegen korrespondierten mit deutschsprachigen Gemeinden nur in der Staatssprache. Vgl. Deutsche Presse vom 1. 3. 1927. Vgl. auch Regierungsverordnung Nr. 17/1926 Slg., Artikel 78.

93 Interpellation des Abgeordneten Dr. Keibl und Genossen an den Minister des Innern betreffend die unerhörte Sprachenpraxis der politischen Bezirksbehörde in Deutsch-Gabel vom 18. 3. 1930, in: TTZPS, 3. WP, Drucksache 295/XXI. Vgl. auch Interpellation der Abgeordneten Horpynka und Genossen an den Minister des Innern und an den Justizminister wegen des sprachlichen Verkehrs der Gerichte und staatlichen Behörden mit den Gemeindeämtern vom 24. 2. 1930, in: TTZPS, 3. WP, Drucksache 247/XVIII bzw. ZfKv 10 (1930), S. 441-442.

94 SÚA, PMR, Karton 463, 1063/2-3, Landesbehörde Prag an Bezirksbehörde Deutsch-Gabel, 4. 7. 1930. Die Bezirksbehörde war jedoch nicht verpflichtet, Erlässe anderer Behörden kostenlos zu übersetzen. Ein identisches Vorgehen - solange es um wichtigere oder komplizierte Fälle ging oder wenn es das Interesse der Angelegenheit erforderte - wurde auch bei Gemeinden empfohlen, die im Sinne der Sprachverordnung verpflichtet waren, eine der Staatssprache mächtige Amtskraft einzustellen.

95 SÚA, MV-SR, Karton 1558, 14/136/107, Aktenvermerk MV, 7. 11. 1935.

96 Vgl. Kapitel I.D.2.

97 Nach wie vor erstreckte sich jedoch diese Regel nicht auf Gemeinden, in denen zu über 20 Prozent Tschechen lebten bzw. die über 3000 Einwohner hatten. Vgl. SÚA, PMR, Karton 1714, 401/7-2, 
Amtssprachen folgte keine Verpflichtung zumindest eines Teils der tschechischen und slowakischen Staatsbeamten zur Kenntnis einer der Minderheitensprachen, mit der sie in ihrer amtlichen Tätigkeit in Berührung kommen konnten oder sogar unvermeidlich kommen mußten; bloß der Entwurf der Durchführungsverordnung zum Sprachengesetz von 1938 legte fest, die Staatsverwaltung müsse die staatlichen Organe, bei denen auch in anderen Sprachen amtiert wurde, mit entsprechend sprachlich qualifizierten Kräften besetzen. ${ }^{98}$

\section{Prüfungen und Prüflinge}

Bereits die erste Fassung der Durchführungsverordnung vom Jahre 1920 legte den Grundsatz fest, daß die sprachliche Befähigung der Staatsangestellten entweder durch eine ganz bzw. teilweise in der Staatssprache abgelegte Fachprüfung99 oder durch eine Prüfung vor einer für diesen Zweck speziell bestellten Kommission nachgewiesen werden mußte. Während die Kommissionen für Fachprüfungen selbstverständlich ein integraler Bestandteil des Aufnahme- bzw. Qualifikationsverfahrens im Staatsdienst mit genau abgesteckten Aufgaben waren, herrschte über die proponierten Sprachprüfungskommissionen zunächst keine Klarheit. Näher ging erst die Fassung der Durchführungsverordnung von 1922 auf diese Frage ein, deren Bestimmungen unverändert in die endgültige Fassung von 1926 Eingang fanden. ${ }^{100}$ Demgemäß wurden Sprachprüfungskommissionen durch den zuständigen Minister ernannt und bestanden aus einem Vorsitzenden und zwei Mitgliedern. Das eigentliche Prüfungsverfahren setzte sich aus einem schriftlichen und einem mündlichen Teil zusammen und sollte insgesamt wenigstens eine Stunde dauern. Gegenstand der schriftlichen Prüfung war die Abfassung eines Gesuches, eines Protokolls oder einer Erledigung in der Staatssprache, die Übersetzung einer Urkunde oder eines Teiles einer Gerichts- bzw. Amtsakte in die Staatssprache und ein Diktat; im mündlichen Teil wurde ein Gespräch über den Gegenstand der schriftlichen Prüfung oder über eine ,in den Dienstbereich fallende Angelegenheit" geführt. Über das Ergebnis entschied die Kommission mit Stimmenmehrheit. Die Prüfung konnte in einer von der Kommission zu bestimmenden Frist, längstens jedoch innerhalb von einem Jahr, einmal wiederholt werden.

Sprachengesetz, Referentenvorlage des Präsidiums des Ministerrates, undat. (nach 27. 5. 1938). Übrigens geschah dies nicht ohne Widerstände: Man verlangte, die doppelsprachige Korrespondenz im bisherigen Umfang aufrechtzuerhalten. Tschechische oder slowakische Bewohner der mehrheitlich andersnationalen Gemeinden, begründete man die Forderung, seien daran interessiert, richtige Informationen aufgrund des amtlichen Wortlautes der Zuschrift zu erhalten und nicht aus „zweifelhaften" schriftlichen oder mündlichen Übersetzungen, die das Gemeindeamt anfertige. AMZV, Sektion VI, Karton 486, Mappe 6, MNO an MV, 9. 7. 1938.

98 SÚA, PMR, Karton 1714, 401/7-2, Information über den Inhalt der vorbereiteten Vorlage einer neuen Durchführungsverordnung zum Sprachengesetz, undat. (vor dem 1. 9. 1938).

99 Grundsätzlich wurden Fachprüfungen („die Richteramts-, politischen, Finanz-, administrativ-technischen, Bezirks- und sonstigen in der Staatsverwaltung der genannten Ressorts vorgeschriebenen Prüfungen ") in der Staatssprache abgehalten; auf Ersuchen des Kandidaten konnte die Prüfung teilweise auch in der Sprache der nationalen Minderheit abgelegt werden, allerdings nur dann, falls es in dem Sprengel, für den die Prüfungskommission bestellt war, eine derartige Minderheit gab. Vgl. Regierungsverordnung Nr. 17/1926 Slg., Artikel 69.

100 SÚA, MV-SR, Karton 506, 20/2/53(2), Entwurf der Regierungsverordnung zur Durchführung des Gesetzes Nr. 122/1920 Slg., undat. (1922). 
Die ersten Sprachprüfungen, die im Staatsdienst überhaupt stattfanden, nämlich im Bereich des Eisenbahnministeriums, das als erstes Ressort überhaupt 1923 Richtlinien für die Sprachprüfungen erließ, wichen in einigen Punkten von dieser Regelung ab. ${ }^{101}$ Die schriftliche Prüfung erfolgte vor einer Kommission, der, soweit der Angestellte einen Sprachkurs besucht hatte, sein Lehrer und sein Vorgesetzter angehörten - in diesem Fall kannte der Prüfling seine Prüfer also persönlich, was ein psychologischer Vorteil gewesen sein dürfte. Der schriftliche Teil der Prüfung, der etwa anderthalb, höchstens zwei Stunden dauerte, schloß eine halbe Seite Diktat und eine Aufsatzarbeit zum Thema „Eisenbahndienst“ ein. Erst der mündliche Teil der Prüfung fand vor einer speziellen Kommission statt, die aus einem als Prüfungskommissar bestellten Staatsbahnbeamten (Vorsitzender) und zwei Mitgliedern bestand, zu denen nicht selten Vorgesetzte bzw. Angestellte der eigenen bzw. der benachbarten Dienststelle oder Lehrer der Sprachkurse gehörten. Die mündliche Prüfung hatte die Form eines Dialogs zwischen dem Prüfling und einem der Kommissionsmitglieder und sollte höchstens fünfzehn Minuten dauern. Der Stand der Sprachkenntnisse wurde als vollkommen, befriedigend in Schrift und Wort ${ }^{102}$, befriedigend in Wort ${ }^{103}$ und unbefriedigend eingestuft; das endgültige Ergebnis der Prüfung (geeignet-ungeeignet) hing jedoch ausdrücklich von den Erfordernissen des Dienstes des Betroffenen ab. ${ }^{104}$ Für die einzelnen Kandidaten wurden unterschiedliche Maßstäbe gesetzt: „Weit strenger sind Beamte oder Angestellte des Kanzleidienstes als Bahn- oder Lagerarbeiter zu prüfen“, hieß es unmißverständlich. ${ }^{105}$

Ermächtigt durch die Durchführungsverordnung zum Sprachengesetz erließen die zuständigen Ministerien zwischen Februar und März 1926 inhaltlich aufeinander abgestimmte Vorschriften, in denen die Bestimmungen über die Sprachprüfungen näher präzisiert wurden. ${ }^{106}$ Viel Neues hierzu enthielten die mehrseitigen Materialien allerdings nicht; vielmehr erschöpften sie sich in administrativ-technischen Angelegenheiten. ${ }^{107}$ Die Rahmenbedingungen, $d$. h. die Form bzw. die Dauer der Prüfungen änderte sich im Vergleich zum Entwurf der Durchführungsverordnung von 1922 nicht. Ähnlich wie die Vorschriften des Eisenbahnministeriums vom Jahre 1923 berücksichtigte man auch diesmal die Beschaffenheit des Dienstes, selbst wenn die Möglichkeit, differenzierte Ansprüche an verschiedene Dienstkategorien (Arbeiter-Beamte) stellen zu

101 Erlaß MŽ Nr. 1742/I-4 vom 27. 1. 1923, in: Úřední věstník MŽ 5 (1923), S. 67-69. Im Jahre 1925 gab auch das Postministerium ähnliche Richtlinien für die Abhaltung von Sprachprüfungen heraus. Abgesehen von technischen Bestimmungen (Zusammensetzung der Prüfungsgremien) waren beide Erlasse sachlich weitgehend identisch. Vgl. DSa 5 (1925), Nr. 8, S. 2-3.

102 Die Bewertung „befriedigend“ sollte gewährleisten, daß die schriftliche Agenda verständlich erledigt wurde, auch wenn sie grammatikalische Fehler enthielt.

103 Die Kenntnis, die ${ }_{n}$ der mündliche Verkehr in seinem Dienst erfordert“.

104 Die erwähnte Richtlinie des Postministeriums von 1925 enthielt eine dreistufige Klassifikation: „vollkommen“, "genügend“ (mündlich „in einem für den Dienst entsprechenden Maße“, schriftlich nverständlich wenn auch mit grammatikalischen Fehlern“) und ungenügend. Die Ansprüche sollten sich nach dem Maße richten, das für die Ausübung des Dienstes am bisherigen Dienstort erforderlich war. Vgl. DSa 5 (1925), Nr. 8, S. 3.

105 Erlaß MŽ Nr. 1742/I-4 vom 27. 1. 1923, in: Ưřední věstník MŽ 5 (1923), S. 69.

106 Vgl. beispielsweise SÚA, MV-P, Karton 293, VIJ3, Erlaß MV, 26. 2. 1926; AKPR D 952, Karton 116, Erlaß der Zentraldirektion der Tabakregie, 19. 3. 1926.

107 Hierzu gehörte u. a. die Zusammensetzung der Prüfungskommissionen. Ihre Vorsitzenden und Mitglieder wurden durch den zuständigen Minister ernannt; die Vorsitzenden mußten eine juristische Ausbildung, die Beisitzer Hochschul- oder zumindest Mittelschulbildung haben; sie durften zu dem Prüfling in keinem unmittelbaren dienstlichen Verhältnis stehen. 
können, explizit nicht erwähnt wurde. Die Klassifizierung des Prüfungsergebnisses war vierstufig: vollkommen entsprochen, entsprochen, teilweise entsprochen und nicht entsprochen. Die zwei letztgenannten Noten bedeuteten im Grunde genommen „nicht bestanden“, in beiden Fällen konnte die Prüfung wiederholt werden. „Vollkommen entsprochen“ hieß, daß der Betroffene „für irgendeinen Dienst“ im gegebenen Ressort, „entsprochen“ jedoch lediglich für ein konkretes Amt oder für einen konkreten Dienst sprachlich qualifiziert war. Ob sich jedoch aus dieser Einteilung beispielsweise bei eventueller Beförderung gewisse Konsequenzen ergaben, bleibt unklar. Zweifellos sehr problematisch war angesichts der sozialpolitischen Brisanz dieser Frage die Bestimmung, daß es gegen die Entscheidung der Prüfungskommission keine Rechtsmittel gab.

Die Welle der Kritik seitens der deutschen Staatsangestellten richtete sich besonders gegen zwei Aspekte: die Objektivität der Kommissionen und die Themenwahl. ${ }^{108} \mathrm{Um}$ die Unvoreingenommenheit sicherzustellen, war nach ihren Vorstellungen zu jeder Prüfungskommission ein Deutscher als Prüfer heranzuziehen. Falls die Kommission ein negatives Ergebnis der Prüfung mit bloßer Stimmenmehrheit feststellte, sollte dem Prüfling das Recht zustehen, sich an eine Prüfungskommission zweiter Instanz zu berufen. Darüber hinaus war einem durchgefallenen Prüfling die zweimalige Wiederholung der Prüfung mit je einjährigem Intervall zu gestatten. Im Hinblick auf die Themenwahl sollte man sich auf Aufgaben und Fragen aus dem Fachgebiet und Wirkungskreis der Prüflinge und außerdem auf den praktischen Sprachgebrauch und weniger auf Grammatik, Literatur, Geschichte und dergleichen konzentrieren. Probleme gab es auch bei der Bewertung der Sprachkenntnisse, vor allem mit der oben erwähnten Note "teilweise entsprochen“: Laut Durchführungsverordnung galt die Unkenntnis der Staatssprache als Grund für die Zuerkennung einer minder entsprechenden oder nicht entsprechenden Qualifikation. Die Tatsache, daß auch eine "teilweise“ Kenntnis des Tschechischen oder Slowakischen dieselben Folgen hatte, bezeichneten deutsche Abgeordnete als einen Verstoß gegen die Verordnung. ${ }^{109}$

Unwillkürlich stellt sich in diesem Zusammenhang die Frage, wie es sich generell mit den Tschechischkenntnissen der Deutschen in der Tschechoslowakei verhielt - inwieweit sie die andere Landessprache, die nunmehr zur Staatssprache mit einem breiten, mancherorts sogar verpflichtenden Anwendungsbereich wurde, lernen wollten, und welche Chancen ein deutscher Bürger überhaupt hatte, im Rahmen der üblichen Schulausbildung tschechisch zu erlernen, um den sprachlichen Ansprüchen des Staatsdienstes zu entsprechen. Es ist gewiß keine überraschende Feststellung, daß die Deutschen mehrheitlich der tschechischen Sprache eher ablehnend gegenüberstanden. Die dafür zu nennenden Gründe sind zahlreich und reichen vom Schwierigkeitsgrad des Tschechischen und dessen kleinem Verbreitungsbereich über die aus dem 19. Jahrhundert überlieferten psychologischen Vorbehalte im Hinblick auf den minderen kulturellen sowie gesellschaftlichen Status des Tschechischen, an dem in den Augen vieler Deutscher die Aufwertung zur offiziellen Sprache eines ohnehin unerwünschten Staa-

DSa 6 (1926), Nr. 8, S. 2; SÚA, PMR, Karton 463, 1063/3, VdDSv an PMR, 1. 11. 1926; Simm, Fragen, S. 17.

109 Interpellation des Abgeordneten Schollich und Genossen an den Finanzminister in Angelegenheiten der Minderqualifizierung deutscher Staatsangestellter aus dem Titel der Kenntnis der Staatssprache vom 15. 9. 1928, in: TTZPS, 2. WP, Drucksache 1788/IV. 
tes kaum etwas ändern konnte, bis hin zu Assimilierungsängsten. „Wenn wir tschechisch lernen, dann werden wir auch Tschechen. Aus ist es mit uns.“ - so hieß die Antwort eines Sudetendeutschen auf den Einwand eines Reichsdeutschen, warum man nicht tschechisch lernen und gleichzeitig deutsch bleiben könne. ${ }^{110}$ Tschechisch zu lernen und zu sprechen, so die Meinung des deutschen Gesandten Koch in Prag Mitte der zwanziger Jahre, heiße die Auffassung der Sudetendeutschen zu bestätigen, daß das Deutsche in der Tschechoslowakei entbehrlich sei, und stehe somit quer zu den Bemühungen der deutschen Politik, die beiden Landessprachen einander gleichzustellen. „Die Sudetendeutschen wollen nicht tschechisch lernen“, resümierte Koch, „oder, wenn sie es in der Jugend gelernt haben, es nicht anwenden müssen. "111

Obwohl Koch als guter Kenner der tschechoslowakischen Verhältnisse galt, kann man seine Urteile nicht verallgemeinern. Vor allem in liberalen deutschen Kreisen war man sich bereits in den frühen zwanziger Jahren darüber im klaren, daß besonders die deutsche Jugend tschechisch lernen müsse; hier wurden angeblich sogar Stimmen laut, tschechisch als Pflichtfach an deutschen Mittelschulen einzuführen. ${ }^{112}$ Das „Prager Tagblatt“ meinte im März 1920, das einzige, was den Deutschen in diesem Staat fehle, „um sich zur höchsten, unentbehrlichen Geltung zu bringen“, sei eben die Kenntnis der tschechischen Sprache; es bezeichnete die Bemühungen der tschechischen nationalistischen Kräfte, diese als Pflichtfach an Grund- und Bürgerschulen einzuführen als "deutschfreundlich“. Die Ablehnung durch die Regierungskoalition sei kaum Zartgefühl den Sudetendeutschen gegenüber gewesen, meinte das Blatt, sondern man wittere wohl die Gefahr, die der tschechischen Vorherrschaft von tschechischsprechenden Deutschen drohe. ${ }^{113}$ Am weitesten gingen in dieser Hinsicht die deutschen Sozialdemokraten, die 1922 im Parlament vorschlugen, daß in einem Schulbezirk, in dem mindestens 20 Prozent der Bewohner eine andere Sprache sprechen als die Bevölkerungsmehrheit, diese Sprache als Pflichtfach an allen Schulen unterrichtet werden sollte. ${ }^{114}$ In der ersten Hälfte der zwanziger Jahre glaubten vor allem die deutschen Sozialdemokraten daran, daß breitere Schichten der deutschen Bevölkerung mit den alten Stereotypen gebrochen hätten: Die Mehrheit der deutschen Bevölkerung, meinte im Jahre 1923 der Abgeordnete O. Hillebrand, habe sich von der „kindischen Losung“ losgesagt, die durch die deutschen nationalistischen Parteien früher herausgegeben worden war und dergemäß es als Verrat am eigenen Volk gegolten habe, wenn man seine Kinder tschechisch lernen ließ. ${ }^{115}$ Auch der deutsche agrarische Abgeordnete F. Spina meinte damals, daß das Bedürfnis und der Wunsch, tschechisch zu können, unter den Deutschen wachse. ${ }^{116}$ Von reichsdeutscher Seite kamen mittlerweile ebenfalls Warnungen „vor jenen deutschen Ideologen ..., die aus mißverständlichem Nationalstolz die Erlernung des Tschechischen ablehnen und perhorreszieren“. Die Kenntnis einer Fremdsprache sei niemals Ursache verminderter nationaler Zuverlässigkeit gewesen, darüber hinaus sei sie im besonderen Fall der Tschechoslowakei „ein nationales Kampfmittel ersten Ranges“, durch

110 PA R 73857, Gesandtschaft Prag an AA, 21. 6. 1926.

111 Ebda.

112 Vgl. Rede Veselýs in der 126. Sitzung der Nationalversammlung am 28. 2. 1920, in: TZRNS, S. 3788.

113 P'T vom 11. 3. 1920.

114 Rede Hillebrands, 211. Sitzung des Abgeordnetenhauses am 12. 5. 1923, in: TZPS, 1. WP, S. 373.

115 Ebda., S. 372.

116 Rede Spinas in der 211. Sitzung des Abgeordnetenhauses am 12. 5. 1923, in: TZPS, 1. WP, S. 367. 
dessen Anwendung beispielsweise die beständige Durchsetzung des deutschen Sprachgebiete durch tschechische Beamte "wirksam" bekämpft werden könne. ${ }^{117}$

Der obligatorische Unterricht des Tschechischen und Slowakischen an bestimmten Schultypen gehörte, wie auch die Staatsangestelltenfrage, während der Vorbereitung des Sprachengesetzes im Januar und Februar 1920 zu einem der vieldiskutierten Themen. Der Vertrag von St. Germain ermöglichte es der tschechoslowakischen Regierung ausdrücklich, den Unterricht der „böhmischen Sprache" verpflichtend festzulegen. Im Einklang damit legte der erste Regierungsentwurf des Gesetzes vom Dezember 1919 die offizielle Sprache der Republik als Pflichtfach „an den niedrigeren und mittleren Schulen sowie an den ihnen gleichgestellten Lehranstalten" fest. ${ }^{18}$ Unter nicht ganz geklärten Umständen - offiziell aus pädagogischen Gründen - sah jedoch die Regierungskoalition selbst in der späteren Fassung des Gesetzes vom Februar 1920 von dieser Bestimmung ab, was die tschechische nationalistische Opposition, die die Einführung der Staatssprache als obligatorisches Fach an allen Schulen und Lehranstalten forderte, somit wohl auch an Grundschulen, besonders entrüstete. ${ }^{119}$ Kramáŕ begründete die Forderung - übrigens nicht ganz abwegig - damit, daß jeder Staatsbürger die Möglichkeit haben müßte, die "Sprache dieses Staates“ zu beherrschen. Auf diesem Wege glaubte er auch die Verpflichtungen im Hinblick auf die Sprachkenntnisse der Staatsangestellten "weit erträglicher" zu gestalten, denn jeder deutsche Schüler würde die Gelegenheit haben, sich die Kenntnis der Staatssprache anzueignen. ${ }^{120}$ Kramár̆ vermochte sich weder im Verfassungsausschuß noch im Plenum der Nationalversammlung mit seinem Änderungsantrag gegen die geschlossene Haltung der Regierungskoalition durchzusetzen, selbst wenn er persönlich schließlich bereit war, seine Forderung nur auf Bürgerschulen und mittlere Schulen einzuschränken. ${ }^{121}$

Die Bestimmungen hinsichtlich der Einführung der tschechischen oder slowakischen Sprache als Unterrichtsfach an Volks- und Bürgerschulen enthielt das sogenannte kleine Schulgesetz Nr. 226 Slg. vom Jahre 1922. Als fakultatives Schulfach an Volksschulen konnte die "tschechoslowakische“ Sprache "nach Maßgabe des örtlichen Bedürfnisses“ durch Entscheidung des Landesschulrates festgesetzt werden. ${ }^{122}$ Die Ko-

117 Arens, Einbußen, S. 421.

118 SÚA, MV-SR, Karton 502, 20/2/28, Regierungsentwurf des Gesetzes betreffend die Festsetzung der Grundsätze des Sprachenrechts in der Tschechoslowakischen Republik, 16.11. 1919. Der Begriff "niedrigere Schulen“ ist nicht ganz eindeutig, höchstwahrscheinlich bezieht er sich auf die Bürgerschulen. Vgl. auch Kapitel I.A.4.

119 Vgl. SÚA, PMR, Karton 253, Mappe: české menšiny, Resolution der Vertreter tschechischer Minderheiten an den Ministerpräsidenten, 18. 1. 1920; SUA, MV-SR, Karton 502, 20/2/58, Entwurf des Sprachengesetzes, ausgearbeitet durch die Sprachkommission des Tschechoslowakischen Nationalrates in Prag, 24. 1. 1920. Zu den Standpunkten der Regierungskoalition vgl. APČR, RNS, Karton 33, 159. Sitzung des Verfassungsausschusses am 25. 2. 1920, Nachmittag, S. 56-60; Rede des Berichterstatters des Verfassungausschusses Hnídek in der 125. Sitzung der Nationalversammlung am 27. 2. 1920, in: TZRNS, S. 3683.

120 Rede Kramářs in der 126. Sitzung der Nationalversammlung am 28. 2. 1920, in: TZRNS, S. 3769.

121 Vorschlag der Minderheit des Verfassungsausschusses auf Änderung der Paragraphen 1, 2 und 5 des Sprachengesetzes vom 26. 2. 1920, in: TZRNS, Drucksache 2442; die Abstimmung über den Vorschlag in der 126. Sitzung der Nationalversammlung am 29. 2. 1920, in: TZRNS, S. 3867.

122 Die Landesschulräte waren in den sogenannten historischen Ländern (Böhmen, Mähren und Schlesien) die obersten Schulbehörden. Geteilt in zwei Sektionen, eine für die tschechischen und eine für die deutschen Schulen, stellten sie einen Übergang zwischen der staatlichen Schulverwaltung und der Selbstverwaltung dar. In der Ersten Republik wurden die Kompetenzen der einzelnen nationalen Sektionen zugunsten der Befugnisse des durch die Regierung ernannten Präsidenten bzw. Vizepräsi- 
stenträger, in diesem Fall meistens die Gemeinden, konnten sich zwar zu dieser Frage äußern, über die Rechtskraft ihrer Äußerung schwieg sich das Gesetz jedoch aus. Die Entscheidung über die Einführung des Tschechischen oder Slowakischen als Pflichtfach wurde dem Schulministerium übertragen, wobei aus dem Gesetz nicht klar hervorging, ob dies erst dann erfolgen konnte, nachdem die Staatssprache als fakultatives Fach festgesetzt worden war oder nicht. Im Hinblick auf die Bürgerschulen hieß es im Gesetz, daß den Schülern Gelegenheit zum Erlernen der "tschechoslowakischen“ Sprache zu bieten war; für die Einführung der Staatssprache als Pflichtfach galten identische Bedingungen wie an den Volkschulen.

Das Gesetz verlieh somit der Staatsverwaltung auf diesem Gebiet zweifellos weitreichende Kompetenzen. Tschechische Nationalisten, die, vom Prinzip ausgehend, daß die Kenntnis der Staatssprache bei jedem Staatsbürger vorausgesetzt werden sollte, weiterhin energisch für ihre Einführung an "allen öffentlichen Lehranstalten“ eintraten, konnten zufrieden sein. ${ }^{123}$ Die Schulverwaltung machte von dieser Ermächtigung jedoch eher flexibel Gebrauch: Im Jahre 1930 gab es insgesamt 3181 deutsche Volksschulen in den böhmischen Ländern, von denen Tschechisch an 803 fakultatives und nur an 6 obligatorisches Unterrichtsfach war; von 432 deutschen Bürgerschulen erhielten die Schüler an 413 fakultativen und an 94 obligatorischen Tschechischunterricht. Insgesamt lernten damals 58828 (16,6 Prozent) deutsche Grundschüler und 50553 (82 Prozent) Bürgerschüler tschechisch. ${ }^{124}$

Im August 1921 legte das Schulministerium einen Gesetzentwurf bezüglich der Regelung des Sprachunterrichts an Mittelschulen und Lehrerbildungsanstalten vor, demgemäß an den genannten Schultypen mit einer anderen Unterrichtssprache als der "tschechoslowakischen" tschechisch (in der Slowakei slowakisch) obligatorisch gelehrt werden sollte. Es sei die Pflicht der Schulverwaltung, begründete das Ministerium seinen Schritt, dafür zu sorgen, daß sich alle Mittelschüler eine vollkommene Kenntnis der Staatssprache aneignen konnten. Alles wäre in Ordnung gewesen, wenn der Schulminister, Historiker J. Susta, nicht gleichzeitig gemeint hätte, es sei „nicht weniger wichtig“, daß die Mittelschulabsolventen mit einer entsprechenden praktischen Kenntnis der Sprache derjenigen Minderheit ins Leben gingen, mit der sie in „engen wirtschaftlichen, amtlichen, kulturellen und dergleichen Beziehungen“ lebten. Diese Kenntnis bedeute, führte er aus, einen augenscheinlichen Vorteil für jeden Beamten, Händler, Gewerbetreibenden usw., der den Existenzkampf bestehen wolle; ebenso sei es für einen Staatsbeamten von großer Bedeutung, die Sprache der „am nächsten stehenden Minderheit" zu beherrschen. Kurz und gut: das Schulministerium schlug vor, an Mittelschulen mit tschechischer Unterrichtssprache in Böhmen, Mähren und Schlesien Deutsch als Pflichtfach einzuführen. ${ }^{125}$

denten sowie durch Einführung neuer Abstimmungsmechanismen weitgehend abgeschwächt, was sich vor allem zuungusten der Deutschen auswirkte. Vgl. Die deutsche Schule, S. 90.

123 SÚA, NRČ, Karton 491, 269, Resolution der öffentlichen Versammlung in Prag, 23. 10. 1921.

${ }^{124}$ Errechnet nach: Zprávy SÚS 13 (1932), S. 515 und 540-541. Stand zum 1. 10. 1931. An manchen deutschen Bürgerschulen wurde das Tschechische sowohl fakultativ als auch obligatorisch gelehrt. Das kam dadurch zustande, daß in manchen Jahrgängen der Tschechischunterricht verpflichtend war, in anderen wahlweise angeboten wurde. Deswegen ist die diesbezügliche Summe größer als die Gesamtzahl der deutschen Bürgerschulen überhaupt.

125 SÚA, PMR, Karton 462, 1063/1, Regierungsentwurf des Gesetzes betreffend die Regelung des Unterrichts in der Staatssprache sowie in den Sprachen der nationalen Minderheiten an den Mittelschulen und Lehrerbildungsanstalten, 11. 8. 1921. 
Der erste Teil des Vorschlages des Schulministeriums ging glatt über die Bühne, der zweite rief jedoch selbst in der Regierung Widerstände hervor. Die Argumention gegen das Vorhaben des Schulministeriums stellte ein überaus buntes Mosaik aus sowohl sachlichen als auch nationalpolitischen Überlegungen dar. Das Innenministerium, das offensichtlich in der gesamten Debatte für die Gegner wortführend war, bezeichnete die Einführung des obligatorischen Deutschunterrichts an tschechischen Mittelschulen als ernste politische Frage, die die tschechische Öffentlichkeit nur widerstrebend akzeptieren würde, und versuchte die Angelegenheit mit dem Hinweis unter den Tisch fallen zu lassen, die Maßnahme stehe im Widerspruch zum Sprachengesetz. ${ }^{126}$ Zunächst gewannen die Opponenten die Oberhand, und in einer Beratung im April 1922 sprachen sich die meisten Ministerien gegen den Gesetzentwurf aus. ${ }^{127}$ Im Frühjahr 1923 trat jedoch ein Meinungsumschwung ein. „Erfahrungen und die Entwicklung der Verhältnisse," schrieb das Verteidigungsministerium, „zwingen uns der hiesigen Ansicht nach, diesen Standpunkt zu revidieren und zu erwägen, ob es nicht in unserem Interesse liegt, daß das Deutsche an Mittelschulen als Pflichtfach eingeführt wird." Richtungsweisend war vor allem die Befürchtung, daß infolge der einseitigen Einführung des Unterrichts der Staatssprache an deutschen Mittelschulen ihre Absolventen im Vergleich zu den Tschechen sprachlich besser qualifiziert seien. „Es ist die Pflicht der Staatsverwaltung dafür zu sorgen“, schlußfolgerten die Militärs "daß auch die Angehörigen unseres Volkes die Mittelschulen sowie Lehreranstalten sprachlich mindenstens so gut ausgerüstet verlassen wie die Angehörigen der nationalen Minderheiten. " 128 Das Ministerium für soziale Fürsorge fügte weitere nationalpolitische Argumente hinzu: Tschechische und slowakische Staatsangestellte, die die Minderheitensprachen ausreichend beherrschten, würden gegenüber den sprachlich nicht qualifizierten Bewerbern aus den Reihen der Minderheiten bevorzugt und die geschlossenen Sprachinseln der Minderheiten zersprengen, "was nur dann möglich sein wird, wenn die Sprache der Minderheiten obligatorisch ist. " 129

Die Gegner der vorgeschlagenen Regelung resignierten jedoch keinesfalls. Das Innenministerium hielt weiterhin an seiner These fest, es widerspreche den Grundsätzen des Sprachengesetzes, daß den Minderheitensprachen im Schulunterricht die gleiche Bedeutung und die gleiche Gültigkeit zuerkannt würden wie der Staatssprache. Das Finanzministerium griff den Gesetzentwurf mit dem Argument an, es sanktioniere die Stellung des Deutschen als vorherrschender Sprache in Mitteleuropa. ${ }^{130}$ Allerdings konnten die Opponenten nicht lange gegen den Strom schwimmen. Sie unternahmen zwar noch einen Vorstoß, der darauf abzielte, die Durchführung des Gesetzes von dem sozialdemokratisch besetzten Schulministerium auf die Gesamtregierung zu übertragen, was gegebenfalls ermöglicht hätte, seine Umsetzung in die Praxis hinauszuzögern. ${ }^{131}$ Diesem sowie dem nachträglichen Versuch, die Anwendung des Gesetzes lediglich auf Bezirke mit einem gewissen Prozentsatz an Minderheitenbevölkerung einzuschränken, blieb je-

126 SÚA, PMR, Karton 462, 1063/1, MV an MŠaNO, 11. 1. 1922.

127 SÚA, PMR, Karton 462, 1063/1, MNO an MŠaNO, 16. 3. 1923.

128 Ebda.

129 SÚA, PMR, Karton 462, 1063/1, Aktenvermerk PMR, 11. 4. 1923.

130 Ebda.

131 Ebda. 
doch ein durchschlagender Erfolg versagt. ${ }^{132}$ Eines gelang trotzdem: während der Tschechischunterricht an deutschen Mittelschulen bereits seit dem Schuljahr 1923/24 eingeführt wurde, entschied sich die Regierung im Falle der tschechischen Mittelschulen für ein etappenweises Vorgehen, das infolge des fortdauernden Widerstandes vor allem des Innenministeriums erst im Schuljahr 1926/27 abgeschlossen werden konnte. ${ }^{133}$

Die Begründung zum Gesetz Nr. 137/1923 über die Einführung des Unterrichts der Staatssprache sowie der Sprachen der nationalen Minderheiten an Mittelschulen brachte die Hoffnung zum Ausdruck, daß die Völker durch Aneignung der Sprachen ihre Kultur kennenlernen würden, sowie die Erwartung, daß sie sich dadurch annähern, sich verstehen und einander unterstützen würden. ${ }^{134}$ An dieser allgemeinen These hatten die deutschen Parteien sicher wenig auszusetzen, der Gesetzentwurf selbst befriedigte sie jedoch nicht. Neben dem Vorwurf, daß das Gesetz ohne Mitwirkung der Deutschen vorbereitet worden war, meldeten die deutschen bürgerlichen Parteien ihre Befürchtung an, dieser Schritt könne eine weitere Etappe der Tschechisierung des deutschen Schulwesens darstellen. Deswegen verlangten sie, daß die Einführung des Tschechischen als Unterrichtsfach keineswegs seinen eventuellen Gebrauch als Unterrichtssprache in anderen Fächern zur Folge haben durfte oder daß der Tschechischunterricht nur deutschen Lehrern anvertraut wurde. ${ }^{135}$ Gerade in den genannten Punkten waren die Vorstellungen der deutschen Sozialdemokratie grundsätzlich unterschiedlich: Um praktische Sprachfertigkeiten zu entwickeln, solle das Tschechische selektiv auch als Unterrichtssprache benutzt und von Muttersprachlern unterrichtet werden. Auf taube Ohren, und zwar sowohl auf deutscher als auch auf tschechischer Seite, stieß ihre Idee, den Unterricht der Staatssprache sowie der Sprachen der nationalen Minderheiten auch an Volks- und Bürgerschulen einzuführen. ${ }^{136}$

Anfang der dreißiger Jahre lernten ca. 82 Prozent der deutschen Bürgerschüler und alle deutschen Mittelschüler tschechisch. ${ }^{137}$ Wenn man auch diejenigen deutschen Schüler berücksichtigt, die aus welchen Gründen auch immer tschechische Schulen besuchten $^{138}$, kommt man auf ungefähr 72000 deutsche Bürger- und Mittelschüler, die

132 SÚA, PMR, Karton 462, 1063/1, Auszug aus dem Protokoll der Sitzung des Ministerrates am 1.8. 1923. Das Gesetz wurde am 8.6. 1923 vom Parlament beschlossen, es erschien in der Sammlung der Gesetze unter der Nr. 137/1923.

133 SÚA, PMR, Karton 462, 1063/1, Auszug aus dem Protokoll der Sitzung des Ministerrates am 7. 8. 1923; Erlaß MŠaNO Nr. 95949-II vom 9. 8. 1923, mit welchem das Gesetz Nr. 137/1923 Slg. durchgeführt wird, in: Věstník MŠaNO 5 (1923), S. 457; SÚA, PMR, Karton 462, 1063/1, MŠ̉ NO an PMR, 23. 6. 1924; ebda MŠaNO an PMR, 29. 5. 1926; ebda, Aktenvermerk MŠ̀aNO, 26. 8. 1926.

${ }^{134}$ Bericht des kulturellen und verfassungsrechtlichen Ausschusses zum Regierungsentwurf des Gesetzes, durch das der Unterricht der Staatssprache sowie der Sprachen der nationalen Minderheiten an Mittelschulen und Lehreranstalten geregelt wird vom 3. 5. 1923, in: TTZPS, 1. WP, Drucksache 4139.

135 Rede Spinas in der 211. Sitzung des Abgeordnetenhauses am 12. 5. 1923, in: TZPS, 1. WP, S. 368.

136 Reden Hillebrands und Warmbrunns in der 211. Sitzung des Abgeordnetenhauses am 12. 5. 1923, in: TZPS, 1. WP, S. 372 bzw. 376.

137 Seit 1928 wurde das Tschechische als Abiturfach an deutschen Mittelschulen festgesetzt. Vgl. Erlaß MŠaNO Nr. 150970/27-II vom 4. 1. 1928, in: Věstník MŠ́aNO 10 (1928), S. 63-64.

138 Einen Überblick über deutsche Schüler an tschechischen Schulen liefert folgende Tabelle: Schultyp: insgesamt deutsche Schüler an in Prozent

$\begin{array}{lrrr} & & \text { tschechischen Schulen } \\ \text { Volkschulen } & 345119 & 4757 & 1,37 \\ \text { Bürgerschulen } & 62562 & 2340 & 3,75 \\ \text { Mittelschulen } & 19732 & 374 & 1,89\end{array}$

Errechnet nach: Zprávy SÚS 13 (1932), S. 20-23 und 515, Stand in: Schuljahr 1930/31. 
über gewisse Tschechischkenntnisse verfügten. Das Niveau dieser Kenntnisse war jedoch offensichtlich nicht besonders hoch, vor allem in den überwiegend deutsch besiedelten Gebieten, wo es im Alltag kaum Gelegenheit gab, die Schulkenntnisse durch praktischen Gebrauch zu festigen. Eine Untersuchung vom Anfang der dreißiger Jahre lieferte gerade in diesen Gebieten kein besonders optimistisches Bild: Lediglich zwischen 3-4 Prozent der deutschen Bürgerschüler waren in der Lage, sich tschechisch zu verständigen. ${ }^{139}$ Umso begreiflicher ist, daß sich zu dieser Zeit auch die deutschen aktivistischen Parteien für einen deutsch-tschechischen Kinderaustausch während der Ferienmonate mit dem Ziel intensiv einsetzten, die Tschechischkenntnisse bei der deutschen Jugend zu festigen. ${ }^{140}$ Selbst wenn man annimmt, daß das Unterrichtsniveau an Mittelschulen höher war, drängt sich trotzdem die Frage auf, ob der Kenntnisstand ausreichend war, um eine Sprachprüfung für den Staatsdienst problemlos zu bestehen.

Die endgültige Antwort auf diese-Frage ist nicht besonders einfach. Die Bereitschaft der deutschen Jugend wachse, meinte Senator F. Jesser Anfang der dreißiger Jahre, sich den neuen sprachlichen Bedürfnissen anzupassen, die Kenntnis der tschechischen Sprache würde ihrerseits als eine Selbstverständlichkeit angesehen. ${ }^{141}$ Dahingehend äußerte sich später auch die Zeitschrift „Der deutsche Staatsangestellte“ und fügte hinzu, es sei selten, daß ein Bewerber die Sprachprüfung im Staatsdienst nicht bestünde. ${ }^{142}$ Auch die Staatsorgane konstatierten Ende der dreißiger Jahre, die Sprachkenntnisse deutscher Bewerber seien besser als "nach dem Umsturz" ${ }^{143}$ Ob die Kenntnisse jedoch den Aufforderungen standhielten, bleibt weiterhin unsicher, zumal keine Angaben über die Ergebnisse der sprachlichen Aufnahmeprüfungen in den Staatsdienst vorgefunden werden konnten. In bestimmten sozialen Schichten bzw. Berufsgruppen blieben die Sprachkenntnisse nach wie vor ein Problem, worauf man aus der Tatsache schließen kann, daß das Memorandum der deutschen aktivistischen Parteien vom Januar 1937 empfahl, die Sprachprüfungen im Staatsdienst auf den faktischen Bedarf, also auf den „für den Prüfungsbewerber in Betracht kommenden Dienst", einzuschränken. ${ }^{144}$ Nachdem sich im Laufe des Jahres 1937 gezeigt hatte, daß Tschechischkenntnisse weiterhin ein Hindernis für den $\mathrm{Zu}$ gang zum Staatsdienst dargestellt hatte, wies die Regierung die Ministerien an, eventuelle Gesuche „wohlwollend“ zu beurteilen, in denen darum gebeten wurde, vom Nachweis der vollkommenen Kenntnis der Staatssprache abzusehen. ${ }^{145}$ Inwieweit das neue Verfahren jedoch in die Praxis tatsächlich umgesetzt werden konnte und ob es doch die Chancen der deutschen Bewerber um den Staatsdienst verbesserte, bleibt immer noch offen.

139 Simek, Znalost, S. 84. Die Untersuchung wurde in den Schulbezirken Böhmisch Leipa, Kaplitz und Nikolsburg durchgeführt.

140 SÚA, BdD, Karton 11, Pressedienst des BdD Nr. 26, 27. 2. 1937.

141 Jesser, Umschichtung, S. 432. Ähnlich bemerkt auch Brügel, Tschechen, S. 530, daß Mitte der DreiBiger eine neue Generation der deutschen Intelligenz herangewachsen sei, die die "Scheuklappen abgelegt hatte und gute Kenntnisse der tschechischen Sprache“ besessen habe.

142 DSa 17 (1937), Nr. 2, S. 6.

143 SÚA, MV-P, Karton 436, VI/40, MV-P an PMR, 20. 5. 1937.

144 Memorandum der drei deutschen Regierungsparteien, überreicht an Ministerpräsident Hodža am 27. 1. 1937, in: Zajicek, Dokumente, S. 6.

145 SÚA, MV-P, Karton 437, VI/40, PMR an alle Ministerien und Zentralbehörden, 27. 1. 1938. Vgl. auch Kapitel II.C.5. 


\section{Die zablenmäßige Entwicklung der deutschen Staatsangestellten 1918-1937}

Es ist beinahe symptomatisch, daß man gerade in den am heftigsten diskutierten nationalpolitischen Fragen des öfteren kaum über verläßliche zahlenmäßige Angaben verfügt, und die Staatsangestelltenfrage in der Ersten Tschechoslowakischen Republik bildet in dieser Hinsicht keine Ausnahme. Bereits der „Nullpunkt", d. h. die Anzahl der deutschen Staatsangestellten kurz vor oder unmittelbar nach dem Umsturz im Oktober 1918 ist nicht bekannt ${ }^{146}$; die österreichische Statistik vom Jahre 1910 enthält im Hinblick auf die Vertretung der einzelnen Nationalitäten im Staatsdienst keine Angaben, die man mit den Daten der tschechoslowakischen Volkszählung von 1921 vergleichen könnte. Die zahlenmäßige Entwicklung der deutschen Staatsangestellten in den Jahren 1918-1921, besonders die Auswirkungen der Übernahme der Staatsangestellten aus Österreich-Ungarn durch den neuen Staat auf den Bestand der Deutschen im Staatsdienst ist somit weitgehend unklar.

Das Interesse, eine funktionierende Exekutive sowie Judikative aufrechtzuerhalten, bedingte, daß die Übernahme der k. u.k Staatsangestellten durch die neue Staatsmacht relativ schnell und reibungslos verlief. Am 7. Februar 1919 beschloß die Revolutionäre Nationalversammlung das Gesetz Nr. 74 Slg., demgemäß alle Beamten und Angestellten des ehemaligen österreichischen Staates und der österreich-ungarischen Monarchie sowie der Unternehmungen und Fonds dieser Staaten weiterhin Staatsangestellte der Tschechoslowakischen Republik blieben, solange sie beim Inkrafttreten des Gesetzes auf dem Gebiet der Tschechoslowakischen Republik bestellt worden waren und sich innerhalb einer festgesetzten Frist melden und einen vorgeschriebenen Diensteid leisten würden. ${ }^{147}$ Denjenigen, die dies ablehnten, wurde der Verlust der Dienststelle sowie aller Ansprüche auf Gehalt und Pension angedroht. Außerdem ermächtigte das Gesetz die Regierung, Beamte und Angestellte, die bereits vor dem 28. Oktober 1918 im Dienst gestanden hatten, zu entlassen, und zwar auch aus anderen Gründen, als die Dienstordnung vom Januar 1914 festgelegt hatte. Diese Maßnahme war vor allem gegen Staatsangestellte gerichtet, übrigens nicht nur gegen Deutsche, die sich für den damaligen Begriff in der alten Monarchie, besonders in der Kriegszeit, am tschechischen Volk „verschuldet", beispielsweise eine "feindliche" Einstellung dem tschechischen Volk gegenüber gezeigt hätten. In welchem Ausmaß die Regierung von dieser Ermächtigung tatsächlich Gebrauch machte, muß jedoch weiteren Forschungen vorbehalten bleiben. Es wurde schließlich nämlich keine derartige Verordnung herausgegeben, nichtsdestotrotz gestand man später zu, daß es Staatsangestellte gegeben habe, die wegen ihres "staats- oder tschechischfeindlichen Verhaltens" nicht übernommen bzw. relativ bald aus dem Staatsdienst entlassen worden seien. ${ }^{148}$

Es ist nicht gelungen, zusammenfassende Ergebnisse der Übernahme der Staatsangestellten in allen Bereichen der Staatsverwaltung sowie in den staatlichen Betrieben ausfindig zu machen. Einen gewissen Einblick ermöglichen die Akten der einzelnen Mini-

146 Der sudetendeutsche nationalsozialistische Politiker $R$. Jung führte in den dreißiger Jahren an, im Jahre 1918 hätten die Deutschen 27 Prozent der Staatsangestellten in den Sudetenländern ausgemacht; worauf sich jedoch diese Angabe stützt, ist unklar. Vgl. Jung, Tschechen, S. 153.

147 Die Regierungsverordnung Nr. 154/1919 Slg. legte die Frist zur Ablegung des Diensteids auf den Zeitraum ab 1.4. bis 30. 4. 1919 fest.

${ }^{148}$ SÚA, MV-SR, Karton 125, 3/41/11, MŽ an MV, 24. 12. 1923. 
sterien, beispielsweise die des Eisenbahnministeriums. Nach den Meldungen der zuständigen Staatsbahndirektionen erreichten bis zum September 1919 etwa 290 Angestellte nicht die vorgeschriebene Vereidigung, die meisten von ihnen - insgesamt 212 Personen - in Brünn. ${ }^{149}$ Die Gründe dafür waren unterschiedlich: Einige der bis dahin nicht übernommenen Eisenbahner waren inzwischen österreichische Staatsbürger geworden, einige waren noch nicht aus der Kriegsgefangenschaft zurückgekehrt; die meisten von ihnen ersuchten jedoch, mit dem Diensteid bis zur endgültigen Entscheidung der Friedenskonferenz über die Grenzziehung abzuwarten. ${ }^{150}$ Die Meinungen, ob die Regierung überhaupt berechtigt war, ein Treuegelöbnis der Tschechoslowakischen Republik gegenüber zu verlangen, wenn der territoriale Bestand des neuen Staates durch die allierten Großmächte noch nicht verbindlich anerkannt worden war, gingen auseinander, und ihre Begründung soll an dieser Stelle nicht untersucht werden. Wichtig ist, daß das Eisenbahnministerium diesen Grund, wenn auch nicht gerade begeistert, akzeptierte und unter Berufung "auf den sozialen Gesichtspunkt sowie auf die Intentionen des Friedensvertrages" mit der Übernahme der Verweigerer, gegebenfalls auch mit ihrer Versetzung in den Ruhestand mit allen Ansprüchen rechnete. ${ }^{151}$ Offensichtlich wurde zumindest ein Teil dieser Angestellten tatsächlich übernommen; einige von ihnen konnten jedoch nicht an ihre ursprünglichen Dienstorte zurückkehren, weil ihre Stellen inzwischen mit anderen Bewerbern besetzt worden waren. ${ }^{152}$ Wenn man berücksichtigt, daß das Eisenbahnministerium im Jahre 1923 die Zahl seiner deutschsprachigen Angestellten mit 32038 angab und daß die Eisenbahn beinahe die Hälfte aller Staatsangestellten beschäftigte ${ }^{153}$, belegen die ermittelten Werte keinen brisanten Abbau der deutschen Staatsangestellten auf dem Wege der Nichtübernahme aus dem österreichischen Staatsdienst. Sie legen vielmehr das vorsichtige Fazit nahe, die durch die Übernahme hervorgerufene Abnahme der Deutschen im Staatsdienst dürfte sich nur auf einige Prozent belaufen haben.

Die sudetendeutschen Parteien gingen von der These aus, daß die Nachfolgestaaten sittlich verpflichtet seien, sich aller Personen ohne Unterschied der Nationalität und Rasse anzunehmen, deren Existenz vom Bestand ihres ehemaligen Dienstgebers, des österreichischen Staates, abhängig war. Diese „sittliche Verpflichtung“, so die Interpellation der Parteien des Deutschen Parlamentarischen Verbandes vom Jahre 1920, habe die Tschechoslowakei „im weiten Umfange“ nicht erfüllt. ${ }^{154}$ Worauf sich das scharfe

149 SÚA, MŽ, Karton 111, 34347/19, Staatsbahndirektion Brünn, 31. 8. 1919; Staatsbahndirektion Olmütz an $M Z ̌, 10.9 .1919 ;$ Staatsbahndirektion Königgrätz an MZV, 25. 9. 1919; Staatsbahndirektion Pilsen an MŽ, 26, 9. 1919. Es fehlt die Meldung der Staatsbahndirektion Prag; Olmütz gab keine genaue Zahl an.

$150 \mathrm{Vgl}$. SÚA, PMR, Karton 3295, 740/1, Deutscher Volksrat in Brünn an KPR, undat. (Eingang KPR 22. 9. 1919).

151 SÚA, MŽ, Karton 111, 34347/19, Aktenvermerk MŽ, undat. (ca Juli 1919).

152 Antwort des Eisenbahnministers auf die Interpellation des Abgeordneten Jung und Genossen wegen Bedrückung und Übergehung deutscher Bahnbediensteter vom 23.7. 1921, in: TTZPS, 1. WP, Drucksache 2955.

153 SÚA, MŽ, Karton 314, 43947/24, Aktenvermerk MŽ, 24. 1. 1924, Anlagen. Die Zählung der Staatsangestellten im Jahre 1924 wies insgesamt 342879 Personen im Staatsdienst auf, davon 164994 im Bereich der Staatseisenbahn. Vgl. Státní zaměstnanci, S. 8.

154 Interpellation der Abgeordneten Křepek, Böhr, Lodgman, Jung, Kafka und Genossen an die Gesamtregierung in Angelegenheit derjenigen ehemaligen österreichischen oder österreichisch-ungarischen Staatsbediensteten deutscher Nationalität, welche durch den Friedensvertrag von St. Germain tschechoslowakische Staatsbürger geworden und durch den Umsturz mittelbar oder unmittelbar in ihrer Existenz gefährdet worden sind vom 4. 11. 1920, in: TTZPS, 1. WP, Drucksache 1145. 
Urteil der deutschen Politiker eigentlich stützte, ist weitgehend unklar, denn die Interpellanten konnten lediglich 195 konkrete Fälle aus dem gesamten Bereich des Staatsdienstes anführen. ${ }^{155}$ Obwohl auch die zeitgenössische sudetendeutsche Publizistik keine genaueren Angaben vorlegen konnte - die Deutschen im Staatsdienst seien, so eine Pressestimme aus dem Jahre 1921, teils suspendiert, später jedoch „in Gnaden wieder aufgenommen“, teils aus den Ämtern verjagt, „zum großen Teil“ aber in ihren Stellen belassen worden ${ }^{156}$ - fand der Prozeß der Übernahme der Staatsangestellten in das Meinungsbild der Sudetendeutschen über die Erste Republik bereits in der Zwischenkriegszeit als ein negatives Erlebnis Eingang. ${ }^{157}$ Es geriet außerdem in Vergessenheit, daß man deutscherseits die sozialen Folgen als "noch tragbar" einschätzte: wie der DNSAP-Abgeordnete und Experte für die Staatsangestelltenfrage, H. Simm, später auseinandersetzte, sei die deutsche Wirtschaft der ersten Nachkriegsjahre noch - im Vergleich zum Zeitraum seit Mitte der Zwanziger - in der Lage, die aus dem Staatsdienst ausgeschiedenen Personen problemlos zu absorbieren; bestimmte Möglichkeiten boten auch das deutsche Organisationswesen (Parteien, Verbände jeder Art) und die deutsche Kommunalverwaltung, in denen der Anteil der Intellektuellen in der Nachkriegszeit bedeutend zunahm, bzw. die freien Berufe. ${ }^{158}$

An der Argumentation der deutschen Parteien ist weniger die niedrige Zahl der angegebenen Fälle erstaunlich. Es nimmt vielmehr Wunder, daß den Interpellanten augenscheinlich die Reziprozität in dieser Frage entfallen war. Denn der Staat, zu dem sie sich 1918 aufgrund ihres Selbstbestimmungsrechts bekannt hatten, nämlich Deutschösterreich, erklärte in seinen Vorschriften für die Übernahme der Staatsangestellten vom Dezember 1918 unmißverständlich: „Die Erwerbung des deutschösterreichischen Staatsbürgerrechtes, das nach dem einschlägigen Gesetz vom 5. Dezember 1918 St.G. Bl. Nr. 91 auch von Nichtdeutschen erworben werden kann, begründet keinen Anspruch auf die Übernahme in den Dienst des deutschösterreichischen Staates. " ${ }^{159}$ Tatsächlich gab später beispielsweise die Staatsbahndirektion Linz einen Erlaß heraus, demzufolge nur jenen Bediensteten der Diensteid für den Staat abgenommen werden konnte, „deren Zugehörigkeit zum deutschen Volk zuverlässig festgestellt" war. ${ }^{160}$ Die deutschböhmische Postdirektion in Aussig verordnete in ihrem Erlaß über die Entlassung überzähliger Hilfskräfte vom 25. November 1918 ebenfalls, daß die

155 Die Interpellation unterschied darüber hinaus nicht, ob die betreffenden Personen nicht übernommen, erst nach der Übernahme aus dem Dienst entlassen, bei der Beförderung übergangen oder, aus welchen Gründen auch immer, an andere Dienstorte versetzt worden waren.

${ }^{156}$ Montagsblatt aus Böhmen vom 16.5. 1921.

157 Vgl. beispielsweise Jesser, Umschichtung, S. 432. Vgl. auch Bohmann, Sudetendeutschtum, S. 57, der von "großen Entlassungen" in diesem Zeitraum spricht.

158 Simm, Fragen, S. 14; Jesser, Umschichtung, S. 432.

159 SÚA, MŽ, Karton 102, 15374/19, Deutschösterreichische Staatsbahndirektion Linz, Angelobung für den deutşchösterreichischen Staat, Nr. 114/Präs/1, 24. 12. 1918.

160 SÚA, MŽ, Karton 102, 15374/19, Deutschösterreichische Staatsbahndirektion Linz, Angelobung für den deutschösterreichischen Staat, Nr. 114/Präs/1, 24. 12. 1918. Die Grundlage der Feststellung der Nationalität war die Volkszählung von 1910, in Zweifelsfällen waren jedoch nicht nur die Umgangssprache, sondern auch die Sprache, in der die Schulbildung genossen wurde, die nationale Zugehörigkeit der Eltern und die „soziale Betätigung“ (d.h. Zugehörigkeit zu Vereinen, politisches Verhalten) ausschlaggebend. Auch „dem eigenen Bekenntnis“ war "eine gewisse Bedeutung " beizumessen, das Bekenntnis allein reichte jedoch nicht aus. Wenn ein "nichtdeutscher" Bediensteter durch Verschweigen seiner Nationalität „die Zulassung zum Gelöbnisse erschlichen hat", war das Gelöbnis nichtig und die Weiterbelassung im Dienst ausgeschlossen. Ein Begleittelegramm vom 4.1. 1919 sprach von 36 entlassenen tschechischen Eisenbahnern. Vgl. Ebda. 
Enthebung aller Aushilfskräfte nichtdeutscher Nationalität „unbedingt durchzuführen" sei. ${ }^{161}$ Dieses Vorgehen der deutschösterreichischen Staatsorgane war zumindest in Prager Ministerialkreisen gut bekannt und machte hier einen entsprechend schlechten Eindruck. ${ }^{162}$ Symptomatisch ist auch, daß der tschechoslowakische Gesandte in Berlin, K. Krofta, in einem Memorandum an das Auswärtige Amt vom Januar 1926, in dem er u. a. die Hauptzüge der tschechoslowakischen Regierungspolitik in der Staatsangestelltenfrage begründete, gerade an den erwähnten Aussiger Vorfall erinnerte. ${ }^{163} \mathrm{Ob}$ Krofta beabsichtigte, damit das Vorgehen der Tschechoslowakei in dieser heiklen Problematik zu rechtfertigen, kann im Prinzip dahingestellt bleiben; auf jeden Fall wies er auf den wohl zu früh in Vergessenheit geratenen Umstand hin, daß das Mißtrauensverhältnis den Staatsangestellten einer anderen Nationalität gegenüber keine tschechische Spezialiät war bzw. daß man 1918 nicht nur in Prag dazu neigte, den Staatsdienst als eine Art Fürsorgeeinrichtung vor allem für die Angehörigen der eigenen Nationalität zu betrachten. Zugestanden: so weit wie das junge Deutschösterreich ging die Tschechoslowakei nie. ${ }^{164}$

Die Abnahme der sudetendeutschen Staatsangestellten in den zwanziger Jahren wird aufgrund der Ergebnisse der Volkszählungen von 1921 und 1930 mit etwa 30000 angegeben. ${ }^{165}$ Dabei muß man sich ständig vor Augen halten, was meistens nicht geschah, daß der Vergleich der Volkszählungsdaten miteinander lediglich bedingt möglich ist. In den einzelnen Berufsgruppen unterschied nämlich die amtliche Statistik nicht zwischen öffentlichen, staatlichen und privaten Angestellten. ${ }^{166}$ Deshalb können nur Angaben für einige Bereiche ermittelt werden, in denen alle Berufszugehörigen oder zumindest deren überwiegender Teil Staatsangestellte waren, wie beispielsweise bei Post, Eisenbahn oder Militär. ${ }^{167}$ Darüber hinaus wich die Zusammensetzung der ein-

161 SÚA, PMR, Karton 521, 1292/S, Runderlaß der deutschösterreichischen Postdirektion Aussig, 25. 11. 1918. Vgl. auch Brügel, Tschechen, S. 531.

162 Vgl. SÚA, MV-SR, Karton 125, 3/41/11, MŻ an MV, 24. 12. 1923.

163 PA R 29368, Bemerkungen über die Beschwerden der Deutschen in der Tschechoslowakei, Januar 1926.

164 Vgl. Brügel, Tschechen, S. 531.

165 Vgl. Oberschall, Gliederung, S. 31. Oberschall gibt insgesamt 30293 (ohne Lehrer) an, Vorbach, [Zweihunderttausend], S. 136, kommt zu 33058 entfernten deutschen Staatsangestellten (einschließlich der Lehrer), abgerundet übernimmt diese Zahl auch Handbuch, S. 34. Die Angaben von Oberschall übernimmt auch Bohmann, Sudetendeutschtum, S. 56. Vgl. auch DSa 15 (1935), Nr. 8, S. 6; Eszler, Jahre, S. 34-38; Bleibtreu, Besitzstand,

166 Der Begriff "öffentlicher Angestellter“" wurde als Oberbegriff aufgefaßt, der neben den Staatsangestellten auch die Angestellten der territorialen, von der kommunalen bis hin zur Landesebene, bzw. der beruflichen Selbstverwaltung sowie der öffentlichen Körperschaften einschloß, weiter die Angestellten von Anstalten, Betrieben, Fonds und Einrichtungen, die den oben angeführten Subjekten angehörten, und schließlich alle Angestellten, für die das Lehrergesetz galt. Vgl. Krejčí, Zaměstnanci, S. 593. Bei der Zählung von 1924 zählten zur Kategorie „Staatsangestellte“ erstens die Angestellten der Staatsverwaltung „im engeren Sinne“ (d.h. der Zentralbehörden sowie der Verwaltung im Bereich einzelner Ministerien), weiter die des Justiz-, des staatlichen Unterrichtsund Bildungswesens, des Heeres, des Wachdienstes (Polizei, Gendarmerie usw.) und der staatlichen Krankenhäuser und Heilanstalten - im Jahre 1924 insgesamt 114319 Personen. Zweitens zählten dazu die Angestellten der Staatsbetriebe, u. a. der Staatsmonopole (die Tabakregie), der staatlichen Verkehrsbetriebe (Post und Eisenbahn) sowie der Staatsforste und -güter, um zumindest diejenigen mit der höchsten Angestelltenzahl zu nennen; die Staatsbetriebe wiesen 1924 insgesamt 228560 Angestellte auf. Vgl. Státní zaměstnanci, S. 2-5. Vgl. auch Ziegler, Gliederung, S. 210 bzw. Übersicht 31.

167 AKPR, D 931, Karton 114, SÚS an KPR, 3. 12. 1936. Vgl. auch Ziegler, Gliederung, S. 210 bzw. Übersicht 31. Mitberücksichtigt werden muß auch die Tatsache, daß diejenigen Personen, die aus 
zelnen Berufsgruppen bei den beiden Volkszählungen, wie im folgenden gezeigt wird, voneinander ab. Selbst der Verband der deutschen Staatsangestellten-Vereinigungen vertrat bei der Veröffentlichung der diesbezüglichen Volkszählungsergebnisse im Jahre 1935 die Ansicht, die zahlenmäßige Entwicklung der deutschen Staatsangestellten könne anhand dieser Daten gar nicht ermittelt werden; man schloß übrigens nicht aus, daß der deutsche Verlust an Arbeitsstellen im Staatsdienst noch größer gewesen sein könnte. ${ }^{168}$

Neben den Angaben der amtlichen Statistik finden sich in den Akten der einzelnen Ministerien verstreute Aufstellungen über die nationale Zusammensetzung der Staatsangestellten in den jeweiligen Ressorts. Leider liegen derartige Unterlagen nur in Ausnahmefällen vor und wurden-so zumindest eine begründete Vermutung-manchmal nachunterschiedlichen Methoden ausgearbeitet, so daß auch in diesem Fall keine einwandfreie Grundlage für ein endgültiges Urteil gegeben ist. ${ }^{169}$ Die Personalakten enthielten nämlich keine Rubrik „Volks-“ oder „Sprachzugehörigkeit", und die Zuordnung zu dieser oder jener Nationalität erfolgte wahrscheinlich entweder aufgrund der Meldungen der einzelnen Dienststellen bzw. anhand zusätzlicher Informationen über die betreffenden Personen, beispielsweise über ihre Sprachkenntnisse, den Besuch von Sprachkursen oder die Ablegung einer Sprachprüfung. ${ }^{170}$

Faßt man diejenigen Angaben zusammen, die entweder publiziert oder in den Akten ermittelt werden konnten, ergibt sich hinsichtlich der Entwicklung des Bestandes der deutschen Staatsangestellten etwa folgendes Bild:

\section{$\begin{array}{lllll}\text { Gruppe }^{171}: & \text { I } & \text { II } & \text { III } & \text { IV }\end{array}$}

Amtliche Statistik (das gesamte Staatsgebiet) ${ }^{172}$

$\begin{array}{lrrrrr}1921 & 21574 & 10022 & 36353 & 1753 & 21093 \\ 1930 & 13653 & 5897 & 19218 & 1061 & 19359\end{array}$

Amtliche Statistik (die böhmischen Länder) ${ }^{173}$

$\begin{array}{rrrrrr}1921 & 20659 & 9870 & 35431 & 1427 & 20566 \\ 1930 & 12948 & 5774 & 18692 & 749 & 18734\end{array}$

Oberschall (die „Sudetenländer") ${ }^{174}$

$\begin{array}{rrrrr}1921 & 15035 & 9817 & 35290 & 2529 \\ 1930 & 7673 & 5772 & 18184 & 749\end{array}$

verschiedenen Gründen nicht berufstätig waren (Arbeitslose, dauerhaft Kranke, Häftlinge, Soldaten), bei der Volkszählung ihren letzten Beruf anführten. Vgl. Československá statistika, Bd. 9, S. 14*, bzw. Bd. 98 , S. $18 *$.

168 Vgl. DSa 15 (1935), Nr. 8, S. 6. Vorsicht beim Vergleich der Daten empfahl in einem Kommentar zu den Ergebnissen der Volkszählung auch das Statistische Staatsamt, selbst wenn es diesen nicht völlig ausschloß. Vgl. Československá statistika, Bd. 104, S. 29*-30*.

169 Beispielsweise variierten die Angaben je nachdem, ob man nur feste oder auch vertragliche Angestellte einbezog.

170 AKPR, D 931, Karton 114, Mappe: Nationalitätenstatistik der Staatsangestellten, Aufzeichnung KPR, 9. 1. 1937.

17 Die Aufteilung wurde aus der Bevölkerungsstatistik übernommen und erstreckt sich auf folgende Bereiche: Gerichtswesen und öffentliche Verwaltung (I), Post (II), Eisenbahnen (III), Militär (IV) sowie Unterrichts- und Erziehungswesen (V).

172 Československá statistika, Bd. 23, S. 36 (Daten für 1921); Bd. 116, S. $72-74$ (Daten für 1930).

173 Československá statistika, Bd. 20, S. 346 bzw. Bd. 22, S. 224 und 248 (Daten für 1921); Bd. 116, S. 6 und 18 (Daten für 1930).

174 Oberschall, Gliederung, S. 31. 
Vorbach (das gesamte Staatsgebiet) ${ }^{175}$

$1921 \quad 21331 \quad 9967$

$1930 \quad 13076 \quad 5895$

36170

18405

1753

527

Andere Angaben

$1923^{176}$

32038

$1925^{177}$

$1930^{178}$

7789

1936

7821

$1937^{181}$

16866

$13248^{179}$
21084

19344

Die Unterschiede in Gruppe I (Gerichtswesen und öffentliche Verwaltung) ergeben sich daraus, daß sich die Angaben der offiziellen Statistik und Vorbachs einerseits und die von Oberschall sowie des Statistischen Staatsamtes für 1930 (Andere Angaben) andererseits auf einen unterschiedlichen Personenkreis bezogen: Die Zweitgenannten schlossen wahrscheinlich bloß die Staatsverwaltung ein, die Gemeindeverwaltung (ca. 20 Prozent der Beschäftigten dieser Gruppe im Jahre 1930 ${ }^{182}$ ) blieb unberücksichtigt. Die Gruppe änderte sich zudem zwischen 1921 und 1930 in gewisser Weise: 1921 wurden auch die "Landes- und Bezirksverwaltung" sowie die „andere öffentliche Verwaltung" (ca. 7 Prozent der Beschäftigten dieser Gruppe im Jahre 1930) einbezogen, die 1930 ausgeklammert und in die Berufsgruppe „anderer öffentlicher Dienst" verschoben wurden. Relativ "sauber" ist Gruppe II (Post), die im Hinblick auf ihre Zusammensetzung zwischen 1921 und 1930 nur unbedeutende Änderungen erfuhr. Der Gruppe III (Eisenbahnen) wurden in den publizierten Ergebnissen der Volkszählungen neben den Angestellten der staatlichen Eisenbahn auch die anderer Bahnen, einschließlich der Straßenbahnen zugeordnet, denen etwa 10 Prozent aller Beschäftigten dieser Berufsgruppe angehörten. Deshalb ist die Aufstellung des Statistischen Staatsamtes aus dem Jahre 1930 (Andere Angaben) wertvoll, die lediglich die Angestellten der Staatseisenbahn enthält. Ebenfalls nur auf diese Beschäftigtengruppe bezogen sich auch die durch das Eisenbahnministerium vorgelegten Angaben für die Jahre 1923 und 1936. Die Reduktion deutscher Staatsangestellter in diesem Bereich in den Jahren 1921-1936 dürfte sich demgemäß auf über 18000 Personen belaufen haben.

Die Differenzen in Gruppe IV (Militär) ergeben sich daraus, daß entweder nur Offiziere (Vorbach) oder auch Unteroffiziere (Oberschall) gezählt wurden, sonst ist diese Gruppe verständlicherweise die beständigste. Nicht unproblematisch ist dagegen

175 Vorbach, [Zweihunderttausend], S. 136.

176 SỨA, MV-SR, Karton 505, 20/2/43, MŽ an MV, 9. 7. 1923, Anlage.

177 SÚA, PMR, Karton 521, 1292/S, MPaT an MZV, 15. 1. 1926, Angestellte im Bereich des Postministeriums.

178 Ergebnisse der Volkszählung 1930. Vgl. AKPR, D 931, Karton 114, SÚS an KPR, 3. 12. 1936.

179 SUUA, PMR, Karton 612, Übersicht über die Angestellten der Staatseisenbahnen nach Nationalitäten, Stand zum 30. 6. 1936.

180 Antwort auf die Interpellation des Senators Enhuber betreffend die Zahl der deutschen aktiven Offiziere in der tschechoslowakischen Armee vom 5.1. 1937, in: TTZS, 4. WP, Drucksache 376/XII. Unter den 457 deutschen Offizieren befand sich ein General. Stand zum 2. 1. 1936.

181 SÚA, PMR, Karton 612, Übersicht über die Zahl der Professoren, Lehrer und wissenschaftlichen Kräfte an den dem MŠaNO unterliegenden Schulen und Anstalten, Stand zum 2. 2. 1937.

182 Hier wie im folgenden errechnet nach: Československá statistika, Bd. 104, S. 10-11 bzw. 22-23. Angaben für die böhmischen Länder. 
Gruppe V (Schul- und Erziehungswesen): Sie enthielt sowohl Lehrer staatlicher (Mittelschulen, Gymnasien, Lehreranstalten und Hochschulen) als auch nichtstaatlicher Schulen (Volks- und Bürgerschulen mit der Ausnahme der sog. Minderheitenschulen). Darüber hinaus waren auch Schulpersonal sowie Angestellte von Bibliotheken, Archiven, wissenschaftlichen Instituten, Kunstsammlungen sowie die der Kindergärten und -krippen in dieser Gruppe zusammenfaßt. Der Bereich des staatlichen Schulwesens beschäftigte 1930 knapp unter 20 Prozent aller Angestellten dieser Berufsgruppe. Die Angaben für das Jahr 1937 (Andere Angaben) schließen lediglich Lehrer bzw. wissenschaftliche Kräfte an allen Schulen und Anstalten ein. Von den deutschen Lehrern waren damals 11197 an staatlichen Schulen tätig, wo sie mit 24 Prozent einen höheren Prozentsatz ausmachten als im nichtstaatlichen Schulwesen (20,7 Prozent). ${ }^{183}$

Man kann nicht einmal ganz genau sagen, wieviele Deutsche 1930 im staatlichen bzw. öffentlichen Sektor insgesamt beschäftigt waren. In den fünf angeführten Hauptgruppen waren es nach Berechnungen des Verbandes der Deutschen StaatsangestelltenVereinigungen ca. $64500 .{ }^{184}$ In dieser Aufstellung blieben die insgesamt über 78000 Angestellten der übrigen staatlichen Betriebe unberücksichtigt, wie beispielsweise der Staatsforste und -güter, der Gruben und Hütten oder der Tabakregie, sowie die Staatsangestellten in anderen Bereichen der Industrie, des Handels und des Geldwesens oder im staatlichen Gesundheitswesen. ${ }^{185}$ Die nationale Zusammensetzung der Staatsangestellten in diesen Bereichen ist vorläufig nur ausnahmsweise bekannt. In der Tabakregie beispielsweise konnte man die Lage selbst nach dem in den dreißiger Jahren im Zuge der Weltwirtschaftskrise erfolgten Abbau nicht als dramatisch bezeichnen: Von den 9470 Beamten und Arbeitern im Jahre 1937 waren 3080, also 32,5 Prozent Deutsche. ${ }^{186}$

Besser als die absoluten Zahlen veranschaulichen die Angaben über den Prozentsatz der deutschen Staatsangestellten den Prozeß der Verdrängung der Deutschen aus dem Staatsdienst bzw. aus den oben bereits untersuchten fünf Berufsgruppen, die in folgender Tabelle angeführt sind:

\begin{tabular}{|c|c|c|c|c|c|}
\hline Gruppe: & I & II & III & IV & $\mathrm{V}$ \\
\hline \multicolumn{6}{|l|}{$1921^{187}$} \\
\hline Böhmen & 21,8 & 29,5 & 28,8 & 11,8 & 34,6 \\
\hline Mähren & 23,1 & 23,1 & 18,3 & 16,8 & 27,2 \\
\hline Schlesien & 48,7 & 50,4 & 28,9 & 24,1 & 48,3 \\
\hline böhmische Länder & 23,7 & 29,2 & 26,3 & 13,6 & 33,4 \\
\hline ČSR & 19,1 & 25,3 & 21,7 & 12,9 & 29,0 \\
\hline
\end{tabular}

183 SÚA, PMR, Karton 612, Übersicht über die Zahl der Professoren, Lehrer und wissenschaftlichen Kräfte an den dem MŠaNO unterliegenden Schulen und Anstalten, Stand zum 2. 2. 1937.

184 Vgl. DSa 15 (1935), Nr. 8, S. 6. Die Berechnung schließt auch 6396 deutsche Staatsangestellte in „anderen öffentlichen Diensten“, also offensichtlich Angestellte der Selbstverwaltungskörper sowie Lehrer und Angestellte an nichtstaatlichen Schulen, ein.

185 AKPR, D 931, Karton 114, SÚS an KPR, 3.12. 1936.

186 SÚA, PMR, Karton 612, Finanzminister Kalfus an Minister Zajicek, 19. 2. 1937. Bei der Arbeiterschaft machte der Prozentsatz der Deutschen 33,6 (diesen Prozentsatz gibt unter Berufung auf Hodžas Rede im Budgetausschuß am 18. 11. 1937 auch Brügel an, vgl. ders. Tschechen, S. 532), bei der Beamtenschaft lediglich 15,5 Prozent aus.

187 Berechnet nach: Československá statistika, Bd. 20, S. 340-347, Bd. 21, S. 210-249, Bd. 23, S. 18-37. 
$1930^{188}$

Böhmen

16,3

$$
15,3
$$

15,9

4,6

29,6

32,3

Mähren-Schlesien

16,0

15,4

12,0

6,4

23,1

22,8

böhmische Länder

16,2

15,3

14,7

5,2

27,2

29,2

12,6

13,1

12,3

5,3

23,1

22,3

Die Zahlen sprechen unmißverständlich für sich selbst. Im Jahre 1921 entsprach der Anteil der Deutschen an einzelnen Bereichen des Staatsdienstes etwa dem Bevölkerungsschlüssel, in einigen waren sie sogar immer noch überrepräsentiert. Eine Ausnahme stellten diejenigen Bereiche dar, die nach 1918 neu aufgebaut bzw. besetzt worden waren, vor allem das Militär und auch die zentralen Verwaltungsorgane - die fast totale Absenz der Deutschen in diesen Bereichen dürfte die ins Auge springende Unterrepräsentierung der Deutschen in Gruppe I (Gerichtswesen und öffentliche Verwaltung) in Böhmen 1921 zur Folge gehabt haben. Bis 1930 sank der Anteil der Deutschen in den einzelnen Gruppen auf die Hälfte des ursprünglichen Standes; bloß in Gruppe V (Schulwesen) konnten sie ihre Positionen einigermaßen halten ${ }^{189}$, was u. a. ein indirekter Beweis für die relativ gute Lage des deutschen Bildungswesens in der Tschechoslowakei in der Zwischenkriegszeit ist. Die relativ niedrigere Abnahme der Deutschen in Gruppe I verursachte wahrscheinlich die Tatsache, daß sie sich auch auf den Bereich der Selbstverwaltung, dessen nationale Zusammensetzung sich nur wenig änderte und somit - aus deutscher Sicht - als stabilisierender Faktor in der gesamten Gruppe wirkte: Eine Untersuchung des Innenministeriums vom Jahre 1937 stellte eindeutig fest, daß die Angestellten der Selbstverwaltungskörper „ausschließlich oder in überwiegender Mehrheit" Angehörige derselben Nationalität waren wie die Mehrheit der Körperschaft, durch die sie bestellt wurden. ${ }^{190} \mathrm{Daß}$ bei diesen Bestellungen die lokalen tschechischen Minderheiten systematisch übergangen wurden, diente im nationalitätenpolitischen Diskurs u. a. auch den Kritikern am „Februarabkommen“ von 1937 als Beweis deutscher Intransigenz in der Angestellten- und Beamtenfrage. ${ }^{191}$ Den Anteil der Deutschen an der Gesamtzahl der Staatsangestellten in den genannten fünf Gruppen gab der Verband der deutschen Staatsangestellten-Vereinigungen 1930 mit 14,7 Prozent an, der Verlust gegenüber dem Bevölkerungsschlüssel im gesamtstaatlichen Rahmen betrug demgemäß ungefähr 30200 Arbeitsplätze; nur für die böhmischen Länder gab man ihn sogar mit 37000 Arbeitsplätzen an. ${ }^{192}$

Den tiefsten Eingriff in den Bestand der Deutschen im Staatsdienst in den zwanziger Jahren bedeutete zweifellos der aufgrund des Gesetzes Nr. 286 Slg. vom Dezember 1924 vollzogene Abbau von Staatsangestellten, in dessen Folge der Personalstand im Staatsdienst im Zeitraum vom 1. Januar 1925 bis 30. Juni 1926 - der eigentliche Abbauprozeß dauerte jedoch nur bis zum 31.12. 1925 - um 36858 Angestellte verrin-

188 Československá statistika, Bd. 104, S. 10-11, Bd. 116, S. 4-7, 16-21 und 72-75.

$184 \mathrm{Vgl}$. auch Brügel, Tschechen, S. 532.

190 SUA, MV-P, Karton 437, VI/40, Aktenvermerk MV, 1. 7. 1937. Der Staat hatte auf diese Bestellungen keinen Einfluß.

191 So machte machte man unter dem Motto „Licht- und Schattenseite des Februarabkommens“ ostentativ darauf aufmerksam, daß nur 388 von den 7829 Angestellten in "verdeutschten Gemeinden“ Tschechen seien. Národní noviny vom 16. 12. 1937. Ähnlich argumentiert auch Brügel, Tschechen, S. 534.

192 Vgl. DSa 15 (1935), Nr. 8, S. 6 bzw. Handbuch, S. 34. Vorbach, [Zweihunderttausend], S. 136, gibt einschließlich Militärs ca. 57240 Personen an. 
gert wurde. ${ }^{193}$ Über die Zahl der insgesamt entfernten Deutschen liegen keine genauen Angaben vor: Zeitgenossen gaben "mindestens“ 18000 an ${ }^{194}$; nach den Meldungen der einzelnen Ministerien aber verließen im Laufe des Jahres 19258040 Deutsche den Staatsdienst, ein Teil von ihnen einvernehmlich, 6718 wurden zwangsweise mit einer Abfindung bzw. mit einer entsprechenden Pension in den Ruhestand versetzt. ${ }^{195}$ Obwohl die Unterlagen nicht vollständig sind - der Bericht des Innenministeriums liegt gar nicht vor; das Eisenbahn- sowie das Postministerium führten lediglich die zwangsweise entfernten Deutschen (4.430 bzw. 1138 Personen ${ }^{196}$ ) an - , scheint die Angabe von 18000 aus dem Staatsdienst ausgeschiedenen Deutschen die höchste überhaupt in Frage kommende Zahl zu sein; tatsächlich dürfte sie etwa um 15000 liegen. ${ }^{197}$ Es sollte an dieser Stelle jedoch erwähnt werden, daß die Grenze zwischen den freiwillig und zwangsweise Ausgeschiedenen ziemlich unscharf war: Die Zweitgenannten, die weniger als 10 Jahre im Dienst standen, hatten gemäß dem Gesetz Nr. 286/1924 Slg. lediglich das Anrecht auf die Hälfte der Abfindung, die den einvernehmlich Ausgeschiedenen zu gewähren war. Falls man jedoch innerhalb von acht Tagen nach der Verständigung von seiner zwangsweisen Versetzung in den Ruhestand nachträglich das freiwillige Ausscheiden beantragte, erhielt man zwei Drittel davon, was natürlich für viele Betroffene ein zugkräftiges Argument war. Selbst wenn die meisten Ministerien keine aufgeschlüsselten Aufstellungen über den Beamtenabbau vorlegten, kann man es als nachgewiesen betrachten, daß der Prozentsatz der betroffenen Deutschen - an welchem Schlüssel auch immer gemessen - höher war als bei den Tschechen bzw. Slowaken. Inwieweit dies in den einzelnen Bereichen tatsächlich "vielfach“ der Fall war, wie die Deutsche Völkerbundliga in der Tschechoslowakei

193 SÚA, PMR, Karton 521, 1292/S, SÚS an PMR, 13. 7. 1926, Anlage. Eigentlich betrug die Abnahme 40466 Personen, der zahlenmäßige Unterschied geht auf die natürliche Fluktuation zurück.

194 Vgl. Rede Jungs in der 16. Sitzung des Abgeordnetenhauses am 17. 3. 1926, in: TZPS, 2. WP, S. 1025. Jung, der sich auf Ausführungen des Senatoren J. Pánek vom Vortag berief, zog die Angabe als zu niedrig in Zweifel. Pánek sprach von insgesamt 33000 Personen, davon 18000 Deutsche, die aus dem Staatsdienst ausgeschieden seien. Vgl. Rede Páneks in der 12. Sitzung des Senats am 16.3. 1926, in: TZS, 2. WP, S. 333. Vgl. auch Rádl, Kampf, S. 187. Der Antrag der deutschen Abgeordneten, einen parlamentarischen Ausschuß einzusetzen, der den Abbau überprüfen sollte, gelangte nicht zur Behandlung im Plenum des Abgeordnetenhauses. Vgl. Antrag der Abgeordneten Spina, Luschka, Jung, Stenzl, Mayr-Harting von Genossen in Sachen des Beamtenabbaus vom 18. 12. 1925, in: TTZPS, 2. WP, Drucksache 24.

195 Berechnet nach: SÚA, PMR, Karton 521, 1292/S, einzelne Ministerien an MZV, datiert zwischen Dezember 1925 und Februar 1926. Laut dem Gesetz 286/1924 Slg. erhielten sowohl die freiwillig als auch die zwangsweise aus dem Staatsdienst ausgeschiedenen Angestellten, die eine kürzere anrechenbare Dienstzeit hatten als 10 Jahre, eine einmalige Abfindung, die aufgrund des letzten Monatsgehaltes und der Dienstjahre errechnet wurde; den Ubrigen wurden Ruhegehälter auf der Pensionsgrundlage gewährt, die ihnen am Tage der Versetzung in den Ruhestand zustand; hinzu kamen Zuschüsse u. a. für diejenigen Angestellten, die mehr als 17 bzw. 20 anrechenbare Dienstjahre aufwiesen.

${ }^{196}$ Demgegenüber meldete die deutsche Gesandtschaft in Prag, daß allein in diesen Bereichen 8938 (davon 2238 freiwillig und 6700 zwangsweise) bzw. 4000 Deutsche aus dem Staatsdienst entfernt worden seien. Vgl. PA R 74070, Gesandtschaft Prag an AA, 18.1. 1926.

197 Das Postministerium habe nach eigenen Angaben insgesamt 3818 Angestellte entlassen, davon waren "mindestens" 1000 Tschechen, so daß die "freiwillig“" ausgeschiedenen Deutschen höchstens 1600 ausmachen konnten. Vgl. SÚA, PMR, Karton 521, 1292/S, MPaT an MZV, 15. 1. 1926. Nimmt man die erwähnten Angaben der deutschen Gesandtschaft in Prag ernst, verließen etwa 4500 Deutsche den Eisenbahndienst "freiwillig". Wenn man davon ausgeht, daß das Innenministerium insgesamt 2189 Stellen abbaute, von denen ca. die Hälfte auf Deutsche entfallen sein dürfte, kommt man zu einer Zahl von ca. 7000 , die mit den bekannten Meldungen der einzelnen Ministerien in Höhe von ca. 8000 die Gesamtsumme von ca. 15000 ergibt. Vgl. ebda., SÚS an PMR, 13. 7. 1926, Anlage. 
in einem „Alarmruf“ nach Genf behauptete, muß jedoch weiteren Forschungen überlassen werden. ${ }^{198}$

Für die dreißiger Jahre sind gar keine statistischen Unterlagen über die zahlenmäßige Entwicklung der deutschen Staatsangestellten vorhanden; es liegen lediglich verschiedenartige Angaben der Staatsverwaltung vor, deren Vergleichbarkeit, wie bereits erläutert wurde, fraglich ist. Die gesamten dreißiger Jahre hindurch war die Politik in der Staatsangestelltenfrage von weiteren Abbaumaßnahmen begleitet, die durch die verschlechterte finanzielle Lage des Staates infolge der Weltwirtschaftskrise hervorgerufen wurden. Darüber hinaus mußte das Finanzministerium im Jahre 1931 mit Stirnrunzeln feststellen, daß die Zahl der Staatsangestellten (einschließlich der Vertragsarbeitskräfte, aber ohne Lehrer) um 7000 höher war als vor dem Abbau im Jahre 1925. ${ }^{199}$ Über die nationalpolitischen Auswirkungen des in den dreißiger Jahren erfolgten Abbaus sind wir vorläufig nicht ausreichend informiert; vereinzelte Angaben in Ministerialakten deuten eine weitere Abnahme der Deutschen im Staatsdienst an, keineswegs jedoch in dem Umfang wie Mitte der zwanziger Jahre. 1936 gab beispielsweise das Eisenbahnministerium den Anteil der deutschen Angestellten in seinem Bereich mit 11,25, das Postministerium mit 10,39 Prozent an, andere vergleichbare Angaben konnten in den Quellen bisher nicht ermittelt werden. ${ }^{200}$ Auch die Zeitgenossen tappten übrigens im dunkeln: der sudetendeutsche Verlust an Arbeitsplätzen im Staatsdienst seit 1919 wurde schwankend zwischen 40000 bis 60000 angegeben. ${ }^{201}$ Eine Benachteiligung der Deutschen im Staatsdienst ist jedenfalls unbestreitbar. Eine Änderung dieser Lage konnte langfristig nur ein grundsätzlicher Kurswechsel in der Staatsangestelltenpolitik herbeiführen, der sich in den Jahren 1937-1938 abzuzeichnen begann.

\section{Bemühungen um eine proportionale Vertretung der Nationalitäten im Staatsdienst}

Die Auffassung, Minderheiten hätten ein Recht darauf, nicht nur entsprechend ihrer zahlenmäßigen Stärke, sondern auch ihrer politischen, wirtschaftlichen und kulturellen Bedeutung in den öffentlichen Diensten jeder Art vertreten zu sein, war seit Anfang der zwanziger Jahre ein fester Bestandteil der Überlegungen der sudetendeutschen Rechtswissenschaft und Politik über eine gerechte Regelung der Verhältnisse in einem national gemischten Staat. ${ }^{202}$ Während dies für kleinere Minderheiten lediglich „soweit möglich“ zutraf, so der deutsche Jurist L. Epstein aus Prag in seinen Grundsätzen des Weltminderheitenrechts vom Jahre 1923, sollte dieses Prinzip bei den großen und bedeutungsvollen Minderheiten gesetzlich festgelegt werden. ${ }^{203}$ Befanden sich die Forderungen, eine derartige Regelung herbeizuführen, in der ersten Hälfte der zwanziger

198 AdV, R 1624, 41/44572/1296, Medinger an den Generalsekretär des Völkerbundes, 6. 6. 1925.

199 Rede des Finanzministers Trapl in der 142. Sitzung des Abgeordnetenhauses am 14. 10. 1931, in: TZPS, 3. WP, S. 39.

200 SÚA, PMR, Karton 612, S 1728/44, Nationale Zusammensetzung der Staatsangestellten, Eisenbahnministerium (Stand zum 30.6. 1936), Postministerium (Stand zum 1. 1. 1937).

201 Von einem „Minus von nahezu 40000 Arbeitsplätzen im Staatsdienst“ sprach im November 1937 W. Jaksch. Vgl. Bachstein, Jaksch, S. 129. Die höhere Zahl wurde auf dem Kongreß der sozialdemokratischen Gewerkschaften im Mai 1936 genannt. Vgl. Jung, Tschechen, S. 153. Vgl. auch Brügel, Tschechen, S. 533.

202 Vgl. beispielsweise DSa 5 (1925), Nr. 1, S. 3 bzw. DSa 5 (1925), Nr. 7, S. 1; Simm, Fragen, S. 15.

203 Epstein, Grundsätze, S. 86 bzw. 95. Vgl. auch Wien-Claudi, in: Bo vom 19. 5. 1929. 
Jahre völlig außerhalb des Erreichbaren, glaubte die deutsche aktivistische Politik nach ihrem Regierungseintritt Ende 1926 bessere Chancen zu haben, eine gerechtere Vertretung der Deutschen im Staatsdienst zumindest via facti zu erreichen. Im Dezember 1928 legten die deutschen Regierungsparteien ein Memorandum vor, das sich vornehmlich der Probleme der deutschen Staatsangestellten annahm. ${ }^{204}$ Die deutschen Politiker machten darauf aufmerksam, daß in manchen Ressorts seit zehn Jahren Deutsche nur ausnahmsweise aufgenommen worden seien, was in der deutschen Bevölkerung „schwere Mißstimmung“ hervorgerufen habe. Deswegen verlangten sie, in $\mathrm{Zu}$ kunft bei der Neuaufnahme von Beamten und Angestellten Bewerber deutscher Nationalität in einem dem nationalen Bevölkerungsschlüssel entsprechenden Umfang zu berücksichtigen. Indirekt zielten diese Forderungen auf eine proportionale Vertretung im gesamten Staatsdienst: Die im deutschen Sprachgebiet gelegenen Post- und Eisenbahnämter waren mit einer dem nationalen Verhältnis der Bevölkerung entsprechenden Anzahl von Beamten und Angestellten deutscher Nationalität auszustatten, dasselbe sollte für die „obersten Rangklassen“ zutreffen, was offensichtlich die ins Auge springende Unterrepräsentanz der Deutschen in den Zentralbehörden zumindest teilweise ausgleichen sollte.

Es zählt, neben der Sprachenfrage, zum weiteren schwerwiegenden Versäumnis der Regierungspolitik der damaligen Zeit, daß die Forderungen der deutschen aktivistischen Parteien tschechischerseits auf taube Ohren stießen. Vielleicht gelang es den deutschen Aktivisten, auf dem Wege von Koalitionsabmachungen und Interventionen die Positionen der Deutschen, besonders eigener Parteigänger, im Staatsapparat doch zumindest stellenweise zu verbessern ${ }^{205}$ - genaue Angaben liegen nicht vor; ein bahnbrechender Erfolg in der Staatsangestelltenfrage blieb ihnen allerdings versagt. Trotzdem wurden aus den Reihen der tschechischen Opposition Klagen über die „Germanisierungstätigkeit der deutschen Minister" laut, in deren Folge die Tschechen die nach dem Umsturz errungenen Positionen im Staatsapparat in den Grenzgebieten wieder verlieren würden ${ }^{206}$; mit ruhigem Gewissen konnte aber die Regierung derartige Vorwürfe zurückweisen. ${ }^{207}$ Eine komplexe Regelung, die gegebenfalls in näherer oder fernerer Zukunft den deutschen Anspruch auf gerechte Vertretung im Staatsdienst wenigstens teilweise hätte befriedigen können, wurde erst in den Jahren 1936 bis 1938 in Angriff genommen. In den Verhandlungen zwischen den tschechisch-slowakischen und deutschen Regierungsparteien in den Jahren 1936 bis 1937 rangierte die Staatsangestelltenfrage ganz oben auf der Liste der unbedingt zu lösenden Probleme, zumal die Weltwirtschaftskrise sowie die darauffolgende wirtschaftliche Depression ihre sozialen Aspekte nachdrücklich unterstrichen. Bereits die deutschen Christsozialen verlangten bei ihrem Regierungseintritt im Juni 1936, daß die Neuanstellungen im Staatsdienst nach dem nationalen Schlüssel erfolgen müßten. ${ }^{208}$ Das Memorandum der deutschen

204 SÚA, PMR, Karton 267, Memorandum der im „Deutschen Verband“ zusammengeschlossenen deutschen Parteien, 20. 12. 1928. Im Verband waren BdL, DCSVP und Deutsche Gewerbepartei zusammengeschlossen.

205 Vgl. Brügel, Tschechen, S. 532.

206 Interpellation der Abgeordneten Bergman, Zemínová, Şpatný und Genossen an die Regierung betreffend die kritische Situation tschechischer Staatsangestellter an den national gemischten Orten vom 6. 6. 1929, in: TTZPS, 2. WP, Drucksache 2313/VII.

207 SÚA, MŽ, Karton 9, 1625/29, Aktenvermerk MŽ, 19. 8. 1929.

208 Zajicek, Dokumente, S. 4. 
aktivistischen Parteien vom Januar 1937 ging noch weiter: Nicht nur die Anstellungssondern auch die Beförderungsmöglichkeiten sowohl im Bereich des öffentlichen Dienstes als auch der staatlichen Betriebe waren für die Angehörigen aller Nationalitäten "nach Maßgabe des Anteils jeder Nation an der Gesamtbevölkerung des Staates" zu sichern. Die „Bedürfnisse der nationalen Siedlungsgebiete“ sollten demgemäß durch Bestellung von öffentlichen Angestellten und Arbeitern derselben Volkszugehörigkeit gewährleistet werden. ${ }^{209}$

Die Forderung der deutschen Aktivisten überraschte die Regierung nicht. Bereits in seiner Rede im Budgetausschuß des Senates im Dezember 1936 gab Premierminister Hodža offen zu, in einigen Bereichen der Staatsverwaltung sei das deutsche Element nicht „im völligen Proporz zu der Anzahl der deutschen Bevölkerung" vertreten, worüber er sein Bedauern aussprach. ${ }^{210} \mathrm{Er}$ signalisierte die Bereitschaft der Regierung, über diese Frage zu verhandeln, machte aber gleichzeitig auf gewisse Grenzen aufmerksam: Die Beamten im Staatsdienst könnten nicht nur unter dem Gesichtspunkt beschäftigt werden, daß der "Proporz" gewahrt bleibe, ohne daß auch auf ihre innere Einstellung zum Staat geachtet wurde. Den Hinweis auf den Zusammenhang zwischen der Loyalität zum Staat und Neuanstellungen im Staatsdienst enthielt auch das Kommuniqué der Regierung vom 20. Februar 1936, das die Antwort auf das aktivistische Memorandum darstellte. ${ }^{211}$ Im Unterschied zu Hodžas Senatsrede erwähnte man hier mit keinem Wort die Disproportion in der Vertretung der einzelnen Nationalitäten im Staatsdienst: „Die sich immer mehr verbreitende Kenntnis der Staatssprache“ ermögliche es der Regierung angeblich, „einen weiteren Schritt zur Aufnahme von Angehörigen der nationalen Minderheiten in die Staatsdienste zu machen und in immer größerem Maße nicht allein auf allgemeine Qualifikations- und regionale Interessen, sondern auch auf die Interessen der Minderheiten in der Richtung einer gerechten Proportionalität Rücksicht zu nehmen." Angesichts der einige Sätze weiter im Einvernehmen mit den aktivistischen Forderungen bekundeten Bereitschaft, das Ausmaß der Sprachprüfungen für den öffentlichen Dienst nach den tatsächlichen Bedürfnissen sowie mit Rücksicht auf die Verwendung des Bewerbers zu regeln, nahm sich die Argumentation der Regierung nicht besonders glaubwürdig aus. Der Wortlaut des eigentlichen Regierungsbeschlusses war selbstverständlich frei von hochtrabenden Formulierungen. Ziel der Staatsangestelltenpolitik war es, durch die Aufnahme von Bewerbern aus den Reihen der Minderheiten jeder Nationalität einen "vernünftigen Anteil“ an Stellen im öffentlichen Dienst zukommen zu lassen, wobei allerdings kein zeitlicher Horizont genannt wurde. ${ }^{212}$ Der Runderlaß der Regierung von Anfang März 1937 ordnete darüber hinaus an, diesen Grundsatz sowohl bei Neuanstellungen als auch bei Beförderungen zu berücksichtigen. ${ }^{213}$ Die Ressorts wurden außerdem angewiesen, dem Präsidium des Ministerrates vierteljährlich Aufstellungen über die Nationalität der aufgenommenen Bewerber für den Staatdienst vorzulegen; es wurde auch eine ständige Konferenz der Personalreferenten der einzelnen Ministerien errichtet, die die Erfül-

209 Ebda., S. 6.

210 ANM, NL Hodža, Karton 7, 406, Rede Hodžas im Budgetausschuß des Senates am 7. 12. 1936.

21 Ursachen, Dokument Nr. 2642, S. 45.

212 SÚA, PMR, Karton 253, Mappe: Směrnice menšinové politiky, Auszug aus dem Protokoll der Sitzung des Ministerrates am 19. 2. 1937.

213 SÚA, PMR, Karton 253, PMR an alle Ministerien, 2. 3. 1937. 
lung des Regierungsbeschlusses überwachen sowie einschlägige Erfahrungen sammeln sollte. $^{214}$

Die aktivistischen Deutschen nahmen die Februar-Abmachungen hinsichtlich der Staatsangestelltenfrage mit gemäßigtem Optimismus entgegen. Man war sich dessen bewußt, daß eine "Reparation des nationalen Verhältnisses im Staatsdienst" nicht "von heute auf morgen" möglich sei. Angesichts der ungünstigen Altersstruktur der deutschen Staatsangestellten, so wie sie sich infolge der Benachteiligung des deutschen Nachwuchses herausgebildet hatte, rechneten Experten des Verbandes der deutschen Staatsangestellten-Vereinigungen mit zwei bis drei Jahrzehnten. ${ }^{215}$ Selbst wenn man nur Deutsche eingestellt hätte, so die Stellungnahme des Verbandes, würde es in manchen Ressorts ungefähr fünf Jahre dauern, in einigen jedoch auch länger, bis das nationale Verhältnis dem Bevölkerungschlüssel entsprochen hätte. ${ }^{216}$ Die Zwischenergebnisse bestätigten das abwartende Urteil in vollem Ausmaß: Im November 1937 mußte Ministerpräsident Hodža zugestehen, der Anteil der Deutschen an der Gesamtzahl der Neuanstellungen im Staatsdienst habe seit Februar 1937 lediglich 8,5 Prozent betragen; auch die etwas besseren Ergebnisse im letzten Erhebungszeitraum vom 1. September bis zum 30. November 1937 - von insgesamt 3595 neu eingestellten Personen waren 434 Deutsche, also 12,07 Prozent - konnten kaum optimistische Erwartungen erwecken. ${ }^{217}$ Die Lage in den einzelnen Ressorts war natürlich unterschiedlich; beunruhigend war vor allem die Tatsache, daß der Prozentsatz der aufgenommenen Deutschen in einigen Bereichen eine sinkende Tendenz zeigte. Als kritisch wurden beispielsweise die Zustände bei der Finanzwache bezeichnet. ${ }^{218} \mathrm{Im}$ Hinblick auf einzelne Staatsangestellten-Kategorien erschien, auf den ersten Blick vielleicht überraschenderweise, die Aufnahme von Deutschen mit Hochschulbildung als „zufriedenstellend“, minder günstig war die Lage bei Mittelschülern. Gering (fünf bis acht Prozent) war der deutsche Anteil in der Kategorie der Kanzleibeamten, als "vollkommen unzufriedenstellend" bezeichnete man die Entwicklung in der Gruppe der Bediensteten. Zusammenfassend wurde festgestellt, daß sich die Aufnahme in den unteren Instanzen "durchwegs besser" gestaltete als in den Zentralbehörden. ${ }^{219}$

Trotz der bescheidenen Ergebnisse fanden die deutschen Aktivisten - offensichtlich nicht aus bloßem politischem Zweckoptimismus - dennoch anerkennde Worte für den neuen Kurs. Auf ihrer Arbeitstagung im Oktober 1937 kamen die drei deutschen Regierungsparteien überein, daß sich die Februarbeschlüsse auf verschiedenen Gebieten der staatlichen Administrative schon zweifellos günstig ausgewirkt hätten, selbst wenn sie gleichzeitig feststellen mußten, daß sowohl das Tempo als auch das Ausmaß

214 SÚA, PMR, Karton 436, VI./40, PMR an alle Ministerien und Zentralbehörden, 2.6. 1937. Die Nachweise wurden jeweils zum 15.6., 31.8., 30.11. 1937, 28.2. und 31.5. 1938 ausgearbeitet. Die Meldungen beispielsweise des Innenministeriums vgl. SÚA, MV-P, Karton 436, VI/40.

215 DSa 17 (1937), Nr. 4, S. 1.

${ }^{216}$ DSa 17 (1937), Nr. 9, S. 1.

217 Rede Hodžas am 17. 11. 1937, in: Bachstein, Jaksch, S. 128-129; SÚA, PMR, Karton 437, Bericht über den Verlauf der ständigen Konferenzen der Personalreferenten am 12. 1. 1938.

218 Im Bereich des Ministeriums für öffentliche Arbeiten wurden beispielsweise im Zeitraum vom 18.2. bis 31.5. 193758 Prozent, vom 1.6. bis 31. 8. 1937 lediglich 38 Prozent Deutsche aufgenommen. Vgl. AMZV, Sektion III, Karton 619, Mappe 4, MVP an MZV, 15. 12. 1937. Zur Finanzwache vgl. Der Sozialdemokrat vom 19. 2. 1938.

219 DSa 18 (1938), Nr. 3, S. 1. 
ihrer Realisierung immer noch unzureichend waren. ${ }^{220}$ Schwankend war das Urteil des Verbandes der deutschen Staatsangestellten-Vereinigungen, der im November 1937 gemeint hatte, es hätten sich vorläufig "nicht einmal die bescheidenen Erwartungen“ erfüllt, in der Jahresbilanz zum 18. Februar jedoch zugestand, auf dem Gebiete der Neuaufnahmen in den Staatsdienst sei „eine wenn auch nicht überwältigende, so doch entschieden beachtenswerte Besserung" herbeigeführt worden, besonders im Vergleich zu dem „totalen Stillstand“" vor dem Februar 1937.221

Während die Staatsverwaltung die Gründe für die hinter den Erwartungen gebliebenen Entwicklung vor allem im Mangel an sprachlich und zum Teil auch fachlich (besonders für höhere Dienstgrade) qualifizierten deutschen Bewerbern erblickte, machten die deutschen Aktivisten auf mannigfaltige Ursachen aufmerksam; dazu gehörten das überdauernde Mißtrauen von Teilen der tschechischen Gesellschaft auch den aktivistischen Deutschen gegenüber, der Widerstand bestimmter tschechischer politischer Kreise - die Regierungsparteien nicht ausgenommen - gegen die neue Nationalitätenpolitik oder die zunächst ablehnende, zumindest aber laxe Einstellung der Bürokratie zu den vereinbarten Grundsätzen. ${ }^{222}$ Ironischerweise mag auch ein gewisses Taktieren Hodžas zu den Verzögerungen in der Personalpolitik beigetragen haben, das auf eine politische Unterstützung der deutschen aktivistischen Parteien abzielte: Im Juni 1937 wurden die einzelnen Ministerien von Hodžas Wunsch informiert, neue Kräfte nicht schrittweise und in geringeren Zahlen aufzunehmen, sondern eine Pause einzulegen und die Aufnahmen massenhaft vor den Kommunalwahlen durchzuführen, die im Herbst 1937 abgehalten werden sollten. ${ }^{223}$ Dieser politisch motivierte Wunsch des Ministerpräsidenten dürfte die Ministerialbürokratie, die noch Mitte April 1937 aufs neue angewiesen worden war, das Prinzip der „angemessenen “ Proportionalität bei Aufnahmen und Beförderungen unverzüglich geltend zu machen, sehr wahrscheinlich verunsichert haben.224

Die deutschen Aktivisten gaben übrigens Schwierigkeiten auch auf deutscher Seite zu. Junge Deutsche, meinte die Zeitschrift „Der deutsche Staatsangestellte“, hätten nicht den Mut, sich für den Staatsdienst zu bewerben: Die einen warteten angeblich erst ab, ob der 18. Februar halten würde, was er versprochen hatte, die anderen seien durch ihre vorausgehenden erfolglosen Bewerbungsversuche von vornherein abgeschreckt. ${ }^{225}$ Deutsche Bewerber, vermutete W. Jaksch, würden eher zu staatlichen Betrieben neigen, während es unter ihnen wenig Interesse für den Verwaltungs- und besonders den Sicherheitsdienst gebe. ${ }^{226}$ Offensichtlich trugen zu dieser Tatsache auch

220 Der Sozialdemokrat vom 11. 10. 1937.

221 DSa 17 (1937), Nr. 9, S. 1 bzw. DSa 18 (1938), Nr. 3, S. 1.

222 DSa 18 (1938), Nr. 2, S. 1-2.

223 SÚA, PMR, Karton 437, Bericht über den Verlauf der ständigen Konferenz der Personalreferenten am 12.1. 1938.

224 SÚA, MV-P, Karton 436, VI/40, PMR an alle Ministerien und Zentralbehörden, 17. 4. 1937.

225 DSa 18 (1938), Nr. 2, S. 4.

226 Jaksch, Funguje dohoda, S. 705. Bis Mitte August 1938 entsprachen nur 38 deutsche Bewerber aus dem gesamten Staatsgebiet allen Bedingungen für den Gendarmeriedienst; selbst die deutschen Aktivisten hatten sich davon überzeugen können, daß man bei der Behandlung der Ansuchen objektiv vorgegangen und bemüht gewesen sei, einen größeren Prozentsatz an Deutschen aufzunehmen. Die Zentralstelle der deutschen aktivistischen Parteien in Prag forderte deshalb die Bezirksstellen auf, „sofort geeignete Bewerber aus(zu)wählen und sie zur Einbringung eines Ansuchens (zu) veranlassen." Vgl. SUA, SdP, Karton 66, Zentralstelle der deutschen aktivistischen Parteien an alle Bezirksstellen, 18. 9. 1937. Auch die SdP machte eventuelle deutsche Bewerber auf freie Stellen im öf- 
die hohen Ansprüche hinsichtlich der staatlichen Loyalität in den zweitgenannten Bereichen bei. Nicht bedeutungslos mag auch der Umstand gewesen sein, daß viele Familien, aus deren Mitte sich Staatsangestellte bzw. -beamte traditionell rekrutiert hatten, enttäuscht durch die Personalpolitik der Regierung im Staatsdienst - die Karriere im Staatsapparat bereits vor Jahren aus dem Katalog der Zukunftsaussichten ihrer Kinder gestrichen hatten; ein diesbezüglicher Wandel konnte natürlich auch erst in einem längeren Zeitraum eintreten. Auch die materielle Lage der deutschen Bewerber erwies sich in manchen Fällen als Hürde: Der Verband der deutschen Staatsangestellten-Vereinigungen schätzte die Durchschnittskosten für ein Bewerbungsverfahren (verschiedene Gebühren, eventuelle Fahrtkosten) auf 100 bis 300 Kronen, was für nicht selten mittellose junge Leute eine beträchliche Summe darstellt, zumal höchstens jede dritte Bewerbung Erfolg gehabt habe. ${ }^{227}$

Nach internen Diskussionen über einige technische Probleme, die nachweislich bereits im April 1937 begonnen hatten, nahm das Präsidium des Ministerrates im Herbst die Vorbereitung einer Regierungsrichtlinie „über die Aufnahme neuer Kräfte in den Staatsdienst mit Rücksicht auf ihre nationale Zugehörigkeit" in Angriff. ${ }^{228}$ Die Vorschrift bezog sich auf die Staatsverwaltung sowie die staatlichen Betriebe, „bis auf weiteres" sollten jedoch das Verteidigungs- und das Finanzministerium, hier namentlich die Finanzwache und die Angestellten der Zollämter, ausgenommen werden. Ansonsten sollte bei Neuanstellungen in allen Ressorts darauf geachtet werden, daß die Angehörigen der einzelnen Nationalitäten in dem Verhältnis aufgenommen würden, das ihrer zahlenmäßigen Stärke in jenem Gebiet entsprach, auf das sich die Zuständigkeit der betreffenden Behörde (Gesamtstaat, Land, Bezirk usw.) erstreckte. ${ }^{229}$ Der Entwurf kam den traditionellen sudetendeutschen Forderungen weitgehend entgegen, und zwar auch in sprachlicher Hinsicht: Eventuelle Gesuche der Bewerber, von der vollkommenen Kenntnis der Staatssprache abzusehen, sollten „wohlwollend beurteilt werden“, falls die Antragsteller zumindest teilweise, also in einem dem Bedarf des Dienstes entsprechenden Maße, tschechisch oder slowakisch beherrschten. Die deutschen Minister schlugen vor, den Erlaß durch die Bestimmung zu ergänzen, nach der denjenigen Ressorts, in denen die Deutschen unterrepräsentiert waren, aufgetragen werden sollte, durch die Aufnahme einer größeren Zahl von Angehörigen der nationalen Minderheiten das dem Regierungsbeschluß vom 18. Februar 1937 entsprechende "nationale Verhältnis“ möglichst bald zu erreichen. ${ }^{230}$ Dies lehnte das Präsidium des Ministerrates mit der eher vorgeschobenen Begründung ab, man könne nicht die Behörden mit einer Richtlinie zur Einhaltung eines gewissen Vorgangs verpflichten, nämlich zu einer dem Bevölkerungsschlüssel entsprechenden Aufnahme der Bewerber, und sie gleichzeitig auffordern, diese Richtlinie zu verletzen. ${ }^{231}$ Demgegenüber reagierte die Staatsverwal-

fentlichen Dienst aufmerksam. Vgl. ebda., Karton 55, Rundschreiben des Klubs der SdP Landesvertreter für Böhmen, 16. 10. 1937.

227 DSa 18 (1938), Nr. 2, S. 4.

228 SÚA, MV-P, Karton 437, VI/40, PMR an alle Ministerien und Zentralbehörden, 17.4. 1937; ebda, PMR an alle Ministerien und Zentralbehörden, 29. 10. 1937.

${ }^{229}$ Das prozentuale Verhältnis war jeweils innerhalb jedes Kalenderjahres zu erreichen; ausgenommen waren auch diejenigen Einrichtungen, die ausschließlich den Bedürfnissen einer bestimmten Nationalität dienten.

${ }_{230}$ SÚA, MV-P, Karton 437, VI/40, Amt des Ministers Spina an PMR, 20. 11. 1937.

231 Ebda., PMR an alle Ministerien und Zentralbehörden, 27. 1. 1938. 
tung Ende Dezember 1937 positiv auf die Hinweise der deutschen Aktivisten hinsichtlich der materiellen Probleme der Bewerber um den Staatsdienst: Von nun an durften mittellose Personen oder Schulabsolventen Gesuche um Aufnahme in den öffentlichen Dienst gebührenfrei einbringen. ${ }^{232}$

Der endgültige Wortlaut der entworfenen Regierungsrichtlinie wurde zwar Anfang Januar 1938 an einzelne Ministerien verschickt, trotzdem verzögerte sich ihre Annahme. Die Gründe dafür sind nicht ganz eindeutig. Die eingeschlagene Politik in der Staatsangestelltenfrage beruhte zwar auf einem offen deklarierten politischen Konsens der Koalitionsparteien, die in einer Resolution des Abgeordnetenhauses von Anfang Dezember 1937 der Regierung auferlegten, das Prinzip. der „gerechten Proportionalität" im Sinne des Regierungsbeschlusses vom 18. Februar 1937 "sehr genau" einzuhalten, wobei in der Resolution u. a. ausdrücklich von der öffentlichen Verwaltung die Rede war. ${ }^{233}$ Möglicherweise wurden intern jedoch gewisse parteipolitische Interessen geltend gemacht bzw. - ob vorgeschoben oder nicht, muß dahingestellt bleiben - gewisse Zweifel rechtlich-technischer Natur formuliert. Letzten Endes war die Herstellung der Proportionalität in den einzelnen Ressorts der Staatsverwaltung angesichts ihrer unterschiedlichen Strukturen, Aufgabenbereiche und -schwerpunkte und nicht zuletzt auch angesichts ihrer unterschiedlichen sicherheitspolitischen Bedeutung ein nicht nur sachlich sondern auch juristisch kompliziertes Problem. Anfang März 1938 meldete sich nämlich das Unifizierungsministerium mit einem unerwarteten Einwand: Die Richtlinie stehe im Widerspruch zu Paragraph 128 der Verfassung, der jedem Staatsbürger den Zutritt zu „öffentlichen Diensten, Ämtern und Würden“ gewährte. ${ }^{234}$ Die Festlegung bestimmter Quoten im Staatsdienst hindere somit einen Staatsbürger, der ansonsten entsprechend qualifiziert - das Ministerium fügte auch hinzu: dem Staat gegenüber loyal - sei, am verfassungsmäßig garantierten freien Zugang zum Staatsdienst. Trotz dieser Vorbehalte billigte die Regierung die Richtlinie in der Sitzung am 18. März. 235

Offensichtlich hielt man es für notwendig, in der turbulenten außen- wie innenpolitischen Entwicklung nach dem Anschluß Österreichs einen klaren Beweis vorzulegen, daß die im Februar 1937 eingeleitete Nationalitätenpolitik nicht nur auf dem Papier bestehen würde. ${ }^{236} \mathrm{Im}$ allmählich schrumpfenden deutschen aktivistischen Lager rief sie tatsächlich eine gewisse Genugtuung hervor, ohne natürlich etwas Grundlegendes an der politischen Entwicklung ändern zu können. ${ }^{237}$ Allerdings war die Vorschrift

${ }^{232}$ Erlaß MF Nr. 41125/37-I vom 28. 12. 1937. Vgl. auch DSa 18 (1938), Nr. 2, S. 4.

233 Die Resolution wurde in der 122. Sitzung des Abgeordnetenhauses am 4.12. 1937 verabschiedet. Wortlaut siehe in: Bericht des Budgetausschusses über den Regierungsentwurf des Staatshaushaltes der Tschechoslowakischen Republik und des Finanzgesetzes für das Jahr 1938, in: TTZPS, 4. WP, Drucksache 1140, S. 239. Vgl. auch SÚA, MV-P, Karton 437, VI/40, PMR an alle Ministerien und Zentralbehörden, 10.12.1937.

${ }_{234}^{23 U}$ SÚ, MV-P, Karton 437, VI/40, MpSZaOS an PMR, 24. 3. 1938.

235 SÚA, PMR, Karton 4138, 19. Sitzung der Regierung am 18. 3. 1938. Irrtümlicherweise schrieb „Der deutsche Staatsangestellte" die Vorbereitung der Richtlinie den deutschen Ministern zu. Vgl. DSa 18 (1938), Nr. 4, S. 2.

${ }^{236}$ Die Presseabteilung des PMR ließ in der Tagespresse die Information veröffentlichen, daß allen Bewerbungsunterlagen für den Staatsdienst auch die Angabe über die Nationalität des Bewerbers beizufügen sei. Damit war automatisch für eine große Publizität der Beschlüsse der Regierung gesorgt. Vgl. LN vom 19. 3. 1938; Der Sozialdemokrat vom 19. 3. 1938.

${ }^{237}$ "Wenn die Verordnung so durchgeführt würde, wie sie schwarz auf weiß beschlossen und besiegelt ist, könnten wir Deutsche im Staatsdienst zufrieden sein.“ in: DSa 18 (1938), Nr. 5, S. 1. 
noch nicht ganz ausgearbeitet. Die erwähnten Einwände des Unifizierungsministeriums beispielsweise sollten erst in weiteren Verhandlungen ausgeräumt werden. Auch war noch zu klären, welche Bereiche aus der Regelung auszunehmen waren; zu den ursprünglich genannten (Streitkräfte, Finanzwache und Zolldienst) kamen nämlich noch die zivile Luftfahrt sowie der mit der Verteidigung des Staates zusammenhängende technische Dienst im Bereich des Postministeriums hinzu. ${ }^{238}$ Das erstere Problem wurde relativ bald geklärt: Indem die diskutierte Bestimmung der Verfassung nicht, argumentierte Ende März das Innenministerium, in das fünfte Haupstück (Die Rechte und Freiheiten sowie die Pflichten der Bürger), sondern in das sechste (Schutz der Minderheiten) aufgenommen worden war, bedeute sie, daß das geschütze Gut nicht die uneingeschränkte Konkurrenz der Staatsbürger um die Stellen im Staatsdienst betreffe, sondern die Gleichberechtigung der Angehörigen der nationalen und religiösen Minderheiten bei der Bewerbung um diese Posten. In der Verfassungsurkunde könne man zwar keine Grundlage für die Einführung von Quoten im Staatsdienst finden, sie verhindere jedoch eine derartige Regelung auch nicht - natürlich vorausgesetzt, daß das Prinzip der bürgerlichen Gleichheit nicht verletzt würde. Dies wäre nach Meinung des Innenministeriums nur dann der Fall, wenn man für Angehörige einer Minderheit bestimmte Stellen im Staatsdienst reservieren würde, während sie sich um die übrigen Stellen frei bewerben könnten, oder wenn die Aufnahmebedingungen für sie günstiger wären als für andere Staatsbürger. ${ }^{239}$

In der ursprünglichen Form wurde die Richtlinie schließlich nie realisiert. Nachdem die Vorbereitung des Nationalitätenstatuts Ende März 1938 verkündet worden war, war bald klar, daß die Bestimmung über die Proportionalität im Staatsdienst ein Bestandteil der neuen Regelung sein würde. ${ }^{240}$ In einem vom Ende März 1938 datierten Konzept zum „Minderheitenstatut in der Tschechoslowakischen Republik“ rechnete Präsident Beneš mit einem nicht näher spezifizierten Gesetz über die Bestellung von Beamten und Angestellten in den Staatsdienst sowie in die staatlichen Betriebe, ferner mit zwei Regierungsverordnungen, die eine proportionale Vertretung der Minderheiten sowohl in den "gemischten Gebieten“ als auch im gesamtstaatlichen Rahmen gewährleisten sollten. ${ }^{241}$ Sinngemäß identische Aussagen enthielt auch der Bericht des Außenministeriums über das Nationalitätenstatut, das am 11. April an die tschechoslowakischen Gesandtschaften in Paris, London und Berlin geschickt wurde. ${ }^{242}$ Die Bestimmungen hinsichtlich der Staatsangestelltenfrage enthielt das fünfte Hauptstück des Nationalitätenstatuts, jedoch in einem Umfang, der Bedenken hervorrufen mußte. Die grundsätzlichen Formulierungen des Abschnittes wurden aus dem Regierungsbeschluß vom März 1938 übernommen. Es stellt sich jedoch die Frage, ob das, was als interne Richtlinie gedacht war, auch für eine umfassende gesetzliche Regelung ausreichte. Das betreffende Haupstück war zwar mit dem Titel „der Proporz im Staatsdienst“ überschrieben, in der Tat sprach man aber

238 SÚA, PMR, Karton 4138, 21. Sitzung der Regierung am 1. 4. 1938.

239 SÚA, MV-P, Karton 437, VI/40, Aktenvermerk MV-P, 28. 3. 1938. Das Innenministerium formulierte seinen Standpunkt das erstemal in einer Beratung am 21. 3. 1938.

240 Vgl. SÚA, PMR, Karton 4138, 21. Sitzung der Regierung am 1. 4. 1938.

241 ANM, NL Beneš, Karton 47, 440, Minderheitenstatut in der Tschechoslowakischen Republik, 29. 3. 1938.

${ }^{242} \mathrm{MZV}$ an Gesandtschaften in Paris, London und Berlin, 11. 4. 1938, in: Beneš, Mnichovské dny, Dokument Nr. 2, S. 352. 
darin lediglich von der Aufnahme und zudem nur in den „zivilen“ Dienst, ohne daß dieser Begriff definiert wurde..$^{243}$ Davon, daß man gegebenfalls beabsichtigt hätte, das Prinzip der Proportionalität auch bei Beförderungen zu berücksichtigen, wie es die deutschen Aktivisten bereits 1937 verlangt hatten, war keine Rede. Der Lage angemessener wäre wohl auch gewesen, vorübergehende Sonderregelungen zu beschließen, um die verhältnismäßige Vertretung im Staatsdienst in absehbarer Zeit zu erreichen.

Der Grund für die Zurückhaltung der Regierung in dieser Frage dürfte in der Befürchtung gelegen haben, die gesamten Bereiche der Staatsverwaltung in den Grenzgebieten der Monopolherrschaft der Sudetendeutschen Partei auszuliefern. Diese ging in ihren Vorschlägen zur Staatsangestelltenfrage von einer weitreichenden nationalen Sektionierung der Staatsverwaltung aus, wobei die Abteilungen, die im deutschen Gebiet lagen oder für dieses zuständig waren, nur mit deutschen Staatsangestellten besetzt werden sollten. ${ }^{244}$ In der Zentralverwaltung oder in denjenigen Einrichtungen des Staates, in denen man keine national getrennten Abteilungen vorsah, sollte eine nicht näher spezifizierte Proportionalität „unter Berücksichtigung der besonderen Verhältnisse“ gelten; beim Personal der staatlichen Unternehmungen war der Amtssprengel bzw. der Stationsbereich maßgebend. Der Überzeugung der SdP nach müßten Deutsche in den nächsten Jahren überproportional in den Staatsdienst aufgenommen werden, bis ein gerechtes Verhältnis im gesamten Angestellten- und Beamtenkörper hergestellt sei. ${ }^{245}$ Als wichtige Voraussetzung für eine gerechte Regelung der Staatsangestelltenfrage bezeichnete sie einen nationalen Kataster, dessen Errichtung im Sinne der Forderungen der SdP die Regierung jedoch zu dieser Zeit entschieden ablehnte. Nur Kataster, durch die die Nationalitäten der Republik „zu fest geschlossenen, jederzeit hinsichtlich ihrer Angehörigen klar bestimmbaren Körperschaften" zusammengefaßt würden, so entlarvte die Partei ihr rassistisches Gedankengut, könnten Gewähr dafür bieten, daß Personen nicht bevorzugt werden, die „sich zwar ihrer Muttersprache nach zu einer bestimmten Volksgruppe bekannt haben, aber ihrer Rasse nach einem anderen Volke oder einer anderen Volksgruppe angehören, oder national indifferent sind." ${ }^{\text {"246 Henlein }}$ verlangte deshalb, nur Personen als Staatsangestellte einer Nationalität anzusehen bzw. aufzunehmen, die durch „ein hierzu befugtes Organ dieser Volksgruppe als für die Aufnahme in den öffentlichen Dienst geeignet bezeichnet" würden. ${ }^{247}$ Dies hätte auch ermöglicht, ihre "Getreuen“ bei Neuanstellungen mehr zu berücksichtigen, denn, wie er kritisch feststellte, würden eben diese Leute, die mit der Volksgruppe „gesinnungsmäßig besonders stark verbunden sind", von der Aufnahme in den öffentlichen Dienst systematisch ausgeschlossen. ${ }^{248}$

Präsident Beneš hielt offensichtlich die Staatsangestelltenfrage für ein Thema, in dem eine Übereinstimmung relativ einfach zu erreichen war: Nicht zufällig stand sie in seinen Aufzeichnungen über den Verhandlungsmodus mit der SdP von Ende August

${ }^{243}$ Nationalitätenstatut I, S. 18. Unverändert enthielt diese Bestimmung bereits eine der früheren Fassungen des Statuts, wahrscheinlich vom Mai 1938. Vgl. ANM, NL Sobota, Karton 13, Gesetz, durch das das Nationalitätenstatut der Tschechoslowakischen Republik herausgegeben wird, undat.

244 Die Zeit vom 20.7. 1938.

245 Nationalitätenstatut II, S. 28.

246 Ebda., S. 29.

247 Ebda.

248 Ebda. 
1938, die als der sogenannte „dritte Plan“ bekannt sind, an erster Stelle. ${ }^{249}$ Trotzdem hielt er es nur teilweise für möglich, den Vorstellungen der SdP zu entsprechen. Daß die einzelnen Nationalitäten des Staates das Recht auf einen Anteil am Personalstand der Staatsverwaltung in allen Rangstufen hätten, der ihrem Prozentsatz an der Gesamtbevölkerung entsprach, war nicht mehr umstritten. ${ }^{250}$ Eine Übereinstimmung wurde auch darin erreicht, daß das Verhältnis bei der Aufnahme neuer Kräfte deutscher $\mathrm{Na}$ tionalität in den nächsten Jahren günstiger als der Bevölkerungsschlüssel ausfallen müsse, um „so schnell wie möglich“ eine gerechte proportionale Vertretung zu erreichen. ${ }^{251}$ Abweichend waren jedoch die Ansichten über den Zeitraum, in dem eine gerechte Vertretung im Staatsdienst ${ }^{252}$ herzustellen war: Während Beneš acht bis zehn Jahre vorgeschlagen hatte, sprach die SdP von „spätestens fünf Jahren“, was jedoch die Experten der Präsidentenkanzlei als zu kurz bezeichneten. ${ }^{253}$ Sie bezweifelten nämlich, daß es überhaupt genug qualifizierte deutsche Kandidaten geben oder daß es der Staatsverwaltung möglich sein würde, so viele unerfahrene Kräfte innerhalb einer derart kurzen Zeit zu absorbieren. Außerdem müßte man, um ein rasches Anschwellen des personellen Bestandes im Staatsdienst zu verhindern, viele andere - der Sachlage nach tschechische - Staatsangestellte vorzeitig entlassen, was auf tschechischer Seite sicher auf politischen Widerstand stoßen würde. Der Präsident schlug vor, beim Präsidium des Ministerrates paritätisch besetzte Kommissionen aus den Repräsentanten der Regierung und der jeweiligen Nationalität unter dem Vorsitz eines Staatsbeamten der entsprechenden Volkszugehörigkeit zu errichten, die das Vorgehen in der Staatsangestelltenpolitik kontrollieren sollten. ${ }^{254}$ Die Henlein-Mannschaft war nicht dagegen, hielt jedoch bloße Kontrollbefugnisse für nicht genug und versuchte deswegen, das

249 Protokoll betreffend den am 24. August 1938 beim Herrn Präsidenten der Republik mit den Herrn Abgeordneten Kundt und Sebekovsky vereinbarten Verhandlungsmodus hinsichtlich der nationalen Angelegenheiten, 29. 8. 1938, in: Beneš, Mnichovské dny, Dokument Nr. 27, S. 445-446. Vgl. auch: SÚA, SdP, Karton 52, 28 PK 1934-38/6, Gedächtnisprotokoll über die Unterredung zwischen Präsident Dr. E. Beneš, Abg. E. Kundt und Dr. W. Sebekovsky am 25. 8. 1938.

250 Im „dritten Plan“" wurde das Prinzip der Proportionalität auf allen Rangstufen nicht ausdrücklich formuliert. Erst nachdem die SdP auf diesen Mangel zu Recht aufmerksam gemacht hatte, nahm Beneš eine entsprechende Bestimmung in den „vierten Plan“ auf.

251 Protokoll betreffend den am 24. August 1938 beim Herrn Präsidenten der Republik mit den Herren Abgeordneten Kundt und Sebekovsky vereinbarten Verhandlungsmodus hinsichtlich der nationalen Angelegenheiten, 29. 8. 1938, in: Beněs, Mnichovské dny, Dokument Nr. 27, S. 445-446.

252 Die SdP plädierte u. a. dafür, das sich der Grundsatz der Proportionalität auch auf die Bestellung von Mitgliedern und Organen der sonstigen staatlichen Einrichtungen und Anstalten, wie Beiräte, ständige Kommissionen oder „privilegierte Unternehmungen“ erstrecken sollte. Vgl. SÚA, SdP, Karton 52, 28 PK 1934-38/6, Entwurf eines Protokolles, in dem der Verhandlungsmodus hinsichtlich der Regelung der nationalen Angelegenheiten zwischen der tschechoslowakischen Regierung und der Sudetendeutschen Partei vereinbart wird, undat. (überreicht am 2.9. 1938 an Präsident Beneš, vgl. Beneš, Mnichovské dny, S. 199-201).

253 SÚA, SdP, Karton 52, 28 PK 1934-38/6, Entwurf eines Protokolles, in dem der Verhandlungsmodus hinsichtlich der Regelung der nationalen Angelegenheiten zwischen der tschechoslowakischen Regierung und der Sudetendeutschen Partei vereinbart wird, undat. (überreicht am 2. 9.1938 an Präsident Beneš, vgl. Beneš, Mnichovské dny, S. 199-201) bzw. ANM, NL Sobota, Karton 13, Erläuterungen zu Punkt 2, undat. (zwischen 2.9. 1938 und 5. 9. 1938).

${ }^{254}$ Protokoll betreffend den am 24. August 1938 beim Herrn Präsidenten der Republik mit den Herren Abgeordneten Kundt und Sebekovsky vereinbarten Verhandlungsmodus hinsichtlich der nationalen Angelegenheiten, 29. 8. 1938, in: Beneš, Mnichovské dny, Dokument Nr. 27, S. 445-446. Die Kommission sollte nicht nur die Einhaltung der Proportionalität überwachen, sondern auch neue Ressortvorschriften für den Bereich des Staatsdienstes unter dem Aspekt der Proportionalität begutachten; ihre Jahresberichte hatte die Regierung dem Parlament vorzulegen. 
Schwergewicht der Tätigkeit der Kommissionen auf die Mitgestaltung der Personalpolitik in einzelnen Ressorts zu verlagern. Nach wie vor bemühte sich die Partei, in dem Gremium ausschließlich den eigenen Einfluß geltend zu machen: Die Kommissionsmitglieder sollten bis auf weiteres durch Mehrheitsbeschluß der Parlamentarier gleicher Volkszugehörigkeit gewählt werden. ${ }^{255}$ Darauf wollte Beneš nicht eingehen und verlangte im „vierten Plan“ von Anfang September, die Mitglieder zwar durch die Abgeordneten der jeweiligen Nationalität wählen zu lassen, jedoch nach dem Verhältnisprinzip, so daß auch andere politische Richtungen, beispielsweise die DSAP, in dem gewählten Organ vertreten sein konnten. ${ }^{256}$

Ein sehr heikler Punkt war auch die räumliche Verteilung der Staatsangestellten. Die SdP ging grundsätzlich davon aus, daß für Behörden, die im „deutschen Gebiet“ lagen, nur deutsche Beamte verwendet werden durften. Als ersten Schritt empfahl sie, wenigstens die im tschechischen Gebiet noch befindlichen deutschen Staatsangestellten gegen die gleiche Anzahl tschechischer auszutauschen. ${ }^{257}$ Diese Forderung kam für die Regierung keinesfalls unerwartet. Letzten Endes enthielt die frühere Fassung des Nationalitätenstatuts im Einklag mit der im Herbst 1937 vorbereiteten Regierungsrichtlinie die Bestimmung, daß Staatsangestellte "nach Möglichkeiten“ in einem Amtssprengel zu bestellen waren, in dem die Bevölkerung derselben Nationalität ansässig war. ${ }^{258}$ In dem am 30. Juni an die SdP übergebenen Entwurf des Statuts fehlte sie jedoch gänzlich, möglicherweise aufgrund der Befürchtung, die Staatsverwaltung in den Grenzgebieten dem Zugriff der nunmehr offen totalitären Henlein-Partei auszuliefern, teilweise wohl auch aus Rücksicht auf die dortigen Tschechen. Deshalb schlug Beneš im "dritten Plan“ vor, daß selbst unter Aufrechterhaltung des Grundsatzes der Versetzbarkeit von Staatsangestellten (mit Ausnahme von Richtern) mindestens 50 Prozent der deutschen Staatsangestellten der einzelnen Kategorien in Gebieten mit deutscher Bevölkerungsmehrheit bestellt werden sollten. ${ }^{259} \mathrm{Die}$ SdP konterte mit der Forderung, daß die Zusammensetzung der Staatsangestellten in einzelnen Verwaltungsgebieten der nationalen Zusammensetzung der dortigen Bevölkerung entsprechen müsse. ${ }^{260}$ Dies hielt die tschechische Seite für unmöglich: Die neue Sprachenregelung im Sinne der Vorschläge der SdP, die bekanntlich auf eine Gleichberechtigung beider Sprachen hinauslief, würde eine gewisse Zahl an tschechischen Beamten im deutschen und noch

255 SÚA, SdP, Karton 52, 28 PK 1934-38/6, Entwurf eines Protokolles, in dem der Verhandlungsmodus hinsichtlich der Regelung der nationalen Angelegenheiten zwischen der tschechoslowakischen Regierung und der Sudetendeutschen Partei vereinbart wird, undat. (überreicht am 2. 9. 1938 an Präsident Beneš, vgl. Beneš, Mnichovské dny, S. 199-201).

256 Protokoll über den Verlauf der Verhandlungen hinsichtlich der Regelung der nationalen Angelegenheiten zwischen der tschechoslowakischen Regierung und der Sudetendeutschen Partei, 5. 9. 1938, in: Beneš, Mnichovské dny, Dokument Nr. 36, S. 471.

257 Die Zeit vom 20. 7. 1938. Vgl. auch Nationalitätenstatut II, S. 28.

258 ANM, NL Sobota, Karton 13, Gesetz, durch das das Nationalitätenstatut der Tschechoslowakischen Republik herausgegeben wird, undat. Bestellung und Versetzung von Staatsangestellten in denjenigen Bereichen, die ausschließlich oder vorwiegend in bestimmten Gebieten des Staates konzentriert waren, sollten durch eine besondere Richtlinie geregelt werden.

259 Protokoll betreffend den am 24. August 1938 beim Herrn Präsidenten der Republik mit den Herren Abgeordneten Kundt und Sebekowsky vereinbarten Verhandlungsmodus hinsichtlich der nationalen Angelegenheiten, 29. 8. 1938, in: Beneš, Mnichovské dny, Dokument Nr. 27, S. 445-446.

260 SÚA, SdP, Karton 52, 28 PK 1934-38/6, Entwurf eines Protokolles, in dem der Verhandlungsmodus hinsichtlich der Regelung der nationalen Angelegenheiten zwischen der tschechoslowakischen Regierung und der Sudetendeutschen Partei vereinbart wird, undat. (überreicht am 2. 9.1938 an Präsident Beneš, vgl. Beneš, Mnichovské dny, S. 199-201). 
viel mehr deutsche Beamte im tschechischen Sprachgebiet erfordern als es dem Bevölkerungsschlüssel entsprechen würde. Hinzu kam auch die Frage der Sprachkenntnisse: In Zukunft würden viele Staatsangestellte, besonders in den Zentralbehörden, erforderlich sein, die mindestens zwei Sprachen beherrschten. Die in diesem Fall notwendigen Sprachkenntnisse könnten nur durch längeres Wirken in einer Region erworben werden, in der die Bevölkerung die betreffende Sprache spreche. ${ }^{261}$ Aufgrund dieser Überlegungen empfahl Beneš im "vierten Plan“, diese Frage dahingehend zu lösen, daß höchstens 30 Prozent der Staatsangestellten deutscher Nationalität im Gebiet bestellt werden durften, in dem die deutsche Bevölkerung keine Mehrheit bildete. ${ }^{262}$ Doch bekanntlich reagierte die SdP nicht mehr auf diesen Vorschlag, und das sicher hoffnungsvolle - wenn auch leider verspätet entstandene - Projekt der Proportionalität im Staatsdienst konnte nicht weiterentwickelt, geschweige denn zumindest ansatzweise realisiert werden.

261 ANM, NL Sobota, Karton 13, Erläuterungen zu Punkt 2, undat. (zwischen 2.9. 1938 und 5.9. 1938).

262 Protokoll über den Verlauf der Verhandlungen hinsichtlich der Regelung der nationalen Angelegenheiten zwischen der tschechoslowakischen Regierung und der Sudetendeutschen Partei, 5. 9. 1938, in: Beneš, Mnichovské dny, Dokument Nr. 36, S. 471. 


\section{Orts- und Straßennamen}

Es ist gewiß symptomatisch, daß das tschechoslowakische Sprachenrecht eine Reihe von speziellen Bestimmungen enthielt, die sich mit Orts- und Straßenbezeichnungen sowie deren Anwendung beschäftigten. Unter den Bedingungen des Nationalitätenkampfes trägt eine Ortsbezeichnung neben dem rein informativen Wert in der Regel auch eine nationalpolitische Aussage: Durch den Gebrauch oder Nichtgebrauch eines Orts- oder Straßennamens in dieser oder jener Sprache manifestiert der Sprecher sein nationales Bekenntnis, er signalisiert gleichzeitig den Grad der Verwurzelung "seines“ Volksstammes in der Ortschaft bzw. deren Zugehörigkeit zu „seinem“ Sprachgebiet. ${ }^{1}$ Althergebrachte Ortsnamen markieren auch den historischen Umfang des Siedlungsgebietes und werden in der Regel als Argumente für die Zugehörigkeit einer Ortschaft oder Region zu einem sprachlich-kulturellen Raum und folglich zu einem Staatswesen ins Feld geführt. Die Versuche, im Gebrauch von Orts- und Straßennamen anderssprachige Äquivalente durchzusetzen, können als Kennzeichen einer angestrebten Durchdringung des geschlossenen Siedlungsgebietes und der darauffolgenden Überfremdung oder Assimilierung empfunden werden.

Vor allem Ortsnamen wurden bald nach dem Umsturz zum Gegenstand von Überlegungen, hinter denen sich nicht nur nationalpolitische Motivationen, sondern auch praktische Bedürfnisse der neuen Administration verbargen. Nach einer schnellen und einheitlichen Regelung riefen vor allem Eisenbahn und Post; die Restitution untergangener oder manchmal vor 1918 künstlich aus dem Amtsverkehr verdrängter tschechischer Ortsnamen als Kennzeichen der Zugehörigkeit vor allem der Grenzgebiete zum neuen Staat verlangte nachdrücklich auch die tschechische Bevölkerung in den deutschsprachigen Gebieten.

Man könnte eine gewisse „kakanische“ Symbolik darin erblicken, daß es Amtsstempel waren, die die Aktivitäten hinsichtlich der Ortsbezeichnungen in Gang setzten. Die in den böhmischen Ländern verwendeten Stempel waren nämlich nur deutsch bzw. deutsch-tschechisch beschriftet. Als erstes entschloß sich das Postministerium, an dessen Spitze der Sozialist J. Stříbrný stand, diesem Zustand ein Ende zu bereiten. Im März 1919 schlug es vor, daß bei Postämtern mit Sitz an Orten, in denen weniger als 20 Prozent Tschechen lebten, Stempel mit tschechisch-deutschen, im übrigen Gebiet mit rein tschechischen Inschriften versehen werden sollten. Die Begründung verriet die um sich greifende Emotionalisierung des tschechisch-deutschen Verhältnisses zu dieser Zeit: „Die Deutschen in Böhmen und Mähren sind Kolonisten; wenn das Tschechische für unsere Republik als Staatssprache festgelegt wurde (sic!), muß es natürlich auch auf Poststempeln geltend gemacht werden."2 Problematisch war jedoch, wie das Ministerium zugeben mußte, daß über 1300 Gemeinden allein in Böhmen überhaupt keine tschechische Bezeichnung besaßen. Aus diesem Grund schlug man vor, eine

1 Vgl. Jaworski, Ortsbezeichnungen, S. 251.

2 SUA, PMR, Karton 3295, 740/6/3, MPaT an PMR, 22. 3. 1919. 
Fachkommission einzusetzen, die die tschechischen Namen entweder anhand von historischen Quellen feststellen oder einfach „nach dem Volksbrauch“ bestimmen sollte. Durch eine rasche Lösung wollte man übrigens einem sprachlichen Chaos vorbeugen: Mancherorts ergriffen nämlich die Öffentlichkeit oder die Behörden selbst die Initiative und führten nicht selten kaum bekannte oder sogar selbsterfundene Namen ein, was natürlich die Tätigkeit gerade der Postverwaltung äußerst erschwerte. ${ }^{3}$

Im November 1919 beschloß der Ministerrat, beim Innenministerium eine Ständige Kommission für die Festsetzung der amtlichen Ortsnamen in der Tschechoslowakischen Republik zu errichten, die im März 1920 ihre Tätigkeit aufnahm. ${ }^{4}$ Die Aufgabe war keineswegs bescheiden: Sie sollte nicht nur dringende Einzelfälle lösen, sondern eine „systematische allgemeine Revision“ der Ortsnamen überhaupt vornehmen. ${ }^{5}$ Die rechtliche Grundlage für dieses Vorgehen schaffte ein besonderes Gesetz über Städte-, Gemeinde-, Ortschafts- und Straßennamen (Nr. 266/1920 Slg.), das in den letzten Tagen der Amtsperiode der Revolutionären Nationalversammlung beschlossen wurde. ${ }^{6}$ Die Norm ging glatt über die Bühne, was teils auf den Zeitdruck, teils auf den Umstand zurückzuführen ist, daß sie ganz allgemeine Rahmenbestimmungen enthielt, deren Konkretisierung man einer im August 1921 erlassenen Regierungsverordnung überließ?

Das Gesetz übertrug dem Innnenminister die Aufgabe, für jede Stadt, Gemeinde und Ortschaft einen amtlichen Namen festzusetzen. Damit wurde von der älteren österreichischen Praxis Abschied genommen, die ein langwieriges Verfahren unter Einbeziehung vieler Behörden vorgesehen und darüber hinaus im Grunde genommen auf der Eigeninitiative der Gemeinden beruht hatte. ${ }^{8}$ Dies begründete das Innenministerium u. a. damit, die Benennung einer Gemeinde sei nicht nur ihre eigene Angelegenheit,

${ }^{3}$ In der Euphorie erfand man z. B. für die Stadt Warnsdorf den tschechischen Namen „Vavř́nov“, die tschechische Form der Ortsbezeichnung hieß später doch Varnsdorf, wie es üblich gewesen war. Vgl. SÚA, MV-SR, Karton 503, 20/2/35(3), MPaT an MV, 24.3.1919.

${ }^{4}$ In der Kommission waren unter dem Vorsitz des Innenministeriums die Vertreter des Justiz-, Finanz-, Post-, Landwirtschafts-, Verteidigungs- und Schulministeriums sowie des Ministeriums für Industrie, Handel und Gewerbe, des Statistischen Staatsamtes, der Landesausschüsse für Böhmen, Mähren und Schlesien sowie deren Archive, des Archivs des Innenministeriums und der Topographischen Kommission der Tschechischen Akademie der Wissenschaften und Künste tätig. Die Kommission sollte Gutachten und Vorschläge ausarbeiten, und zwar auf Anregung des Innenministeriums oder aus eigener Initiative; bei Namensänderungen war auch der Standpunkt der betroffenen Gemeinde einzuholen, vgl. Erlaß MV Nr. 11709/15 vom 6. 3. 1920, in: Věstník MV 2 (1920), S. 105.

5 Prokop, O úpravě, S. 323.

6 Die tschechischen nationalen Radikalen verlangten zwar, die Bestimmungen über den Gebrauch von Ortsnamen in das Sprachengesetz aufzunehmen. Während den Vorbereitungen zu dieser Rechtsnorm wurde dies jedoch gar nicht in Erwägung gezogen. Vgl. Entwurf des Abgeordneten Dr. Lukavský und Genossen zu dem vorbereiteten Sprachgesetz vom 13.1. 1920, in: TZRNS, Drucksache 2187.

7 Vgl. Regierungsentwurf des Gesetzes über die Städte-, Gemeinde-, Ortschafts- und Gassennamen sowie über die Bezeichnung der Gemeinden mit Ortstafeln und die Numerierung der Häuser vom 20. 3. 1920, in: TZRNS, Drucksache 2645; APČR, RNS, Karton 34, 175. Sitzung des Verfassungsauschusses am 30. 3. 1920, S. 23-41; 144. Sitzung der Revolutionären Nationalversammlung am 14.4. 1920, in: TZRNS, S. 4166-4172.

8 Im Unterschied zu Ungarn, wo ein Gesetz über die Ortsnamen aus dem Jahre 1898 gegolten hatte, verfügte das österreichische Recht über keine besonderen rechtlichen Bestimmungen hinsichtlich der Festlegung der Ortsnamen, die sich im Grunde genommen via facti etablierten. Eine eventuelle Ortsnamensänderung wurde der Initiative der Kommunalvertretungen überlassen und erfolgte nach Anhörung von verschiedenen Institutionen (Innen-, Finanz- Justizministerium, Landesausschuß, Landesfinanzdirektion und anderen), indem sie durch einen im Landesgesetzblatt veröffentlichten Erlaß des Landesstatthalters bewilligt wurde. Vgl. Prokop, O úpravě, S. 322. 
sondern sie betreffe auch andere öffentliche Interessen, beispielsweise verkehrsmäßige, statistische oder aber nationalpolitische; in letztgenannter Hinsicht fiel offen das einleuchtende Argument, man könne den deutschen Gemeinden kaum zumuten, selbst eine amtliche tschechische Bezeichnung zu beantragen. ${ }^{9}$ Im Sinne des Gesetzes sollten alle Städte, Gemeinden und Ortschaften denjenigen Namen als Amtsbezeichnung erhalten, den "sich die tschechoslowakische Sprache geschaffen hat". Auch konnte ein Name, "den die Sprache der Minderheit geschaffen hatte", als amtlich festgesetzt werden, falls in der betreffenden Stadt, Gemeinde oder Ortschaft mindestens 20 Prozent Staatsangehörige „derselben, jedoch einer anderen als der tschechoslowakischen Sprache" wohnhaft waren, oder in der Stadt ein Gericht oder eine Behörde ihren Sitz hatte, deren Wirkungskreis sich auf einen sprachlich qualifizierten Gerichtsbezirk erstreckte, bzw. falls es für die betreffende Ortschaft keinen tschechischen Namen gab. Die Fakultativbestimmung legte zwar die Entscheidungsgewalt eindeutig in die Hände der Exekutive, allerdings wurde die Festsetzung amtlicher Ortsnamen auch in Minderheitensprachen, abgesehen von den speziellen im folgenden behandelten Fällen, zur Regel. Dies führte freilich zur Mißstimmung der tschechischen Volkstumsverbände, die noch nach Jahren darauf drangen, diese Bestimmung nicht geltend zu machen, und die "schöne“ Gelegenheiten zu nutzen, die „durch die alte Monarchie unseren Städten aufgezwungenen Namen zu verwerfen". ${ }^{10}$

Die amtlichen Ortsnamen wurden in ein beim Innenministerium geführtes Register aufgenommen, das nach jeder Volkszählung zu aktualisieren war. ${ }^{11}$ Für ihren Gebrauch wurden Regeln festgelegt, die nicht nur für Staatsorgane sondern auch für den Parteienverkehr mit ihnen verbindlich waren, ja sogar im privaten Sprachgebrauch war ratsam, sich daran zu halten: Entsprach man nicht der Vorschrift, konnten Staatsorgane eine Eingabe als unzulänglich abweisen; im Postverkehr hatte dies manchmal die Nichtzustellung von Sendungen zur Folge, was nicht selten Briefe oder Pakete auch aus dem Ausland traf. ${ }^{12}$ Die Regeln basierten grundsätzlich auf dem Prinzip der Kongruenz: Falls es eine deutsche amtliche Ortsbezeichnung gab, durfte in einem deutschsprachigen Text nur diese gebraucht werden. Eine Ausnahme bildete die Korrespondenz der Staatsorgane mit dem Ausland - in diesem Fall mußten stets die tschechischen (slowakischen) Bezeichnungen verwendet werden; war der Text ins Ausland in der Sprache einer nationalen Minderheit abgefaßt, mußte man der "tschechoslowakischen" amtlichen Bezeichnung auch den amtlichen Namen in ihrer Sprache hinzufügen. Die Intention dieser Bestimmung zielte eindeutig darauf ab, wie damals das Außenministerium bestätigte, die tschechischen oder slowakischen Namen statt der in der Regel viel bekannteren deutsch- bzw. ungarischsprachigen Bezeichnungen im internationalen Verkehr zu etablieren. ${ }^{13}$ Probleme in verschiedendsten Bereichen ließen

9 SÚA, MV-SR, Karton 503, 20/2/35(3), Aktenvermerk MV, 22. 9. 1919. Vgl. auch Prokop, O úpravě, S. 322.

10 SÚA, PMR, Karton 463, 1063/2-3, Resolution der tschechischen Grenzler, vorgelegt durch NJS, 10. 12.1936.

11 Die Herausgabe der amtlichen Ortsverzeichnisse wurde durch das Innenministerium in der "Sammlung der Gesetze und Verordnungen" bekanntgegeben, vgl. Kundmachung des Ministers des Innern Nr. 22/1925 Slg., 237/1934 Slg. (Ortsverzeichnis für das Land Böhmen) und 231/1935 Slg. (Ortsverzeichnis für das Land Mähren-Schlesien), vgl. Statistický lexikon obcí v Republice Československé, Praha 1924, 1934 und 1935.

12 Vgl. Kapitel I.C.

${ }^{13}$ SUA, MV-SR, Karton 508, 20/2/70, MZV an MV, 31. 10. 1921. 
nicht lange auf sich warten: So waren beispielsweise die Stadtväter von Franzensbad von der Anziehungskraft der Werbung „Welcome to Františkovy Lázně“ offensichtlich nicht überzeugt, die Behörden vertraten jedoch die Meinung, daß auch in der Werbung die deutsche Bezeichnung lediglich in einem deutschen Text gebraucht werden durfte. Schließlich akzeptierten sie den Rechtsstandpunkt, demgemäß eine Gemeinde in Ausübung des Kurbetriebes gar nicht als öffentliches Amt sondern als privatrechtliches Subjekt auftrat, und somit den Bestimmungen des Sprachenrechts nicht unterworfen war. ${ }^{14}$

Die Festsetzung von amtlichen Namen hatte natürlich auch „im Terrain“ unmittelbare Folgen: Ortstafeln sollten von nun an nur Aufschriften in der Staatssprache tragen; wenn es die Gemeindevertretung beschloß, konnten auch Bezeichnungen in einer anderen Sprache dazukommen - in diesem Fall mußte die Bezeichnung in der Staatssprache stets an erster Stelle stehen. ${ }^{15}$ Gemeinden, in denen eine nationale Minderheit über 20 Prozent der Bevölkerung ausmachte und die somit über einen amtlichen Namen in der betreffenden Minderheitensprache verfügten, mußten auf Ortstafeln somit nicht automatisch auch in dieser Sprache bezeichnet werden, solange dies die jeweilige Gemeindevertretung nicht beschloß - auf ein Entgegenkommen der jeweiligen tschechischen Mehrheit der Vertreter war in dieser Frage offensichtlich kaum zu hoffen.

Die umfangreiche Revision der Ortsnamen, die die „Bohemia“ - im Chor der deutschen Klagelieder - als „Umtaufexzesse“ bezeichnete ${ }^{16}$, verfolgte im Grund genommen drei Ziele: erstens die Abschaffung von deutschen Bezeichnungen tschechischer Gemeinden, zweitens die Wiederherstellung von historischen tschechischen Ortsnamen dort, wo sie in Vergessenheit geraten waren, und drittens die Überprüfung aller Ortsnamen auf ihre Form, Schreibweise, historische Berechtigung sowie sachliche und philologische Richtigkeit. ${ }^{17}$ Besonders im Hinblick auf die zweitgenannte Aufgabe mußte die Kommission sprachlich-puristischen Tendenzen entschieden begegnen, schließlich siegten grundsätzlich fachliche Standpunkte. Als Grundprinzip galt, daß die Namen unverändert bleiben sollten, wie sie sich durch ihre natürliche, sprachliche und historische Entwicklung herausgebildet hatten. Falls diese Entwicklung künstlich oder durch Verstümmelung „unterbrochen“ worden war, war die Wiederherstellung des ursprünglichen Namens zulässig, solange dieser noch nicht aus der Tradition verschwunden war. Eine künstlich geschaffene "slawische“ Bezeichnung war nur in Ausnahmefällen akzeptabel, und zwar falls dies „wichtige“ öffentliche - u. a. auch nationale - Interessen erfordern würden; wie oft man jedoch diese Regel tatsächlich anwandte, muß weiteren Forschungen vorbehalten werden. Generell konnte jedoch auch in Zukunft nur dann ein "slawischer" Ortsname als amtliche Bezeichnung festgelegt werden, wenn dieser als Folge einer natürlichen sprachlichen Entwicklung entstehen sollte; dadurch

14 Vgl. Interpellation des Senators Friedrich und Genossen an die Gesamtregierung betreffend gesetzwidrigen Zwang zur tschechischen Benennung der Stadt Franzensbad seitens der politischen Bezirksverwaltung in Eger vom 8.11. 1923, in: TTZS, 1. WP, Drucksache 1721/6; SÜA, MV-SR, Karton $1489,14 / 1 / 36, \mathrm{MV}$ an MZV, 22. 4. 1924.

15 Die Tafeln mußten einem beigefügten Muster entsprechen. Dadurch wurde gewährleistet, daß die Buchstabengröße und der Buchstabentyp gleich waren.

${ }^{16}$ Bo vom 1. 7. 1922. - Zu deutschen Beschwerden vgl. beispielsweise Interpellation der Abgeordneten Ing. Jung und Genossen an die Gesamtregierung in Angelegenheit der sinnlosen Vertschechung deutscher Ortsnamen vom 17. 11. 1921, in: TTZPS, 1. WP, Drucksache 3190/XVII.

17 SÚA, MV-SR, Karton 503, 20/2/35(3), A ktenvermerk MV, undat. (1920). Als Grundlage für die Revision sollten die Ortsnamenslisten aus den Jahren 1913-1917 herangezogen werden. 
gedachte man, künstlichen tschechischen Namesbildungen für deutsche Städte und Gemeinden und damit auch verschiedenen Verwirrungen einen Riegel vorzuschieben.

Eine äußerst problematische Regelung entwickelte die Durchführungsverordnung zum Gesetz über die Ortsnamen hinsichtlich der amtlichen Bezeichnungen in den Minderheitensprachen. Bei bloßen Anpassungen "tschechoslowakischer" Ortsnamen an die Sprache der nationalen Minderheit in der Rechtschreibung oder durch Endungen (im Deutschen beispielsweise -itz, -etz, oder -au), ebenso wie bei „künstlichen“ späteren Übersetzungen und Neubildungen lehnte man es „in der Regel“ ab, sie als "historisch ursprüngliche Namen“ in der Sprache der Minderheit anzusehen. ${ }^{18}$ Ungeachtet der Zusammensetzung der Bevölkerung drohte vielen deutschen Gemeinden nur im Bezirk Saaz soll es sich um etwa 55 von insgesamt 61 gehandelt haben ${ }^{19}$-, daß sie ihren gängigen, des öfteren Jahrhunderte alten deutschen Namen im amtlichen Verkehr mit den vorgesetzten Bezirksbehörden oder Staatsorganen überhaupt nicht würden gebrauchen dürfen. Das Innenministerium befürchtete, die Staatsmacht sei im Falle passiven Widerstandes seitens der deutschen Gemeinden nicht in der Lage, die Kommunikation mit ihnen aufrechtzuerhalten. Es schlug deshalb einen Kompromiß vor, der einen weiteren Beweis für das mühevolle und engherzige Balancieren zwischen dem Prestige der Staatssprache und der Zweckmäßigkeit des administrativen Verkehrs liefert. Demgemäß konnten Gemeinden, die in mehrheitlich deutschen Bezirken lagen und in denen mindestens 80 Prozent der Bevölkerung deutschsprachig waren, derartige deutsche Namen - unter der Voraussetzung einer Vereinheitlichung der manchmal unterschiedlichen Schreibweise - als Amtsbezeichnung behalten. Ansonsten sollte ausschließlich der tschechische Name als amtliche Bezeichnung gebraucht werden. ${ }^{20}$ Diese Regelung wurde ziemlich merkwürdig begründet: “. . in Gemeinden und Ortschaften, in denen mindestens zu 20 Prozent Angehörige der Staatssprache leben, kann der verstümmelte oder transkribierte tschechoslowakische Namen nicht für eine unantastbare deutsche Bezeichnung gehalten werden, die zum allgemeinen Kulturbesitz des deutschen Volkes geworden ist." Kurz und gut: man machte allen Ernstes die Frage, ob ein deutscher Ortsname Bestandteil des "deutschen Kulturbesitzes“ war oder nicht, vom Prozentsatz der tschechischsprachigen Bewohner der betreffenden Gemeinde abhängig. Diese merkwürdige Logik störte jedoch die Ministerialbürokratie offensichtlich nicht, und die Regel wurde akzeptiert; so hatte beispielsweise die Stadt Prachatitz in Südböhmen nur einen tschechischen amtlichen Namen, also Prachatice, obwohl hier nach den Volkszählungsergebnissen von 1930 50,7 Prozent Deutsche lebten. ${ }^{21}$

Im Vergleich zur Problematik der Ortsnamen mag die der Benennung von Straßen und Plätzen als untergeordnet erscheinen. Aber wie jede Ortstafel, jedes Eisenbahnschild oder jede Firmenaufschrift waren auch Straßenschilder wichtige Posten im Nationalitätenkampf zwischen Tschechen und Deutschen. Wiederum ging es um den sprachlichen Charakter von Städten und Gemeinden, um offene Demonstrationen des

18 Vgl. auch SÚA, PMR, Karton 3266, 731/48, MV an PMR, 11. 6. 1922.

19 Ebda.

20 SÚA, PMR, Karton 3266, 731/48, MV am MS, 21. 8. 1922.

21 Eine Beschwerde der Stadt gegen die Nichtzulassung des deutschen Namens wies das Oberste Verwaltungsgericht im Jahre 1927 mit der Begründung zurück, daß kein Recht der Gemeinde verletzt worden sei. Vgl. AMZV, Sektion VI, Karton 105, MV an PMR, 8. 4. 1938. Vgl. auch Bo vom 7. 10. 1928. 
Nationalgefühls und schließlich auch um die sprachliche Selbstbestimmung der Gemeinden.

Die Frage der Straßennamen wurde bereits in den ersten Tagen nach der Entstehung der Republik aktuell, und zwar im Zusammenhang mit der typischen Begleiterscheinung wohl jedes Machtwechsels, nämlich mit der Entfernung von Straßennamen, die an die alten politischen Verhältnisse erinnerten. Was jedoch die Tschechen im tschechischen Landesinneren begeistert innerhalb von wenigen Stunden geschaffen hatten, weigerten sich die Deutschen jahrelang nachzuvollziehen. Es ging dabei jedoch nicht nur um Kompetenzen und beleidigte Eitelkeit; das Geschichtsbild der Sudetendeutschen war doch anders als das der Tschechen, woraus sich unausweislich auch ein unterschiedliches Verhältnis zu vielen der Namen ergeben mußte, die plötzlich zur Diskussion standen. Deren Liste war nicht gerade kurz: Es standen Namen auf ihr, die an die Mitglieder des ehemaligen Herrschergeschlechts oder an Persönlichkeiten erinnerten, die in Vergangenheit oder Gegenwart "mit offensichtlicher Feindseligkeit“ gegen das tschechoslowakische Volk und seinen Staat aufgetreten waren oder noch auftraten. ${ }^{22}$ Die Angelegenheit mußte relativ schnell entschieden werden, denn die tschechische Öffentlichkeit, reagierte empfindlich auf jegliche Erinnerungen an die vergangenen politischen Verhältnisse, und nicht selten nahmen radikale Gruppen aus ihrer Mitte die Entfernung derartiger Straßenschilder eigenmächtig vor. Damit war automatisch für ständigen Konfliktstoff gesorgt, zumal die deutsche Öffentlichkeit solchen $\mathrm{Ge}$ schehnissen nicht immer tatenlos zusah. Unter diesen Bedingungen konnte es nicht lange dauern, bis das Innenministerium anordnete, die oben charakterisierten Namen von Gebäuden, Betrieben und Anstalten sowie Straßen und öffentlichen Plätzen innerhalb von drei Monaten zu entfernen; in Vorahnung von Unklarheiten hinsichtlich der Bewertung der historischen oder aktuellpolitischen Rolle verschiedener Persönlichkeiten riet das Ministerium, im Zweifelsfall nicht näher spezifizierte „unparteiische“ Sachverständige hinzuziehen. ${ }^{23}$

Die deutschen Gemeinden folgten der Anweisung offensichtlich nur halbherzig bzw. gar nicht, denn das Gesetz Nr. 266 vom April 1920 über die Orts- und Straßennamen legte abermals eine Frist zur Entfernung von „unpassenden“ Bezeichnungen fest; darüber hinaus wurde sogar eine Geldstrafe im Fall der Nichteinhaltung angedroht. Der Kreis der betroffenen Namen wurde erheblich erweitert, indem Benennungen zu entfernen waren, die „mit der Geschichte und den äußeren Beziehungen der tschechoslowakischen Nation" nicht in Einklang zu bringen waren, insbesondere solche, die an Personen erinnerten, die „eine feindliche Gesinnung gegen die tschechoslowakische Nation oder die verbündeten Nationen geäußert haben oder die an Ereignisse staatsfeindlichen Charakters erinnern“. Um Probleme auch in Zukunft zu vermeiden, waren zwar für die Benennung von Straßen und Plätzen nach wie vor Gemeindevertretungen zuständig, ihr Beschluß mußte jedoch binnen acht Tagen der vorgesetzten politischen Behörde vorgelegt werden, die seine Ausführung untersagen konnte, falls die Bezeichnung den diesbezüglichen Bestimmungen des Gesetzes widersprach. ${ }^{24}$ Trotzdem waren

${ }^{22}$ SÚA, PMR, Karton 3295, 740/11, Rundschreiben MV, 19. 5. 1919.

${ }^{23}$ Ebda.

24 Gleichzeitig mit dem Gesetz Nr. 266/1920 Slg. wurde das Gesetz Nr. 267/1920 Slg. über die Beseitigung unpassender Namen beschlossen, das sich auf Körperschaften, juristische Personen, öffentlich zugängliche Räume, Betriebe, Anstalten, Erzeugnisse und „dergleichen“ bezog. 
„unpassende“ Namen mancherorts noch jahrelang anzutreffen. ${ }^{25}$ Gegen die Entscheidungen der politischen Bezirksverwaltungen bezüglich der Entfernung von bestimmten Straßennamen legten die deutschen Gemeinden Beschwerden beim Obersten Verwaltungsgericht ein, das sich damit wegen Überlastung erst in den Jahren 1923 bis 1924 befassen konnte. Natürlich hatten Namen wie „Friedrich-Wilhelm-Spital“ oder „Kaiser-Franz-Josef-Suppenanstalt" keine Chancen zu überdauern; umstritten waren jedoch auch solche, deren Zusammenhang mit den politischen Verhältnissen vor 1918 nicht so eindeutig war, wie Königstraße, Rudolfs- oder Stefaniegasse, Kaiser- oder Elisabethbad. Gnade fand bei dem Gericht nur der Name „Königstraße“, weil er, so die Urteilsbegründung, an die Zeit erinnern konnte, als in den böhmischen Ländern böhmische Könige geherrscht hätten. Auf den Einwand einer Gemeinde dagegen, daß sich die ehemalige Kaiserin Elisabeth politisch nicht betätigt und keine Feindschaft dem "tschechoslowakischen" Volk gegenüber gezeigt habe, erwiderte das Gericht, daß nach Absicht des Gesetzes die Namen der Mitglieder des Hauses Habsburg zu denjenigen Namen gehörten, die nicht für öffentliche Benennungen gebraucht werden dürften. ${ }^{26}$ Im Hinblick auf die Namen Rudolf oder Stephanie, von denen der deutsche Beschwerdeführer behauptete, sie würden sich nicht auf die Mitglieder der ehemaligen Herrscherfamilie beziehen, beschloß das Gericht, das Gesetz spreche von Namen, die an solche Personen oder Ereignisse erinnerten. Daraus könne man schließen, daß dem Gesetz gleichgültig sei, was für Motive seinerzeit zur Festlegung dieser Namen geführt hätten; entscheidend sei ausschließlich, welche Vorstellungen sie in der heutigen Bevölkerung hervorrufen könnten. ${ }^{27}$

Die Straßenbenennung unterlag freilich nicht nur in inhaltlicher sondern auch in sprachlicher Hinsicht gewissen Regeln. Die bereits erwähnte Durchführungsverordnung zum Gesetz über die Orts- und Straßennamen vom August 1921 bestätigte zwar das Recht der Gemeindevertretung, darüber zu entscheiden, in welcher Sprache die Straßen und öffentliche Plätze in der Gemeinde benannt wurden. Gleichzeitig hieß es: „Beschließt die Gemeindevertretung die Benennung in einer anderen als der tschechoslowakischen Sprache, so sind in Gemeinden, in denen nach der letzten Volkszählung mindestens 20 Prozent Staatsangehörige tschechoslowakischer Sprache wohnen, Straßen und öffentliche Plätze außerdem stets in der Staatssprache, und zwar an erster Stelle, zu bezeichnen." Das gleiche galt auch für Gemeinden, die Sitz von Gerichten und Behörden der politischen Verwaltung waren, deren Wirkungskreis sich auf einen Gerichtsbezirk erstreckte, in dem mindestens 20 Prozent Staatsbürger "tschechoslowakischer" Sprache wohnten, sowie für Kurorte. Von nun an mußten die Sudetendeutschen in „ihren“ Städten neben tschechischen Ortstafeln auch tschechische Straßentafeln dulden, was manchen schwerfiel. Ärgerlich war verständlicherweise die mangelnde Reziprozität dieser Regelung: Den mehrheitlich tschechischen Gemeinden wurde die Pflicht, sprachliche Belangen im Hinblick auf die Straßenbezeichnungen zu berücksichtigen, nicht auferlegt. Auch in der Hauptstadt Prag, für die die sudetendeut-

${ }^{25}$ Vgl. kritische Äußerungen des Chefs des Volkstumsvereins für Nordböhmen, E Hrubý, in: Národní obzor vom 7.5. 1921; auch die Tagung der tschechischen Minderheiten in Reichenberg im August 1921 verlarigte, das "verdeutschte“ Gebiet von deutschen und österreichischen („rakušáckých“) Straßen-, Plätze- und Gebäudenamen zu „säubern“. NM 1 (1921), Nr. 10, S. 7-8.

${ }^{26}$ Beschluß NSS Nr. 20421 vom 3. 1. 1923, in: Vẽstník MV 5 (1923), S. 257-258.

27 Beschluß NSS Nr. 7440 vom 24. 4. 1924, in: Vẽstník MV 6 (1924), S. 430. 
sche Politik in ihrer Eigenschaft als Landeshauptstadt jahrelang eine Sonderregelung anstrebte, gab es nur tschechische Orts- und Orientierungstafeln. Besonders brisant war diese Frage im Fall der Kurorte, die gegen diese Regelung sowie die weitergehenden Tendenzen, das Bäderwesen verstärkt der staatlichen Reglementierung zu unterwerfen, in den Jahren 1924 bis 1925 in zwei an den Völkerbund gerichteten Petitionen protestierten. ${ }^{28}$

Gegen die Verpflichtung, ihre Straßen auch tschechisch benennen zu müssen, versuchten deutsche Gemeinden mitunter trickreich vorzugehen. Die Stadträte von Teplitz-Schönau interpretierten die Bestimmungen der Verordung beispielsweise dahingehend, als würden sie sich lediglich auf Bezeichnungen beziehen, die seit ihrem Inkrafttreten, also seit dem 6. September 1921 beschlossen wurden, was das Oberste Verwaltungsgericht in einem Urteil vom Jahre 1923 widerlegen mußte. ${ }^{29}$ Am weitesten ging zweifellos die Gemeinde Trautenau, die im März 1922 beschloß - wohl durch das Beispiel von New York inspiriert -, ihre Straßen und Plätze mit arabischen Ziffern zu bezeichnen. Die Antwort des Innenministers auf eine diesbezügliche Interpellation der deutschen Abgeordneten war hochgradig sophistisch: Das Gesetz benutze das Wort „Benennung“, und Nummern könnten nicht als Namen angesehen werden. Übrigens lege das Gesetz fest, Straßen auch in der Staatssprache zu bezeichnen, und die Gemeinde könne somit keine Bezeichnung beschließen, die die Benutzung der Staatssprache ausschließe. ${ }^{30}$

Die meisten Schwierigkeiten auf dem Gebiet der Orts- und Gassennamen traten im Postverkehr auf. Natürlich war aufgrund des Gesetzes über die Orts- und Straßennamen auch die Postverwaltung verpflichtet, in ihrer Amtsführung sowie im Parteienverkehr den Gebrauch der amtlich zugelassenen Ortsnamen zu fordern; problematisch war jedoch, daß eine Sendung einer privaten Person an eine andere kein Akt des Parteienverkehrs sein konnte. Trotzdem wurden Sendungen, die nicht die richtigen Bezeichnungen trugen, als unzustellbar zurückgeschickt, was als Eingriff in den privaten Sprachgebrauch gewertet werden kann. Dies komplizierte die private Korrespondenz, denn nicht jeder Absender war sich über die nationale Zusammensetzung des Zielortes im klaren, manchen waren die tschechischen Äquivalente, besonders der Straßennamen, nicht bekannt. Selbst die Gestaltung der Adresse war nicht einfach: Bei Sendungen nach Prag durfte man zwar beide Formen gebrauchen, also Prag oder Praha, bei Straßennamen waren jedoch nur die tschechischen Namen zulässig. Aufpassen mußte man auch auf die Absenderadresse, denn auch deren sprachlich fehlerhafte Angabe konnte ein Grund für die Nichtzustellung sein. ${ }^{31}$

Während die Sudetendeutschen in ihrer Abwehrstellung gegen die „Tschechisierungsversuche" am Sinn des Kampfes um die Orts- und Straßennamen keinen Zweifel hegten, waren die Standpunkte der tschechischen Gesellschaft differenzierter. Für ei-

28 Vgl. Eingabe sowie Zweite Eingabe, passim.

29 Beschluß NSS Nr. 9314 vom 30. 5. 1923, in: Věstník MV 5 (1923), S. 396.

30 Antwort des Ministers des Inneren auf die Interpellation des Abgeordneten Lodgman und Genossen wegen eigenmächtiger Entfernung von Straßentafeln in Trautenau durch den Leiter der dortigen politischen Bezirksverwaltung vom 29. 9. 1922, in: TTZPS, 1. WP, Drucksache 3801/XXI.

31 Bereits im Oktober 1921 machte die Prager Postdirektion darauf aufmerksam, daß Sendungen mit deutschen Bezeichnungen der Prager Straßen nur noch vorübergehend zugestellt werden sollten, doch bereits zu diesem Zeitpunkt gab es Beschwerden, die auf eine umgekehrte Praxis in manchen Fällen deuteten. Vgl. Bo vom 9. 9. 1921 bzw. vom 10. 9. 1921. 
nen Teil war die Straßentafel-Politik ein Sinnbild nationaler Intransigenz und der Lösung der Nationalitätenprobleme von der Art, die die Erste Republik ursprünglich zu vermeiden beabsichtigte. Manche tschechische Prominente äußerten sich despektierlich darüber, Präsident Masaryk beispielsweise bezeichnete eine "nationale Politik mit Fahnen und Tafeln" als Krähwinkelei. ${ }^{32}$ Dagegen wurden aus den Reihen besonders der tschechischen Minderheiten im deutschen Siedlungsgebiet und der Volkstumsvereine Stimmen laut, in dieser Frage konsequent vorzugehen. Ihrerseits wurde 1921 auch die Forderung erhoben, Gemeinden, Ortschaften, Wege, Straßen und Plätze nur in der Staatssprache zu bezeichnen. ${ }^{33}$ Noch Ende der dreißiger Jahre war in diesen Kreisen offene Unzufriedenheit mit der Praxis der staatlichen Postverwaltung festzustellen, die, indem sie Briefe mit deutschen Bezeichnungen von tschechischen Dörfern zustellte, die Deutschen ,in ihrer Kühnheit und in der Ignorierung der tschechischen $\mathrm{Na}$ men" angeblich unterstützte. ${ }^{34}$ Deshalb verlangten sie, derartige Sendungen von der Beförderung überhaupt auszuschließen. Tschechische Gemeinden waren in allen Geographielehrbüchern und Karten, die in deutschen Schulen benutzt wurden, nur tschechisch zu bezeichnen. Mit einer verblüffenden Offenheit gab man sich Illusionen hin: "Nur dadurch, daß sich die deutsche Schülerschaft daran gewöhne, tschechische Namen zu benutzen, wird sie diese auch im weiteren Leben gebrauchen, und die deutschen geraten in Vergessenheit." Auf die Indoktrinierung der Jugend reagierten die Sudetendeutschen überhaupt äußerst empfindlich, zumal man offensichtlich die allmähliche Verdrängung deutscher Ortsnamen auch aus dem privaten Sprachgebrauch ernstlich befürchtete: Deutsche Namensschöpfungen, behauptete 1936 der SdP-Abgeordnete F. Karmasin, seien ein „Kulturgut der Deutschen in aller Welt“, und deshalb müsse man im Schulunterricht nicht nur deutsche amtliche Ortsnamen, sondern deutsche Ortsnamen überhaupt gebrauchen und lernen. ${ }^{35}$

Obwohl die Problematik der Orts- und Straßennamen aus den deutsch-tschechischen Diskussionen Ende der dreißiger Jahre nicht verschwand, blieb sie bei den Verhandlungen über das Nationalitätenstatut und das neue Sprachengesetz im Jahre 1938 praktisch unberührt. Tschechischerseits sind keine Anzeichen dafür bekannt, daß man eine Änderung der bisherigen Regeln und Praxis ins Auge gefaßt hätte, die Vorschläge besonders der Sudetendeutschen Partei implizierten offensichtlich grundsätzliche Kompetenzerweiterungen auch auf diesem Gebiet, konkrete Vorstellungen wurden jedoch nicht vorgelegt.

32 ANM, NL Sobota, Karton 13, Aufzeichnung über ein Teegespräch beim Präsidenten der Republik am 7. 7. 1924; Ripka, Národnostní problém, S. 421.

${ }^{33}$ SÚ́A, NRĆ, Karton 491, 269, Resolution einer öffentlichen Versammlung am 23. 10. 1921.

${ }^{34}$ SÚA, PMR, Karton 463,1063/2-3, Resolution der tschechischen Grenzler, vorgelegt durch NJS, 19. 12.1936.

35 Interpellation des Abgeordneten Karmasin an den Minister für Schulwesen und Volkskultur wegen Nichtbeachtung der im verfassungsmäßigen, freien Sprachgebrauch verwendeten Ortsbezeichnungen im Geographieunterricht vom 9. 10. 1936, in: TTZPS, 4. WP, Drucksache 655/XV. 